RAFAEL DUARTE

Metodologia de análise da qualidade de mapeamentos antigos. Estudo de caso: a cartografia produzida no Estado de São Paulo na década de 1960 
RAFAEL DUARTE

Metodologia de análise da qualidade de mapeamentos antigos. Estudo de caso: a cartografia produzida no Estado de São Paulo na década de 1960

Dissertação apresentada à Escola Politécnica da Universidade de São Paulo para obtenção do Título de Mestre em Ciências. 


\title{
Metodologia de análise da qualidade de mapeamentos antigos. Estudo de caso: a cartografia produzida no Estado de São Paulo na década de 1960
}

\author{
Versão Corrigida
}

Dissertação apresentada à Escola Politécnica da Universidade de São Paulo para obtenção do Título de Mestre em Ciências.

Área de Concentração:

Engenharia de Transportes

Orientador:

Prof. Dr. Jorge Pimentel Cintra 
Autorizo a reprodução e divulgação total ou parcial deste trabalho, por qualquer meio convencional ou eletrônico, para fins de estudo e pesquisa, desde que citada a fonte.

Este exemplar foi revisado e corrigido em relação à versão original, sob responsabilidade única do autor e com a anuência de seu orientador.

São Paulo, de de

Assinatura do autor:

Assinatura do orientador:

\section{Catalogação-na-publicação}

Duarte, Rafael

Metodologia de análise da qualidade de mapeamentos antigos. Estudo de caso: a cartografia produzida no Estado de São Paulo na década de 1960 / R. Duarte -- versão corr. -- São Paulo, 2020. $234 \mathrm{p}$.

Dissertação (Mestrado) - Escola Politécnica da Universidade de São Paulo. Departamento de Engenharia de Transportes.

1.Cartografia 2.Geodésia 3.História 4.Metodologia 5.Qualidade I.Universidade de São Paulo. Escola Politécnica. Departamento de Engenharia de Transportes II.t. 
Dedicatória

Para finalizar um desafio pessoal, como é por definição uma dissertação de Mestrado, os agradecimentos são, indubitavelmente, uma parte muito agradável de se fazer. É nesse momento que recordamos os momentos bons e também os difíceis, que foram superados. É a oportunidade de agradecer aqueles que nos incentivaram e apoiaram mostrando como manter o equilíbrio entre a razão e o sentimento de ansiedade. Desta forma agradeço ao meu orientador Prof. Dr. Jorge Pimentel Cintra, que dedicou muito de seu tempo contribuindo para este trabalho, e ao Prof. Dr. Paulo de Oliveira Camargo, pelas importantes contribuições teóricas para sua finalização. A ambos o meu muito obrigado por sua generosidade e competência científica, que foram determinantes nesta jornada. 


\section{AGRADECIMENTOS}

Realizar este estudo foi muito gratificante e não poderia alcançar esta satisfação sem agradecer a pessoas que foram essenciais durante esta jornada. A primeira pessoa que me apoiou desde o início até chegar a este bom porto foi minha esposa e amiga Kátia, que teve paciência e me encorajou nos momentos mais difíceis com seus sábios conselhos, outras pessoas que não poderia esquecer são meus pais (Carlos e Maria) e avós (Margarida, Lauzerina e José) por proporcionarem um berço esplêndido, que foi de sua importância para que alcançasse este tão desejado feito pessoal. Outra figura que me forneceu um grande apoiado na realização desta pesquisa foi o diretor do Instituto Geográfico e Cartográfico Celso Donizetti Talamoni por fornecer o material de suma importância para a realização desta pesquisa, ao Sr. Ruy Natividade pelas informações e documentações sobre a empresa de seu pai o Aviador Nestor H. Natividade. Aos senhores Ântonio Cobo Neto e José Bueno Conti por gentilmente atender ao pedido de entrevista, fornecendo relatos importantes da época. O ente federativo que foi primordial para a realização desta pesquisa foi o Governo do Estado de São Paulo, em especial as seguintes instituições: Instituto Geográfico e Cartográfico, Museu Geológico do Instituto Geológico e Diário oficial. A estas instituições o agradecimento pela disponibilização dos dados necessários para esta dissertação, pois sem eles este trabalho não teria sido possível. 


\section{"Epigrafe"}

-Afirmo muitas vezes que, se você medir aquilo de que está falando e o expressar em números, você conhece alguma coisa sobre o assunto; mas, quando você não o pode exprimir em números, seu conhecimento é pobre e insatisfatório; pode ser o início do conhecimento, mas dificilmente seu espírito terá progredido até o estágio da Ciência, qualquer que seja o assunto.- William Thomson, Lord 


\section{RESUMO}

A utilização de mapas antigos é recorrente em diversos trabalhos técnicos e científicos como, por exemplo: em questões ambientais, ocupação urbana e territoriais. Por se tratarem de registros espaciais, muitas vezes únicos, estes são utilizados para determinar a existência e o posicionamento de antigas feições. Considerados documentos cartográficos, os mapas antigos, estão sujeitos a inconformidades, considerando padrões atuais, que por vezes não são conhecidas. O presente trabalho propõe elaborar metodologia de análise da qualidade de alguns destes produtos. Esta foi desenvolvida a partir da análise qualitativa do mapeamento sistêmico, produzido durante a década de 1960 em parte do território paulista. Neste conjunto de documentos destaca-se a coleção de cartas, que estão se tornando históricas, na escala 1:25.000 (não publicadas) e outras na escala 1:50.000. Foram realizadas pelo Instituto Geográfico e Geológico do Estado de São Paulo (IGGSP) e produzidos por empresas de aerofotogrametria. Parte importante desta proposta metodológica foi a consulta a documentos técnicos e a realização de entrevistas, que colaboraram para o resgate de detalhes técnicos ocorridos durante a produção destes mapeamentos. Outro ponto, de destaque, foi a escolha da técnica mais adequada a ser utilizada para a transformação de coordenadas. Esta escolha permitiu a realização de comparações entre os mapeamentos antigos e produtos cartográficos atuais e mais precisos, além de referenciados a sistemas de coordenadas atuais. Assim utilizando-se das discrepâncias observadas, nestas comparações, e de parâmetros qualitativos, como o Padrão de Exatidão Cartográfico - PEC, foi possível definir metodologia para avaliar a qualidade dos mapeamentos em questão. Desta forma, a partir desse estudo de caso, propor uma metodologia que possa ser aplicada a outros mapas antigos.

Palavras-Chave - Instituto Geográfico de Geológico, Mapa histórico, Verificação posicional, Cartografia, Mapa Topográfico. 


\section{ABSTRACT}

The use of old maps is recurrent in several scientific technical works, as for example: in environmental, urban and territorial occupation. Because they are spatial records, often unique, old maps are used to determine the existence and positioning of features. Considered cartographic documents, these old maps, are subject to nonconformities, with the new standards, that sometimes are not known. The present work proposes the elaboration of a methodology for the analysis of the quality of these maps. It was elaborated from the qualitative analysis of the systemic mapping, produced during the 1960s in part of the territory of São Paulo. In this set of documents stands out the collection of letters, which are becoming historical, in the scale 1: 25,000 (unpublished) and others in the scale 1: 50,000. Realization of the Geographic and Geological Institute of the State of São Paulo (IGGSP) and produced by aerial photogrammetry companies. An important part of this methodological proposal was the consultation of technical documents and interviews. That collaborated to find technical details that not was docummented of the production these mappings. Another point, detached in this method, was the definition of which technique to be used for coordinate transformation. This allowed comparisons to be made between the older mappings and more current and accurate cartographic products, referenced to different coordinate systems. Thus, using the observed discrepancies, in these comparisons, and qualitative parameters, such as the Cartographic Accuracy Standard (PEC), it was possible to define the quality of the mappings in question. And so, from this case study, propose a methodology that can be applied to other ancient maps.

Keywords - Institute of Geographical and Geology, Historical Map, Positional Verification, Cartography, Topographic Map. 


\section{LISTA DE FIGURAS}

1 Diagrama de organização da pesquisa . . . . . . . . . . . . . . . 24

2 Mapa da Exploração do Extremo Sertão de São Paulo (1905) . . . . . . . . 26

3 Cartas Topográficas em escala 1:100.000 publicadas pelo IGGSP/CGGSP . 27

$4 \quad$ Legendas encontradas CGGSP/IGGSP (1:100.000) . . . . . . . . . . . 28

5 Legendas encontradas nos mapas municipais do IGGSP . . . . . . . . . . 30

$6 \quad$ Produção cartográfica do IGGSP durante sua atuação . . . . . . . . . . . . 31

7 Mapas municipais produzidos pelo IGG . . . . . . . . . . . . . 32

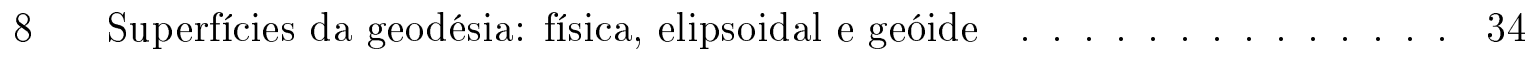

$9 \quad$ Desvio astronômico da vertical em relação ao geodésico $\ldots$. . . . . . . . . 36

10 Rede de triangulação geodésica $\ldots \ldots \ldots$. . . . . . . . . . 36

11 Medição da linha de base utilizando invar . . . . . . . . . . . . . . . 37

12 Triangulação geodésica da CGGSP entre 1886 e 1898 . . . . . . . . . . . 38

13 Técnicas de nivelamento . . . . . . . . . . . . . . . . . 39

14 Equipamento aerokartograph . . . . . . . . . . . . . . . . . 40

15 Esquema de leitura de pontos (1 a 6 ) para remoção da paralaxe em y . . . 41

16 Evolução da técnica aerofotogramétrica no Brasil e outros países . . . . . . 42

17 Distância focal fotogramétrica $\ldots \ldots \ldots \ldots$. . . . . . . . . 43

18 Sobreposição lateral e longitudinal . . . . . . . . . . . . . . . . . 44

19 Reportagem com fotografia aérea (1) e no detalhe foto tirada em solo (2) . 46

20 Municípios com pequenos voos entre 1940 e 1956 . . . . . . . . . . . . . 47

21 Rede de Triangulação brasileira $\left(1^{\mathrm{a}}\right.$ ordem $) 1944-1961 \ldots$. . . . . . . . . . 53

22 Redes americanas de posicionamento horizontal 1940-1961 . . . . . . . . 55

23 Esquema de cálculo de interferometria por satélite . . . . . . . . . . . 56 
24 Geometria de observação pela técnica MINITRACK . . . . . . . . . . 57

25 Distribuição dos pontos de apoio e técnicas (SAD69/96) . . . . . . . . 58

26 Pontos utilizados no ajustamento SIRGAS 2000 . . . . . . . . . . . 60

27 Evolução da rede de nivelamento RAAP Brasileira . . . . . . . . . . . . . 61

28 Marégrafo de Torres $\ldots \ldots \ldots \ldots$. . . . . . . . . . . . . . 62

29 Rede de nivelamento de São Paulo 1940/60 - IGGSP . . . . . . . . . . . . 63

$30 \quad$ Estações gravimétricas usadas no modelo geoidal sul-americano . . . . . . 66

$31 \quad$ A esquerda rede gravimétrica de São Paulo em 2011 e a direita em 2013 . . 67

32 Rede gravimétrica de referência do Mapgeo2015 . . . . . . . . . . . . . 67

33 Plano cartesiano e coordenadas geodésicas . . . . . . . . . . . 70

34 Ilustração da transformação tridimensional de Helmert $\ldots$. . . . . . . . . 72

35 Transformação por três parâmetros . . . . . . . . . . . . . . 74

$36 \quad$ Região de abrangência do Grid NTV2 . . . . . . . . . . . . . . . 80

37 Diagrama representando relação entre tipos de erros e acurácia e precisão . 83

38 Ilustração da acurácia e precisão com e sem tendência . . . . . . . . . . . . 84

39 Distribuição amostral $\ldots \ldots \ldots \ldots \ldots$. . . . . . . . . . . . 88

$40 \quad$ Esquema de blocos do voo de 1962 sobreposto com a área do mapeamento 99

$41 \quad$ Esquema de áreas do mapeamento $1962 / 74 \ldots \ldots$. . . . . . . . . . . . 100

42 Rede de triangulação entre Santo Ângelo e Capão Bonito . . . . . . . . . . . 101

43 Pontos de controle e representações poligonais do mapeamento 1969 . . . . 102

45 Visualização dos fotoindices no Geoportal IGCSP . . . . . . . . . . . . . 104

46 À esquerda fotografia e a direita câmera (detalhe das marcas fiduciais) . . 105

47 Câmeras FairChild (laterais) e Wild (central) década de 1960 . . . . . . . . 105

48 Restituidores Galileo Santoni analog stereoplotter Modelo III e IV] . . . . . 106

49 Propaganda do Stereocartograph $\ldots \ldots \ldots$. . . . . . . . . 106

$50 \quad$ Esq. Foto construção MASP 1964 dir. foto 09240 do voo 1962 . . . . . . . 107 
51 Comparação da imagem de 1961 e 2010 (Igreja Matriz de Votuporanga) . . 108

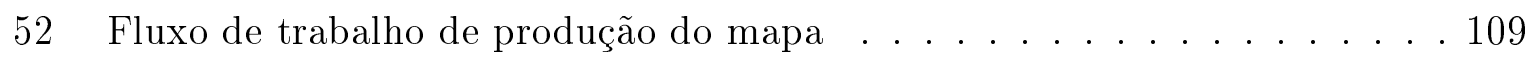

53 Comparação da coloração dos mapas 1:50.000 e 1:25.000 . . . . . . . . . . 110

54 Esquema de áreas do mapeamento 25.000 e 50.000 . . . . . . . . . . . . . 111

55 Distribuição das folhas impressas na escala 1:50.000 no Brasil. . . . . . . . 112

56 Distribuição das folhas (1:50.000) e seus executores/parceiros . . . . . . . . 114

57 Municípios com mapas municipais e anos de sua criação (leis) . . . . . . 115

59 Pontos utilizados no cálculo dos parâmetros de Helmert e de translação . . 120

60 Diagrama das transformações utilizadas nos testes posicionais . . . . . . 120

61 Diagrama representando ajustamento paramétrico (Helmert) . . . . . . . . 122

62 Pontos utilizados no cálculo dos parâmetros de Helmert e translação . . . . 125

63 Folhas escolhidas para as análises de qualidade . . . . . . . . . . . . 129

64 Metodologia de escolha dos pontos homólogos . . . . . . . . . . . . . . 131

65 Distribuição dos pontos coletados para análise posicional . . . . . . . . . . 132

66 Histograma de valores estatísticos para das diferenças DE,DN e DZ . . . . 134

67 Anotação 50.000 na legenda da carta de escala 1:25.000 . . . . . . . . . . 139

68 Feições medidas em fotografias de 1961 e 2010 . . . . . . . . . . . . . . . . 141

69 Notas feitas na carta 1:25.000 e omitidas nas 1:50.000 . . . . . . . . . . . . 144

70 Exploração CGGSP - Rio do Peixe São Paulo (1905) . . . . . . . . . . . . . 151

71 Caderneta de Campo com calculo de Latitude e Sterneck . . . . . . . . . . 156

72 Telurômetro utilizado pelo IGGSP . . . . . . . . . . . . . . . . . 156

73 Última organização institucional do IGG $(1969 / 74)$. . . . . . . . . . . . . 163

74 Wild PUG 4 (perfurador de fotografias) . . . . . . . . . . . . . . . 164

$75 \quad$ Cidades e capitanias na região sudeste de 1532-1700 . . . . . . . . . . 166

77 Ilustração de contraforte e talvegue à esquerda e a direita por curvas de nível 173

78 Ilustração de divisor de águas acima e perspectiva abaixo em curvas de nível 174 
79 Ilustração de morro à esquerda e à direita em curvas de nível . . . . . . . . 174

80 Resumo da evolução do quadro territorial paulista entre 1938 e 1997 . . . . 175

81 Detalhes de legendas folhas topográficas do Texas (E.U.A.) $\ldots \ldots \ldots$. . . 177

82 Carta Topográfica do Rio de Janeiro $1922 \ldots \ldots \ldots$

83 Áreas de levantamento Trimetron na região nordeste do Brasil (1943 a 1945) 181

84 Avião e equipe da USAF Missão AST10 … . . . . . . . . . . . . . . 182

85 Informações de legenda de um fotoindice (São Paulo) do voo da USAF . . 183

$86 \quad$ Aviões da Natividade Vultee BT-13A (PP-RTL) e Lockheed (PT-CDU) . . 186

87 Organização institucional do IGG e suas seç̧ões entre 1938/69 . . 202

88 Organização institucional inicial do IGC - 1979 . . . . . . . . 203

89 Organograma Institucional do IGG - Fonte: Acervo IG Museu Geológico . 207 


\section{LISTA DE TABELAS}

$1 \quad$ Módulo de escala da foto para diversas escalas de carta . . . . . . . . . . 45

2 Comparação das medidas do raio equatorial da terra e do achatamento . . 49

3 Tabela comparativa entre ajustamento do IBGE e marégrafos diversos . . . 64

$4 \quad$ PEC e Erro padrão (altimétrico e Planimétrico) $\ldots \ldots$. . . . . . . . . . 89

$5 \quad$ Valores gerais do PEC PCD . . . . . . . . . . . . . . 90

$6 \quad$ Valores PEC e PEC Digital aplicado as escalas 1:25.000 e 1:50.000 . . . . . 90

$7 \quad$ Valores e Erro Médio e Erro Padrão . . . . . . . . . . . . . . . . . . . . . . 91

$8 \quad$ Folhas topográficas $(1: 50.000)$ do Estado de São Paulo . . . . . . . . . . . 113

9 Distorções na conversão entre SIRGAS2000 em Córrego 1961 . . . . . . . . 119

10 Coordenadas XYZ utilizadas para a Calculo de Helmert . . . . . . . . . . . 121

11 Parâmetros calculados e estatística para transformação entre SIRGAS2000 e Córrego Alegre . . . . . . . . . . . . . . . . . . . . . . . . 122

12 Coordenadas XYZ utilizadas para a Calculo de translação . . . . . . . . . 123

13 Parâmetros calculados para a transformação de SIRGAS para Córrego utilizando três translações . . . . . . . . . . . . . . . . . . . 123

14 Coordenadas de Monografias em Córrego Alegre utilizadas na comparação 124

15 Coordenadas de Monografias em SIRGAS 2000 utilizadas na comparação . 126

16 Coordenadas de Monografias em SIRGAS 2000 utilizadas na comparação . 126

17 Discrepâncias entre coordenadas transformadas e das monografias $\mid 15$. . . 127

18 Medidas estatísticas para discrepâncias apresentadas na tabela 17 . . . . . 128

19 Medidas estatísticas para os valores de discrepâncias observados . . . . . . 134

20 Coordenadas Planimétricas e discrepâncias em milímetros para cálculo do

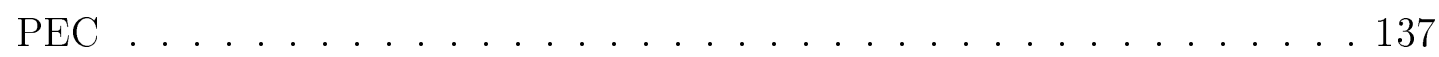

21 Valores de PEC calculados . . . . . . . . . . . . . . . . 137 
$22 \quad$ Valores de Erro Padrão (EP) calculados . . . . . . . . . . . . . . . 138

23 Valores calculados para o PEC altimétrico . . . . . . . . . . 138

24 Valores calculados para Erro Padrão (EP) altimétrico . . . . . . . . . . . 139

$25 \quad$ Valores de PEC calculados . . . . . . . . . . . . . . . . 140

26 Análise de sobreposição das aerofotografias . . . . . . . . . . . . . . . . . . 142

27 Comissões e omissões de quadras das folhas analisadas . . . . . . . . . . 142

28 Tabela do histórico de áreas técnicas entre IGG e IGC (1938-2018) . . . . . 165

29 Tabela de levantamentos de 1947 feitos pela Natividade . . . . . . . . . 185

$30 \quad$ Coordenadas coletadas na área C para avaliação posicional . . . . . . . . . 198

31 Coordenadas altimétricas e suas discrepâncias para verificação posicional 199

32 Pontos Planimétricos e Altimétricos da comparação e suas diferenças . . . 200

33 Cartas topográficas produzidas pela CGG/IGG - Fonte Acervo IGC . . . . 204

34 Produção do IGG entre 1938 e 1975 . . . . . . . . . . . . . . . . . 205

35 Voos Executados nas décadas 40 e 50 Acervo IGG/IGC . . . . . . . . . 206

36 Coordenadas de apoio horizontal córrego alegre IGG 1958/61 . . . . . . . . 207 


\section{LISTA DE SIGLAS}

ASP - American Society of Photogrametry (Sociedade Americana de Fotogrametria)

CNG - Comissão Nacional de Geografia

CGGSP - Comissão Geográfica e Geológica do Estado de São Paulo

DAEE - Departamento de Águas o Energia Elétrica

DSG - Diretoria de Serviço Geográfico

GIS - Geographic Information System (Sistema de Informações Geográficas)

GPS - Global Positioning System (Sistema de Posicionamento Global)

GNSS - Global Navigation Satellite Systems (Sistema de Navegação Global por Satélites)

IAGS - Inter American Geodetic Survey (Levantamento Geodésico Interamericano)

IBGE - Instituto Brasileiro de Geografia e Estatística

IBC - Instituto Brasileiro do Café

IGCSP - Instituto Geográfico e Cartográfico de São Paulo

IGGSP - Instituto Geográfico e Geológico de São Paulo

NMAS - National Map Accuracy Standards

NRL - Naval Research Laboratory (Laboratório de Pesquisa Naval)

PEC - Padrão de Exatidão Cartográfico

SAD - South American Datum (Datum Sul-Americano)

SCM - Sistema Cartográfico Metropolitano

SCN - Sistema Cartográfico Nacional

USCGS - United States Coast and Geodetic Survey (Levantamentos geodésicos e Costa dos Estados Unidos)

USGS - United States Geological Survey (Levantamentos Geológicos dos Estados Unidos) 


\section{SUMÁRIO}

\begin{tabular}{lll}
\hline 1 & Introdução & 19
\end{tabular}

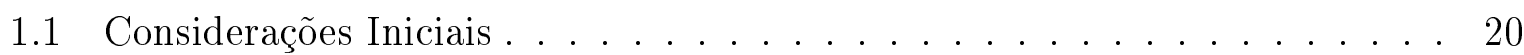

1.2 Justificativa . . . . . . . . . . . . . . . . . . . . . . . 21

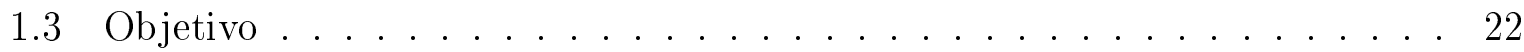

1.4 Estrutura do Trabalho . . . . . . . . . . . . . . . . . . 22

2 A instituição que produziu o mapeamento e as técnicas utilizadas 25

2.1 Os mapeamentos produzidos pela instituição antecessora (CGGSP) . . . . 25

$2.1 .1 \quad$ Primeiros mapeamentos publicados pelo IGGSP . . . . . . . . . . . 26

2.1.1.1 Divisas municipais . . . . . . . . . . . . 29

2.2 Técnicas de posicionamento geodésico utilizadas no mapeamento . . . . . . 33

$2.2 .1 \quad$ Posicionamento Planimétrico . . . . . . . . . . . . . . . 35

2.2.1.1 Astronomia de Posição . . . . . . . . . . . . . 35

2.2.1.2 Triangulação . . . . . . . . . . . . . 36

2.2 .2 Posicionamento Altimétrico . . . . . . . . . . . . . . . 38

2.3 Técnicas aerofotogramétricas utilizadas nos mapeamentos . . . . . . . . . 39

2.3.1 Conceitos Fotogramétricos . . . . . . . . . . . . . 43

$2.3 .2 \quad$ Aerofotogrametria no Estado de São Paulo . . . . . . . . . . . . . 45

\begin{tabular}{|ll}
\hline 3 & Referenciais geodésicos \\
\hline
\end{tabular}

3.1 Redes Geodésicas e Sistemas Geodésicos Brasileiros - SGBs . . . . . . . . . 51

3.1 .1 Datum Córrego Alegre . . . . . . . . . . . . . . . 53

3.1 .2 Datum Sul Americano de 1969 e SAD96 . . . . . . . . . . . 54

3.1 .3 O Sistema SIRGAS2000 . . . . . . . . . . . . . . 59 
$3.2 \quad$ A Rede Altimétrica do Sistema Geodésico Brasileiro . . . . . . . . . . . . . 60

3.2 .1 Datum de Torres . . . . . . . . . . . . . . . . . . 61

3.2.1.1 Rede de Nivelamento do IGGSP . . . . . . . . . . . . 62

3.2 .2 Datum de Imbituba . . . . . . . . . . . . . . 63

$3.2 .3 \quad$ Referenciais altimétricos e o geoide . . . . . . . . . . . . . 65

3.2.3.1 Medidas do geoide no Brasil . . . . . . . . . . . . 66

4 Transformação de coordenadas e controle de qualidade 68

4.1 Transformação de coordenadas entre Sistemas Geodésicos Brasileiros . . . 68

4.1 .1 Conversão entre diferentes tipos de coordenadas . . . . . . . . . . 69

4.1.1.1 Transformação entre coordenadas (UTM e Geodésica) . 69

4.1.1.2 Transformação (Geodésicas e Cartesianas) . . . . . . . . . 69

4.1 .2 Transformação por parâmetros . . . . . . . . . . . . . . . 71

4.1.2.1 Transformação de Helmert . . . . . . . . . . . . . . 71

4.1.2.2 Transformação por Três Parâmetros . . . . . . . . . . . 74

4.1.2.3 Ajustamento pelo método dos mínimos quadrados . . . . . 75

4.1 .3 Transformação por grade NTv2 (IBGE) . . . . . . . . . . . . . . . 78

4.2 Controle de qualidade em processos de mapeamento . . . . . . . . . . . 80

4.2 .1 Controle de qualidade geométrico . . . . . . . . . . . . . . 81

4.2.1.1 Análise de Acurácia . . . . . . . . . . . . . . 83

4.2.1.2 Determinação da quantidade e distribuição amostral . . 87

4.2.1.3 Controle de qualidade posicional no Brasil . . . . . . . . . 88

4.2 .2 Controle de qualidade qualitativo de seu conteúdo . . . . . . . . . 93

5 Análise dos materiais utilizados nos mapas do IGGSP (1960-1974) 96

5.1 Contratação e Execução $\ldots \ldots \ldots$. . . . . . . . . . . 96

5.1.1 Primeiro Levantamento Aerofotogramétrico do Estado de São Paulo 98

$5.1 .2 \quad$ Mapeamento 1:25.000 e 1:50.000 . . . . . . . . . . . . . 99 
$5.1 .2 .1 \quad$ Área de abrangência . . . . . . . . . . . . . . . 100

$5.1 .2 .2 \quad$ Apoio Terrestre de Campo . . . . . . . . . . . . 100

$5.1 .2 .3 \quad$ Aerofotografias e estereorestituição . . . . . . . . . . . 104

$5.1 .2 .4 \quad$ Cartas topográficas . . . . . . . . . . . . . . . 108

5.2 Continuidade das publicações cartográficas $\ldots \ldots \ldots \ldots$. . . . . . 112

$5.2 .1 \quad$ Mapas Municipais . . . . . . . . . . . . . . . . . . . . . 114

$6 \quad$ Metodologia de análise da qualidade dos mapas 1:25.000 116

6.1 Transformações entre o Sistema Córrego Alegre e outros SGBs . . . . . . 117

6.1 .1 Transformação pelo modelo Matemático de Helmert . . . . . . . . . 121

6.1.1.1 Determinação dos parâmetros de Helmert . . . . . . . . . 122

6.1 .2 Transformação utilizando três translações . . . . . . . . . . . . 123

6.2 Resultado da comparação entre as formas de transformação . . . . . . . . . 124

6.3 Área de estudo e análises posicional e qualitativa . . . . . . . . . . . . 129

$6.3 .1 \quad$ Análise posicional . . . . . . . . . . . . . . . . . . 130

6.3.1.1 Definição de pontos homólogos . . . . . . . . . . . 130

6.3 .1 .2 Análise estatística . . . . . . . . . . . . . 131

6.3.1.3 Análise posicional segundo normativas brasileiras . . . . . 134

6.3 .2 Análise qualitativa $\ldots \ldots \ldots \ldots \ldots \ldots$

$6.3 .2 .1 \quad$ Análise da escala de voo . . . . . . . . . . . . . . 140

6.3.2.2 Análise de sobreposições aerofotográficas . . . . . . . . . 141

6.3.2.3 Análise de completude de feições (integridade) . . . . . . . 142

6.3.2.4 Análise de legenda e topônimos (atributos) . . . . . . . . . 143

\begin{tabular}{lll}
\hline 7 Conclusões & 145
\end{tabular}

Apêndice A - História do IGGSP e de sua predecessora, a CGGSP 151

A.1 A criação e as atribuições do IGGSP $\ldots \ldots \ldots \ldots \ldots$. . . . . . . . 153 
A.1.1 Estrutura administrativa . . . . . . . . . . . . . . . . . . . . 154

A.1.2 Personalidades de destaque do IGGSP $\ldots \ldots \ldots \ldots \ldots$

A.1.3 Publicações Científicas de Cartografia do IGGSP . . . . . . . . 160

A.2 Fim do IGGSP e órgãos que receberam suas atribuições . . . . . . . . . . . 161

\begin{tabular}{lll}
\hline Apêndice B - Histórico sobre as demarcações territoriais paulistas & 166
\end{tabular}

B.1 Limites estaduais paulistas . . . . . . . . . . . . . . . . . . 168

B.2 Divisas municipais a partir de 1938 . . . . . . . . . . . . . 169

B.2.1 Os primeiros Mapas Municipais . . . . . . . . . . . . . 170

B.2.2 Descrição de demarcações das divisas municipais. . . . . . . . . 172

Apêndice C - Resumo histórico da Aerofotogrametria 176

C.1 Aerofotogrametria no Brasil . . . . . . . . . . . . . . . . . 177

C.1.1 Aerofotogrametria da Força Aérea Americana no Brasil . . . . . . . 180

C.1.2 Empresas Paulistas de Aerofotogrametria (1945-1969) . . . . . . . . 184

\begin{tabular}{ll}
\hline Apêndice D - Entrevistas & 189
\end{tabular}

D.1 Antônio Cobo Neto . . . . . . . . . . . . . . . . . . . . . . . . . . 189

D.2 José Bueno Conti . . . . . . . . . . . . . . . . . . . . . . . . . 190

\begin{tabular}{|l|}
\hline Apêndice E - Script para Cálculo do Ajustamento \\
\hline
\end{tabular}

E.1 Cálculo dos parâmetros de Herlmert. . . . . . . . . . . . . . . . . . 192

E.2 Cálculo por três parâmetros … . . . . . . . . . . . . 195

\begin{tabular}{ll}
\hline Apêndice F - Tabelas de coordenadas e cálculos posicionais & 198
\end{tabular}

\begin{tabular}{ll}
\hline Anexo A & 202
\end{tabular}

$\begin{array}{ll}\text { Referências } & 210\end{array}$ 


\section{INTRODUÇÃO}

Com o passar do tempo as bases cartográficas, principalmente mapas, tornam-se documentos históricos. Por vezes estes apresentam informações que tem suma relevância por serem registros, muitas vezes únicos, do espaço mapeado na época em que foram produzidos. Para se conhecer a ocupação espacial, de determinados lugares no passado, é comum a utilização de mapas antigos para auxiliar o entendimento de determinados fenômenos. Dentre as utilidades destes mapas cabe destacar a utilização em: perícias judiciais, questões urbanísticas, transformações urbanas e sociais, dentre outras. Embora muitas destas aplicações utilizam-se de material cartográfico poucas consideram suas qualidades e limitações. O estudo destes mapas antigos, de forma a entender estas características, apresenta-se como uma importante contribuição.

Quando se trata de medição da qualidade de mapas antigos devem ser considerados alguns marcos temporais. Por exemplo, o século XIX segundo Harley (2018) foi marcado por um grande interesse na elaboração de mapas, principalmente depois de 1850 com a institucionalização da Geografia como área científica (CAPEL, 1981). Embora existam muitos mapas antigos que se propõe representar determinados locais, em suas épocas, o desconhecimento de seus erros pode comprometer algumas de suas utilizações. Mapas produzidos antes do século XIX são normalmente manuscritos e feitos em escala pequena: 1:5.000.000 ou ainda menores. Já sobre a qualidade destes mapas Cintra (2012) propõe a adoção de uma metodologia que considera elementos como a presença ou não de longitudẹ de escala, de projeção e a utilização de pontos para aferir sua qualidade.

A partir do século XIX foram produzidas as primeiras séries de mapas, utilizandose de recobrimento sistemático. Estes normalmente tinham utilizações cadastrais, com escalas grandes: 1:10.000 e ainda maiores, ou aplicações que necessitavam representar áreas de maior extensão, estes com escalas médias variando entre 1:100.000 e 1:10.000. Um exemplo de análise da qualidade em série de mapas cadastrais antigos é descrito por

\footnotetext{
${ }^{1}$ Diferente da latitude o problema da longitude só foi resolvido no século XVIII com a invenção do relógio marítimo preciso de John Harrison (SOBEL, 2004)
} 
Lima (2012), tratando-se do Levantamento da cidade de São Paulo (1934). No presente trabalho apresenta-se um estudo de análise da qualidade de uma série de mapas antigos, nas escalas de 1:25.000 e 1:50.000. A partir dos resultados deste estudo, é proposta uma metodologia que visa analisar a qualidade em séries de mapas antigos.

Como material de estudo esse trabalho utiliza-se da série de mapas, produzida pelo Instituto Geográfico e Geológico do Estado de São Paulo (IGGSP), com enfoque nas cartas produzidas na escala 1:25.000 e 1:50.000, durante na década de 1960. Leva-se em consideração a tecnologia da época e que os dois referidos mapeamentos foram iniciados em 1960, porém somente um destes foi finalizado no início da década de 1970. Sobre estes mapeamentos Cintra e Silva (2002) destacam que substituíram as antigas cartas de 1:100.000, elaboradas pela Comissão Geográfica do Estado de São Paulo (CGGSP) no final do século XIX (FIGUEIRÔA, 1987). Apesar disso, é interessante atentar que até o momento este mapeamento, de escala 1:25.000, é uma fonte de informação desconhecida, e sobre ele não foi realizado nenhum estudo quanto a seus aspectos históricos e técnicos. Esta dissertação se propõe a preencher esta lacuna, ou seja, apresentar e analisar este mapeamento, desenvolvendo uma metodologia aplicável em casos similares.

Durante a análise dos mapeamentos estudados foram realizadas avaliações das características destes e de outros documentos; ressaltando o papel dos atores envolvidos na sua elaboração, com enfoque nas instituições e em seu processo produtivo. Além disso, se apresentará o pioneirismo do IGGSP na utilização de técnicas e equipamentos. Para a análise de sua qualidade se apresentará uma metodologia que aborda tanto aspectos de precisão geométrica, como de outras características deste mapeamento.

\subsection{Considerações Iniciais}

A cartografia feita pelo Estado não é um fim em si, mas um meio para representar regiões ou feições do território de seu interesse e assim fornecer subsídios para que diversos órgãos e entidades façam planejamento e analisem projetos públicos e privados. Neste sentido a atuação do IGGSP (inclusive no mapeamento estudado) teve objetivos que se alinham com os interesses do Estado e da sociedade civil. De forma geral, pode-se considerar que estes objetivos, no caso específico de se executar e manter trabalhos na área de cartografia/geodésia/topografia, visam diretamente a subsidiar estudos e projetos em diversas áreas como: obras civis (estradas, ferrovias, represas, etc..), geologia, petrologia, minerais, hidrogeológicas, dentre outras (SIDALC, 1978; FERNANDES; COIMBRA, 1994, BARTH, 2002, FILHO et al., ; ALMEIDA; CARNEIRO, 2017; ARID, 2018). Outra 
área que foi beneficiada com estes estudos foi a da ordenação territorial, que se utiliza deste material para o estabelecimento e materialização de divisas municipais e estaduais (PERRONI; LEFĖVRE, 1960, BORGES et al. 2016). Assim observa-se que os mapeamentos, objetos deste trabalho, são importantes insumos para áreas que necessitam de informações sobre o espaço geográfico. Para detalhar a elaboração destes mapeamentos foram necessários estudos técnicos, com informações históricas, que descrevem o contexto de sua produção e da Instituição responsável por sua contratação e parte de sua execução.

\section{$1.2 \quad$ Justificativa}

Os mapas históricos têm oferecido desde os primórdios um acervo de informações, mesmo em povos que não tinham escrita. O estudo destes documentos permite conhecer a ciência e a tecnologia envolvidas, situando-as na época em que foram produzidas (HARLEY, 1989, p.3). Ao mesmo tempo estes estudos contribuem para o entendimento da evolução qualitativa dos mapas históricos, por meio de estudo das técnicas produtivas utilizadas (HARLEY, 1989, CINTRA, 2003).

A verificação da qualidade de mapeamentos, por vezes considerados históricos, se faz importante principalmente quando são necessárias comparações destes com outras bases cartográficas. Um exemplo desta utilização são as análises de mudanças urbanas ou a alteração da cobertura do solo, principalmente quando estas são realizadas por meio de comparações entre produtos mais recentes e mapas históricos (PETIT; LAMBIN, 2002, TUCCI; GIORDANO, 2011). Outros autores também realizam aplicações que necessitam de certa qualidade no posicionamento como, por exemplo, aqueles que visam elucidar questões de análise da ocupação do espaço a partir do registro cartográfico temporal, tais como: cobertura vegetal (relacionadas à ocupação antrópica), geomorfológica (para avaliação de riscos), análise do sequestro de carbono, erosões costeiras, questões judiciais sobre histórico de ocupação urbana, dentre outras (ANBALAGAN, 1992, CAMPOS, 1999, LEYK et al., 2006; TORTORA et al., 2006; GIANNINI et al., 2011; LIMA, 2012).

A falta de estudos que verifiquem a qualidade de produtos cartográficos, dos quais muitos vêm se tornando históricos, implica no desconhecimento do seu grau de confiabilidade, o que pode produzir erros em sua utilização indiscriminada. Especificamente sobre a análise qualitativa de produtos cartográficos Galo e Camargo (1994) ressaltam que é poucas vezes realizado. Assim, a proposta metodológica, objeto de estudo desta pesquisa, se justifica pelos motivos aqui apresentados. 


\subsection{Objetivo}

O objetivo geral deste trabalho é desenvolver uma metodologia de avaliação da qualidade de mapas antigos. Para isso utilizou-se da análise dos produtos e do processo produtivo de mapeamentos, executados no Estado de São Paulo, mais especificamente, o mapeamento não finalizado na escala de 1:25.000 executado nas décadas de 60 e 70 . Desta forma faz-se necessário o resgate de parte dos processos de elaboração cartográfica executados pelos atores envolvidos com enfase no IGGSP, que foi o principal ator de produção destes mapeamentos, e para isso analisam-se as ciências fotogramétricas e geodésicas envolvidas durante a atuação desta Instituição.

Além de desenvolver a metodologia e estudar os aspectos técnicos e históricos tem-se como objetivo específico avaliar por amostragem a qualidade do mapeamento 1:25.000, bem como estudar os processos cartográficos utilizados na época. Visando este objetivo, foram realizados os seguintes estudos, que constituem objetivos mais específicos:

- Estudo da estrutura técnica do IGGSP em seu conteúdo histórico levando-se em consideração as ciências e técnicas cartográficas utilizadas na época;

- Estudo da história dos processos cartográficos, geodésicos e aerofotogramétricos utilizados na época do mapeamento em questão, bem como as tecnologias empregadas (equipamentos);

- Estudo e aplicação da proposta metodológica de determinação da qualidade posicional, ou seja, analisar a precisão a partir de uma amostra das cartas (1:25.000) e transformações de coordenadas necessárias para a execução dessa tarefa.

Importante ressaltar que como complementação desses estudos foram feitas entrevistas com fontes testemunhais, que permitiram contrastar informações descritas em documentos diversos. Sendo também importantes para elucidar fatos ocorridos que, utilizando somente os documentos, não poderiam ser bem explicados.

\subsection{Estrutura do Trabalho}

Conforme descrito este trabalho procura retratar os mapeamentos executados pelo IGGSP durante as décadas de 1960 e 1970. Com este objetivo a organização foi feita para que aspectos técnicos e científicos fossem abordados, quando possível, na ordem 
cronológica dos fatos. A necessidade de análise destes mapeamentos levou a elaboração da revisão bibliográfica a qual fundamentaram-se técnicas e práticas da época de sua produção e, em um contexto mais atual, das metodologias para seu controle de qualidade. Os itens que compreendem a estrutura deste trabalho podem ser resumidos conforme descrito a seguir:

- Introdução - apresenta itens como a estrutura, considerações iniciais sobre o tema e as justificativas para sua elaboração (Capítulo 1);

- Revisão bibliográfica de produção dos mapeamentos - apresenta às técnicas cartográficas utilizadas na época em que foram gerados os produtos cartográficos, objetos de estudo deste trabalho, e parte da história de seus executores (Capítulo 2);

- Revisão bibliográfica metodológica - descreve a fundamentação teórica para as projeções e método de conversão entre estas; e subsídios para às verificações qualitativas e quantitativas a respeito das cartas 1:25.000, objeto principal deste trabalho (Capítulo 3 e 4);

- Desenvolvimento - apresenta os resultados das análises dos produtos cartográficos do Instituto em dois âmbitos: o primeiro histórico, ou seja, como foi criado e desenvolvido o projeto e um segundo que analisa quais os produtos encontrados e faz análise qualitativa e quantitativa dos mapeamentos produzidos na década de 1960, na escala 1:25.000 (Capítulo 5 e 6);

- Conclusões - apresenta os resultados dos testes elaborados e descreve recomendações a futuros trabalhos (Capítulo 7).

A partir da descrição anterior foi elaborado um diagrama esquemático da estrutura deste trabalho, a fim de facilitar o entendimento, sendo esta apresentada no esquema da figura 1 


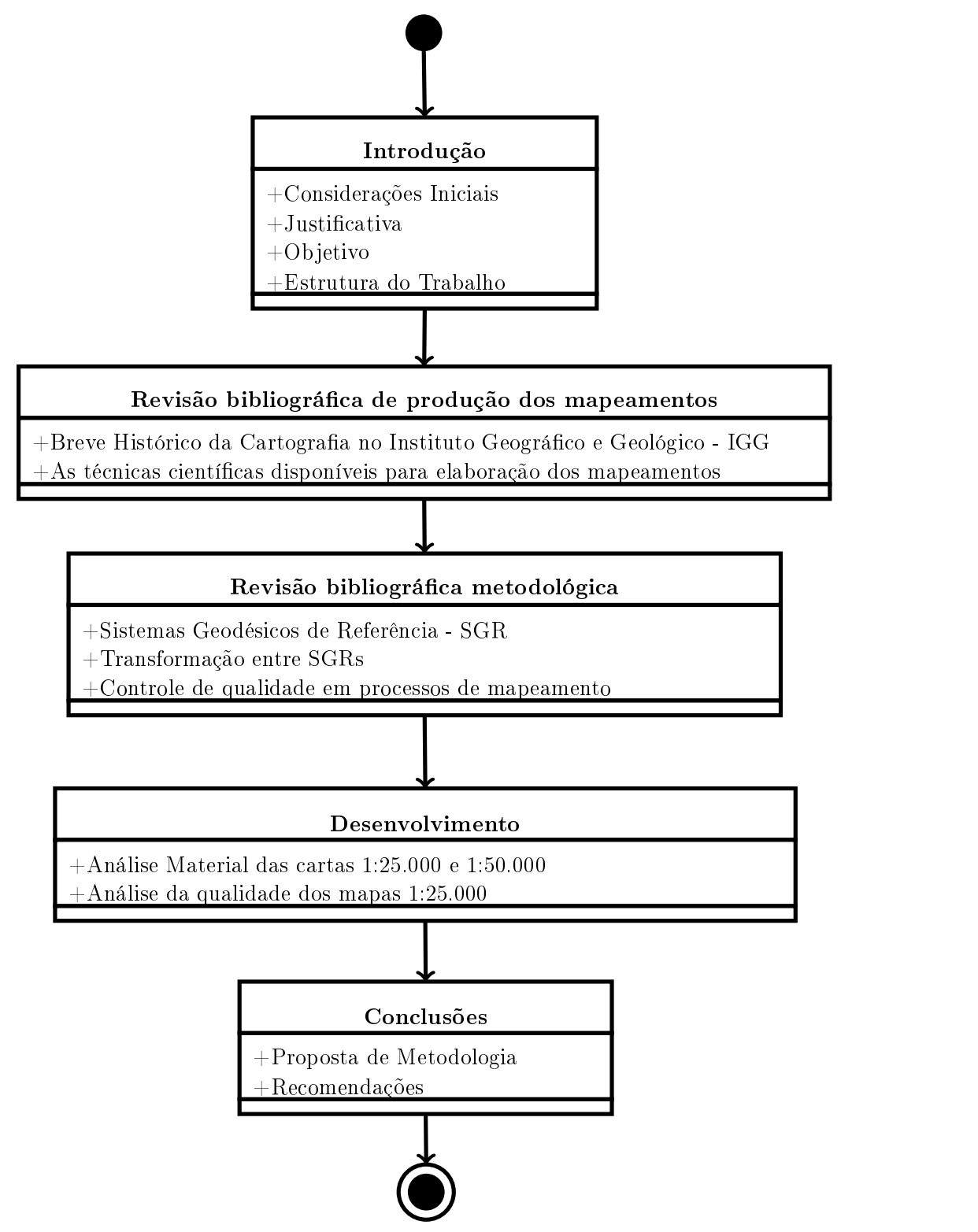

Figura 1: Diagrama de organização da pesquisa 


\section{A INSTITUIÇÃO QUE PRODUZIU O MAPEAMENTO E AS TÉCNICAS UTILIZADAS}

As ciências cartográficas possuem diversos ramos (geodésia, cartografia, aerofotogrametria) que existiam desde a criação do IGGSP. Porém, antes do início do IGGSP, já eram empregados em trabalhos realizados pela Instituição predecessora, a Comissão Geográfica e Geológica de São Paulo (CGGSP). Assim, a CGGSP executou diversos levantamentos sendo estes necessários para a elaboração do primeiro mapeamento no Estado de São Paulo.

\subsection{Os mapeamentos produzidos pela instituição ante- cessora (CGGSP)}

A necessidade de conhecer e cartografar o território paulista é antiga, porém as primeiras ações práticas remontam ao século XIX. Iniciaram-se a partir das explorações da CGGSP, criada pela lei provincial nº 9 em 27 de março de 1886ㅁำ às vésperas da República, tendo como influência inicial os estudos feitos por Hartt e Agassiz (1870). Um documento internd $2^{2}$ do IGGSP informa que em 1897 a CGGSP foi reorganizada ficando integrada pelas seguintes secções: Geografia, Geologia, Botânica e Meteorologia.

Para Figueirôa (2008) a CGGSP foi criada visando atender principalmente os interesses de cafeicultores e políticos paulistas. Estes tinham como objetivo o conhecimento do território paulista, isso para exploração econômica no plantio do café. Pois, até então, muitas regiões, eram retratadas como "Extremo Sertã $\tilde{g}^{3}$ "figura 2. Diversos materiais técnicos foram produzidos com este objetivo, tais como: mapas, cartas, documentações

${ }^{1}$ A CGGSP foi criada com as seguintes seções/chefias: geologia e geografia, chefiadas pelo então diretor Orville Adalbert Derby (primeiro diretor da CGGSP) e Teodoro Fernandes Sampaio como primeiro ajudante até 1892 (SANTOS; CARLOS, 2017).

2 IGGSP. Segunda reunião brasileira de consulta sobre cartografia. In: ACERVO INSTITUTO GEOLÓGICO (MUGEO). Curitiba - PR: Instituto Geográfico Geológico de São Paulo, 1959. p. 1-6.

${ }^{3}$ O termo "sertão", em meados do século XIX, ainda era entendido ou empregado como um espaço oposto àquele da "civilização", isto é, era percebido como o espaço da natureza e, com ela, dos "selvagens" (BEIER; MARHTIN, 2018). 
técnicas, análises de solo, etc... De fato como exemplo tem-se o relatório do ano de 1906; que dentre as diversas dificuldades retratadas destaca que, no avanço pelos rios, eram encontrados diversos obstáculos, tais como: os enfrentamentos com indígenas, as barreiras físicas (como corredeiras e cachoeiras), dentre outras... Outras publicações cartográficas foram produzidas, das quais destacasse: mapas das plantações de café e o levantamento da linha limítrofe entre os Estados de São Paulo e Minas Gerais (CARDOSO, 1907).

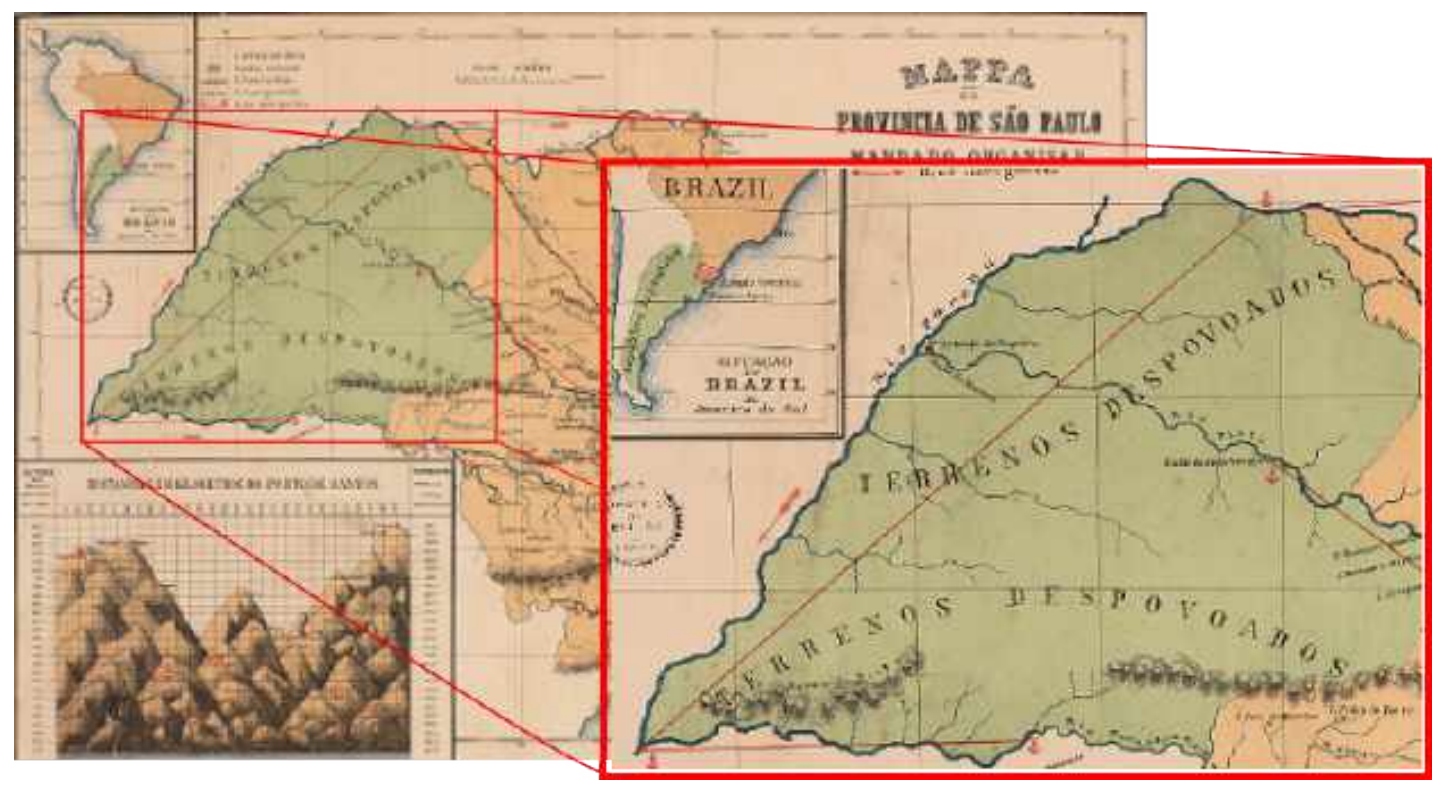

Figura 2: Mapa da Exploração do Extremo Sertão de São Paulo (1905) - CGGSP Fonte: IGCSP (2017)

A CGGSP realizou trabalhos durante o início do século XX, até que na década de 1930 quando teve suas atividades encerradas, para logo depois dar origem ao IGGSP. No Apêndice A (página 151) encontra-se um histórico mais detalhado do fim da CGGSP e do início do IGGSP.

\subsubsection{Primeiros mapeamentos publicados pelo IGGSP}

Os primeiros mapas sistemáticos elaborados pelo IGGSP foram os de escala de 1:100.000, os quais deram continuidade aos de mesma escala criados pela CGGSP. Sobre este trabalho destaca-se seu início realizado por Theodoro Sampaio entre 1886 e 1896 (CINTRA; SILVA, 2001). Sendo substituído por Horácio E. Willians (1896-1910), engenheiro conhecido por realizar diversos trabalhos em outros estados, como a demarcação das divisas litigiosas do Acre (SILVA, 2017a); e com trabalhos finais de triangulação executados por Cornelio Schmidt (1911-1930). Como método de levantamento de feições das cartas 1:100.000 empregava-se a topografia com o foco na representação de recursos hídricos, minerais e 
de infraestrutura. Ao se consultar a descrição, encontrada no relatório de 1959, citada a seguir, tem-se notícia da técnica e tecnologia empregada nesse processo LEFÈVRE, 1959):

Os primeiros levantamentos realizados pela Comissão Geográfica e Geológica, a partir de 1886, foram feitos pelo método expedito, com a utilização de bússola, podômetro e aneróide, apoiados em alguns pontos de triangulação topográfica, pontos astronômicos e linhas taquiométricas. Posteriormente, passou aquela Comissão com maiores recursos orçamentários a empregar processos clássicos [...] Atualmente, o levantamento vem sendo feito com o emprego de teodolitos Kern e Wild. A planimetria é apoiada em pontos de coordenadas geográficas, enquanto a altimetria, obtida por nivelamento trigonométrico, apoiando-se na rede de nivelamento geométrico de primeira ordem. As cartas são desenhadas na escala 1:50.000 e reduzidas para a de 1:100.000, usando-se as tabelas da Coast and Geodetic Survey - CGS, projeção policônica.

Dando continuidade aos mapas produzidos pela CGGSP, o IGGSP produziu 26 folhas (4 não finalizadas) além das 38 folhas publicadas pela CGGSP, conforme ilustra a figura 3. Sobre os levantamentos topográficos, especificamente os presentes em regiões sem cartas topográficas, embora não tenham sido utilizados para elaboração de cartas, contribuíram para demarcação das divisas com Rio de Janeiro e a realização de outros trabalhos. A lista de anos da produção destas cartas está descrita no Anexo A (página 204).

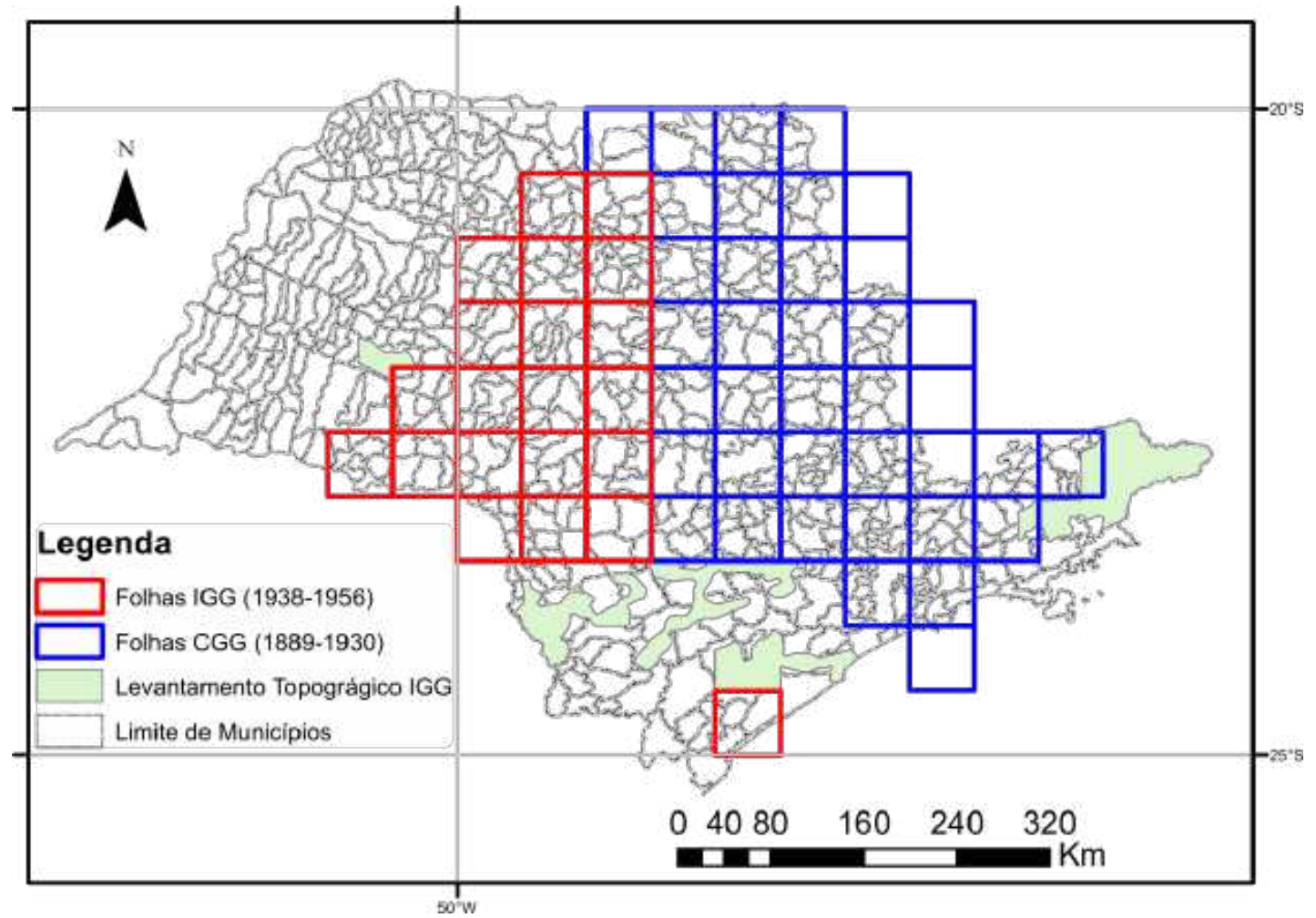

Figura 3: Cartas Topográficas em escala 1:100.000 publicadas pelo IGGSP/CGGSP

Fonte: Autor em compilação de dados do Acervo IGCSP (2017) 
Com vistas a representar diversas feições em seus mapas, a CGGSP dispunha de algumas convenções sucintas - Signaes convencionaes (legendas), como se pode observar na figura 4 (tipo 1), além de adotar o meridiano do Morro do Castelo, no Rio de Janeiro. Como alguns trabalhos da CGGSP não foram publicados, antes de sua extinção, o IGGSP deu continuidade e publicou entre 1938 e 1942 as últimas cartas. Já em 1945 o IGGSP começa a produzir suas primeiras cartas sistemáticas na mesma escala (1:100.000), porém com as legendas mais detalhadas, como se pode observar na figura 4 (tipo 2) e já referenciadas ao meridiano de Greenwich. Esta legenda ganhou mais alguns itens nos mapas realizados na década de 1950, como se observa na figura 4 (tipo 3). Algumas dificuldades foram encontradas como a não padronização da articulação, somente resolvida partir de um esquema iniciado pela Carta do Brasil em escala 1:1.000.000. Este surgiu com vistas a uniformizar os mapeamentos em outras escalas e permitir a padronização das referências cartográficas a nível internacional, ocorrendo só em 1962 (UN, 1962).

\begin{tabular}{|c|c|c|c|c|c|c|}
\hline Legenda & Hidrografia & Relevo & Viário & $\begin{array}{l}\text { Linhas de } \\
\text { Interesse }\end{array}$ & Localidades & Topônimos \\
\hline $\begin{array}{c}\text { Tipo } 1 \\
1908-1942\end{array}$ & Dryojo & 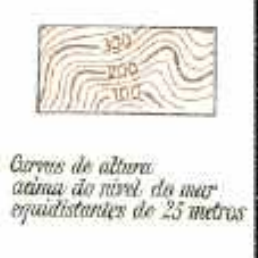 & 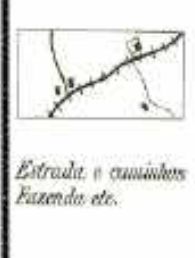 & 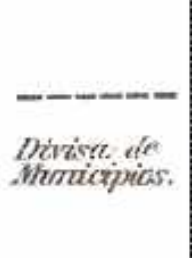 & 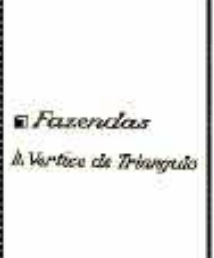 & $\begin{array}{l}\text { CIDADES } \\
\text { Willas } \\
\text { Districtos se Paz } \\
\text { Bumbers }\end{array}$ \\
\hline $\begin{array}{c}\text { Tipo } 2 \\
1943-1949\end{array}$ & & 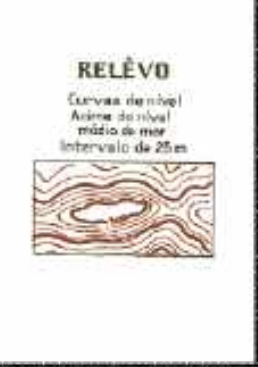 & 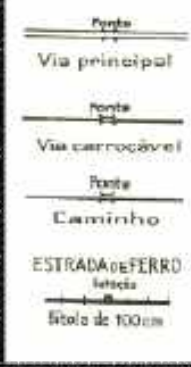 & 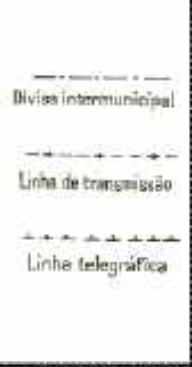 & 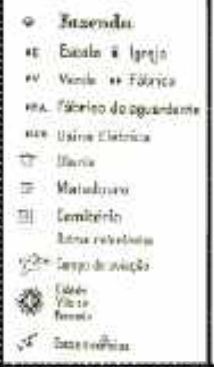 & $\begin{array}{l}\text { CDDADE } \\
\text { (Sede da tomarea) } \\
\text { VIliA } \\
\text { Povoado } \\
\text { Bairro }\end{array}$ \\
\hline $\begin{array}{c}\text { Tipo } 3 \\
1950-1956\end{array}$ & 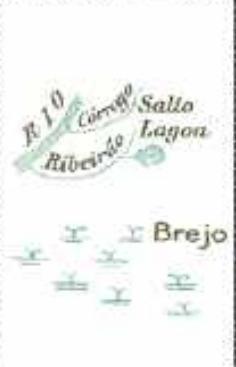 & 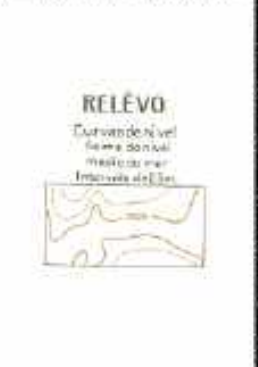 & 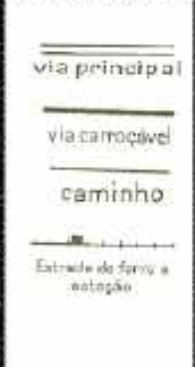 & 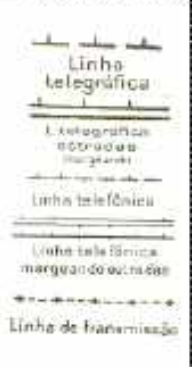 & 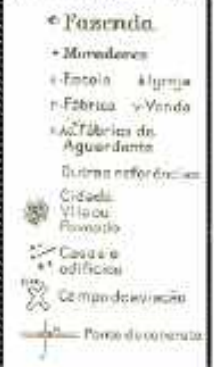 & $\begin{array}{l}\text { CIDADE } \\
\text { (sécede Comarcal } \\
\text { VIL.A } \\
\text { Povoado } \\
\text { Bairro }\end{array}$ \\
\hline
\end{tabular}

Figura 4: Legendas encontradas CGGSP/IGGSP (1:100.000)

Fonte: Autor em compilação de dados do Acervo IGCSP (2017)

Os motivos que levaram à não finalização do mapeamento 1:100.000, como se observa na figura 3, não foram documentados pelo IGGSP. Alguns motivos podem ser supostos: 
como a precisão requerida nos levantamentos (alta para os padrões da época), a imensidão do território, o custo associado e falta de pessoal. Porém, o que fica mais patente é a inviabilidade temporal e econômica em consequência da metodologia clássica empregada para a elaboração dos mapas nesta escala. Além disso, economicamente não havia prioridade, pois muitas das regiões do estado não estavam desenvolvidas a ponto de gerar demanda por mapas.

\subsubsection{Divisas municipais}

Desde sua origem o IGGSP teve como principal atribuição, herdada da CGGSP, a elaboração de demarcação das divisas dos municípios paulistas, outras de suas atribuições estão descritas no Apêndice A (seção A.1). Tal atribuição, decretada em 1938, impunha o prazo inicial de até o final de 1939 para a elaboração de mapas contendo estas divisas. Maiores informações sobre a metodologia e o histórico destas demarcações territoriais podem ser encontradas no Apêndice B. De forma resumida pode-se dizer que entre 1938-39 foram elaborados 221 mapas de divisas assinados sem datação (IGCSP, 2017). Conforme definido por lei $\bigsqcup^{1}$ a Comissão Nacional de Geografia - CNG publicou norma para a elaboração destes mapas (SOARES, 1939). Nesta pode-se destacar, em termos cartográficos, que dentre diversas recomendações aquela que definia a escala final do mapa a qual deveria ser múltipla de $50.000(10.000,25.000,50.000,100.000$, etc...). Outro ponto descrito é sobre as feições a serem cartografadas e sua apresentação no mapa. Desta forma elementos como: limites, lugares e feições de interesse e como seriam representados (legenda, layout, fonte, etc...) como se indica na figura 5 .

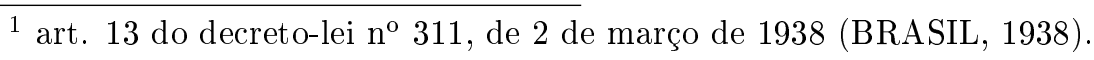




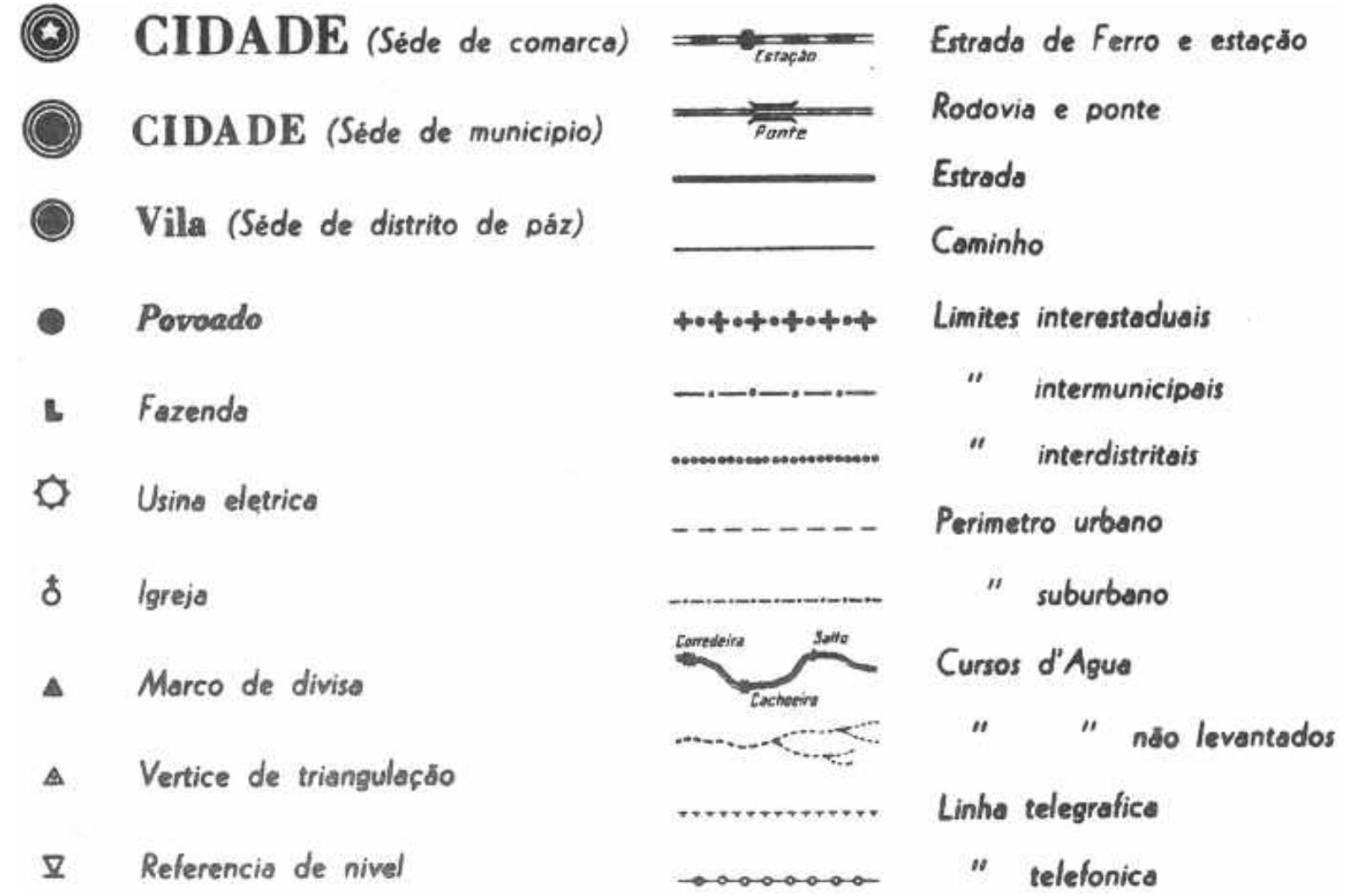

Figura 5: Legendas encontradas nos mapas municipais do IGGSP

Fonte: IGCSP (2017)

De forma geral, em se tratando de trabalhos cartográficos, a elaboração de mapas municipais utilizava-se inicialmente dos mapas em escala 1:100.000. No entanto, quando eram necessárias densificações, ou seja, elementos não cartografados nestes eram realizados em outros trabalhos topográficos. Para ilustrar graficamente a produção de mapas municipais e outros trabalhos realizados pelo IGGSP apresenta-se na figura 6 um gráfico que representa a quantidade de documentação produzida (eixo y) em relação aos anos de existência do IGG 1938-1974 (eixo x). Em lilás o gráfico mostra a quantidade de municípios criados pelas leis estaduais entre 1938-1964ㅁำ. Mais detalhes no Anexo A (página 205).

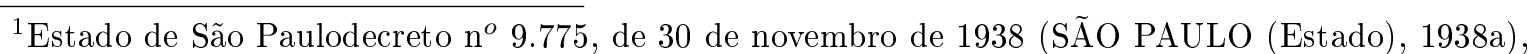
decreto-lei 14.334, de 30 de novembro de 1944 (SAO PAULO (Estado), 1944), lei n ${ }^{\circ} 233$, de 24 de dezembro de 1948 (SAO PAULO (Estado), 1948), lei n ${ }^{\circ}$ 2.456, de 30 de dezembro de 1953 (SAO PAULO (Estado), 1953), lei $\mathrm{n}^{\circ} 5.285$, de 18 de fevereiro de 1959 (SAO PAULO (Estado), 1959), lei $\mathrm{n}^{\circ} 8.092$, de 28 de fevereiro de 1964 (SAO PAULO (Estado), 1964). 


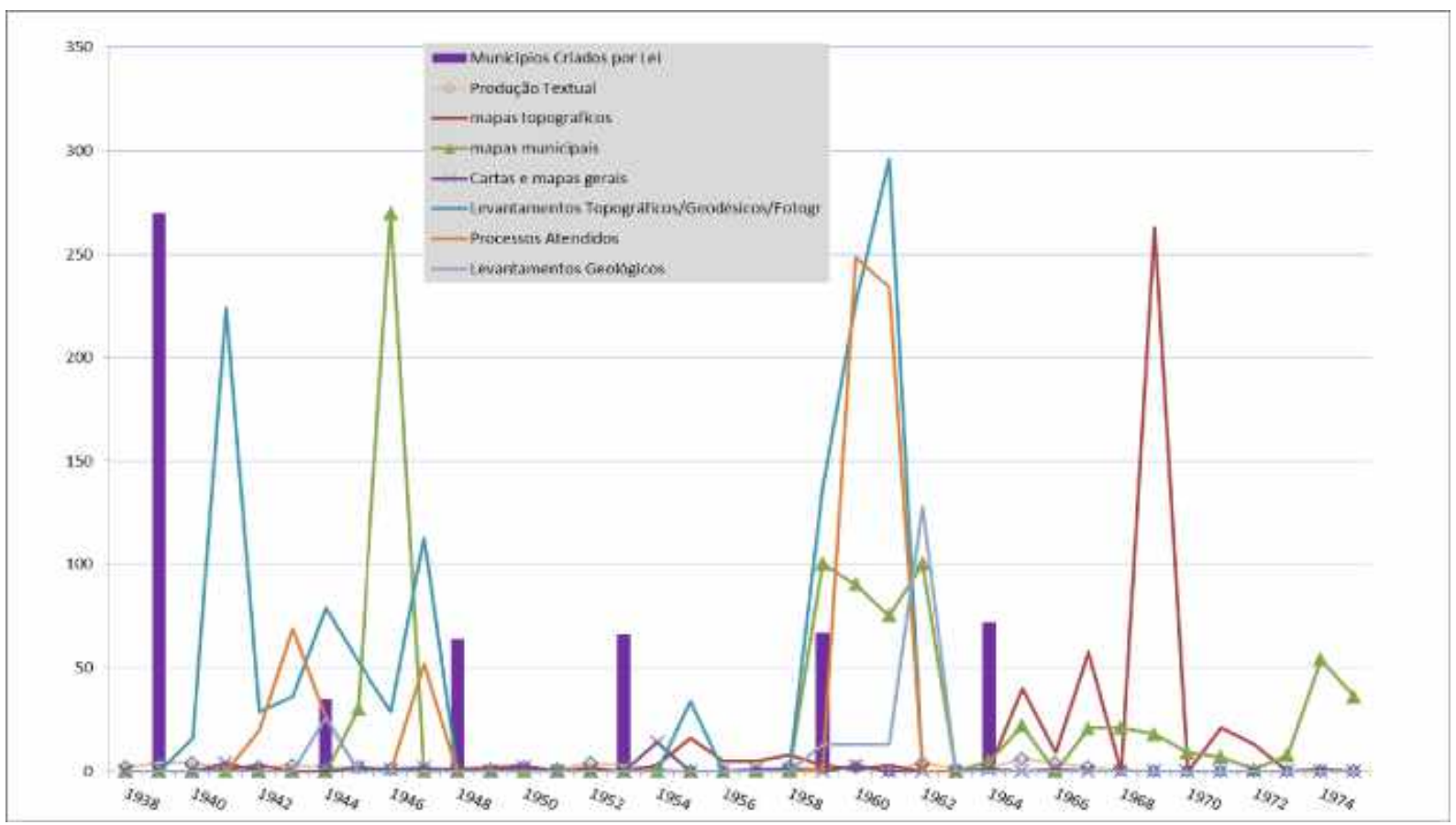

Figura 6: Produção cartográfica do IGGSP durante sua atuação

Fonte: Autor a partir de compilação do acervo IGCSP (2017)

Como ilustra o gráfico da figura 6 deve-se ter em conta que estes mapas exigiam levantamentos topográficos, prévios ou concomitantes. Esta fonte de informação topográfica era utilizada como base na elaboração de trabalhos técnicos e mapas municipais. Ou seja, a partir de levantamentos topográficos eram confeccionados mapas municipais e elaboradas descrições de linhas divisórias, as quais eram posteriormente transformadas em lei que descreveriam o quadro territorial dos municípios paulistas. Porém, nem todas as áreas já dispunham de cartas topográficas 1:100.000. Além disso, o tempo de execução dos métodos clássicos de levantamentos topográficos passaram a inviabilizar a criação/demarcação de uma grande quantidade de novos municípios.

Com a promulgação da última lei que tratou de questões de limites municipais a lei $\mathrm{n}^{\circ} 8.092^{1}$ de 1964, foram criados ou modificados os limites de 573 municípios no território paulista, sendo que esta lei definiu como atribuição do IGGSP a de organizar os mapas e materializar, ou demarcar, as divisas municipais definidas na mesma lei. Sobre este trabalho a engenheira Zilda Sampaio Perroni em depoimento apontou:

Bom, na última revisão territorial em 1963, nós trabalhamos — eu com o Wilson, o Altair, o Manoel e o Domingos Ferreira Gomes — trabalhamos 60 horas sem dormir, dia e noite. Porque essa lei tinha que sair no dia 31 de dezembro, senão só daí a 5 anos. Já tinham preparado até o autógrafo

\footnotetext{
${ }^{1}$ Estado de São Paulo decreto n ${ }^{\circ} 8.092$, de 28 de fevereiro de 1964 (SÃO PAULO (Estado), 1964 ).
} 
do Governador, só faltava assinar a última folha. Era só chegar lá na Assembleia. Quando nós já tínhamos passado uma noite em claro, eu disse a eles: "amanhã é só conferir, vocês não precisam vir". O Domingos estava bastante doente[...](FIGUEIRÔA et al., 1985).

Para atender a esta demanda do Estado foi essencial a adoção da metodologia fotogramétrica utilizando o voo. Estes foram realizados em dois momentos e em escalas diferentes. Sobre a interpretação das fotografias o Geógrafo e professor da Universidade de São Paulo José Bueno Conti, comentou em sua entrevista para o presente trabalho:

[...]Quando em 1961 foram apresentadas as recentes fotografias do noroeste do Estado de São Paulo, as quais auxiliaram a interpretação principalmente para definir os divisores de águas em regiões que não tinham mapeamento $100.000 ;[\ldots]$

Este primeiro voo, realizado entre 1961 e 1964, ficou conhecido como o voo de 1962 (financiado pelo Estado de São Paulo), na época em escala considerada como de detalhe. Este levantamento permitiu a atualização de grande parte dos mapas municipais, até hoje em vigor. A figura 7 apresenta a grande quantidade de mapas municipais depois do voo executado entre 1961-1964. Outra utilização deste voo foi na elaboração de mapeamentos (cartas topográficas) que serão descritas no decorrer do presente trabalho.

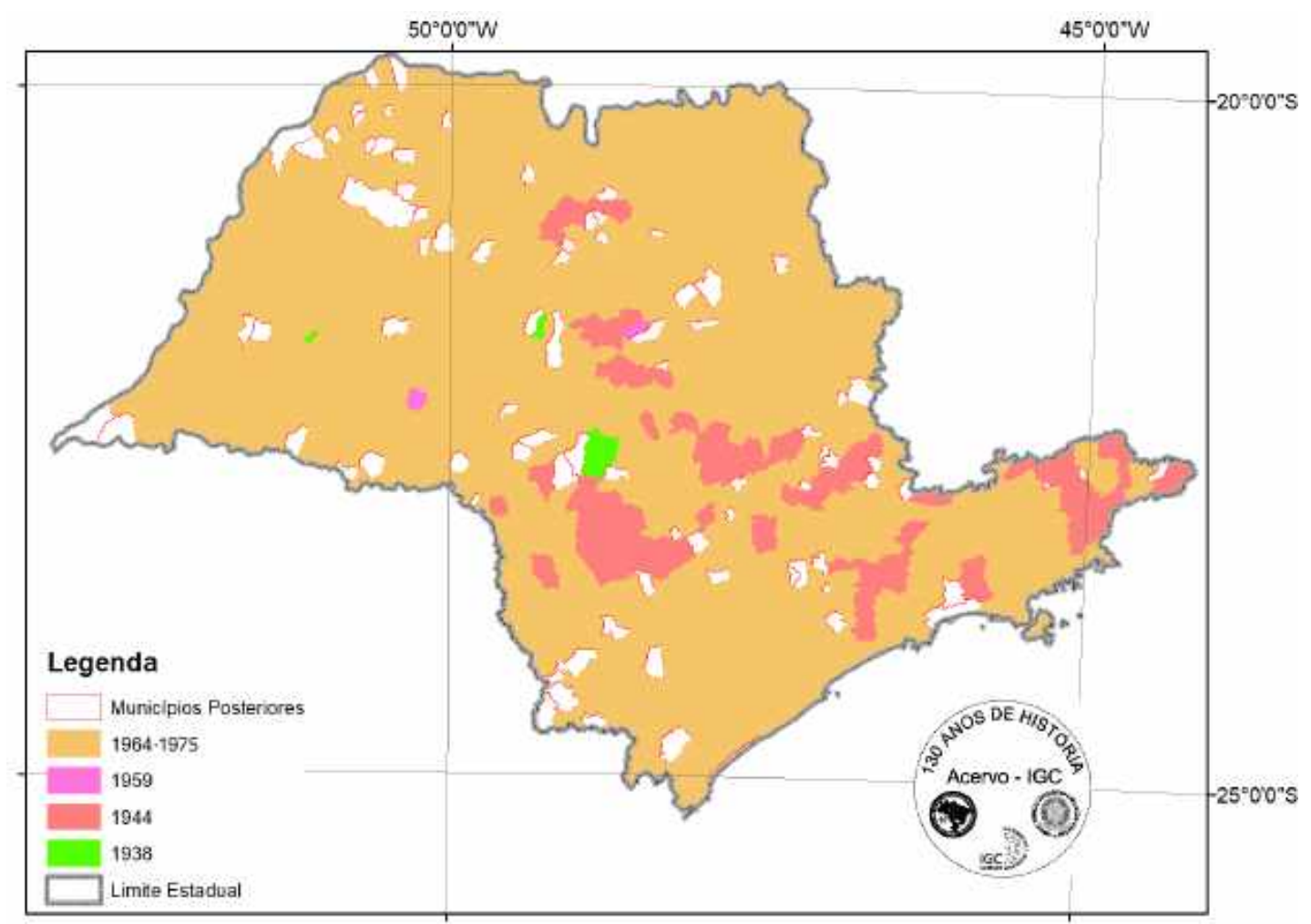

Figura 7: Mapas municipais produzidos pelo IGG

Fonte: Compilação do autor de IGCSP (2017) 


\subsection{Técnicas de posicionamento geodésico utilizadas no mapeamento}

Neste item apresenta-se, de forma resumida, as técnicas científicas empregadas durante a execução dos mapeamentos executados pelo IGGSP, com foco nas décadas entre 1940 e 1970. Estes conceitos se fazem importantes para a contextualização das técnicas utilizadas durante a sua atuação e para o entendimento de algumas características das cartas topográficas, objeto principal neste trabalho.

Sobre os profissionais que elaboravam trabalhos de posicionamento geodésico no IGGSP que, na sua maioria, se formaram entre as décadas de 1920 e 1940, como engenheiros civis. Que normalmente, em São Paulo-SP, estudava-se no Mackenzie, ou na Escola Politécnica, com as disciplinas (cadeiras) de astronomia, geodesia e topografia. Sendo estas fundamentais para a obtenção do título de engenheiro civil (WADDELL, 1923, BASTOS, 1968. SOUZA, 2006; ALTIMEYER, 2016).

Segundo Helmert (1880) a definição clássica da geodésia $(\gamma \eta=$ terra, $\delta \alpha i ́ \omega=$ dividida) pode ser resumida como: "science of the measurement and mapping of the earth's surface." - ciência da medição e mapeamento da superfície da Terra. Esta definição evoluiu e segundo Fischer (1975b), Torge e Müller (2012), a geodésia é a ciência que determina a forma e o campo de gravidade externo da terra e de outros corpos celestes, em função do tempo e determina o elipsoide que melhor representa a forma da terra, calculado a partir de parâmetros observados no exterior à superfície terrestre. Quanto a este último, a forma irregular da superfície (física ou topográfica) terrestre implica em certas dificuldades para a realização de cálculos matemáticos, resultando em problemas para sua representação cartográfica. Assim, é necessário a simplificação da forma da Terra por um modelo que permita sua representação matemática de forma adequada, simplificação esta conhecida como elipsoide (BORGES et al., 2017). Já a forma física atribuída à Terra é definida como geoide, sendo este limitado pela superfície geoidal, que pode ser materializada pela superfície equipotencial que melhor se ajustada ao nível médio não perturbado dos mares. Assim, a Geodésia está preocupada com o estudo do geoide e com a sua determinação, o que é feito através do campo de gravidade que modela a distribuição de massa e o efeito rotacional da Terra e, consequentemente, permite deduzir a sua forma (FREITAS; BLITZKOW, 1999b). A representação destas superfícies pode ser observada na figura 8. 


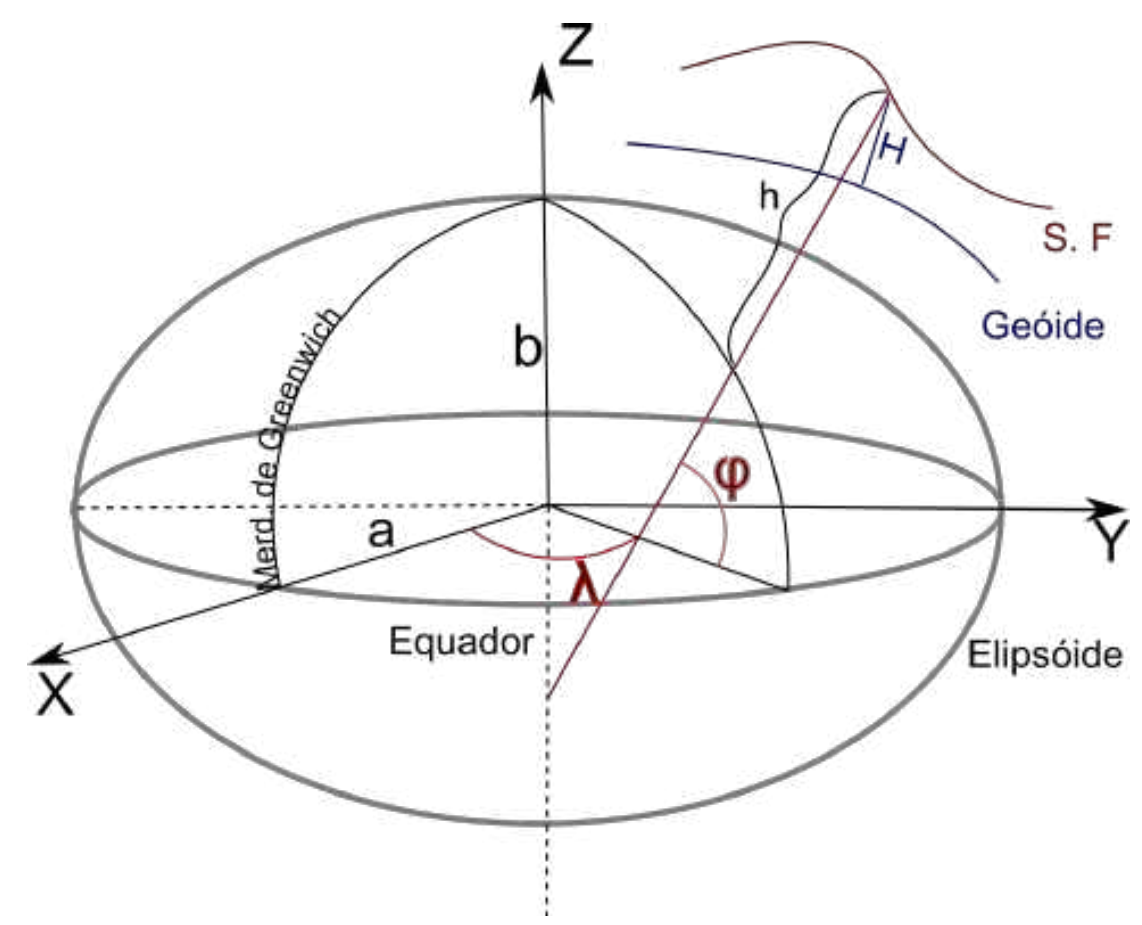

Figura 8: Superfícies da geodésia: física, elipsoidal e geóide Fonte: Borges et al. (2017)

O elipsoide de revolução é definido exclusivamente especificando duas dimensões: os geodesistas, por convenção, utilizam o semi eixo maior e o achatamento. O semi eixo maior é representado pelo raio equatorial $a$ na figura 8 . Já o achatamento, dado por $f$, que indica quão próximo um elipsoide está de uma forma esférica e é obtido a partir da relação entre o semi eixo maior (a) e o semi eixo menor (b), outros elementos $\mathrm{h}$ e $\mathrm{H}$, respectivamente altitude elipsoidal e ortométrica, que estão relacionados à componente altimétrica. A primeira é a distância contada sobre a normal entre o ponto ( $P$ na S.F.) e o elipsoide, já a segunda é a distância contada sobre a vertical entre o ponto ( $P$ na S.F.) e o geoide. Os elipsoides, com seus parâmetros, utilizados neste trabalho estão descritos na secção 3.1 . Durante a concepção dos sistemas de referência utilizados até a década de 1970 os conceitos de geodésia geométrica eram os mais utilizados. Nestes conceitos, os procedimentos de medição visam a determinação de coordenadas, base para os sistemas de referência locais. Para a geodesia geométrica utilizou-se o que ficou conhecido posteriormente, como uma dicotomia de separação entre o posicionamento planimétrico e o altimétrico (GEMAEL, 1999 pg.21). Estes serão descritos nos tópicos a seguir. 


\subsubsection{Posicionamento Planimétrico}

Para a determinação do posicionamento planimétrico, antes do advento de tecnologias de posicionamento por satélite artificial (Global Navigation Satellite System - GNSS), as técnicas disponíveis eram a determinação de coordenadas primárias de pontos por astronomia de posição (latitude e longitude). Assim como a utilização de cadeias de triangulação, a partir da medida de ângulos e distâncias, isso para o transporte das coordenadas (primárias). Ambas as técnicas descritas a seguir:

\subsubsection{Astronomia de Posição}

A Astronomia de Posição, também conhecida como Astronomia Esférica, ou Astronomia de Campo, utiliza-se dos astros para o posicionamento e orientação na superfície da Terra, ou seja, utiliza métodos e técnicas para obter as coordenadas astronômicas de um ponto, a partir da ascensão reta e declinação de determinada estrela bem como a diferença de horário para um observatório e com isso calcular o azimute e coordenadas de qualquer local materializado no terreno. Esta determinação foi realizada pelo IGGSP com o uso de teodolitos e cronômetros observando-se os corpos celestes (estrelas), com coordenadas astronômicas conhecidas, possibilitando a determinação da posição geográfica; utilizando a medição de latitude e do tempo com cronômetron (LIMA; COLUCCI, 1940). Quando se efetuava medições astronômicas, leva-se em consideração a direção da linha de prumo e o nível de bolha por isso denomina-se latitude astronômica. Já a medição de um ponto sobre a superfície que considera a normal ao elipsoide, tem-se a chamada latitude geodésica. A determinação da diferença entre as duas depende do conhecimento, em um mesmo ponto, das coordenadas astronômicas e geodésicas sendo esta denominada desvio da vertical, ou seja, a diferença entre a linha de prumo do equipamento e a normal ao elipsoide de referência conforme se pode observar na figura 9 (SICKLE, 2010, p. 16).

\footnotetext{
${ }^{1}$ Utilizado para cálculo de longitude.
} 


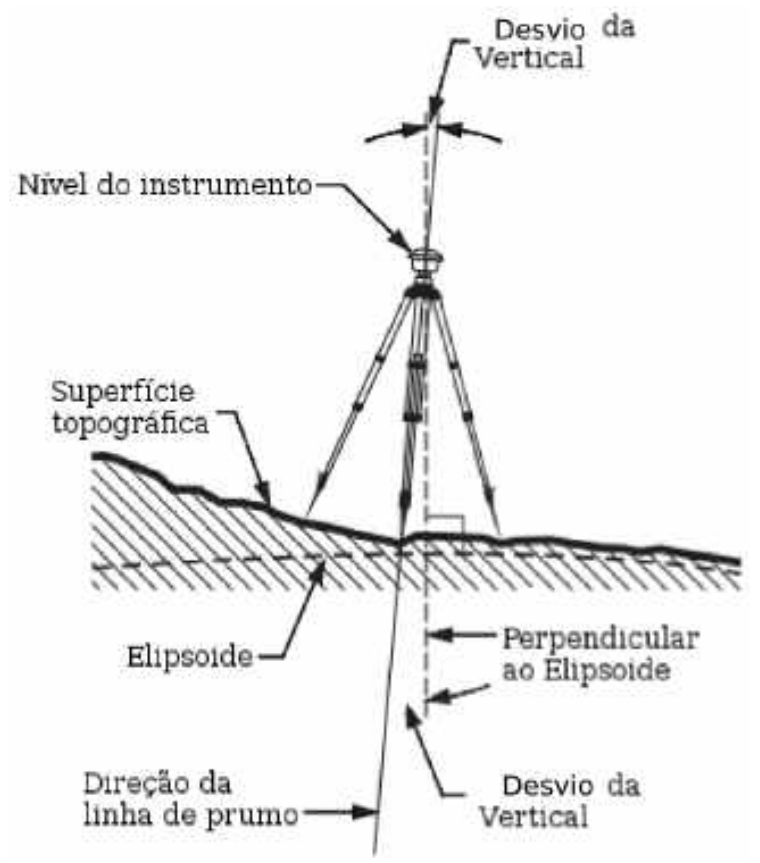

Figura 9: Desvio astronômico da vertical em relação ao geodésico

Fonte: Adaptado de Sickle (2010)

\subsubsection{Triangulação}

Basicamente, a triangulação consiste no estabelecimento físico de uma rede no terreno e na medição dos ângulos de uma série de triângulos conforme ilustrado na figura 10 . O princípio metodológico da triangulação baseia-se em procedimentos trigonométricos simples. Sendo conhecido o comprimento de um lado do triângulo de partida (denominado base) e os ângulos, em direção a outros vértices, os lados e ângulos podem ser calculados ${ }^{1}$.

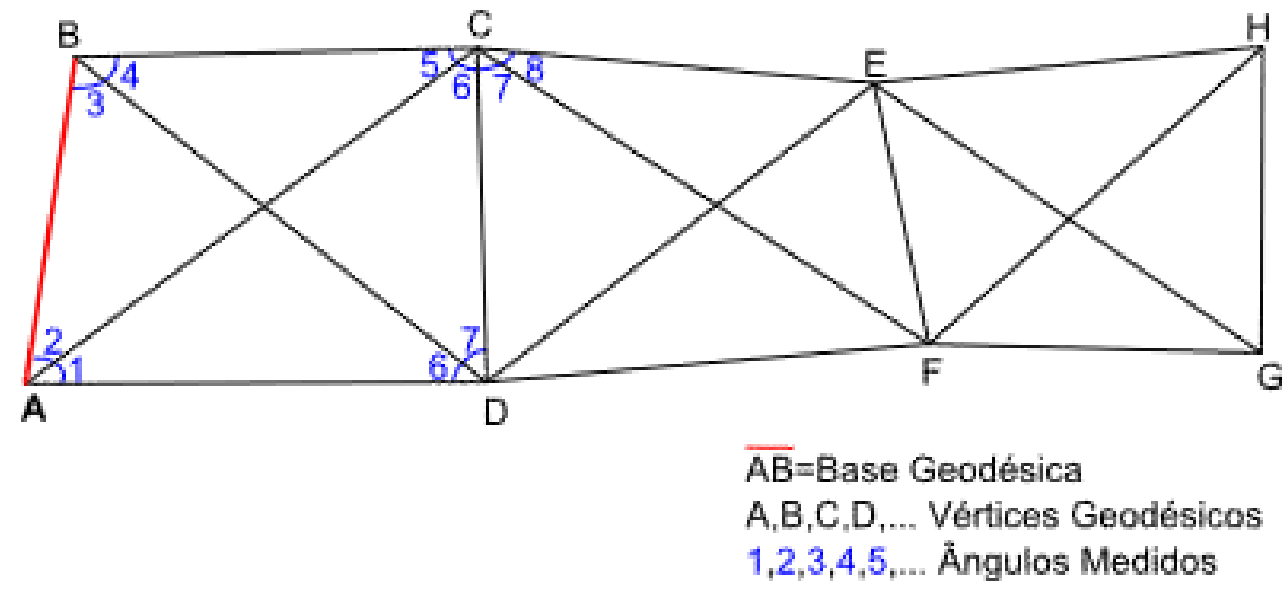

Figura 10: Rede de triangulação geodésica

Fonte: GEMAEL 1987, p. 10)

\footnotetext{
ções.

${ }^{1}$ Se forem medidos, além das distâncias, os três ângulos de um triângulo pode-se ajustar as observa-
} 
Para exemplificar uma rede de triangulação geodésica apresenta-se a figura 10 , onde as letras $\mathrm{A}, \mathrm{B}, \mathrm{C}, \mathrm{D}$, etc... representam vértices da triangulação que são materializados fisicamente por marcos devidamente implantados no solo. Já os lados AB, BC, CB, etc... representam geometricamente as visadas feitas por equipamento de medição angular sobre vértices vizinhos isso significa que ângulos horizontais $1,2,3, \ldots$ representam interligação geométrica de todos os vértices (GEMAEL, 1987).

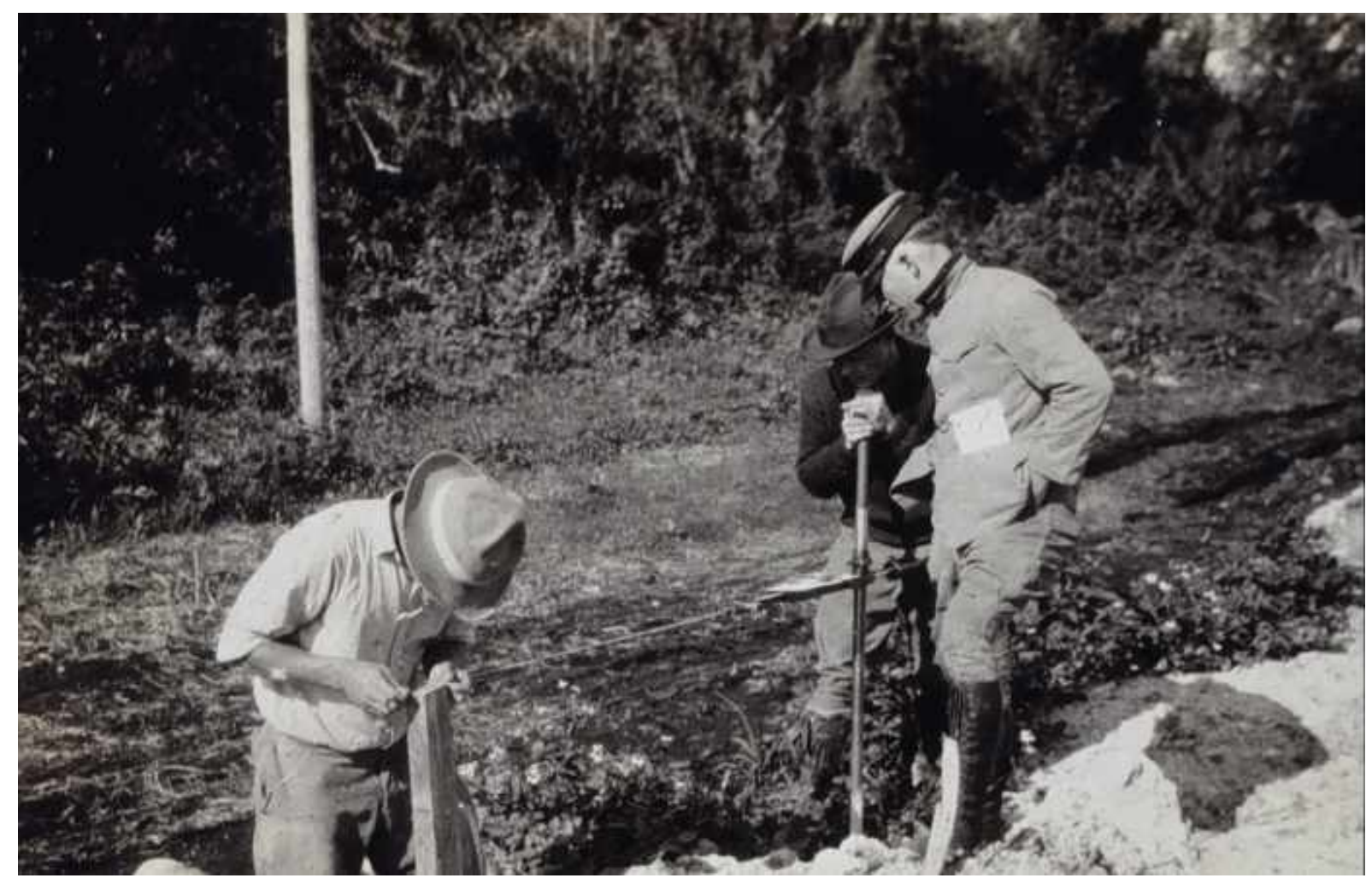

Figura 11: Medição da linha de base utilizando invar

Fonte: Family of Captain Carl I. Aslakson, CGS ${ }^{1}$

O lado medido no primeiro triângulo é chamado de linha de base. As medições eram feitas com muito cuidado, usando fitas ou fios de invar especialmente calibrados (ver figura 11), uma liga altamente resistente às mudanças de comprimento resultantes de mudanças de temperatura.

Como estudado por Cintra (2003) esta técnica foi muito utilizada desde o início dos trabalhos da CGGSP em 1886 como se pode observar na figura 12. Mesmo posteriormente com a utilização de medidores eletrônicos de distância, que serão vistos mais adiante, esta técnica continuou a ser utilizada e somente foi substituída com o emprego dos posicionamentos por satélites artificiais.

\footnotetext{
CGS.

${ }^{1}$ Medida de linha de Base na costa da Georgia E.U.A - Acervo NOAA da Coast Geodetic Survey -
} 

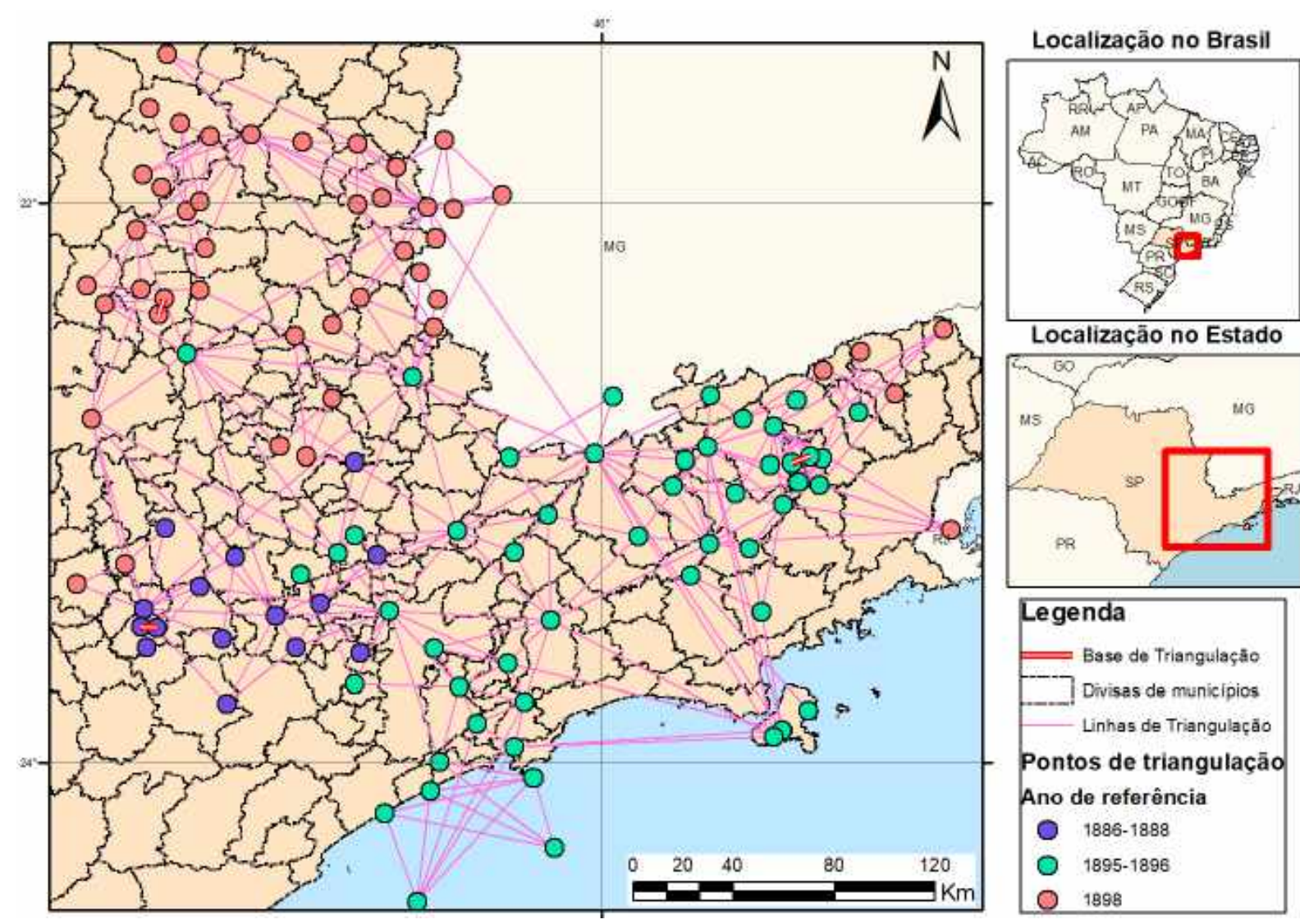

Figura 12: Triangulação geodésica da CGGSP entre 1886 e 1898

Compilação do autor com fonte no acervo do IGCSP (2017)

\subsubsection{Posicionamento Altimétrico}

O levantamento vertical é o processo de determinação das alturas de vértices elevados acima do nível médio da superfície dos mares. O nivelamento geodésico é utilizado no estabelecimento de rede primária com vértices de coordenadas verticais acuradas. Como referência inicial são feitas medições, utilizando marégrafos, para a determinação de uma superfície média do nível mar. Estas medições são realizadas a cada hora, por um período de vários anos. Para que estas alturas sejam determinadas são necessárias técnicas de medição por nivelamento, a saber: geométrico ou diferencial, trigonométrico, taqueométrico e barométrico - que produzem informações de precisão variável. O método mais utilizado foi o diferencial por produzir resultados relativamente precisos (ver figura 13). 


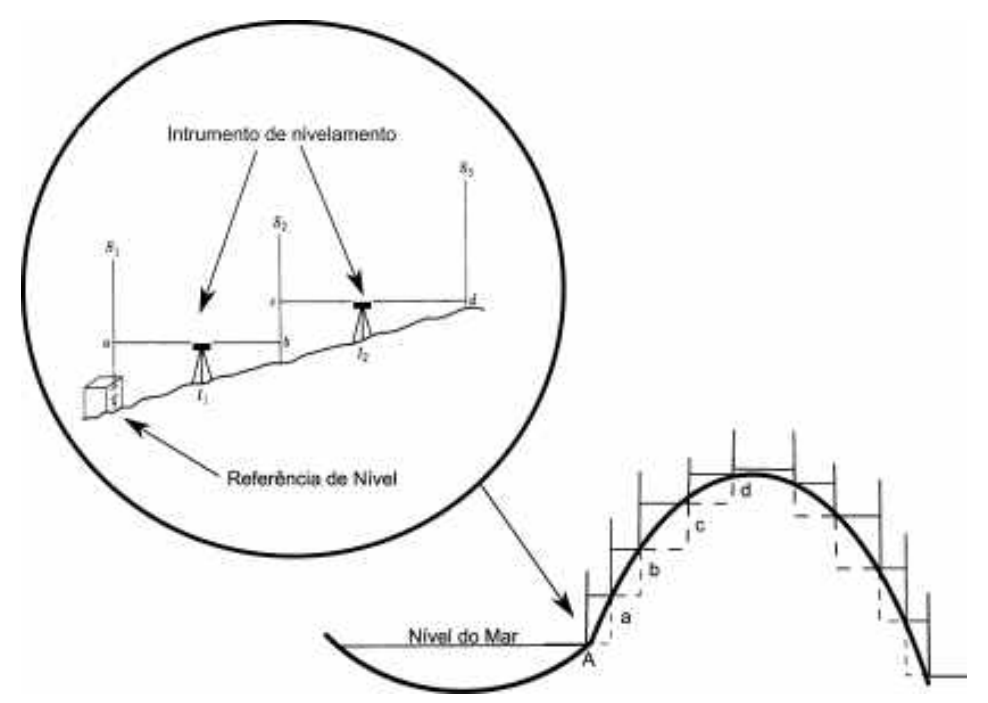

Figura 13: Técnicas de nivelamento

Fonte: Adaptação do autor de DMA (1983, p. 72)

Os pontos de referência utilizados para estas medições devem ser referenciados a uma superfície geopotencial que tradicionalmente era o "nível médio dos mares", através de marégrafos, como se detalhará na secção 3.2.1.1.

Em termos da época, por considerar que as altitudes estavam referidas ao nível médio dos mares estas eram denominadas altitudes ortométricas; com o passar do tempo está denominação foi modificada, para trabalhar com o geoide e definições mais bem colocadas leva-se em conta, entre outras coisas, a distribuição de massas no interior da terra. Na impossibilidade de tal conhecimento, atualmente estas altitudes denominam-se de pseudoortométricas (GEMAEL, 1999).

\subsection{Técnicas aerofotogramétricas utilizadas nos mape- amentos}

Com o avanço do tempo, grandes áreas passaram a ser mapeadas e para isso foi desenvolvida a técnica aerofotogramétrica, que utiliza a geodésia para determinar coordenadas de pontos de apoio visíveis nas fotografias; o que permite a aplicação da aerotriangulação (FORREST, 1964).

Procurando entender o estado da arte da aerofotogrametria nas décadas de 1940 a 1960 DOYLE (1964) descreveu parte da evolução das técnicas fotogramétricas ocasionadas pela influência de trabalhos de cientistas, técnicos e inventores, como: Pulfrich (1858-1927), Hugershoff (1882-1941), Otto von Gruber (1884-1942), Earl Church (1890-1956) e outros. 
Estes forneceram subsídios para diversas inovações cientificas e tecnológicas que foram essenciais para o desenvolvimento da técnica aerofotogramétrica analógica, até meados da década de 50 e 60 (SCHMID, 1953, ING, 1956).

Segundo DOYLE (1964) as técnicas instrumentais, embora posteriormente substituídas pelas analíticas e hoje pelas digitais, foram utilizadas desde o surgimento do Aerokartograph (aerocartógrafo, ver figura 14), desde 1926 até meados da década de 60. Segundo Ghosh (1993) na fotogrametria, o termo "analítico" foi utilizado de forma sinônima a "computacional", sendo as soluções obtidas por métodos matemáticos de forma oposta ao termo "Analógico" em que as soluções eram obtidas por analogia ou semelhança desenvolvidas através de procedimentos ópticos mecânicos.

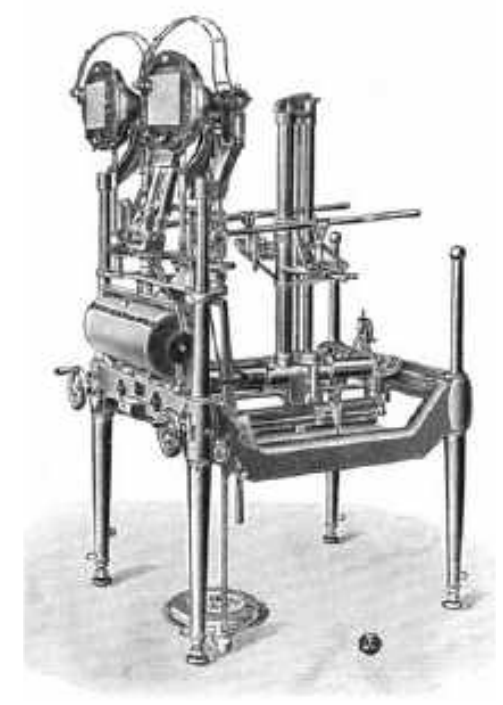

Figura 14: Equipamento aerokartograph

Fonte: Hugershoff (2013, p.100)

Para a orientação dos pares de fotografia com estereoscopia, a técnica de eliminação de paralaxe foi utilizada durante toda a vigência do processo fotogramétrico analógico. Este procedimento em que são feitas transferências de orientações de pares estereoscópicos é descrito por Franco (1962), McGlone et al. (1980). Esta metodologia consiste inicialmente em inserir no equipamento as fotografias e posicioná-las em relação ao seu feixe perspectivo (Orientação Interior), depois a orientação de cada feixe perspectivo deve ser relacionada com seu homólogo de modo que ambas assumam a mesma posição relativa que tinham durante a tomada (Orientação Relativa), e depois se posiciona o conjunto destes dois feixes em relação ao terreno (Orientação Absoluta). Outra forma de descrever o processo de orientação relativa em conjunto com a absoluta é chamado de orientação exterior; parte deste processo consiste em remover inicialmente a paralaxe em y utilizando a leitura de 
seis pontos em cada modelo (ver figura 15). Koper (1974) salienta que se persistir a paralaxe em y, depois deste processo, isso é um forte indício de que há inclinação em uma ou ambas as fotografias e / ou uma diferença na altura do voo que interfere no ajuste estereoscópico do par.

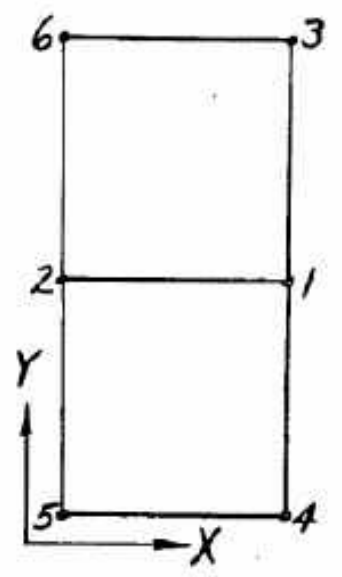

Figura 15: Esquema de leitura de pontos (1 a 6) para remoção da paralaxe em y Fonte : Forrest 1964, p.4)

Como descrito por Ghosh (1993), em meados da década de 1960 formou-se um consenso sobre a melhora da qualidade das medidas obtidas por fotogrametria quando se utilizam técnicas analíticas. Durante a década de 1950 a solução analítica viável tecnicamente se mostrava pouco prática, e assim uma alternativa foi a adoção da técnica de orientação relativa numérica proposta por Franco (1962 apud JERIE, 1957), porém também pouco viável, pois era considerada demorada para ser aplicada sistematicamente devido ao grande número de cálculos necessários, conforme descrito por Franco 1962 , p.31-43).

A década de 60 foi marcada por diversos avanços na ciência fotogramétrica como descrito por Ghosh (1993, p.315) sendo caracterizada pelo advento de equipamentos eletrônicos e computação para cálculo, viabilizando técnicas de ajustamento por blocos, estudadas no início do século XX e que foram melhor compreendidas e implementadas nesta época.

A triangulação analítica inicialmente era utilizada para controlar a aerotriangulação instrumental, como apontado por McNair (1957), mas posteriormente foi utilizada para densificar pontos de controle e fornecer pontos, calculados eletronicamente, para orientar estereomodelos em equipamentos analógicos. O objetivo inicial de utilizar as técnicas analíticas era resolver alguns problemas associados a diversas dificuldades do método ins- 
trumental (MCNAIR, 1957; FORREST, 1964), tais como: distorção da objetiva (câmera), curvatura da terra, refração atmosférica, diminuição de erros instrumentais, trabalhar com diferentes focais e fotografias em um mesmo bloco. Esse processo tinha como principal desvantagem, na década de 50, a adoção metodológica de cálculos eletrônicos e computacionais durante o processo triangulação. Porém, isso com o passar do tempo, se tornou uma grande vantagem pela evolução eletrônica e computacional, permitindo o desenvolvimento da triangulação em bloco da fotogrametria digital (MCGLONE et al., 1980, p. 847). As inovações da década de 60 no âmbito da fotogrametria analítica não foram implementadas imediatamente; como forma intermediária foi utilizada a técnica conhecida como semianalógica sendo definida por Lugnani (1987) como sendo uma combinação entre ambos os processamentos, o analógico para construir modelos estereoscópicos e o numérico para a concatenação dos modelos, além de permitir a gravação dos elementos restituídos em computador. Sobre as técnicas para a aerotriangulação utilizadas no Brasil e no exterior durante as décadas de 60 e posteriores, veja-se Cintra e Ribeiro (1991) em que se aponta que no Brasil não se empregou, praticamente, a fotogrametria analítica, passando-se diretamente da analógica para a digital. Ilustrando esta evolução observe-se a figura 16 que descreve como foram as tendências de utilização destas tecnologias (analítica, analógica, semi-analítica e digital) entre 1960 e 2000.

\section{USO}

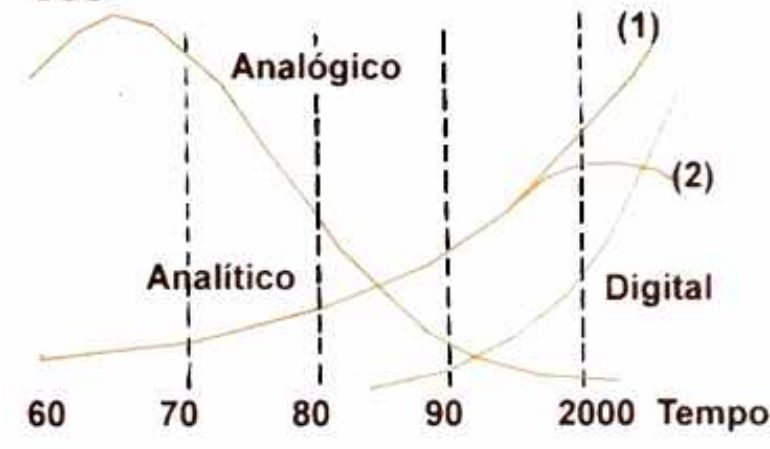

(A) PAISES DESENVOLVIDOS

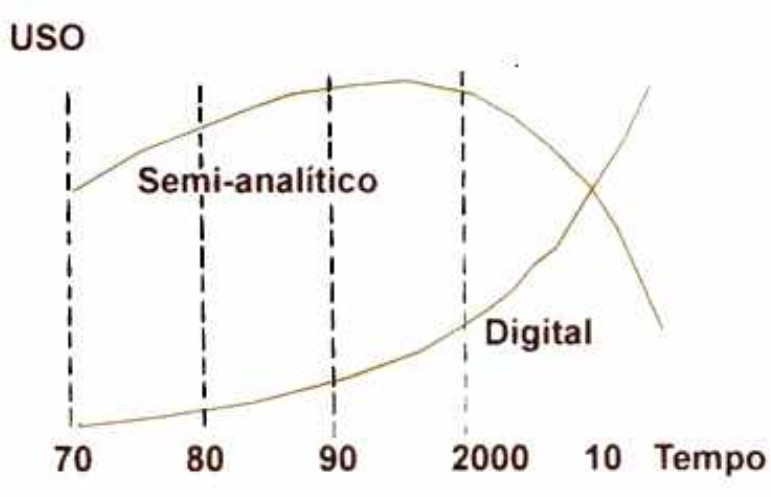

(B) BRASIL

Figura 16: Evolução da técnica aerofotogramétrica no Brasil e outros países Fonte: Cintra e Ribeiro (1991)

Os primeiros levantamentos aerofotogramétricos no Brasil foram executados pelo Exército Brasileiro em meados de 1922, conforme descrito no Apêndice C (na página 176). Além da atuação da força aérea, o governo americano e o governo brasileiro através do Instituto de Geografia e Estatística (IBGE), desde a década de 1940 iniciaram processos conjuntos de elaboração de mapeamentos. Mais detalhes destas iniciativas estão na secção no C, mais especificamente na página 177 . 
Pode-se considerar assim que somente com auxílio externo foram elaborados os primeiros mapeamentos de grande extensão territorial, ou seja, com o acordo entre o governo brasileiro e o norte-americano. Este proporcionou ao Brasil, e outros países, um aumento considerável de produção cartográfica. Neste sentido destaca-se a atuação da Força área americana na execução de levantamentos aerofotogramétricos executados no Brasil durante a década de 1960. Detalhes desta execução podem ser vistos no Apêndice C.1.1 (na página 180). A seguir, será apresentado um breve resumo de alguns conceitos técnicos da aerofotogrametria, destacando-se pontos importantes utilizados na análise do mapeamento, objeto de estudo, deste trabalho.

\subsubsection{Conceitos Fotogramétricos}

Para analisar a cartas topográficas produzidas a partir de aerolevantamentos abordaremos alguns conceitos fotogramétricos. Para isso serão observadas características das fotografias utilizadas para este fim. Alguns conceitos fotogramétricos de interesse são:

- Distância focal - pode-se definir como sendo a distância entre o centro perspectivo da lente e o plano sensível à luz que irá registrar a fotografia (filme fotográfico ou sensor digital), conforme ilustrado pela figura 17 .

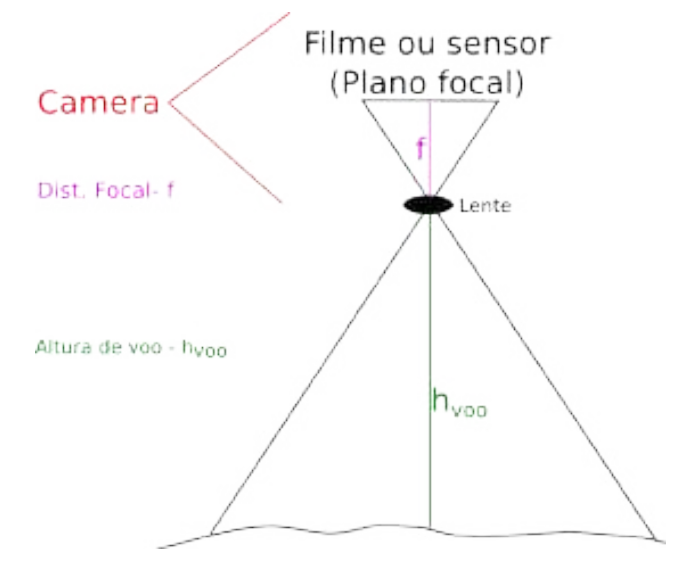

Figura 17: Distância focal fotogramétrica Fonte: Autor

- Escala de fotografia aérea - É decorrente da relação entre a distância focal da câmara e a altura de vôo da aeronave. Entende-se ainda que quando a distância focal aumenta a escala das fotografias torna-se maior; logo para qualquer altura de voo as câmaras com lentes de distância focal grande podem produzir fotografias de escala maior do que as de distância focal curta. Se uma fotografia for ampliada ou 
reduzida, a distância focal equivalente para esta nova fotografia será também modificada proporcionalmente à ampliação ou redução (TEMBA, 2000). Para analisar a escala das fotografias utiliza-se a expressão proposta por Jensen e Epiphanio 2011. p. 157), conforme a expressão 2.1. Nela $a b$ representa a medida da fotografia e $A B$ a distância considerada verdadeira;

$$
E=\frac{a b}{A B}
$$

- Sobreposição - é o valor pelo qual uma fotografia se sobrepõe a área coberta por outra fotografia contígua e é expressa em porcentagem. A tomada fotográfica é projetada para produzir $60 \%$ de sobreposição longitudinal (entre fotos na mesma linha de vôo) e $30 \%$ de sobreposição lateral (entre fotos em linhas de vôo adjacentes). Para garantir isso eram utilizados equipamentos chamados intervalômetros, que permitem a tomada da fotografia em tempos determinados previamente, supondo que o avião esteja voando em uma velocidade constante ARMY; FORCE, 1970, p. 8). Estes conceitos são ilustrados na figura 18. Também se procura corrigir a deriva lateral provocada pelo vento.

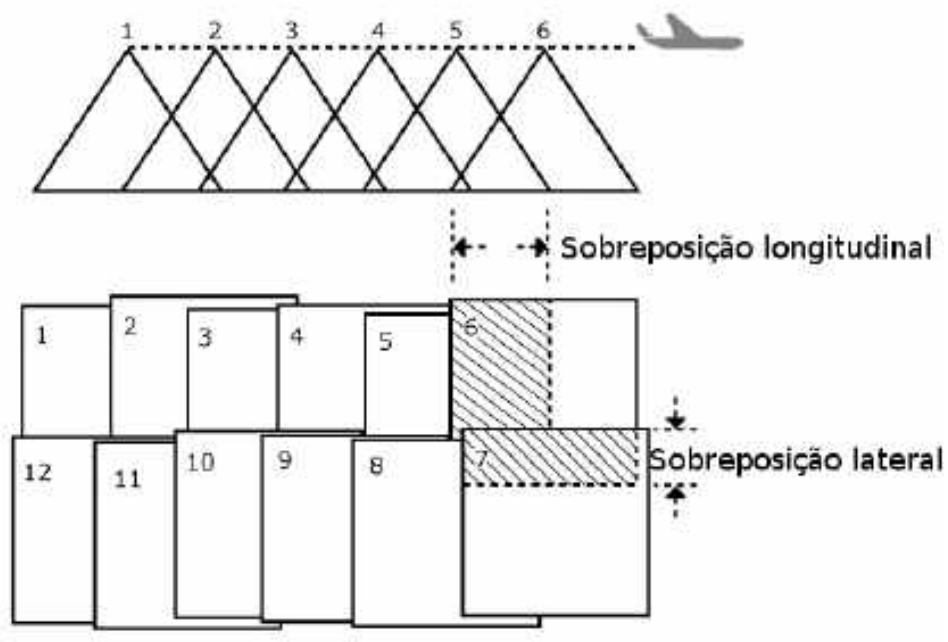

Figura 18: Sobreposição lateral e longitudinal

Fonte: Autor

Para analisar a compatibilidade da escala, proposta para a elaboração de cartas topográficas, Redweik (2007) estabelece empiricamente a regra da expressão 2.2 para determinar a escala da foto em função da escala da carta pretendida (Von Gruber), para câmeras digitais. Nela $c$ é a distância constante (focal) da câmera, $m c$ é o módulo da escala da 
carta e mf é o módulo da escala da foto.

$$
m f=c \sqrt{m c}
$$

A partir desta equação pode-se calcular os valores de escala da fotografia (mf) e da carta, descrito na tabela 1 .

\begin{tabular}{l|l}
\hline \multicolumn{1}{c|}{$\mathbf{1 : m c}$} & \multicolumn{1}{c}{$\mathbf{1 : m f}$} \\
\hline $1: 500$ & $1: 3.500-1: 5.000$ \\
\hline $1: 1.000$ & $1: 5.100-1: 8.000$ \\
\hline $1: 2.500$ & $1: 8.500-1: 13.000$ \\
\hline $1: 5.000$ & $1: 12.100-1: 18.000$ \\
\hline $1: 10.000$ & $1: 17.000-1: 26.000$ \\
\hline $1: 25.000$ & $1: 28.000-1: 42.000$ \\
\hline $1: 50.000$ & $1: 40.000-1: 60.000$ \\
\hline $1: 100.000$ & $1: 60.000-1: 90.000$ \\
\hline
\end{tabular}

Tabela 1: Módulo de escala da foto para diversas escalas de carta

Autor: Redweik (2007, p.5)

Porém, com a utilização de câmaras analógicas Redweik (2007) opta frequentemente por escalas maiores do que as indicadas na tabela 1, como exemplo para a carta 1:25000 é corrente utilizarem-se fotografias à escala 1:220001․

\subsubsection{Aerofotogrametria no Estado de São Paulo}

Embora tenha executado muitos aerolevantamentos no Estado de São Paulo o IGGSP não teve o pioneirismo na contratação de trabalhos fotogramétricos em território paulista. O governo do município de São Paulo financiou um mapeamento detalhado, considerado um dos pioneiros no mundo, em escala urbana. Assim, a prefeitura da cidade de São Paulo, contratou para elaboração de um mapa cadastral, a empresa italiana Sociedade anonima de levantamentos aerofotogramétricos Società Anonima Rilevamenti Aerofotogrammetrici - S.A.R.A, que formou aqui a empresa SARA Brasil (ALTIĆ et al., 2017, p. 20).

Foi utiliza a técnica NISTRI entre 1928 e 1932, com os equipamentos fotográficos, o Fotocartógrafo e o Fotomultiplex da OTTICO MECCANICA ITALIANA - OMI, na escala de 1:5000 e 1:1.000 (NISTRI, 1954). A análise dos produtos cartográficos produzidos pela

\footnotetext{
${ }^{1}$ Acredita-se que a qualidade dos filmes tem influência neste valor
} 
SARA foi objeto de estudo na dissertação produzida por Lima (2012) e foram analisados diversos tópicos que, além de levantar a história do documento cartográfico e dos insumos utilizados para a elaboração do mesmo, analisou a precisão dos documentos cartográficos produzidos pela SARA.

Com o sucesso do mapeamento de São Paulo, outras prefeituras começaram a contratar voos aerofotogramétricos para a obtenção dos mapeamentos topográficos cadastrais, e isso foi o primeiro incentivo para a criação das primeiras empresas paulistas de fotogrametria em décadas posteriores. O decreto de 19251 proibiu a tomada de fotografias em voo; mas mesmo assim a revolução constitucionalista de São Paulo (1932) utilizou este recurso durante os combates, como se pode observar na figura 19 que traz uma reportagem que mostra o detalhe de uma ponte destruída, pelos constitucionalistas, na região de Cachoeira Paulista durante as batalhas 2 .

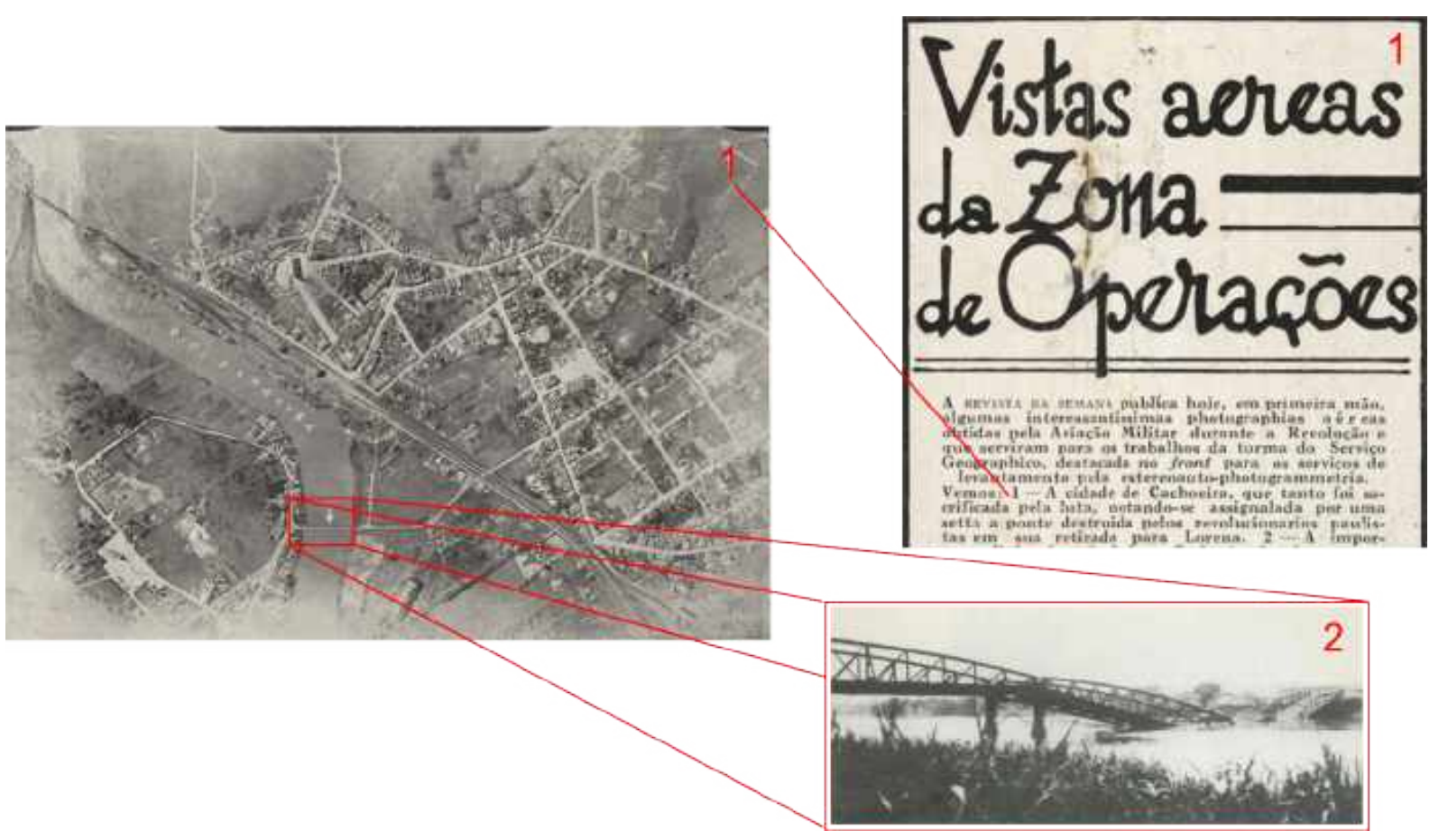

Figura 19: Reportagem com fotografia aérea (1) e no detalhe foto tirada em solo (2) Fonte: Autor a partir de compilação da Revista da semana (1932) e Murakami (1982)

Nos anos seguintes os levantamentos aerofotogramétricos foram utilizados para auxiliar nos antigos processos de elaboração de mapeamentos. Como descrito por Rocha (1941) os primeiros levantamentos com auxílio da cartografia sistemática foram da década de 1940, conforme também noticiado por jornais da épocas? Elaborado a partir de

\footnotetext{
${ }^{1}$ Câmara federal Decreto $^{o}$ 16.983, de 22 de Julho de 1925 (BRASIL, 1925).

${ }^{2}$ Reportagem da Revista da Semana n ${ }^{\circ} 48$ de 12 de novembro de 1932 - Acervo da Biblioteca Nacional.

${ }^{3}$ Inauguração dos Serviços Aerofotogramétricos de São Paulo. O Estado de S. Paulo, 16/05/40,
} 
fotografias aéreas verticais e feitas com equipamentos e pessoal financiados pelo Departamento de Águas do Ministério da Agricultura, já se faziam, ao menos em alguns locais, os levantamentos topográficos com o auxílio destas técnicas, ou seja, já se contava com a utilização de pares aerofotogramétricos com apoio dos trabalhos de topografia, porém a título de analisar questões pontuais como, por exemplo, nos municípios de: Itu, Cananéia, Iguápe, Santos e São Paulo, coisa que pode ser vista, de forma resumida, na figura 20 e comparada com a lista completa que consta no acervo do IGCSP (ver Anexo A pg. 206). Embora estes avanços tenham sido importantes não foram capazes de produzir cartas topográficas, mas auxiliaram na produção de alguns mapas municipais durante as décadas de 1950 pelo IGGSP.

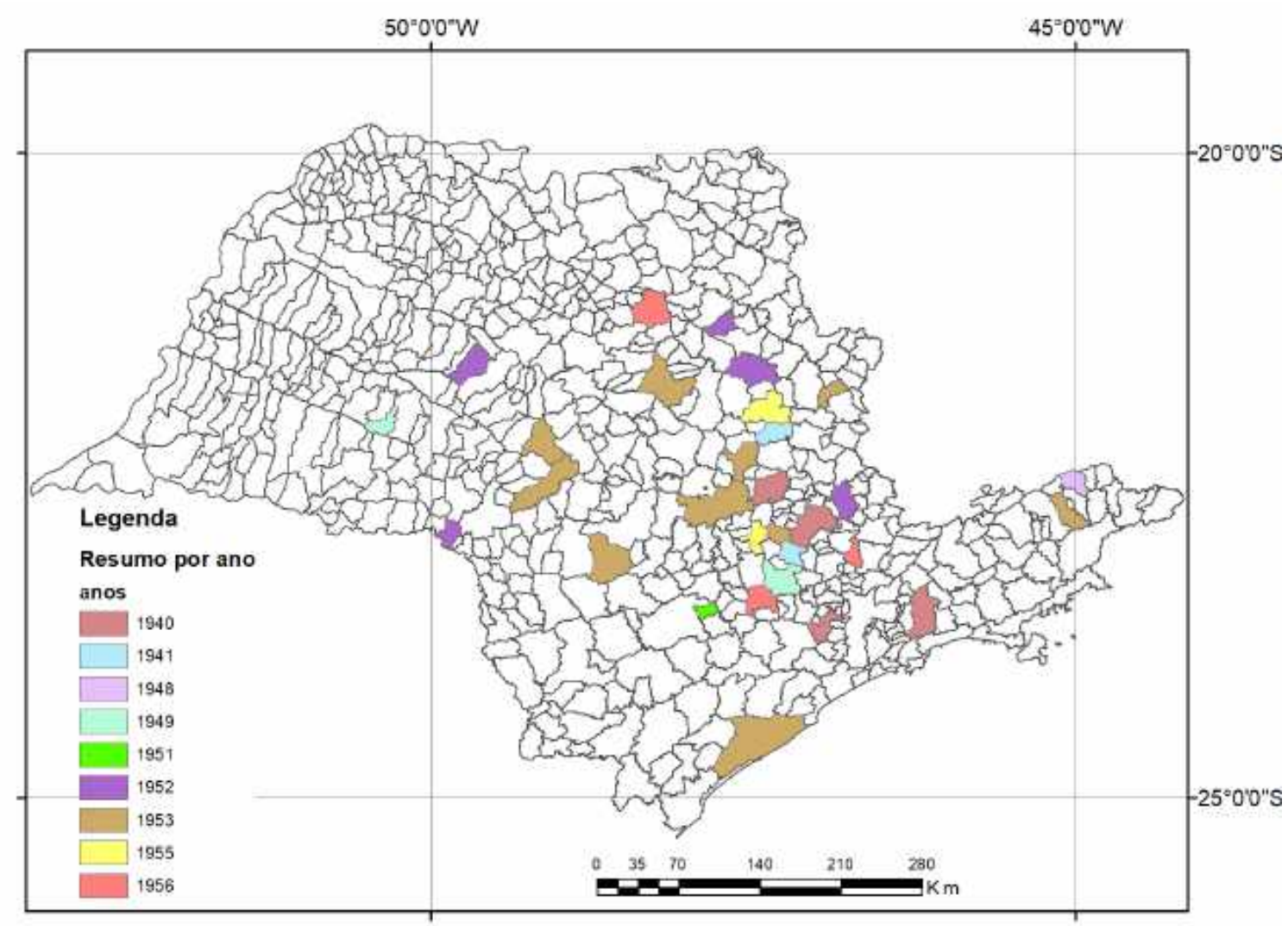

Figura 20: Municípios com pequenos voos entre 1940 e 1956

Fonte: Autor a partir de compilação do acervo IGCSP (2017) (detalhes Anexo A pg 206)

O desconhecimento dos recursos naturais ainda se fazia presente nas décadas de 50, principalmente no tocante à hidrografia e assim se destacava a necessidade de mapeamentos. Um exemplo desta necessidade foi a utilização das antigas cartas da CGGSP (1:1.000.000) pela Comissão Interestadual da Bacia Paraná-Uruguai (CIBPU), pois não existiam levantamentos de maior detalhe nessa área. Embora estas cartas tivessem suas página 7. 
limitações, foram de grande utilidade para executar estudos de potencial energético na região dos Saltos do Urubupungá (região noroeste do Estado), para a geração de energia (CHIQUITO, 2011).

Observando a necessidade da gestão dos recursos hídricos, e para isso o necessário mapeamento para conhecimento destes recursos, em 1951 foi aprovada a lei estadual $n^{o}$ 1350 $0^{1}$ que criou o DAEE e lhe deu atribuições para proceder à realização de levantamentos topográficos, sondagens e estudos geológicos no que tange às atividades de recursos hídricos (SÃO PAULO (Estado), 1951). A partir desta lei o DAEE contratou em 1953 diversos levantamentos como, por exemplo, o levantamento aerofotogramétrico de 4.064 $\mathrm{km}^{2}$ em áreas do vale do Paraíba.

Depois de apresentar o estado da técnica utilizada na época de produção dos mapeamentos objetos do presente trabalho, passa-se a estudar, no próximo capítulo os referenciais teóricos para o desenvolvimento da análise deste material.

\footnotetext{
${ }^{1}$ Lei no 1350 da Assembleia Legislativa do Estado de São Paulo 12 de dezembro de 1951 (SÃO PAULO (Estado), 1951).
} 


\section{REFERENCIAIS GEODÉSICOS}

Neste capítulo serão apresentados os referenciais geodésicos utilizados à execução deste trabalho, acompanhados de um breve histórico sobre a fundamentação destes, de forma a apresentar alguns conceitos importantes. Os primeiros sistemas geodésicos a serem definidos pela ciência partiram da comprovação cientifica da forma elipsoidal da terra. Esta foi comprovada e avaliada por duas expedições, uma próxima ao polo norte (região da Lapônia) outra ao equador (região onde fica hoje o Equador) nas quais se demostrou que a teoria de Newton, quanto ao achatamento dos polos, estava correta (KONVITZ, 1982). Ocorreram diversas tentativas para definir melhor as medidas do semieixo maior e do achatamento terrestre. Fischer (1975b) relaciona alguns valores os quais adiciona-se valores: para GRS80, calculado posteriormente pela International Union of Geodesy and Geophysics - IUGG (União Internacional de Geodésia e Geofísica), para o WGS84, calculado pela United States Defense Mapping Agency - DMA (Agência de defesa e mapeamento dos Estados Unidos) conforme apresentado na tabela 2 .

\begin{tabular}{l|l|l}
\hline \multicolumn{1}{c|}{ Propositor } & \multicolumn{1}{c|}{ Raio - km } & Achatamento \\
\hline Erastóstenes & 5.936 ou $6.337^{1}$ & 0 \\
\hline Posidonio & $5.672,3$ ou $4254,2^{1}$ & 0 \\
\hline Al-Mamum & 7.013 & 0 \\
\hline Colombo & $4.821,4$ & 0 \\
\hline Snellius & $6.368,7$ & 0 \\
\hline Picard & $6.371,98$ & 0 \\
\hline Academia Real de Paris & $6.375,73$ & $1 / 334$ \\
\hline Elipsoide Inter. 1924 & $6.378,388$ & $1 / 297$ \\
\hline IUGG Elipsoide 1967 & $6.378,160$ & $1 / 298,25$ \\
\hline Elipsoide Fischer 1968 & $6.378,150$ & $1 / 298,3$ \\
\hline IUGG 1979 & $6.378,137$ & $1 / 298,257222101$ \\
\hline DMA ${ }^{2} 1987$ & $6.378,137$ & $1 / 298,257223563$ \\
\hline
\end{tabular}

Tabela 2: Comparação das medidas do raio equatorial da terra e do achatamento Fontes: Fischer (1975b), DMA (1987) e Moritz (2000)

\footnotetext{
${ }^{1}$ Medidas duplicadas pois a unidade da época utilizada para a medição poderia ser em stadium ou jardas (FISCHER, 1975b).

${ }^{2} \mathrm{~A}$ partir de 1996 a DMA teve suas atividades repassadas a National Imagery and Mapping Agency - NIMA (DMA, 1987)
} 
Nas primeiras determinações do achatamento terrestre as técnicas de posicionamento utilizavam referências celestes para a determinação de coordenadas de referência sobre a superfície terrestre. Pontos de origem eram utilizados como base para a definição de Datum Geodésico, que além das coordenadas dos mesmos determinavam ou definiam um conjunto de parâmetros, que constituem uma referência para um determinado sistema de coordenadas. Neste inclui-se a definição do elipsoide de referência e a sua posição relativamente ao globo terrestre. A materialização do referencial é feita através do cálculo de coordenadas de pontos sobre a superfície a partir de observações geodésicas de distâncias, ângulos e azimutes. Historicamente estas observações eram feitas a partir de métodos geodésicos clássicos: triangulação e poligonação, permitindo que se obtivesse coordenadas de pontos, devidamente materializados no terreno, vinculadas ao ponto de origem. O conjunto de marcos assim estabelecidos com as respectivas coordenadas correspondem ao conceito de sistema geodésico materializado. Os data (plural de datum) utilizados no Brasil serão descritos na sequência.

Com as observações astronômicas constatou-se que as órbitas dos satélites e corpos celestes eram perturbadas, como documentado por Caley em 1859, e isso causava falhas nos cálculos de coordenadas. Porém, com o advento dos satélites artificiais, a partir da década de 1950, obteve-se um número maior de observações. Com isso, e com a proximidade dos satélites em relação à Terra, houve melhoria no cálculo de suas órbitas, e de suas pertubações, o que permitiu calcular melhor os parâmetros da forma terrestre (MUSEN et al., 1961). Com estes estudos foram propostas novas metodologias como a descrita po Guier e Weiffenbach (1958), do Applied Physics Laboratory (APL) (em português: Laboratório de Física Aplicada) da Universidade Johns Hopkins, onde o autor calcula, a partir da análise dos sinais dos satélites Sputnik I e Explorer I, a órbita de cada satélite. O sucesso da técnica foi relatado por Kershner (1979 apud YIONOULIS, 1998). Em 1957 os pesquisadores George Weiffenback e William Guier relataram a possibilidade de determinar a posição de um ponto na Terra (utilizando o conhecimento das órbitas dos satélites) e fizeram com que o projeto até então experimental tivesse financiamento para a elaboração de um sistema de posicionamento. Estes estudos foram básicos para a tecnologia empregada nos sistemas de posicionamento moderno por satélite, hoje conhecido por GNSS.

As determinações de coordenadas por satélite e outros estudos fizeram com que os sistemas geodésicos fossem classificados conforme sua concepção para determinar as coordenadas de origem. Estas concepções, descritas a seguir, são utilizadas de forma a diferenciar os sistemas geodésicos utilizados neste trabalho (OLIVEIRA, 1993). 
- sistema de referência geocêntrico: é aquele que tem sua origem no centro de massa da Terra;

- sistema de referência quase geocêntrico: sistema definido em caráter regional cuja origem não coincide com o centro de massa da Terra, embora estejam relativa muito próximas e os eixos sejam paralelo aos geocêntricos;

- sistema de referência topocêntrico: é o sistema cuja origem está situada na superfície física da Terra;

Com a possibilidade da determinação de coordenadas de pontos em diversos locais da superfície terrestre, a definição de sistemas geodésicos de referência sofreu modificações, pois agora estes não são mais caracterizados por medições em pontos esparsos, mas sim por um arcabouço conceitual, seguido de sua materialização (MONICO, 2008). Atualmente, um Sistema Geodésico de Referência (SGR) é definido por parâmetros e convenções, levando-se em consideração um elipsoide que é ajustado às dimensões da Terra e devidamente orientado, constituindo um referencial adequado para a atribuição de coordenadas a pontos sobre a superfície física.

Quando um referencial é definido e adotado por convenção, a etapa seguinte é caracterizada pela coleta de observações a partir de pontos sobre a superfície terrestre (rede), devidamente materializados. Fazem parte, ainda, o processamento e análise, bem como a divulgação dos resultados, que é, essencialmente, um conjunto de coordenadas associado a uma determinada época. As coordenadas podem vir acompanhadas de suas respectivas velocidades [taxa de variação do valor com o tempo]. Esse conjunto materializa o sistema de referência.(MONICO, 2008, p. 60).

No decorrer deste tópico serão abordados os diferentes sistemas de referência utilizados no Brasil. Outro assunto desta seç̧ão serão os processos de transformação entre estes sistemas para posterior compatibilização entre bases cartográficas, visando a execução das análises propostas neste trabalho.

\subsection{Redes Geodésicas e Sistemas Geodésicos Brasileiros - SGBs}

Os predecessores dos sistemas geodésicos de referência utilizados no Brasil foram as triangulações realizadas por levantamentos geodésicos durante o Império. Com seus primeiros trabalhos sendo executados entre 1852 e 1857, para a demarcação das fronteiras 
brasileiras entre Brasil e Uruguai (LIEBENBERG; DEMHARDT, 2012, p. 173). Outras triangulações foram realizadas para definir algumas referências locais, como a do município neutro de 1866 utilizado para a elaboração da carta topográfica do Rio de Janeiro. O primeiro trabalho com objetivo de dar referência a maiores áreas foi a criação em 1870 da Comissão da Carta Geral do Império. Utilizou a experiência adquirida na base do município neutro, utilizando inicialmente o elipsoide de Bessel (1841) depois o de Clarke (1866) de Projeção Esférica Ortogonal do Brasil (MENEZES, 2011). Mesmo antes do fim do Império a província de São Paulo deu continuidade aos trabalhos da Comissão da Carta Geral em território paulista com apoio da Comissão Geológica americana, iniciativa que cedeu com a criação da Comissão Geográfica e Geológica de São Paulo - CGGSP, em abril de 1886. Com o apoio do engenheiro Carpenter sob ordens do Tenente Wheeler e consultoria do Major J. W. Powell foram iniciados os trabalhos pela medição da base de Campo Largo (DERBY, 1889). Só depois do estabelecimento da República já em 1903 deu-se origem das bases para o primeiro Sistema de Coordenadas Brasileiro denominado CCGB - Comissão da Carta Geral do Brasil (ANCIÃES, 2003, p.28).

As primeiras experiências para estabelecer um sistema de referência geodésico nacional deram-se na década de 1940, com o início do estabelecimento do Sistema Geodésico Brasileiro (SGB). Este tinha como objetivo permitir a localização e representação cartográfica em todo território brasileiro. A caracterização do SGB foi realizada pela ocupação de pontos na superfície terrestre que representavam o controle horizontal e vertical. Seu estabelecimento e manutenção eram de atribuições da antiga CNG e atualmente são do IBGE através de seu Departamento de Geodésia (IBGE, 2000). Sobre o controle horizontal estes podem ser determinados por métodos de triangulação, trilateração e poligonação conforme Torge (1983 apud ASHKENAZI, 1973). A materialização do Sistema Geodésico Brasileiro dá-se hoje através das Redes Geodésicas Brasileiras (RGB): Rede Horizontal, Rede Vertical e Rede Tridimensional (Rede Brasileira de Monitoramento Contínuo RBMC), que são formadas por conjuntos de estações com suas coordenadas geodésicas calculadas e oficializadas. Mais detalhes sobre as realizações, destes sistemas, serão descritos a seguir. O estudo dos referenciais já utilizados no Brasil faz-se necessária quando se quer avaliar a qualidade de mapeamentos antigos, pois necessita-se comparar as coordenadas de pontos dos mapeamentos antigos estudados e os atuais. 


\subsubsection{Datum Córrego Alegre}

De forma a uniformizar a cartografia nacional o IBGE através da CNG $\square^{1}$ estabeleceu, em 1946, o Datum Córrego Alegre (SAMPAIO; MELO, 2015). Para sua representação adotou-se como superfície de referência o elipsoide Internacional de Hayford de 1924, que é caracterizado por um semi-eixo maior (a) de $6.378 .388 \mathrm{~m}$ e um achatamento (f) de 1/297. Como ponto origem foi escolhido o vértice Córrego Alegre, situado em Minas Gerais, no qual o posicionamento e a orientação do elipsoide de referência foram feitos astronomicamente, tendo sido calculada sua orientação para o vértice Uberaba, a partir da rede de triangulação geodésica nacional iniciada em 1944 em Criciúma - SC e onde se adotou valores nulos para as componentes do desvio da vertical e para a ondulação geoidal (IBGE, 1996). Assim esta rede compreende os estados do sul e do sudeste brasileiro, sendo acrescido de poligonações em outros Estados, como apresentado pela figura 21 .

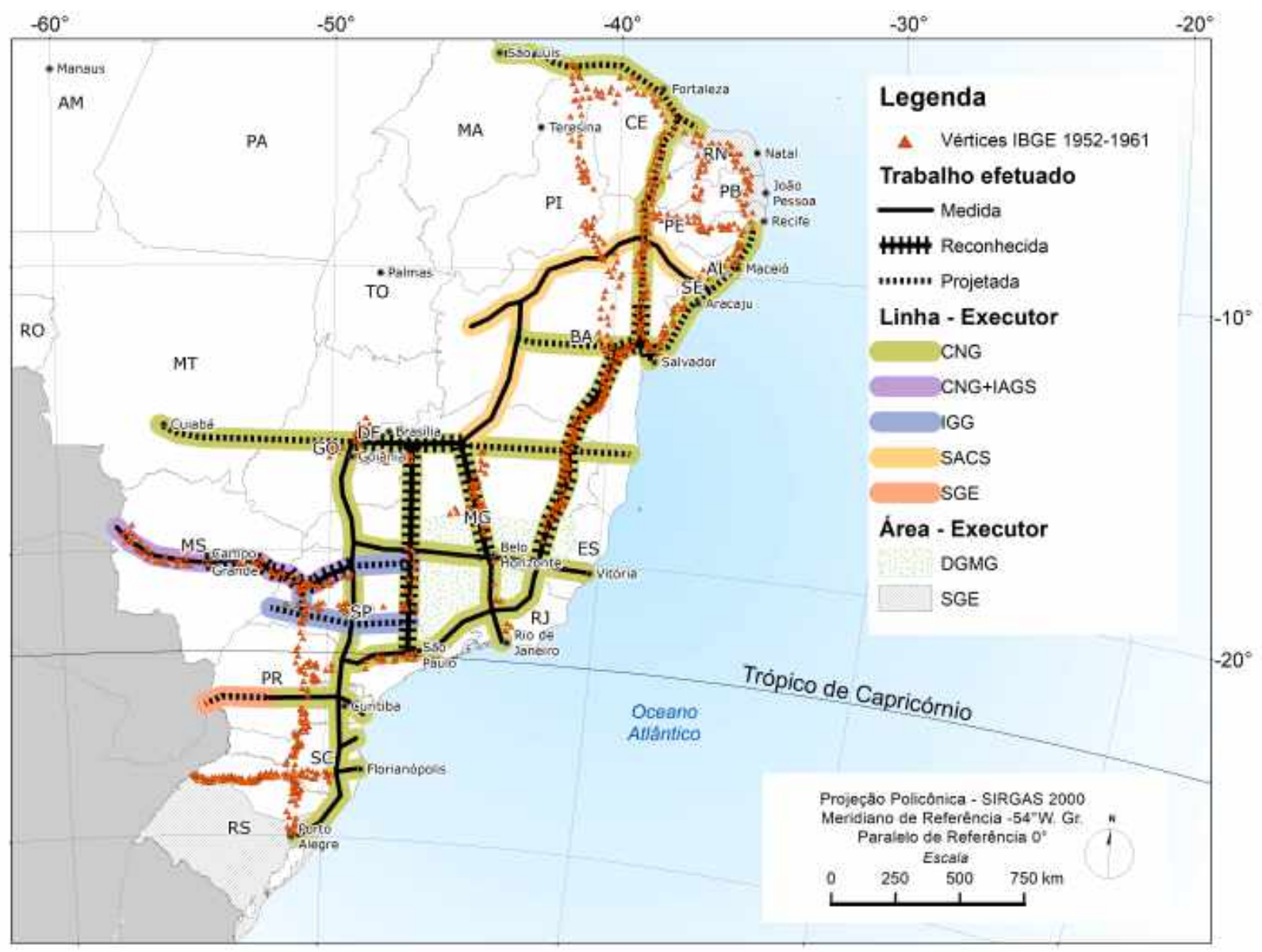

Figura 21: Rede de Triangulação brasileira (1ª ordem) 1944-1961

Fonte: Autor, em compilação de dados de CNG (1952) e IBGE (1996)

${ }^{1}$ Decreto-Lei 9.210, 29 de abril de 1946 (BRASIL, 1946). 
A figura 21 apresenta as linhas de triangulação executadas e em planejamento, isso para o ano de 1952. Os pontos representam os locais levantados até 1961. A rede Córrego Alegre foi concluída em 1961 sendo executada, embora com dificuldades, pela CNG. Como observado na figura 21 representado pelas linhas tracejadas como projeto, em território paulista, deveriam ser executadas pelo IGGSP. Nas pesquisas exaustivas não foram encontrados relatos desta execução. Já os levantamentos executados pela Serviços Aerofotogramétricos Cruzeiro do Sul S/A (SACS), entre 1945 e 1951, foram utilizados para a elaboração de cartas em escala 1:25.000 do projeto Comissão Vale do São Francisco (DORR, 1969, p. 5). Outras instituições como a Serviço Geográfico Exercito (SGE) executaram levantamentos mais ao sul do Brasil e nordeste o Departamento Geográfico de Minas Gerais (DGMG) fez levantamentos concentrados no Estado da instituição. Essa rede contou com 1010 vértices, adotando-se medições em pontos de Laplace, utilizando determinações astronômicas, a cada 200 quilômetros com o objetivo de garantir a rigidez horizontal das cadeias de triangulação, ou seja, medir azimutes de direções para evitar giros e distorções na rede (CNG, 1952).

\subsubsection{Datum Sul Americano de 1969 e SAD96}

Para se obter um único Sistema de Referência para a América do Sul e a necessidade do conhecimento mais detalhado do geóide no continente, foram realizadas, por agências norte-americanas como a Defense Mapping Agency (DMA-TOPOCOM), várias observações astronômicas nos vértices das cadeias de triangulação de alguns países da América do Sul. Inicialmente os estudos conduziram ao estabelecimento do datum provisório PSAD-56 (Provisional South American Datum of 1956), com origem no vértice La Canoa (Venezuela) (CASTAÑEDA, 1986, IBGE, 1996). Nesta tarefa, foi estabelecida a rede de trilateração SHORAN, HIRAN, ligando as cadeias de triangulação clássicas estabelecidas em diversos países, conforme pode ser observado na figura 22: as linhas em cinza são as redes clássicas e as pretas triangulação SHORAN/HIRAN. 


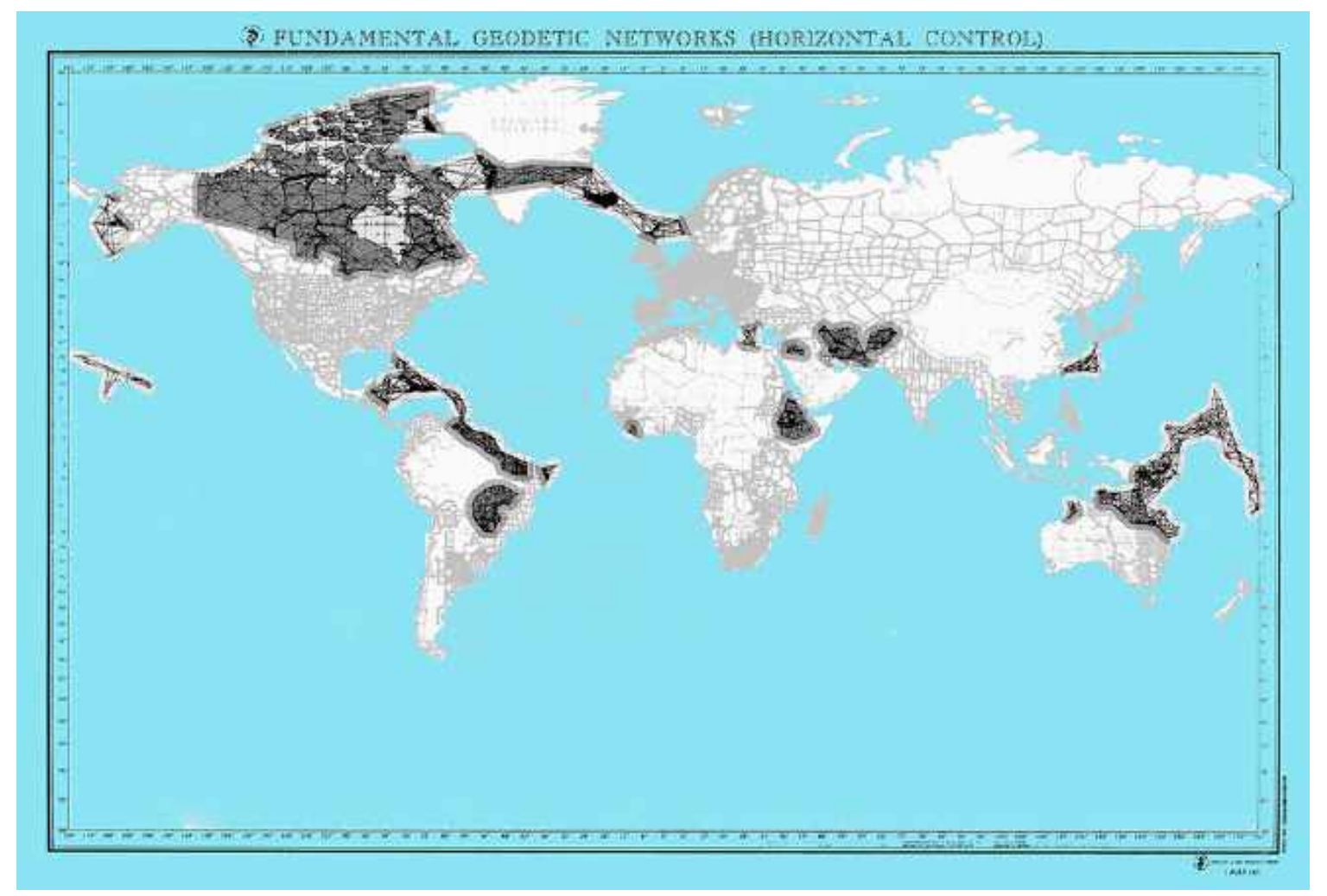

Figura 22: Redes americanas de posicionamento horizontal 1940-1961

Fonte: Rankin (2016)

Em 1958 com o lançamento Vanguard 1, pelo Naval Research Laboratory - NRL, iniciaram-se as determinações de coordenadas utilizando tecnologia espacial. Inicialmente, esta técnica consistia em observar a passagem dos satélites por determinados pontos que tinham suas coordenadas conhecidas e utilizar técnicas como a MINITRACK, que consistia em medir a direção da órbita do satélite (depois de removidas as pertubações gravitacionais da lua e do sol) por meio da interferometria, ou seja, a partir da diferença de fase medida do sinal de $136 \mathrm{MHZ}$ recebido do satélite em locais de coordenadas conhecidas, calculava-se com mais confiabilidade a órbita do satélite. Portanto, a técnica para verificar o posicionamento dos satélites artificiais foi a tecnologia de interferometria por ondas de rádio, sendo esta controlada por câmeras balísticas. Neste processo um sinal era enviado a partir de um transmissor e repetido pelo satélite a dois receptores em solo, permitiram calcular a linha de base (em comprimentos de onda $n \lambda$ ) entre um ponto X e outro $\mathrm{Y}$, assim utilizando para o cálculo eletrônico de diferença da fase $A$ e depois o cálculo do ângulo $(\phi)$ entre o ponto X e o satélite. Isso era feito utilizando a equação básica da interferometria $(\cos \phi=A / n \lambda)$, desta forma obtendo-se a inclinação da órbita, como mostra a figura 23 . 


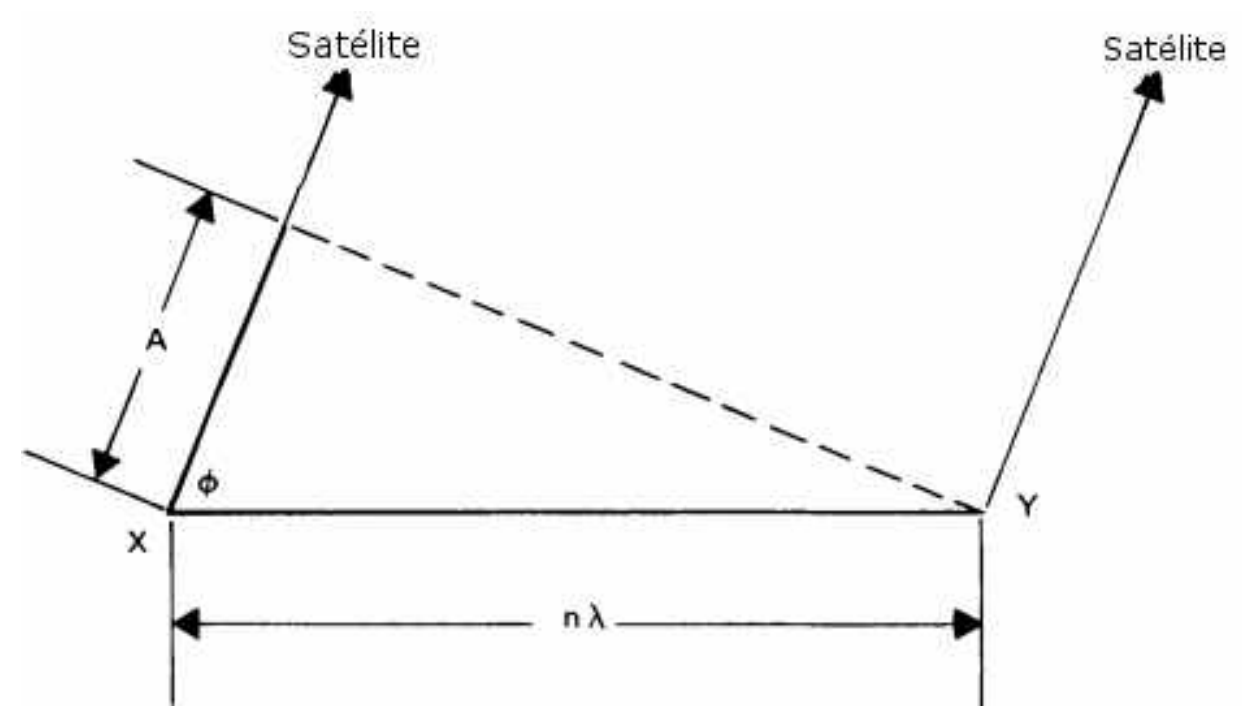

Figura 23: Esquema de cálculo de interferometria por satélite

Fonte: Easton e Fleming (1960)

Depois de mais satélites serem lançados em órbita, como a missão Explorer, foram calculadas as influências das gravidades lunar e solar em sua órbita (MUSEN et al. 1961, p. 41). Com isso, em 1960, a Nasa iniciou sua operação no projeto Minitrack reestruturando-o e rebatizando-o de Spacecraft Tracking and Data (Acquisition) Network $S T A D A N$. A técnica utilizada neste projeto consistia basicamente em realizar observações durante um intervalo de tempo conhecido nos quais eram calculadas as diferenças na fase do sinal emitido pelo satélite, uma vez que esse é recebido em duas antenas separadas $A_{I}$ e $A_{G}$. As posições previstas do satélite para estes tempos eram comparadas com as posições deduzidas teoricamente do satélite para os mesmos tempos. A partir dessas comparações, as correções para a latitude e longitude do ponto $P$ (mas não a altura acima do elipsoide de referência) eram obtidas (figura 24). Esses trabalhos permitiram os primeiros testes que levaram a determinações mais precisas de posição do centro de massa da terra, que foi utilizado posteriormente, nos referenciais cartesianos geocêntricos (MUSEN et al., 1961; UAGS; STATES, 1977; SEEBER, 2003). 


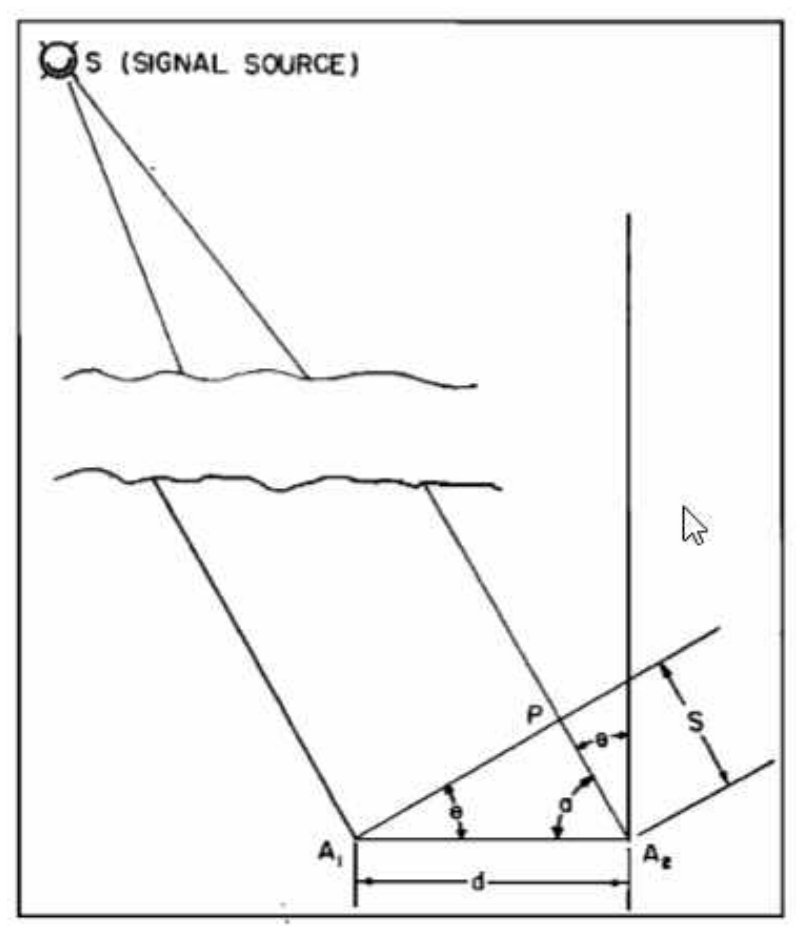

Figura 24: Geometria de observação pela técnica MINITRACK Fonte: Kahn (1960)

Com o advento de novas observações e o estabelecimento de novas redes geodésicas horizontais, em meados da década de 70, foi necessário um novo ajuste para que estas redes horizontais fossem compatibilizadas. Este foi realizado utilizando um sistema computacional executado pelo IAGS, e neste momento referido ao SAD-69 (South American Datum 69). O software utilizado foi o HAVOC (Horizontal Adjustment by Variation of Coordinates), que adota a modelagem matemática da Geodésia clássica (COSTA et al., 1997). Em consequência das limitações impostas pelos meios computacionais da época, a rede brasileira, foi processada através de blocos separados (IBGE, 1996).

Para estes cálculos foram adotados os parâmetros de definição da terra convencionados na UGGI (União de Geodésia e Geofísica Internacional) que propôs na Assembléia Geral de Lucerna, em 1967, a substituição do Elipsoide de 1924 por um associado ao chamado "Sistema Geodésico de Referência 1967", cujos elementos são: superfície de referência elipsoide Internacional de 1967(UGGI67), com semi-eixo maior (a) 6.378.160 metros, e achatamento (f) 1/298,25 (FISCHER, 1975b). No Brasil o ponto de origem foi materializado no vértice Chuá (CASTAÑEDA, 1986; IBGE, 1996). As alturas do geoide para as estações no Datum sul-americano 1969 (South American Datum - SAD) foram fornecidas pelo DMA ( Topographic Center) levando em consideração, por definição, uma separação nula do geoide na estação CHUÁ (UAGS; STATES, 1977; CASTAÑEDA, 1986). 
Conforme descrito pelo IBGE (1996) foram realizados ajustamentos posteriores da rede planimétrica (SAD69) que, com o avanço da capacidade computacional e a utilização de tecnologias como o Global Positioning System - GPS e Sistema TRANSIT, conhecido como NAVSAT (Navy Navigation Satellite System) - efeto Doppler, possibilitaram a realização de um ajustamento do SAD para uma realização que facilitasse sua integração com o Sistema GPS. Esta realização do SAD ficou conhecida como SAD69/96 e a distribuição de pontos utilizada para esta realização pode ser observada na figura 25.

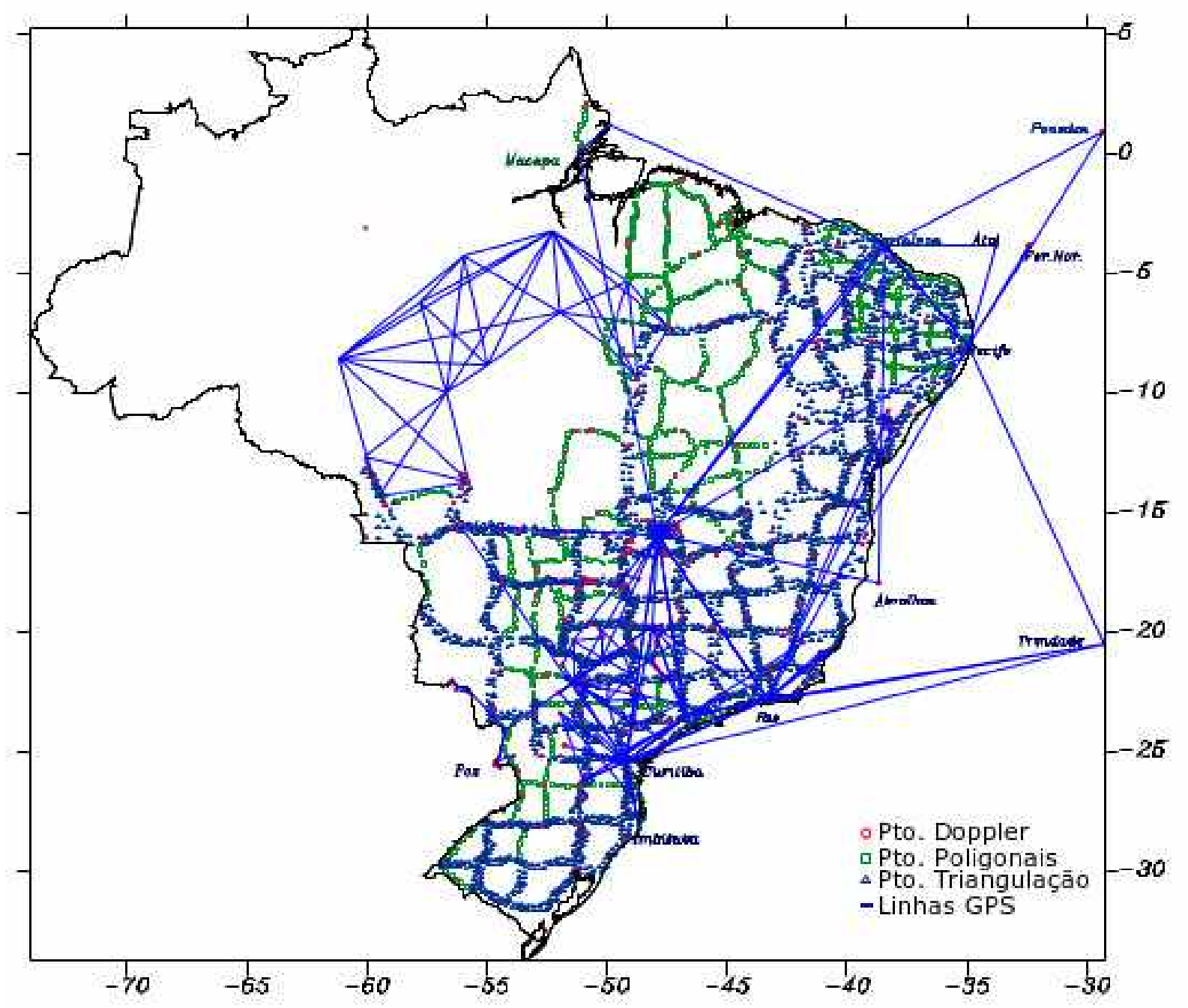

Figura 25: Distribuição dos pontos de apoio e técnicas (SAD69/96)

Fonte: IBGE (1996)

Outro avanço da tecnologia foram os medidores eletrônicos de longas distâncias, por volta de metade de 1965. Com medições mais precisas foi possível melhorar o cálculo e efetuar com mais rapidez as triangulações. Assim possibilitando que novas campanhas de levantamento obtivessem coordenadas mais precisas, densificando os pontos em território sul-americano. A utilização destes equipamentos e das medições por satélites, durante a 
década de 1970, e cooperações internacionais e nacionais permitiram importantes avanços nos processos de medição. No Brasil houve a cooperação entre o IBGE e a DSG na execução de alguns levantamentos de campo UAGS; STATES, 1977, CASTAÑEDA, 1986). A partir de então as coordenadas no território sul-americano já não foram mais calculadas somente por astros naturais (astronomia de posição clássica), como no passado, mas também utilizando satélites artificias que já utilizavam de medições laser, conhecidas como técnica Doppler utilizando o satélite TRANSIT (UAGS; STATES, 1977).

\subsubsection{O Sistema SIRGAS2000}

Segundo Fortes (2000) o Sistema de Referência Geocêntrico para a América do Sul SIRGAS foi um projeto criado na Conferência Internacional para definição de um Datum Geocêntrico para a América do Sul, ocorrida de 04 a 07 de outubro de 1993, em Assunção, Paraguai, a convite da Associação Internacional de Geodésia - IAG, do Instituto Pan-americano de Geografia e História - IPGH e da Agência Cartográfica do Departamento de Defesa dos EUA - DMA (atualmente, Agência Nacional de Mapas e Imagens NIMA). Tendo como objetivo principal a adoção de um sistema geocêntrico materializado por pontos de referência no continente sul-americano. Neste evento ficou convencionada a utilização do elipsoide GRS80 ( $\mathrm{a}=6.378 .137 \mathrm{~m}$ e f=1/298,257222101), além de estabelecer e manter uma rede de referência coletada. Posteriormente, entre os meses de maio e junho de 1995, realizou-se a primeira parte do projeto, formando uma rede GPS de precisão com 58 estações para toda a América do Sul, que tem suas coordenadas referidas ao ITRF94, época 1995,4. Diferentemente do SAD69 e Córrego Alegre, denominados topocêntricos, sua origem é no centro de massas da Terra (geocêntrico). A Escola Politécnica da Universidade de São Paulo - Poli USP participou desse projeto com a instalação e rastreamento a partir de uma estaçã ${ }^{1}$.

Com campanha realizada no ano de 2002 o IBGE realizou o processamento de 182 estações referenciadas ao ITRF97 (2000,3). Estas estações foram divididas em 9 blocos que foram ajustadas em uma solução final de posicionamento. Como resultado foram encontrados erros planimétricos de no máximo $10 \mathrm{~mm}$ e altimétricos (h) $16 \mathrm{~mm}$ KANIUTH; COSTA, 2002). A distribuição destes pontos, e seus blocos, é ilustrada pela figura 26.

\footnotetext{
${ }^{1}$ A Escola Politécnica em suas dependências a estação denominada Poli, que continua rastreando os satélites em sistema de monitoramento contínuo.
} 


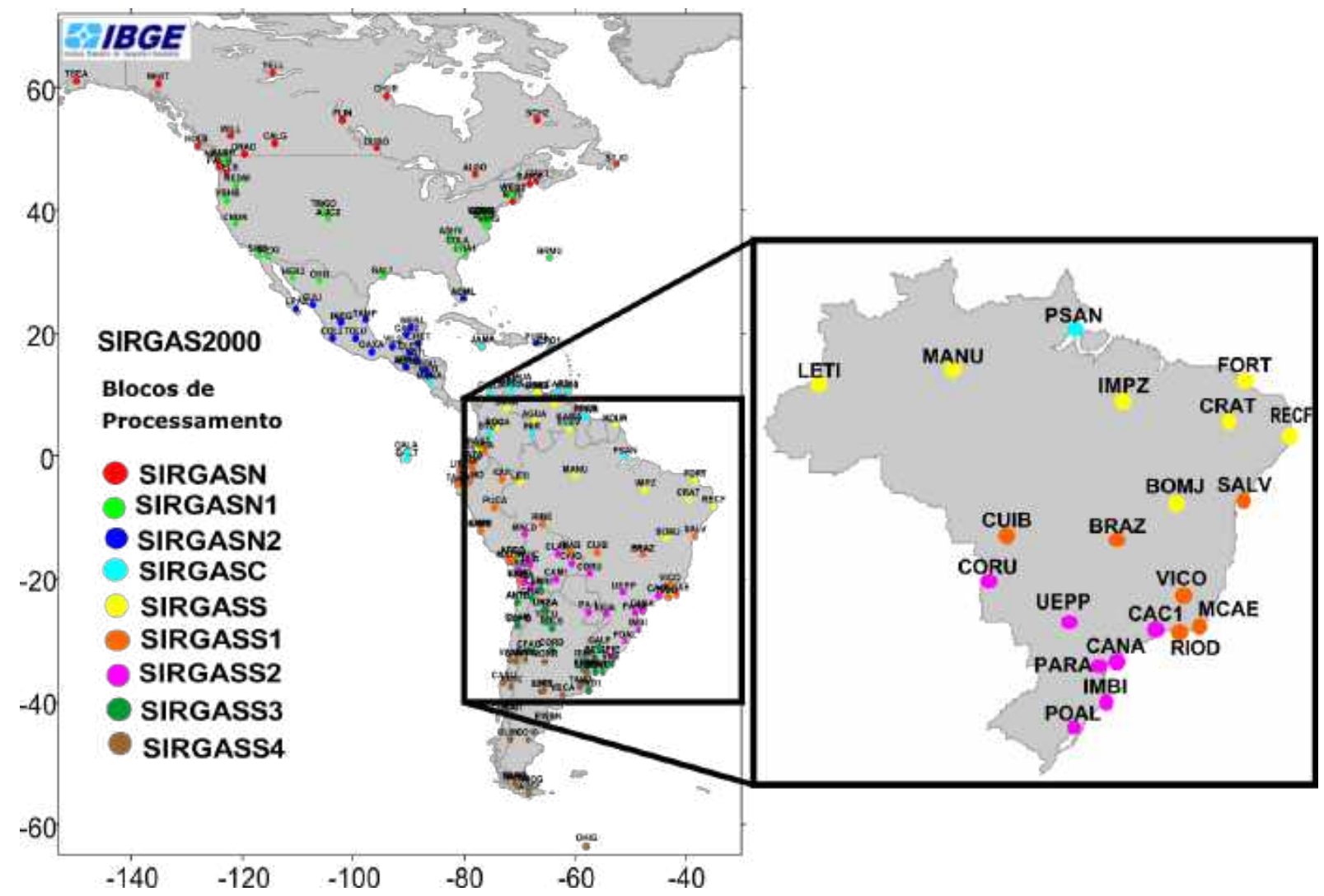

Figura 26: Pontos utilizados no ajustamento SIRGAS 2000

Fonte: Kaniuth e Costa (2002)

A Resolução do IBGE Nº1/2005 de 25/02/2005 estabeleceu o Sistema de Referência Geocêntrico para as Américas (SIRGAS), em sua realização para o ano de 2000 (SIRGAS 2000), como novo SGR para o Sistema Geodésico Brasileiro (SGB) e para o Sistema Cartográfico Nacional (SCN). Foi concedido um período de transição não superior a dez anos, terminado em 2015, em que o SAD69/96 poderia ser utilizado em concomitância com o SIRGAS 2000 para o SCN. Com essa adoção garantem a qualidade dos levantamentos GPS, devido à existência de um sistema de referência geocêntrico compatível com a precisão dos métodos e técnicas de posicionamento atuais e com os demais sistemas adotados em outros países (ZANETTI, 2006).

\subsection{A Rede Altimétrica do Sistema Geodésico Brasi- leiro}

A Rede Altimétrica de Alta Precisão (RAAP) é a estrutura de referência vertical do SGB, com mais de 65 mil estações altimétricas (denominadas RN = Referências de Nível) implantadas em todo o país desde 1945, medidas a partir de marégrafo de referência, como 
se mostra na figura 27 (LUZ et al. 2002).
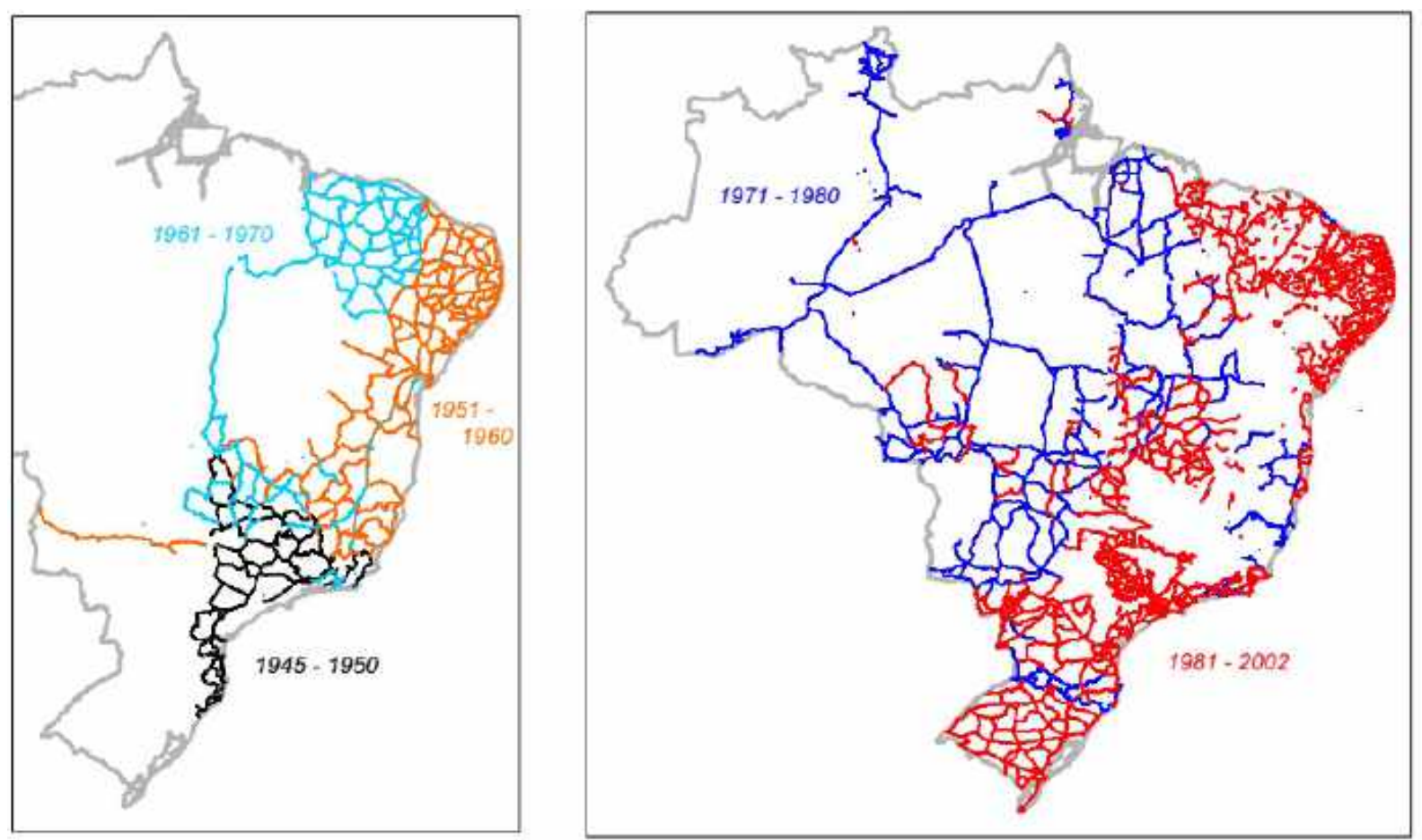

Figura 27: Evolução da rede de nivelamento RAAP Brasileira Fonte: Luz et al. (2002)

\subsubsection{Datum de Torres}

Na localidade de Cocal, Município de Uruçanga, Santa Catarina, em 13 de outubro de 1945, o IBGE, através da Seção de Nivelamento - SNI, do antigo Conselho Nacional de Geografia, deu início à medição da sua Rede de Nivelamento Geodésico, rede que ainda não tinha um ponto de referência (ALENCAR, 1990). Somente em 1946, foi estabelecida a primeira superfície de referência a partir da qual foram calculadas todas as altitudes no nosso País. Ou seja, até esse momento não havia sido eleito ainda o Datum Altimétrico Brasileiro. Esta rede de Nivelamento foi considerada a primeira de precisão e foi adotado o nível médio do mar referido ao Marégrafo de Torres (RS), conforme mostra a figura 28. 


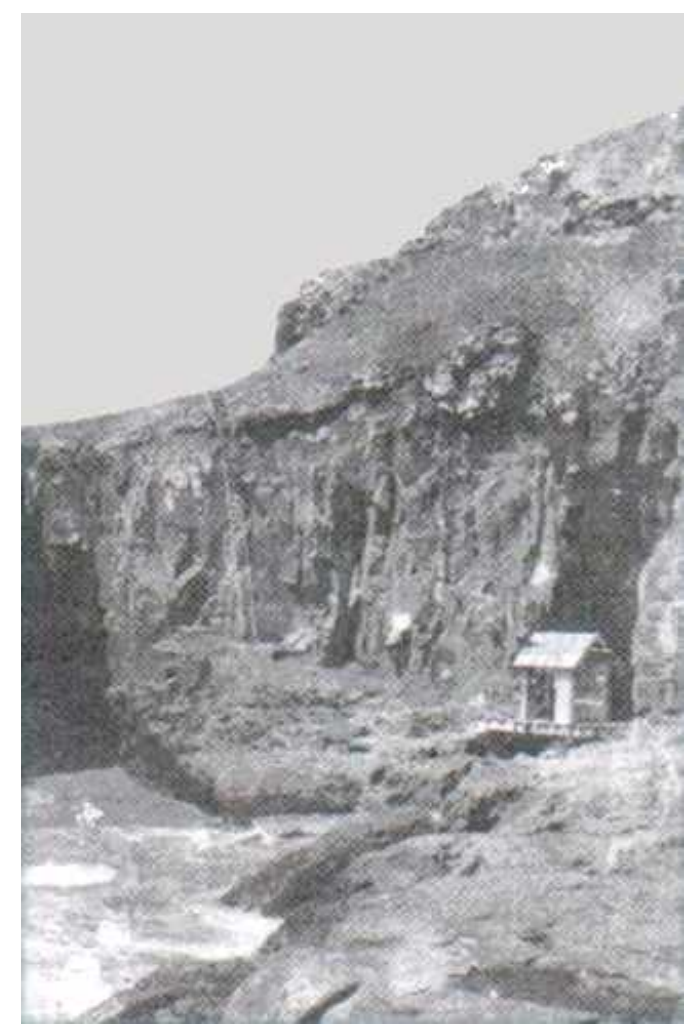

Figura 28: Marégrafo de Torres

Fonte: Acervo Museu Histórico de Torres

Segundo Alencar (1990) justificava-se o caráter provisório do Datum de Torres, estabelecido pela antiga Comissão da Carta Geral do Brasil, em função de seu curto período de observações maregráficas, apenas um ano (1919), considerando que o ciclo de 19 anos é o mínimo desejável para que sejam reduzidos os efeitos das variações periódicas provocadas pelas influências astronômicas nas marés.

\subsubsection{Rede de Nivelamento do IGGSP}

Em 1940, iniciou-se no Estado de São Paulo o nivelamento de precisão. A realização dessa tarefa coube ao IGGSP que implantou uma rede de nivelamento a qual partiu da referência do nível médio do mar (marégrafo da Mortona $a^{1}$ ), no porto de Santos. O primeiro marco foi implantado no prédio da Alfândega daquele porto, pela Companhia Docas de Santos, cuja altitude ortométrica determinada foi de 3,065 m (COLUCCI, 1962). Utilizavam níveis e miras da marca "Zeiss tipo A"ou miras da fabricante "Wild"; a leitura chegava até 0,05 de milímetro (LEFĖVRE, 1944). Após alguns anos de trabalho, as

\footnotetext{
${ }^{1} \mathrm{O}$ complexo da Mortona foi inaugurado pela então Companhia de Docas de Santos no dia 28 de fevereiro de 1901, atualmente compreende à área onde está instalada Capitania dos Portos de São Paulo. O nome "Mortona"é atribuído ao sobrenome do engenheiro inglês Thomas Morton (1781-1832), inventor e detentor da patente da doca seca e seus equipamentos (SILVARES, 2007).
} 
equipes chegaram até o município de Itapeva onde tiveram o primeiro contato com uma RN do então Conselho Nacional de Geografia do IBGE, referida ao marégrafo de Torres. A diferença de altitude encontrada naquela RN foi de $3 \mathrm{~cm}$, sendo considerada pequena para a época e distância da origem. Decidiu-se então adotar como referência do nivelamento do IGGSP o nível médio do mar fornecido pelo marégrafo de Torres (COLUCCI, 1962). O nivelamento realizado pelo IGGSP consistiu em circuitos, obedecendo a uma precisão de $\pm 4 m m \sqrt{K}$ (sendo $K$ em quilômetros). Segundo observado por Guimarães (2010, p. 49) as linhas de nivelamento acompanharam as principais rodovias do Estado (Figura 29) e a materialização das RNs foi realizada a cada $5 \mathrm{~km}$. Após 20 anos de trabalho o governo estadual já contava com mais de $10.000 \mathrm{~km}$ de linhas niveladas em circuitos entre diversas cidades como: Santos - São Paulo, Campinas - Jundiaí - São Paulo, Bauru - Ibitinga, dentre outros (COLUCCI, 1962).

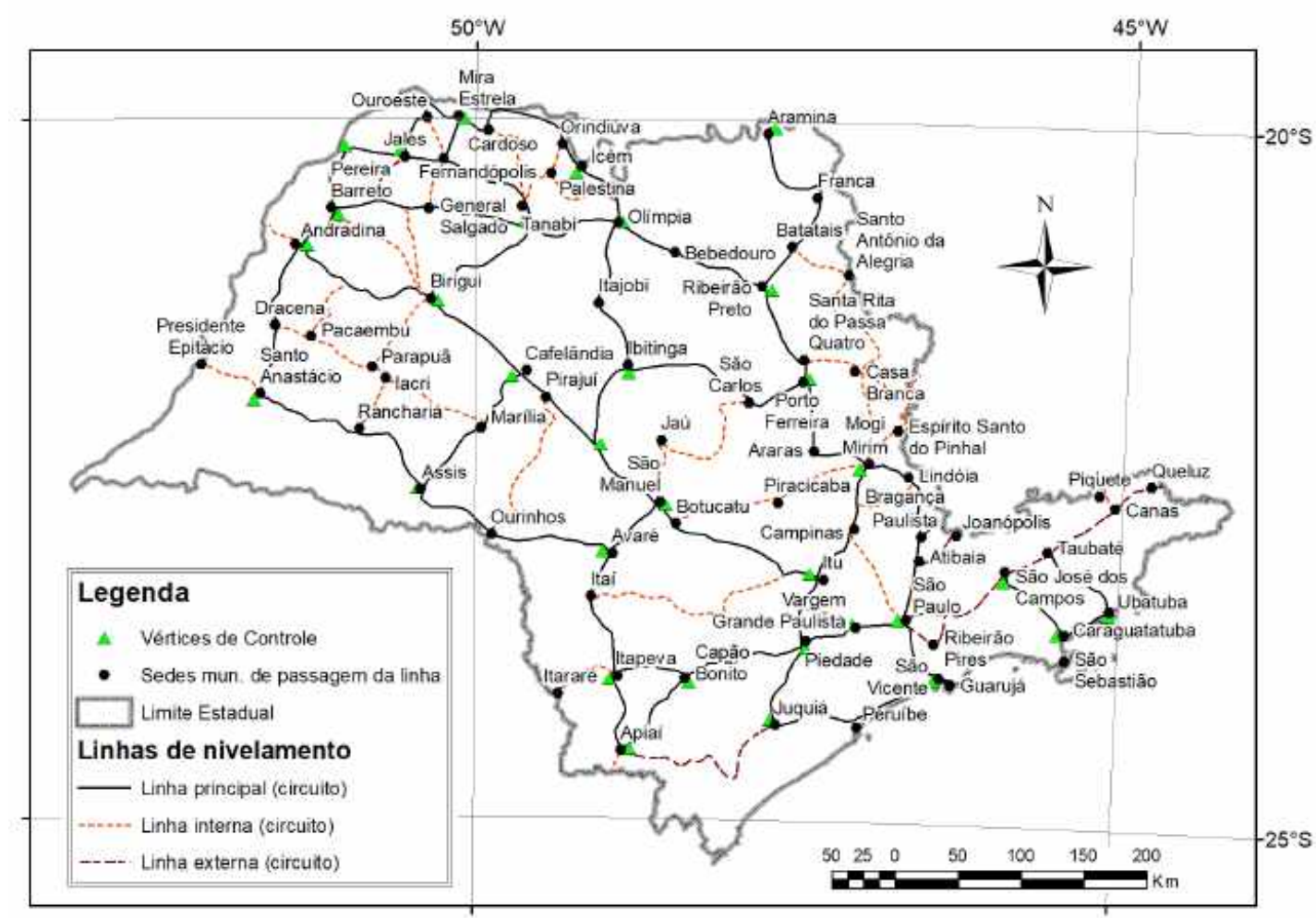

Figura 29: Rede de nivelamento de São Paulo 1940/60 - IGGSP

Fonte: Compilação do autor a partir da publicação de Colucci (1962)

\subsubsection{Datum de Imbituba}

O Datum Altimétrico Brasileiro (mais tarde nomeado como Imbituba) foi calculado levando-se em consideração observações maregráficas ocorridas entre 1949 e 1957, sob a supervisão e manutenção do IAGS. Essa Instituição norte-americana, que muito cooperou 
com o Brasil na determinação do Nível Médio do Mar, cuidava também dos Marégrafos de Niterói, Canavieiras, Salvador, Recife, Fortaleza, Salinópolis e Belém. Assim, o Datum de Torres foi substituído pelo de Imbituba, SC, em 1958, quando a rede de nivelamento já tinha alcançado o Estado da Paraíba, totalizando mais de 30 mil quilômetros, espalhados em 78 circuitos que estavam sendo ajustados em bloco (ALENCAR, 1990). As medidas destes marégrafos passaram a ser realizadas de forma constante em um serviço que é conhecido internacionalmente como Permanent Service for Mean Sea Level - PSMSL. Outros marégrafos foram instalados porém, sem medidas em longos períodos.

Ainda sobre a substituição ocorrida em 1958 segundo Luz et al. (2002) os nivelamentos das RN da Estação Maregráfica de Imbituba iniciaram-se em dezembro de 1948, quando o USCGS (United States Coast and Geodetic Survey) publicou os primeiros resultados referentes ao nivelamento de alguns pontos na região do Datum. Em junho de 1958, o IAGS renivelou a maioria destes pontos. Já o IBGE realizou operações de nivelamento na região do Datum em 1946 (antes da instalação do marégrafo) nos anos de: 1980, 1986, 1995, 2001 (quando os equipamentos digitais foram instalados) e 2002 (instalação de uma segunda régua junto ao marégrafo). Alencar (1990) fez a comparação entre altitudes de marégrafos e as ajustadas pelo IBGE com base nas observações do IAGS, como se mostra na tabela 3 .

\begin{tabular}{l|l|l|l|l}
\hline MARÉGRAFO & RN & IBGE $(\mathrm{m})$ & MARÉGRAFOS(m) & DIVERGÊNCIA(m) \\
\hline Torres & IV-SGE & 3,639 & 3,581 & $+0,058$ \\
\hline Laguna & 1-DNPRC & 0,617 & 0,744 & $-0,126$ \\
\hline Florianópolis & S/N-DNPRC & 2,009 & 2,082 & $-0,072$ \\
\hline Porto Belo & 1-DHN & 1,928 & 1,686 & $+0,242$ \\
\hline Itajaí & 1-DNPRC & 1,168 & 1,029 & $+0,139$ \\
\hline S. Fco. do Sul & S/N-DNPRC & 2,462 & 2,449 & $+0,013$ \\
\hline Paranaguá & 3-DNPRC & 2,396 & 2,395 & $+0,001$ \\
\hline Santos & 0-ADOCAS & 3,117 & 3,065 & $+0,052$ \\
\hline Sepetiba & 1-SGE & 2,361 & 2,527 & $+0,165$ \\
\hline Rio de Janeiro & 5-IAGS & 10,017 & 10,140 & $-0,123$ \\
\hline Vitória & S/N-DNPRC & 1,608 & 1,324 & $+0,284$ \\
\hline Canavieiras & 2-IAGS & 3,234 & 3,285 & $-0,050$ \\
\hline Salvador & 1-IAGS & 1,703 & 1,692 & $+0,011$ \\
\hline Recife & 1-IAGS & 2,870 & 2,732 & $+0,138$ \\
\hline Fortaleza & 1-IAGS & 3,239 & 2,947 & $+0,292$ \\
\hline Salinópolis & 2-IAGS & 6,901 & 6,248 & $+0,653$ \\
\hline Belém & 2-IAGS & 3,909 & 3,029 & $+0,880$ \\
\hline
\end{tabular}

Tabela 3: Tabela comparativa entre ajustamento do IBGE e marégrafos diversos Fonte: Alencar (1990) 
Conforme consta da tabela 3 foi feita uma comparação entre Imbituba e os outros 17 marégrafos, relacionados em ordem decrescente de Latitude, todos conectados com a Rede de Nivelamento. O sinal positivo indica que o plano do nível médio do mar registrado pelas observações do Marégrafo local é mais alto do que o determinado em Imbituba, e transportado pelo nivelamento, abstraído o erro nesse transporte. Estas comparações apresentam divergências que devem ser consideradas ao se utilizar a rede de Imbituba quando se considera a proximidade a estes marégrafos.

\subsubsection{Referenciais altimétricos e o geoide}

Os primeiros experimentos mais relevantes que tentaram medir a variação na gravidade com altitude, segundo as leis de Newton, foram elaborados por Bouguer durante viagem da academia francesa ao Peru entre 1737 e 1740 (SMALLWOOD, 2010). Utilizando-se de pêndulos modernos para a época ${ }^{1}$, utilizando dados desta expedição, Bouguer propõe que a presença de grandes picos não alterava (tanto quanto se pensava) as medidas dos pêndulos (HOWARTH, 2007a).

O primeiro a relacionar a aceleração da gravidade e uma superfície, o geóide, foi Stokes em 1849, através do que ficou conhecido como teorema de Stokes (HOWARTH, 2007a). Em termos práticos as observações de gravidade, desde o início do século XX, utilizando-se de equipamentos gravímetros proporcionaram medições mais convergentes de anomalias gravitacionais. Estes experimentos foram importantes nos primeiros estudos na indústria do petróleo, ou seja, a utilização da anomalia de gravidade para determinar locais com pequenas variações na distribuição de massa no interior da terra (HOWARTH, 2007b).

A relação entre as altitudes com referência ao nível do mar (marégrafo) e as medidas de gravidade relacionadas ao geoide e está descrita em diversos estudos (MITCHELL, 1975; FISCHER, 1975a; BLITZKOW et al., 2004; SKAGGS; HIRAM, 1980; FILMER; FEATHERSTONE, 2011). Utiliza-se o não paralelismo entre as superfícies geopotenciais conforme descrito por Freitas e Blitzkow (1999a), as altitudes científicas são as que relacionam medidas gravimétricas e geométricas de altitude (nivelamento).

\footnotetext{
${ }^{1}$ Duas eram as inovações tecnológicas a primeira chamada de dead-beat que melhorava a forma com que a energia proporcionava o movimento contínuo do pêndulo e a segunda era um engenhoso mecanismo de compensação de temperatura (MILSOM, 2018, p. 128).
} 


\subsubsection{Medidas do geoide no Brasil}

No Brasil as primeiras medições de gravimetria foram executadas pelo Observatório Nacional (ON). Em outubro de 1851 foram empreendidas medições com o pêndulo de Foucault. Posteriormente, nos primeiros anos do século XX, novas medições foram realizadas, utilizando-se um dispositivo tetrapendular de Sterneck. Já em 1967, um primeiro gravímetro L \& G, modelo G, foi cedido pelo InterAmerican Geodetic Survey(IAGS) e passou a operar em substituição ao antigo gravímetro Worden (ON, 1986).

As contribuições realizadas pelo IBGE se iniciaram em 1956 onde chegou a contar com mais de 2000 até 1980 onde a parceria com o Instituto de Astronomia e Geofísica da USP (IAG) para à elaboração de um pioneiro modelo geoidal brasileiro. Este modelo, denominado MAPGEO, é desenvolvido a partir de observações feitas na rede gravimétrica Brasileira, distribuídas conforme ilustra a figura 30 (CORREIA JÚNIOR et al., 2019).

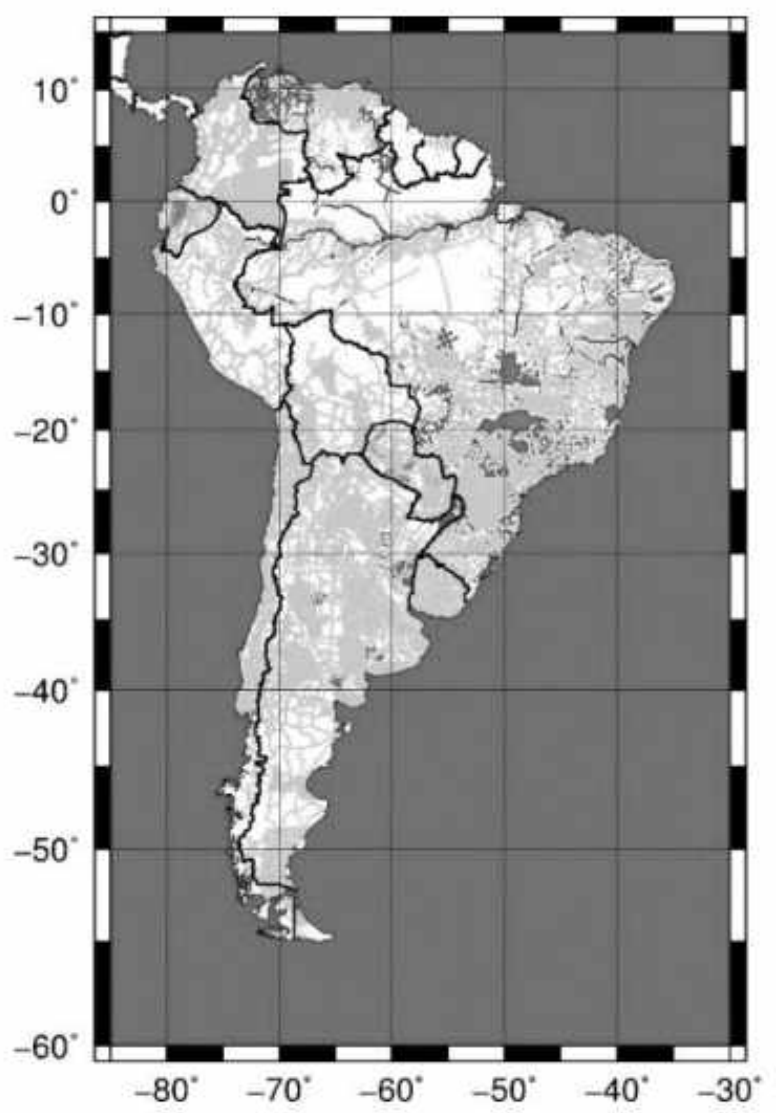

Figura 30: Estações gravimétricas usadas no modelo geoidal sul-americano

Fonte: Blitzkow et al. (2016)

No caso do Estado de São Paulo densificações de medidas gravimétricas vem aprimorando o modelo geoidal no estado, conforme ilustra a figura 31 . 

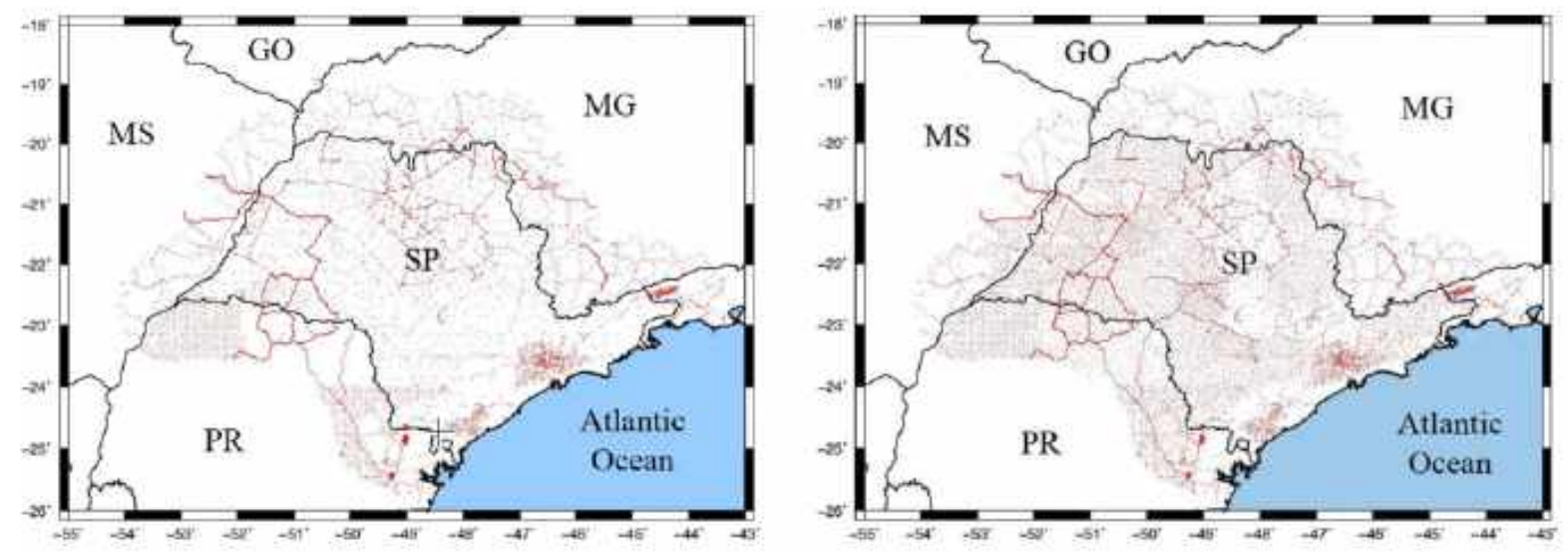

Figura 31: A esquerda rede gravimétrica de São Paulo em 2011 e a direita em 2013 Fonte: Guimarães et al. (2013)

A adição destas observações permite atualizações do modelo geoidal brasileiro (MATOS et al. 2012). Atualmente, em sua versão 2015, o modelo tem como base de referência a sua rede apresentada na figura 32 .

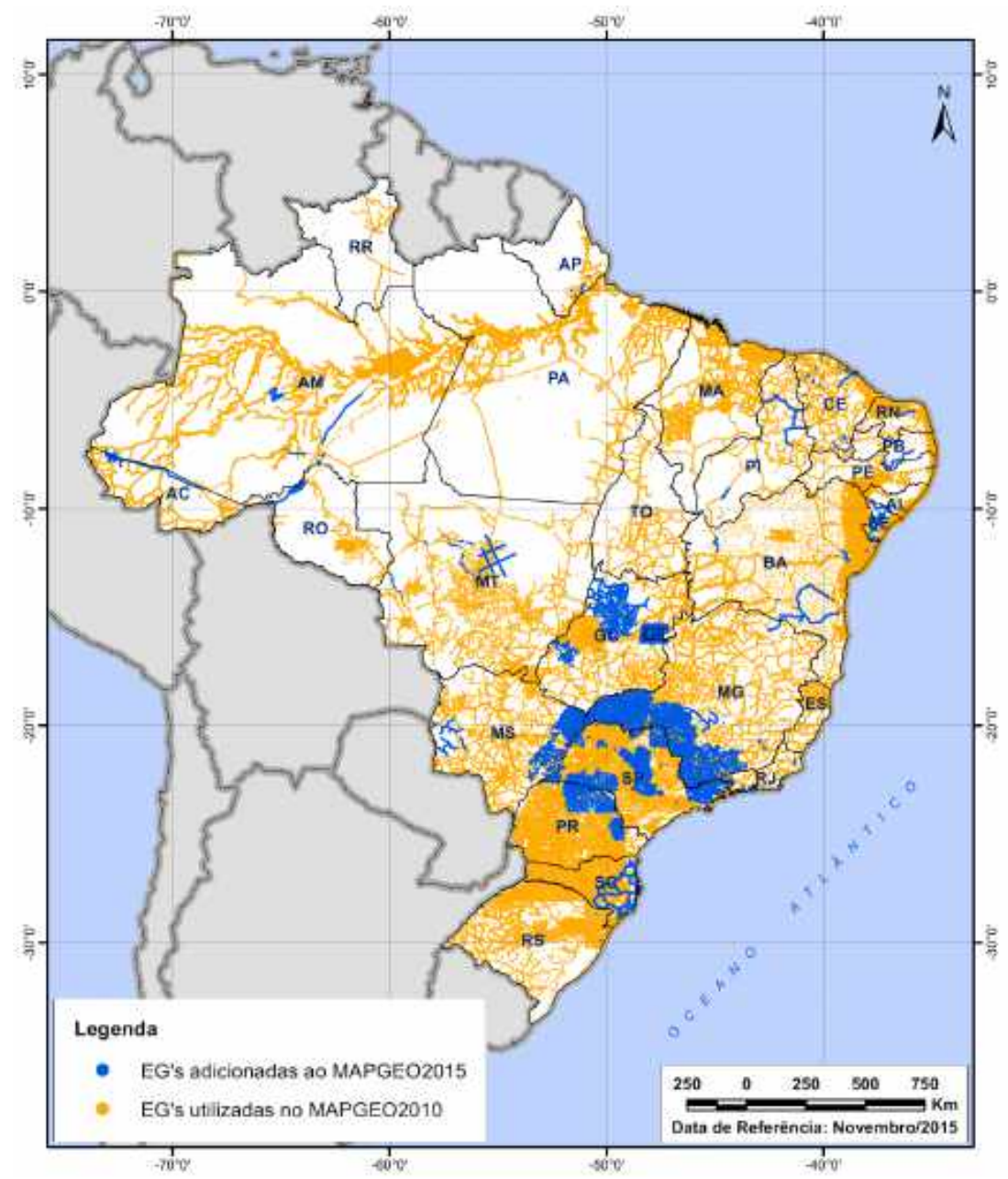

Figura 32: Rede gravimétrica de referência do Mapgeo2015

Fonte: IBGE (2015) 


\section{TRANSFORMAÇÃO DE COORDENADAS E CONTROLE DE QUALIDADE}

Conforme mencionado na secção anterior, no Brasil foram utilizados diversos referenciais geodésicos, em destaque: Córrego Alegre, SAD69/96 e SIRGAS2000. Neste capítulo serão apresentados os modelos de transformação entre estes referenciais. Além disso, será apresentado conceitos sobre o controle de qualidade em mapeamentos.

\subsection{Transformação de coordenadas entre Sistemas Ge- odésicos Brasileiros}

Parte do acervo cartográfico oficial existente no Brasil ainda está vinculada ao datum Córrego Alegre (como os produtos do presente trabalho). Independentemente das coordenadas desejadas e do datum especificado, frequentemente existe a necessidade de realizar transformações entre coordenadas de diferentes referenciais (AGUIAR et al., 2002). Os referenciais geodésicos materializados mediante procedimentos clássicos são afetados por distorções sistemáticas, as quais têm sido alvo de estudos para a aplicação de transformações (VERONEZ, 1998; OLIVEIRA, 2006, MAGNA JÚNIOR, 2012). Isso ocorre, pois, as aplicações nas Ciências Geodésicas têm exigido precisões cada vez maiores quando se faz necessária a comparação entre coordenadas de diferentes épocas, com o objetivo de compatibilizar as bases, por isso a transformação acurada torna-se um desafio. Inicialmente serão abordados os formulários necessários para a conversão entre os diferentes tipos de coordenadas, dentre estas: Universal Transversa de Mercator - UTM, Geodésicas e Cartesianas. Em seguida apresentam-se os métodos de transformação entre os diferentes sistemas geodésicos. 


\subsubsection{Conversão entre diferentes tipos de coordenadas}

Para a realização de transformações em sistemas de coordenadas faz-se necessária a utilização de formulas específicas. Estas são utilizadas para realizar conversões entre diferentes tipos de coordenadas, estas transformações são descritas a seguir.

\subsubsection{Transformação entre coordenadas (UTM e Geodésica)}

Neste trabalho, nos mapas em questão, a projeção UTM é utilizada, sendo uma derivação do Sistema de Projeção Transversa de Mercator (TM), cuja principal propriedade é a conformidade. Assim, as coordenadas (E,N) no sistema UTM podem ser obtidas a partir das coordenadas (x,y) no sistema TM, pelas seguintes expressões AGUIAR et al. 2002):

$$
\begin{aligned}
& N=N^{\prime}+m_{0} x \\
& E=E^{\prime}+m_{0} y
\end{aligned}
$$

Temos na expressão 4.1 e 4.2 os valores $m_{o}=0,9996$ que corresponde ao fator de escala ao longo do meridiano central $\left(\lambda_{0}\right), N^{\prime}=10.000 .000 \mathrm{~m}$ e $E^{\prime}=500.000 \mathrm{~m}$ (ambos valores para o hemisfério sul). Já para a transformação de coordenadas TM em geodésicas, foram utilizadas as equações da expressão 4.3 .

$$
\begin{gathered}
\phi=\phi_{1}+b_{2} y^{2}+b_{4} y^{4}+b_{6} y^{6}+\cdots \\
\lambda=\lambda_{0}+b_{1} y+b_{3} y^{3}+b_{5} y^{5}+\cdots
\end{gathered}
$$

Onde $\lambda_{0}$ é a longitude do meridiano central e $\phi_{1}$ é a latitude correspondente ao arco de meridiano de comprimento $\mathrm{x}$, ambos dados em radianos; e $b_{1}, \ldots, b_{1}$ são os coeficientes calculados em função da latitude $\phi_{1}$ e da segunda excentricidade do elipsoide adotado como referência. Maiores detalhes sobre o desenvolvimento das expressões deste tópico e equações finais para aplicação podem ser encontrados em Blachut et al. (1979).

\subsubsection{Transformação (Geodésicas e Cartesianas)}

Transformação entre coordenadas (Geodésicas e Cartesianas) Esta consiste em realizar a transformação entre as coordenadas geodésicas angulares $\left(\lambda, \phi, h^{g}\right)$ e plano cartesiano 
(X,Y e Z), também conhecida como coordenadas do referencial terrestre convencional ALFRED, 2004). O sistema cartesiano representado pelos eixos X, Y e Z tem como referência o centro de massa da terra, como se pode observar na figura 33 (CLYNCH, 2006).

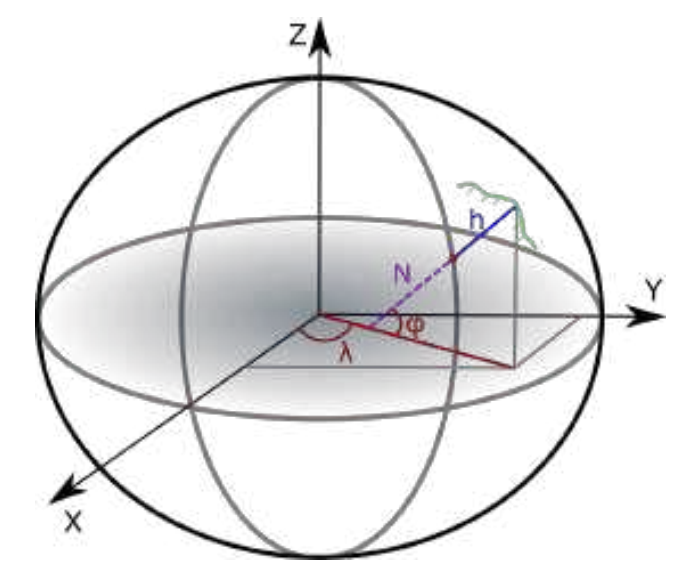

Figura 33: Plano cartesiano e coordenadas geodésicas

Fonte: O autor

Para realizar esta transformação pode-se utilizar a formulação descrita nas expressões 4.4 e mais detalhes sobre sua formulação podem ser contrados em Hofmann-Wellenhof et al. (2012).

$$
\begin{aligned}
X & =(N(\varphi)+h) \cos \varphi \cos \lambda \\
Y & =(N(\varphi)+h) \cos \varphi \sin \lambda \\
Z & =\left(\frac{b^{2}}{a^{2}} N(\varphi)+h\right) \sin \varphi
\end{aligned}
$$

Onde N é o raio de curvatura da primeira vertical, que pode ser calculado pela expressão 4.5 .

$$
N=\frac{a^{2}}{\sqrt{a^{2} \cos ^{2} \varphi+b 2 \operatorname{sen}^{2} \varphi}},
$$

Para a solução inversa, ou seja, a transformação de coordenadas cartesianas (X,Y,Z) em coordenadas geodésicas $(\varphi, \lambda, \mathrm{h})$ utiliza-se a forma iterativa que é expressa por: 4.6 , 4.7 e 4.8. Sendo e a excentricidade do elipsoide de referência e o parâmetro $h$ dado pela 
expressão 4.9 .

$$
\begin{gathered}
h=0 \ldots \tan \varphi=\frac{Z}{\sqrt{X^{2}+Y^{2}}} \cdot\left(1-e^{2}\right)^{-1} \\
h \neq 0 \ldots \tan \varphi=\frac{Z}{\sqrt{X^{2}+Y^{2}}} \cdot\left(1-e^{2} \cdot \frac{N}{N+h}\right)^{-1} \\
N(\varphi)=\frac{a^{2}}{\sqrt{a^{2} \cos ^{2} \varphi+b^{2} \sin ^{2} \varphi}}=\frac{a}{\sqrt{1-e^{2} \sin ^{2} \varphi}}, \\
h=\frac{\sqrt{X^{2}+Y^{2}}}{\cos \varphi}-N
\end{gathered}
$$

Em uma primeira aproximação, faz-se $\mathrm{h}=0$ e obtém-se $\varphi$ 4.6. A partir deste $\varphi$ calcula-se $N(\varphi)$ 4.8 e depois h (4.9). Com este novo h calcula-se novamente $\varphi$ 4.7) e assim sucessivamente até haver convergência no valor de $\varphi$, ou de h, estando abaixo de uma tolerância estabelecida.

\subsubsection{Transformação por parâmetros}

Para realizar comparações entre diferentes sistemas de coordenadas podem ser utilizados diversos modelos matemáticos. A comparação destes vêm sendo estudada. Pode-se citar diversos modelos aproximados tais como os de Molodensky ou Bursa; porém neste trabalho será utilizado o modelo de Helmert, mais rigoroso e que apresenta resultados compatíveis com outros modelos disponíveis (VERONEZ, 1998). A utilização do modelo de Helmert simplificado (três parâmetros) e completo (sete parâmetros) para transformação entre referenciais geodésicos é descrita por Marotta e Rodrigues (2011) que sugere a utilização do modelo de 7 parâmetros, pois este apresentou resultados mais adequados (em termos de desvio padrão e resíduos) em relação à transformação local entre os sistemas: Córrego Alegre e SIRGAS 2000. A seguir serão apresentados os modelos utilizados na transformação de Helmert e Helmert simplificado (Três Parâmetros).

\subsubsection{Transformação de Helmert}

Este método de transformação por similaridade ou isogonal é conhecido como método de transformação de Helmert no espaço tridimensional (LUGNANI, 1987). O modelo expressa a relação entre dois sistemas de coordenadas por meio de três translações $\left(T_{x}\right.$, 
$\left.T_{y}, T_{z}\right)$, três rotações $\left(\alpha_{1}, \alpha_{2}, \alpha_{3}\right)$ e um fator de escala $(\mu)$ como mostrado na figura 34 .

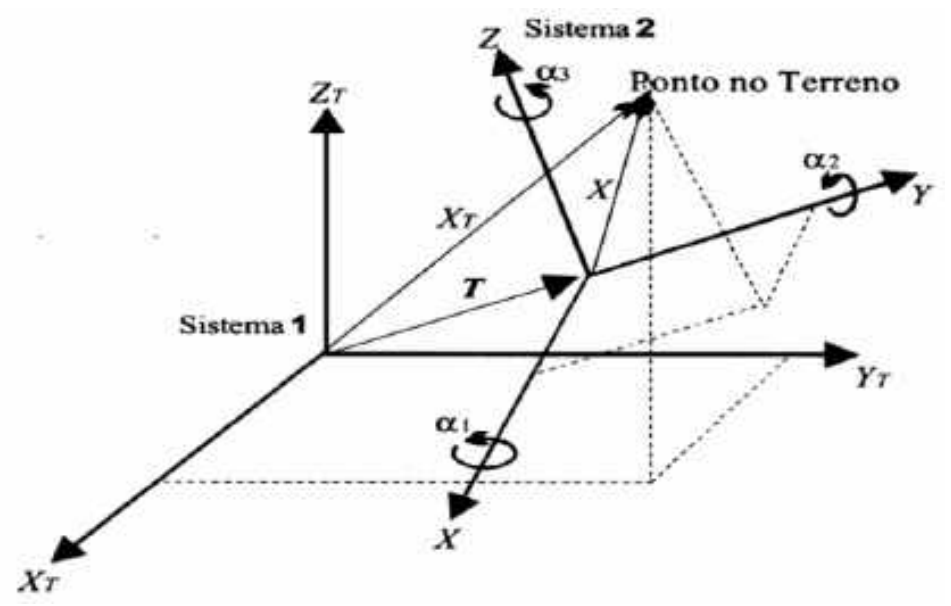

Figura 34: Ilustração da transformação tridimensional de Helmert

Fonte: Gemael (1994)

As translações são justificadas pela não coincidência da origem entre os sistemas geodésicos; as três rotações são necessárias para expressar o não paralelismo dos eixos coordenados desses dois sistemas e um fator de escala é requerido para homogeneizar os sistemas, devido à utilização de diferentes instrumentos.

É necessário ainda que se tenham pontos comuns nos dois sistemas para aplicar a transformação, sendo um mínimo de três pontos requeridos para a obtenção dos sete parâmetros. Cada ponto comum aos dois sistemas propicia um conjunto de três equações e dados três ou mais pontos, os sete parâmetros da transformação são estimados pelo método dos mínimos quadrados. O processo de estimação utilizando o método paramétrico e sua formulação será tratada de modo simplificado (utilizando-se de fórmulas gerais), mas pode ser vista com detalhes em Gemael (1994).

Para a aplicação da transformação de similaridade no espaço, é necessário que as coordenadas geodésicas $(\lambda, \varphi, h)$ sejam transformadas em coordenadas cartesianas tridimensionais $(\mathrm{X}, \mathrm{Y}, \mathrm{Z})$.

Dados dois sistemas de coordenadas cartesianas tridimensionais formando os vetores $X$ e $X_{T}$, estando associados, respectivamente, aos sistemas 1 e 2, a transformação entre eles é expressa pela relação, (HOFMANN-WELLENHOF et al., 1994b):

$$
X_{T}=T+\mu \cdot R \cdot X
$$

onde: 
$\mu$ corresponde ao fator de escala;

$\mathrm{T}$ corresponde ao vetor de translação;

$\mathrm{R}$ corresponde a uma matriz resultante de um produto de três matrizes ortogonais de rotação em torno dos eixos $\mathrm{X}, \mathrm{Y}$ e Z, nesta ordem;

$X_{T}$ corresponde ao vetor com origem no sistema de coordenadas 1 , unido a um dado ponto na superfície da Terra;

$X$ corresponde ao vetor com origem no sistema de coordenadas 2 , unido ao mesmo ponto na superfície da Terra.

As componentes do vetor translação, que parte de um sistema de coordenadas até o outro sistema geodésico é:

$$
T=\left(\begin{array}{c}
T_{X} \\
T_{Y} \\
T_{Z}
\end{array}\right)
$$

A matriz de rotação R é uma matriz ortogonal composta de três rotações sucessivas (expressão 4.12):

$$
R=R_{x}\left(\alpha_{1}\right) \cdot R_{y}\left(\alpha_{2}\right) \cdot R_{z}\left(\alpha_{3}\right)
$$

O produto da expressão 4.12 permite a representação matricial conforme 4.13 (VERONEZ, 1998).

$$
R=\left(\begin{array}{ccc}
\cos \alpha_{2} \cdot \cos \alpha_{3} & \cos \alpha_{1} \cdot \operatorname{sen} \alpha_{3}+\operatorname{sen} \alpha_{1} \cdot \operatorname{sen} \alpha_{2} \cdot \cos \alpha_{3} & \operatorname{sen} \alpha_{1} \cdot \operatorname{sen} \alpha_{3}-\cos \alpha_{1} \cdot \operatorname{sen} \alpha_{2} \cdot \cos \alpha_{3} \\
-\cos \alpha_{1} \cdot \operatorname{sen} \alpha_{3} & \cos \alpha_{1} \cdot \cos \alpha_{3}-\operatorname{sen} \alpha_{1} \cdot \operatorname{sen} \alpha_{2} \cdot \operatorname{sen} \alpha_{3} & \operatorname{sen} \alpha_{1} \cdot \cos \alpha_{3}+\cos \alpha_{1} \cdot \operatorname{sen} \alpha_{2} \cdot \operatorname{sen} \alpha_{3} \\
\operatorname{sen} \alpha_{2} & -\operatorname{sen} \alpha_{1} \cdot \cos \alpha_{2} & \cos \alpha_{1} \cdot \cos \alpha_{2}
\end{array}\right)
$$

Na Geodésia, as rotações fundamentais são ângulos de pequena magnitude (ordem de segundos de arco). Desta forma podemos simplificar 4.13 tomando $\cos d \alpha_{i}=1 \mathrm{e}$ sen $=d \alpha_{i}$, conforme apresentado em 4.14 .

$$
R=\left[\begin{array}{ccc}
1 & d \alpha_{3} & -d \alpha_{2} \\
-d \alpha_{3} & 1 & d \alpha_{1} \\
d \alpha_{2} & -d \alpha_{1} & 1
\end{array}\right]
$$


Tendo os parâmetros T, $\mu$ e R (matriz 4.13), pode-se transformar um determinado ponto relacionado a um sistema $X_{T}$ para outro $X$ através da expressão 4.10 .

\subsubsection{Transformação por Três Parâmetros}

Dado dois sistemas geodésicos pode-se considerar, em determinados casos, o paralelismo entre estes sistemas como ilustrado pela figura 35. Esta forma foi adotada pelo IBGE para conversão entre os sistemas SAD69/96 e SIRGAS 2000ำ.

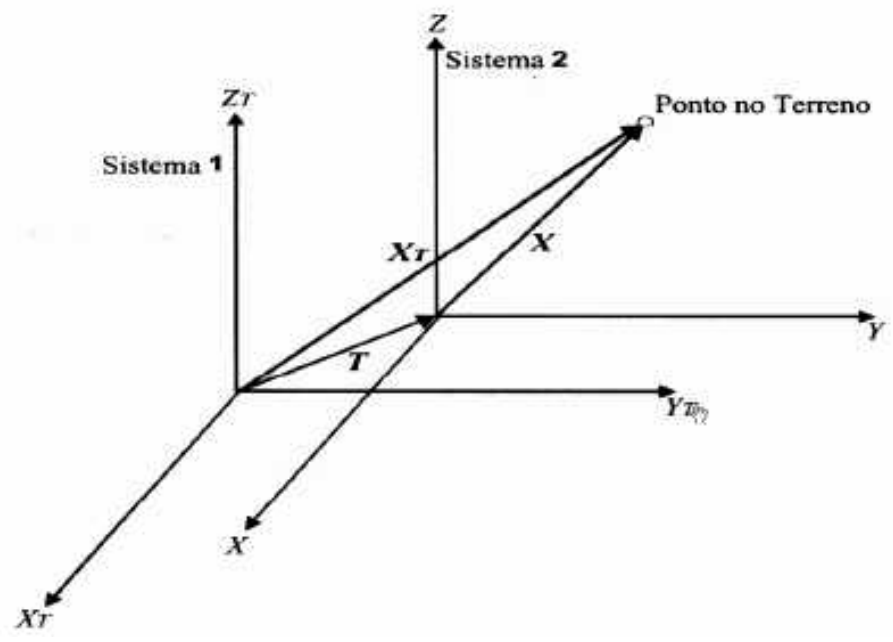

Figura 35: Transformação por três parâmetros

Fonte: Oliveira (2006)

O ajustamento destes valores se dá por meio da utilização do método paramétrico, por se tratar de um modelo matemático de sistemas com eixos paralelos, havendo somente translações. Desta forma temos o vetor de translação descrito na expressão 4.15 (GEMAEL, 1994).

$$
T=X_{T}-X
$$

Onde:

$X_{T}$ corresponde ao vetor com origem no sistema de coordenadas 1 , unido a um dado ponto na superfície da Terra, definido pelas coordenadas $X_{T}, Y_{T}, Z_{T}$;

$X$ corresponde ao vetor com origem no Sistema de coordenadas 2 , que une o mesmo ponto na superfície da Terra, definido pelas coordenadas $\mathbf{X , Y , Z ; ~}$

\footnotetext{
${ }^{1} \mathrm{Na}$ resolução $\mathrm{n}^{o} 22$ do IBGE $(\sqrt{1983})$ apresentou parâmetros para a conversão entre o sistema SAD69 e Córrego Alegre. Já na resolução $n^{\circ} 23$ do IBGE (1989) foram apresentados parâmetros para a transformação entre WGS84 e SAD69, nenhuma delas não mais em vigor.
} 
$T$ corresponde ao vetor de translação entre os dois sistemas geodésicos de referência. Suas componentes correspondem a $X_{T}, Y_{T}, Z_{T}$ que são as translações em $\mathbf{X}, \mathbf{Y}$ e $\mathbf{Z}$, respectivamente.

Para um ponto i qualquer se tem 4.16 .

$$
\begin{gathered}
X_{T_{i}}-X_{i}=T_{X} \\
Y_{T_{i}}-Y_{i}=T_{Y} \\
Z_{T_{i}}-Z_{i}=T_{Z}
\end{gathered}
$$

\subsubsection{Ajustamento pelo método dos mínimos quadrados}

Tendo-se observações indiretas onde se deseja estimar grandezas vinculadas a estas utiliza-se modelo matemático baseado no Método dos Mínimos Quadrados (MMQ). Uma forma de se determinar estas grandezas é utilizando o método paramétrico, o qual descreve-se brevemente neste tópico.

Caso se tenha coordenadas de pontos e deseje a determinação de parâmetros para sua transformação, no caso: T, $\mu$ e R utilizando Helmert (expressão 4.10) e $X_{T}$ utilizando três parâmetros (expressão 4.15). Neste tipo de determinação Wolf e Ghilani (1997) sugere a aplicação o método paramétrico, onde as observações são expressas como parâmetros desconhecidos que não são medidos diretamente.

Na aplicação do método paramétrico as equações de observação são escritas relacionando os valores observados, resíduos e parâmetros. Na expressão 4.17 tem-se vetor das observações ${ }^{1}\left(L_{b}\right)$ para a transformação por Helmert.

$$
L_{b}=\left(\begin{array}{c}
X_{T 1}-X_{1} \\
Y_{T 1}-Y_{1} \\
Z_{T 1}-Z_{1} \\
\cdots \\
\cdots \\
\cdots \\
X_{T_{i}}-X_{i} \\
Y_{T_{i}}-Y_{i} \\
Z_{T_{i}}-Z_{i}
\end{array}\right) i=(1,2,3, \ldots)
$$

\footnotetext{
${ }^{1}$ Quanto os valores iniciais $\left(L_{o}\right)$ considera-se nulo, fazendo que com isso $L=-L_{b}$.
} 
Para o cálculo dos valores observados ajustados $\left(L_{a}\right)$ Gemael (1994) apresenta estes em função explicita dos parâmetros ajustados, como apresenta-se em 4.18 .

$$
L_{a}=F\left(X_{a}\right)
$$

Ainda pelo mesmo autor o vetor dos parâmetros ajustados $\left(X_{a}\right)$ pode ser expresso pelo vetor de correção $(X)$ e um vetor de valores aproximados dos parâmetros $\left(X_{o}\right)$, conforme expressão.

$$
X_{a}=X_{o}+X
$$

Os parâmetros ajustados $\left(X_{a}\right)$ é calculado substituindo-se em 4.18 e linearizando segundo a fórmula de Taylor resultando na expressão 4.20 .

$$
F\left(X_{o}+X\right)=F\left(X_{o}\right)+\left.\frac{\partial F}{\partial X_{a}}\right|_{X_{a}=X_{o}} . X
$$

Para o caso da transformação de Helmert, conforme apresentado na secção 4.1.2.1. temos na expressão 4.10. Sendo que esta contem: os parâmetros a serem ajustados (T, $\mu^{1}$ e R) e as observações ( $T X, T Y, T Z, X_{i}, Y_{i}, Z_{i}$ com i=1,2,..n). Com estes elementos elabora-se a formulação expressa em 4.21 , que tem forma linear e matricial para um dado ponto $(\mathrm{i}=1)$, utilizando-se também as expressões: 4.16, 4.11 e 4.14 (VERONEZ, 1998).

$$
\left(\begin{array}{c}
X T_{1}-X_{1}-T_{X} \\
Y T_{1}-Y_{1}-T_{Y} \\
Z T_{1}-Z_{1}-T_{Z}
\end{array}\right)=\left(\begin{array}{l}
d T_{X} \\
d T_{Y} \\
d T_{Z}
\end{array}\right)+d \mu^{1} \cdot\left(\begin{array}{c}
X_{1} \\
Y_{1} \\
Z_{1}
\end{array}\right)+\left(\begin{array}{c}
X_{1} \\
Y_{1} \\
Z_{1}
\end{array}\right) \cdot\left(\begin{array}{ccc}
0 & d \alpha_{3} & -d \alpha_{2} \\
-d \alpha_{3} & 0 & d \alpha_{1} \\
d \alpha_{2} & -d \alpha_{1} & 0
\end{array}\right)
$$

A partir da derivaçãd ${ }^{2}$ da expressão 4.21 foram determinados os coeficientes e as

\footnotetext{
${ }_{1}^{1}$ Wolf e Ghilani (1997) no caso entre conversão de sistemas locais e geocêntricos (ex. WGS84) o fator de escala $\mu=1+d \mu$.

${ }^{2}$ Mais detalhes sobre esta derivação são demonstrados por Hofmann-Wellenhof et al. (1994a).
} 
variáveis que formam matriz das equações de observação derivadas, na expressão 4.22 apresenta-se a matriz $A$ para o caso de Helmert (WOLF; GHILANI, 1997).

$$
A=\left(\begin{array}{ccccccc}
1 & 0 & 0 & X_{1} & 0 & -Z_{1} & Y_{1} \\
0 & 1 & 0 & Y_{1} & Z_{1} & 0 & -X_{1} \\
0 & 0 & 1 & Z_{1} & -Y_{1} & X_{1} & 0 \\
\cdots & \cdots & \cdots & \cdots & \cdots & \cdots & \cdots \\
\cdots & \cdots & \cdots & \cdots & \cdots & \cdots & \cdots \\
\cdots & \cdots & \cdots & \cdots & \cdots & \cdots & \cdots \\
1 & 0 & 0 & X_{i} & 0 & -Z_{i} & Y_{i} \\
0 & 1 & 0 & Y_{i} & Z_{i} & 0 & -X_{i} \\
0 & 0 & 1 & Z_{i} & -Y_{i} & X_{i} & 0
\end{array}\right) i=(1,2,3, \ldots)
$$

Agora é possível determinar os parâmetros expressos pelo vetor de correção $X \bigvee$ e mostrado na expressão 4.23 .

$$
X=\left(\left(A^{T} \cdot A\right)^{-1}\right) \cdot\left(A^{T} \cdot L_{b}\right)
$$

A partir de 4.23 calcula-se o vetor dos resíduos $V$ a partir da expressão 4.24 e com isso o sigma a priori conforme apresentado em 4.25 .

$$
\begin{gathered}
V=A X-L_{b} \\
\hat{\sigma}_{0}^{2}=\frac{V^{T} V}{n-u}
\end{gathered}
$$

Depois da estimativa dos parâmetros $(X)$ e seus respetivos resíduos $(V)$ é possível calcular as precisões dos parâmetros ajustados, que são definidos como Matriz Variância Covariância $\left(\sum X_{a}\right)$. A MVC corresponde a uma matriz quadrada e simétrica cujos componentes são variâncias e covariâncias, conforme apresentado na expressão 4.26 .

$$
\sum X_{a}=\hat{\sigma}_{0}^{2}\left(A^{T} \cdot A\right)^{-1}
$$

Onde:

$\sum \mathbf{X}_{\mathbf{a}}-$ MVC dos parâmetros ajustados;

\footnotetext{
${ }^{1} \mathrm{~A}$ formulação completa para a aplicação do método paramétrico pode ser encontrada em Gemael (1994, p. 117).
} 
A - matriz $A$ do sistema de equações normais;

n - número de observações;

u - número de incógnitas.

\section{a) Validação estatística dos parâmetros}

Existem inúmeros métodos para a transformação de coordenadas, porém deve-se ter precaução uma vez que os parâmetros de transformação calculados podem não ser estatisticamente significantes. Para checar a validade estatística dos parâmetros calculados pelo ajustamento $\left(X_{a}\right)$ Wolf e Ghilani (1997) propõe que estes sejam divididos, respectivamente, pelo seu desvio $\left(\sigma_{\text {par }}\right)$ que é obtido pela 4.26 , isso representa a tendência (teste t-Student) para um determinado grau de liberdade $(v=n-u)$, onde $n$ é o número de observações e $u$ o de incógnitas), conforme apresenta 4.27 .

$$
t_{\text {par }}=\frac{\text { parametro }}{\sigma_{\text {par }}}
$$

Para que o parâmetro seja julgado como estatisticamente diferente de zero, portanto significativo, o valor calculado $\left(t_{p a r}\right)$ deve ser maior que o tabelado $\left(t_{\alpha / 2, v}\right)$. O teste estatístico de hipótese para análise da média populacional (teste t-Student) será abortado com mais detalhes na secção 4.2.1.1 (pg. 85).

\subsubsection{Transformação por grade NTv2 (IBGE)}

Em 2005, o IBGE disponibilizou o aplicativo denominado TCGEO, que possibilita aos usuários a conversão de coordenadas entre os referenciais SAD69 e SIRGAS2000. A conversão também se baseia na aplicação de parâmetros de transformação oficiais. O TCGEO apresenta como saída um resíduo da transformação, que serve como indicativo do valor de distorção no ponto considerado. Para o cálculo dos resíduos dois fatores foram considerados: a posição geográfica do ponto e a realização da qual faz parte. A necessidade de atualização da metodologia utilizada pelo programa foi discutida por diversos autores (VERONEZ, 1998; OLIVEIRA, 2006). Conforme descrito por Magna Júnior (2007), o Grupo de Trabalho 3 (GT3), que é o grupo que trata especificamente da conversão de referenciais no IBGE, estudou diversas alternativas propostas e escolheu a utilização da forma de conversão utilizada no Canadá, que resultou no grid NTv2 (OLIVEIRA et al. 2009). Este grid é calculado pelo programa ESTPM (Estimation of Secondary Terrestrial Positions for Mapping). Este foi desenvolvido para estimar correções às coordenadas geo- 
désicas através de uma técnica confiável e uniforme que prediz a diferença de coordenadas para quaisquer pontos até os que não são coincidentes com a rede estabelecida COSTA, 1999a).

A modificação do TCGEO foi realizada em dezembro de 2008 com o desenvolvimento de outro programa denominado ProGriD. O ProGriD foi desenvolvido visando permitir a migração de banco de dados e mapas de Córrego Alegre e SAD69 para o SIRGAS2000, em um esforço de prover a comunidade de usuários de dados geoespaciais do Brasil, de uma ferramenta que facilite a transição para o SIRGAS2000 (IBGE, 2009).

Para realizar as transformações o ProGriD utiliza grades de distorções no formato NTv2 que, como apontado, é um software desenvolvido e utilizado no Canadá (JUNKINS; ERICKSON, 1996). As grades, utilizadas no ProGriD, foram geradas a partir de estações homólogas utilizando as seguintes realizações (IBGE, 2009, p.7):

- 1961 do Córrego Alegre, referida no ProGriD como Córrego Alegre (1961);

- 1970 e 1972 do Córrego Alegre, tratadas em conjunto, e referidas como Córrego Alegre $(1970+1972)$ no ProGriD;

- Realização original do SAD69, incluindo apenas a rede clássica, chamada simplesmente de SAD69 Rede Clássica;

- 1996 do SAD69, incluindo apenas a rede clássica, chamada no ProGriD de SAD69/96.

Com relação à precisão da transformação, segundo IBGE (2009), o ProGrid expressa os valores em função do desvio padrão para latitude e longitude. Nas transformações bidimensionais, o desvio padrão é obtido diretamente da grade utilizada; nas transformações tridimensionais é calculado em função dos parâmetros envolvidos e nas transformações mistas é obtido propagando-se os desvios padrão da grade e dos parâmetros de transformação. A área de abrangência do grid, para cada sistema de referência presente no ProGrid, é exposta na figura 36 . 


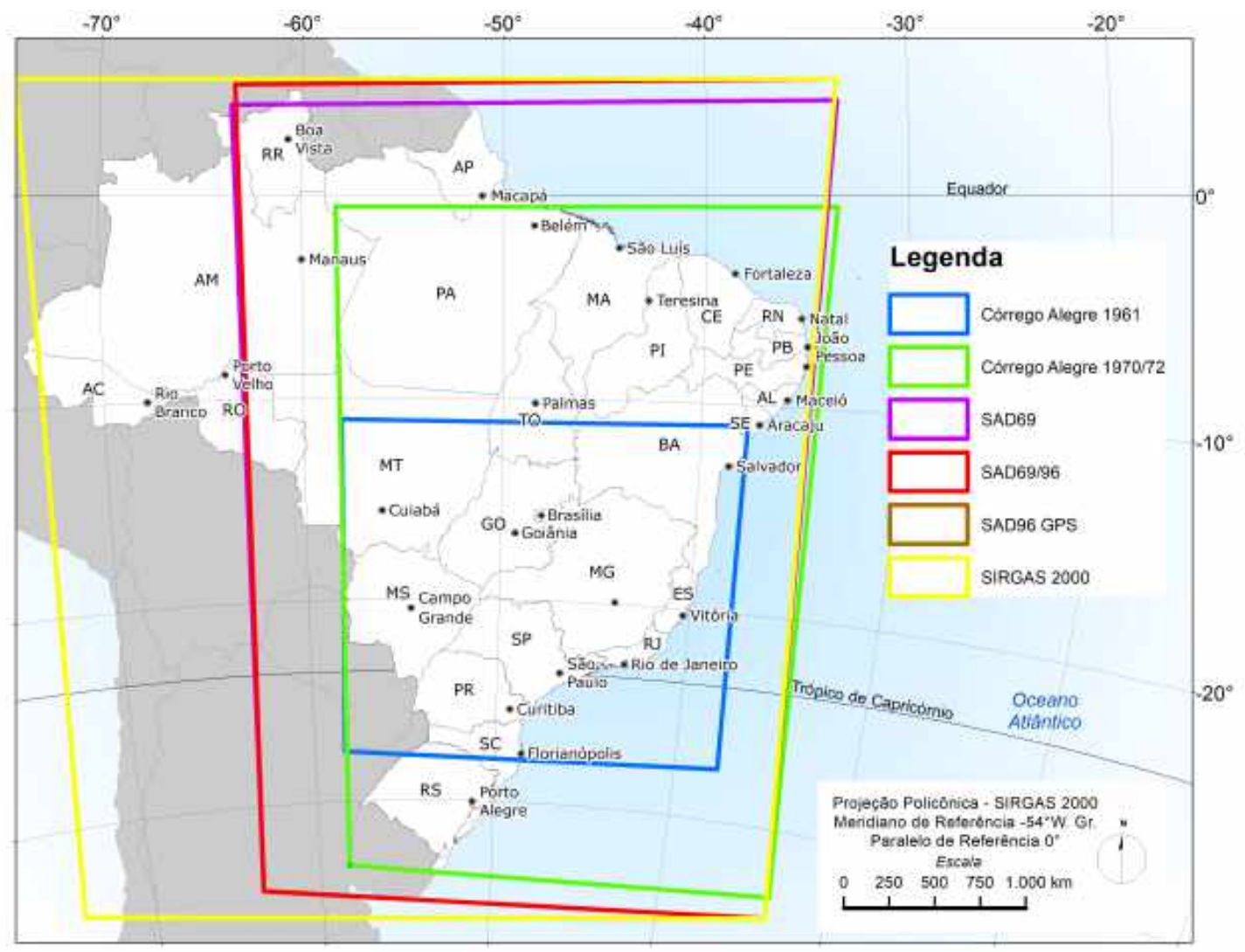

Figura 36: Região de abrangência do Grid NTV2

Fonte: Autor em compilação de dados do IBGE (2018)

Para Santos et al. (2012) o grid NTv2 relaciona dois frames de referência planimétrica. Para isso, utiliza-se uma transformação de Helmert e um grid de cálculo, a este grid aplicase uma correção baseada em modelos de distorção derivados da materialização desses sistemas de referência. Deve-se notar que o ProGrid, que utiliza o grid NTv2, realiza a transformação tridimensional entre o SAD69 e SIRGAS2000, porém somente deve-se as alturas como geométricas.

\subsection{Controle de qualidade em processos de mapeamento}

Levantamentos topográficos foram as primeiras fontes a auxiliar na elaboração de cartas topográficas, por se tratarem de observações levantadas a partir de métodos clássicos, ou seja, utilizando equipamentos topográficos. Seu controle de qualidade se fez a partir de técnicas matemáticas que controlavam estas observações em campo, como por exemplo o trabalho realizado pela CGGSP e analisado por Mann e Cintra (2000). Ressalta-se que para realizar tais análises faz-se necessário o conhecimento de técnicas estatísticas desenvolvidas desde o século XVIII, que são descritas resumidamente a seguir. Logo na 
sequencia são apresentados os primeiros estudos de controle de qualidade estatístico utilizados em mapeamentos e métodos mais atuais, sendo estas referências para análise dos mapeamentos objeto deste estudo.

\section{a) Contribuições estatísticas importantes}

A utilização de técnicas estatísticas dependia de conhecimentos teóricos da teoria de probabilidades, pois estes estudos envolvem um determinado número de observações permutadas e suas combinações. Segundo Stigler (1986) as primeiras utilizações de técnicas estatísticas foram feitas sobre determinações astronômicas. Os experimentos consistiam na comparação de medidas, feitas a partir de lunetas, realizadas em diferentes instantes para cálculo de medidas astronômicas. Estes cálculos permitiram a avaliação de qualidade destas observações bem como o desenvolvimento de métodos de tratamento dos erros.

Com o desenvolvimento da teoria dos mínimos quadrados por Gauss (1809)1 alguns conceitos passaram a ser melhor entendidos, como por exemplo a relação entre o número de observações e a acurácia (STIGLER, 1986, p.38). O primeiro geodesista a utilizar técnicas estatísticas, especificamente mínimos quadrados, para a determinação de questões relacionadas a medidas geodésicas foi Bessel (1837) (OGUNDARE, 2018, p. 128). Outra medida estatística utilizada na análise de erros em geodésia foi a distribuição de t-student, com primeira variação desenvolvida por Lüroth (1876). No mesmo ano, Helmert constata a efetividade das teorias da curva normal e do método dos mínimos quadrados; além propor componentes importantes que seriam utilizados em versões posteriores (1906) da distribuição de t-student (GORROOCHURN, 2016, p. 363).

\subsubsection{Controle de qualidade geométrico}

Com o desenvolvimento do campo da estatística no século XX o campo dos levantamentos topográficos, que já contava com tecnologia que permitia medições mais acuradas, passou a ser uma área de aplicabilidade daquela ciência. Em 1937 foi realizado um estudo por um comite criado pelo governo federal norte americano e impulsionado por agências estatais, incluindo o USGS, as quais iniciaram investigações sobre quais seriam os padrões de precisão em mapas. Em 1941, o escritório de orçamento dos Estados Unidos emitiu uma normativa definia quais os padrões de precisão nacionais a serem utilizados na produção de mapas, a United States National Map Accuracy Standards, que se aplicava a

\footnotetext{
${ }^{1}$ Existem autores, como Stigler $(1986)$, que apresentam Legendre teórico fundador desta teoria e outros, como Archibald e Karl (1926) e Sprott (1978), que atribuem a Gauss.
} 
todas as agências federais que produzissem mapas. Os padrões foram revisados várias vezes e a versão final desta proposta foi publicada em 1947 denominada National Map Accuracy Standards (NMAS) (USBB, 1947). Esta norma propõe que o teste de qualidade seja feito por meio de comparação de amostras, e verifica a aceitabilidade utilizando a porcentagem da quantidade encontrada de erros. Dentre as recomendações citadas na norma destacam-se (USBB, 1947 apud SOUTHARD, 1983):

- acurácia horizontal - em mapas de escala 1:20.000 ou menores, 10\% de todos os pontos testados não pode ser maior que $0,89 \mathrm{~mm}$ (na escala da carta), já para mapas com escala 1:20.000 ou maiores esse erro seria de $0,50 \mathrm{~mm}$ (na escala da carta);

- acurácia vertical - só $10 \%$ das elevações testadas podem ter erro superior à metade do intervalo das curvas de nível;

- referência de comparação - A precisão de qualquer mapa pode ser testada comparando as posições de pontos cujas localizações ou elevações (coordenadas) sejam identificadas em produtos com maior acurácia.

Durante décadas posteriores, as medidas estatísticas passaram a ser difundidas em disciplinas da área de exatas, destacando-se conceitos como: curva normal, distribuição qui quadrado, variância e curtose (FERGUSON, 1959).

Para Preston e Dietz (1991) o controle estatístico do erro na aquisição de dados é classificado pelos tipos: experimental, sistemático e aleatório. Gemael (1994) descreve que os erros grosseiros (experimentais) podem e devem ser evitados. Para a detecção destes erros grosseiros em mapas, Barbato e Reissig (2002) descrevem que estes resultam em valores da ordem de três a vinte vezes maiores que o erro padrão (pré-definido). Utilizando métrica próxima, Nero (2005), Lima (2012) analisam as discrepâncias por componente (no caso coordenadas E e N) de forma que o critério para que sejam aceitas observações é que sua "média amostral \pm 3 vezes o desvio padrão amostral", teste resumido na expressão 4.28 (SZTUTMAN, 2014).

$$
(\bar{x}-3 s)>\left(X_{r_{i}}-X_{a_{i}}\right)>(\bar{x}+3 s)
$$

Onde:

$\mathbf{X}_{\mathbf{r}_{\mathbf{i}}}$ - Coordenada de um dado ponto i (E, N e H) da base de referência;

$\mathbf{X}_{\mathrm{a}_{\mathbf{i}}}$ - Coordenada de um dado ponto i (E, N e H) do produto analisado; 
$\boldsymbol{s}$ - desvio padrão (E ou N);

$\overline{\boldsymbol{x}}$ - Média das discrepâncias (E ou N).

O fundamento teórico para este critério é que a probabilidade em uma distribuição normal de ter valores menores que $3 s$ é menor que $0.1 \%$ (GORDON, 2006, p. 2). Quando existem é que pode haver alguma anomalia no processo, quando possível devem ser checados levando-se em consideração erros, tais como: erro de coleta, alteração posterior a coleta, etc (ASPRS, 2015).

\subsubsection{Análise de Acurácia}

Para Mikhail e Ackermann (1976, p. 64) pode-se definir acurácia como sendo o grau de proximidade de uma estimativa com seu parâmetro (ou valor tido como verdadeiro), enquanto precisão expressa o grau de consistência da grandeza medida com sua média. Os erros podem ser classificados como sistemáticos e aleatórios. Estes para Monico et al. (2009) estão relacionados como os termos: acurácia que envolveria tanto erros sistemáticos como aleatórios e a precisão que estaria unicamente vinculada com erros aleatórios. Menditto et al. (2006) apresenta a importância diferenciar o termo acurácia de exatidão (do inglês trueness), como ilustrado pela figura 37 .

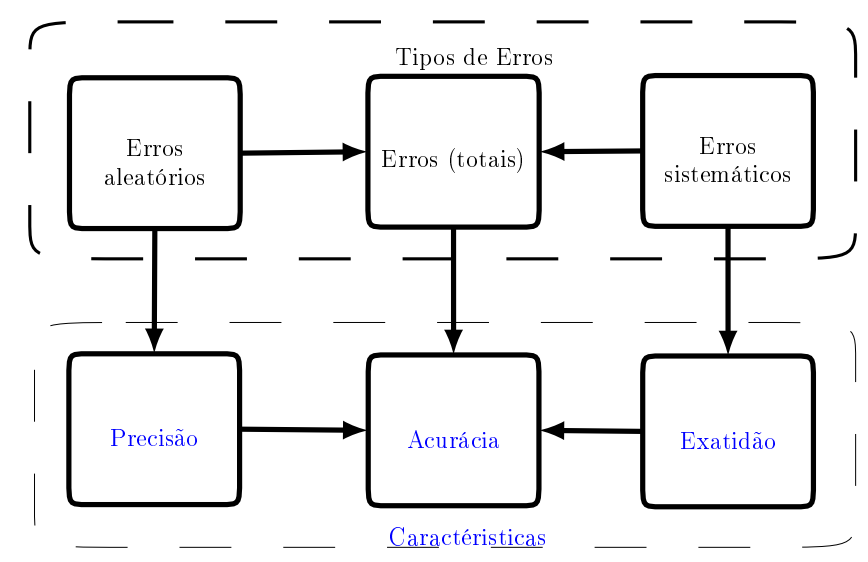

Figura 37: Diagrama representando relação entre tipos de erros e acurácia e precisão Fonte: Adaptado de Menditto et al. (2006)

Para diferenciar os termos de característica qualitativa Menditto et al. (2006) apresenta a acurácia como dependentes de precisão e exatidão, sendo estes, respectivamente, a proximidade entre os resultados de testes independentes obtidos sob condições estipuladas e a proximidade entre o valor médio obtido de uma grande série de resultados do teste e um valor aceito como referência. Conforme descrito fica clara a diferenciação entre precisão e exatidão, mesmo que a acurácia seja dependente de ambas. 
Para ilustrar este conceito de acurácia e precisão e apresentar a análise de tendência conforme demonstra Monico et al. (2009) por meio da clássica ilustração do alvo. Ao observar os retângulos apresentados na figura 38 estes representam quatro alvos em que a média dos resultados advindos do atirador A coincide exatamente com o centro do alvo, caracterizando tendência nula.

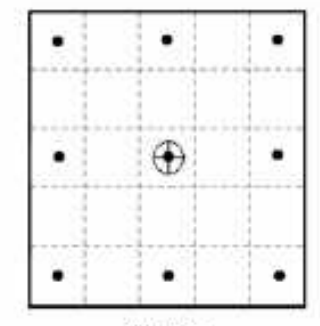

Atriador $A$

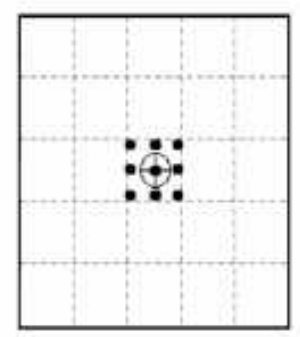

Atiredor C

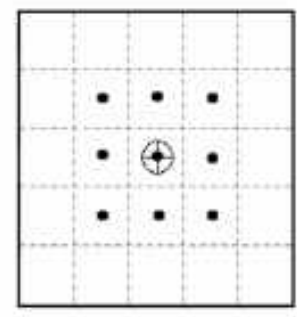

Atindor B

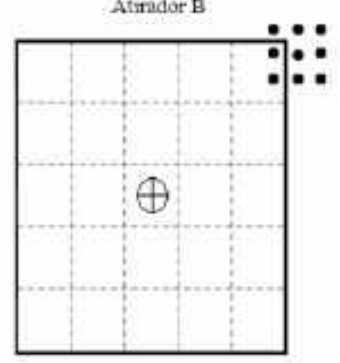

Atrador D

Figura 38: Ilustração da acurácia e precisão com e sem tendência

Fonte: Monico et al. (2009)

Continuando na análise da figura 38, o alvo do atirador B o mesmo ocorre porém, os tiros apresentam menor dispersão (melhor precisão) que o atirador A. Desta forma pode-se considerar o atirador $\mathrm{B}$ mais preciso que o atirador $\mathrm{A}$, e também mais acurado, muito embora ambos tenham tendência nula, ou seja, tem a mesma equidistância entre as observações. Por outro lado, ao observar o conceito de tendência, Monico et al. (2009) define que este apresenta erros sistemáticos e ao se observar o atirador D que possui uma pequena dispersão, porém existe uma tendência quando se considera o centro do alvo, que o diferencia do Atirador C. Desta forma os atiradores C e D apresentam nível de precisão semelhante, mas considera-se que o atirador C é mais acurado que o D. Desta forma considera-se que a acurácia leva em consideração efeitos sistemáticos e aleatórios e, deste modo, a tendência do atirador D deteriora a qualidade de seus resultados.

Para mapas Merchant (1982) apresenta os testes de confiabilidades baseado em erros sistemáticos (Exatidão) e aleatórios (Precisão). Os quais, respectivamente, utilizam-se das seguintes distribuições estatísticas: t-Student e Qui-quadrado. Que serão detalhados nos itens seguintes t-Student (a) e Qui-quadrado (b). Porém, para a aplicação destes 
testes é necessário o cálculo das discrepâncias entre as coordenadas espaciais do produto testado e seus pontos correspondentes em campo (ou mapeamento mais acurado). Sendo estas calculadas, de forma independente para cada componente tridimensional, como se apresenta na expressão 4.29 .

$$
\overline{\Delta X}=\frac{1}{n} \sum_{i=1}^{n} \Delta X_{i}
$$

Com:

$\Delta X_{i}=X_{r_{i}}-X_{a_{i}}$

Onde:

$\mathbf{X}_{\mathbf{r}_{\mathbf{i}}}$ - Coordenada de um dado ponto i (E, N e H) da base de referência;

$\mathbf{X}_{\mathbf{a}_{\mathbf{i}}}$ - Coordenada de um dado ponto i (E, N e H) do produto analisado;

$\mathbf{n}$ - número de pontos do teste.

Além do cálculo da discrepância também é necessário seu desvio padrão, para cada componente testada, conforme apresenta-se na expressão 4.30 .

$$
S_{\Delta X}=\sqrt{\frac{1}{n-1} \sum_{i=1}^{n}\left(\Delta X_{i}-\overline{\Delta X}\right)^{2}}
$$

Para que seja verificada a qualidade geométrica de mapas será utilizado os testes de hipótese para a média (análise de tendência) e para a variância (análise de precisão), conforme descritos nos itens a seguir:

\section{a) Teste $t$ de Student}

O chamado teste t-Student é um teste de hipótese para média populacional onde se identifica, ou não, a existência viés de tendência nas medidas de discrepâncias. Sendo um teste de hipótese nulo este pode ser feito com uma cauda ou bicaudal. Para o caso da análise mapas uma possível abordagem é identificar se a média da amostra é estatisticamente maior ou menor que da média populacional, para isso utiliza-se o teste monocaudal conforme apresentado em 4.31 .

$$
H_{0}: \overline{\Delta X}=0, \quad \text { hipótese nula } \quad \text { ou } \quad H_{1}: \overline{\Delta X} \neq 0, \text { hipótese alternativa }
$$


Para o teste t amostral a formula de cálculo é a 4.32

$$
t_{X}=\frac{\overline{\Delta X}}{S_{\Delta X}} \sqrt{n}
$$

Já o intervalo de confiança é definido pela equação 4.33 , sendo esse valor fornecido por tabelas.

$$
t_{X}<t_{(n-1, \alpha / 2)}
$$

Uma vez que o produto apresente um valor estatístico amostral $t_{X}$ fora deste intervalo considera-se que a carta não esta livre de tendências, pelos mais diversos motivos.

\section{b) Teste Qui-quadrado $\left(\chi^{2}\right)$}

Como apresentado por Galo e Camargo (1994) o teste de hipótese para variância populacional, também conhecido como teste de precisão, Qui-quadrado $\left(\chi^{2}\right)$ deve ser feito comparando o desvio padrão $\left(S_{\Delta X}\right)$ das discrepâncias ${ }^{1}$ com o erro padrão (EP) esperado, para a classe na qual deseja testar. Portanto, o teste de hipótese a ser formulado é apresentado em 4.34 .

$$
H_{0}: S_{\Delta X}^{2}=\sigma_{X}^{2}, \quad \text { contra } H_{1}: S_{\Delta X}^{2}>\sigma_{X}^{2}
$$

Tendo-se que $S_{\Delta X}$ corresponde ao desvio padrão esperado para a componente avaliada que é o Erro Padrão (EP) esperado para a classe pertencente ao teste realizado. Considerando que o Erro Padrão é fixo no teste de cada uma das componentes considera-se o disposto na expressão 4.35 .

$$
\sigma_{X}=E P
$$

Uma vez calculada a variância esperada calculam-se os valores do teste qui-quadrado para a amostra utilizando a expressão 4.36 .

$$
\chi_{X}^{2}=(n-1) \frac{S_{\Delta X}^{2}}{\sigma_{X}^{2}}
$$

\footnotetext{
${ }^{1}$ Defini-se discrepância $(\Delta X)$ como sendo o valor de erro calculado pela diferença entre as coordenadas, de uma mesma componente, entre o ponto homólogo no produto testado e o de referência.
} 
Dessa forma pode-se verificar se o valor calculado na expressão 4.36 está no intervalo de aceitação como se vê na expressão 4.37. Desta forma a hipótese inicial (nula) indica que o produto testado atende à precisão estabelecida para a respectiva classe com n-1 graus de liberdade e intervalo de confiança de $1-\alpha$.

$$
\chi_{X}^{2}<=\chi_{(n-1, \alpha)}^{2}
$$

Caso a expressão 4.37 seja verdadeira então com o $\chi_{(n-1, \alpha)}^{2}$ obtido de tabelas estatísticas, pode-se concluir que a hipótese será aceita, lembrando que com um nível de confiança $90 \%$ sendo $1-\alpha=90 \%$ e $n$ o tamanho da amostra. Caso contrário rejeita-se a hipótese inicial.

\subsubsection{Determinação da quantidade e distribuição amostral}

A amostra utilizada como base análise da acurácia posicional é um tema abordado em diversos trabalhos do gênero que discutem ou empregam a metodologia, proposta por Merchant (1982), que utiliza 20 pontos amostrais para a verificação estatística de acuracidade de cartas topográficas (TOMMASELLI et al., 1988; GALO; CAMARGO, 1994, LÓPEZ; GORDO, 2008; NERO et al. 2017).

Por outro lado a norma DSG (2016b) propõe a metodologia de escolha amostral descrita na norma ISO (2003) que utiliza nível de qualidade aceitável que é determinado a partir de três parâmetros: N que é o número de produtos (ou população), n que é o número de amostras e Ac é o número de aceitação (ou não) da inspeção das amostras. Para definir o tamanho da amostra a norma utiliza valores tabelados para $\mathrm{N}$ e $\mathrm{n}$ os quais determinam qual é o nível de aceitação (Ac) que deve ser avaliado quando comparado ao encontrado durante a análise posicional.

Quanto à distribuição da amostra de avaliação Nero et al. (2017) propõem que esta seja feita por classes homogêneas. Na avaliação elaborada, em seu trabalho, utilizam a premissa do conhecimento da distribuição de pontos que foram utilizados como controle para a elaboração das cartas topográficas, o que é utilizado como parâmetro de escolha de amostras. Com uma abordagem mais simplificada a norma DSG (2016b), utilizada no desenvolvimento deste trabalho, propõe a distribuição das amostras de forma homogênea no produto (amostra) testado, conforme monstra a figura 39.

Dada uma carta topográfica cada parte do reticulado é considerada uma área de busca e em cada uma destas células deve-se escolher somente uma amostra. No exemplo 


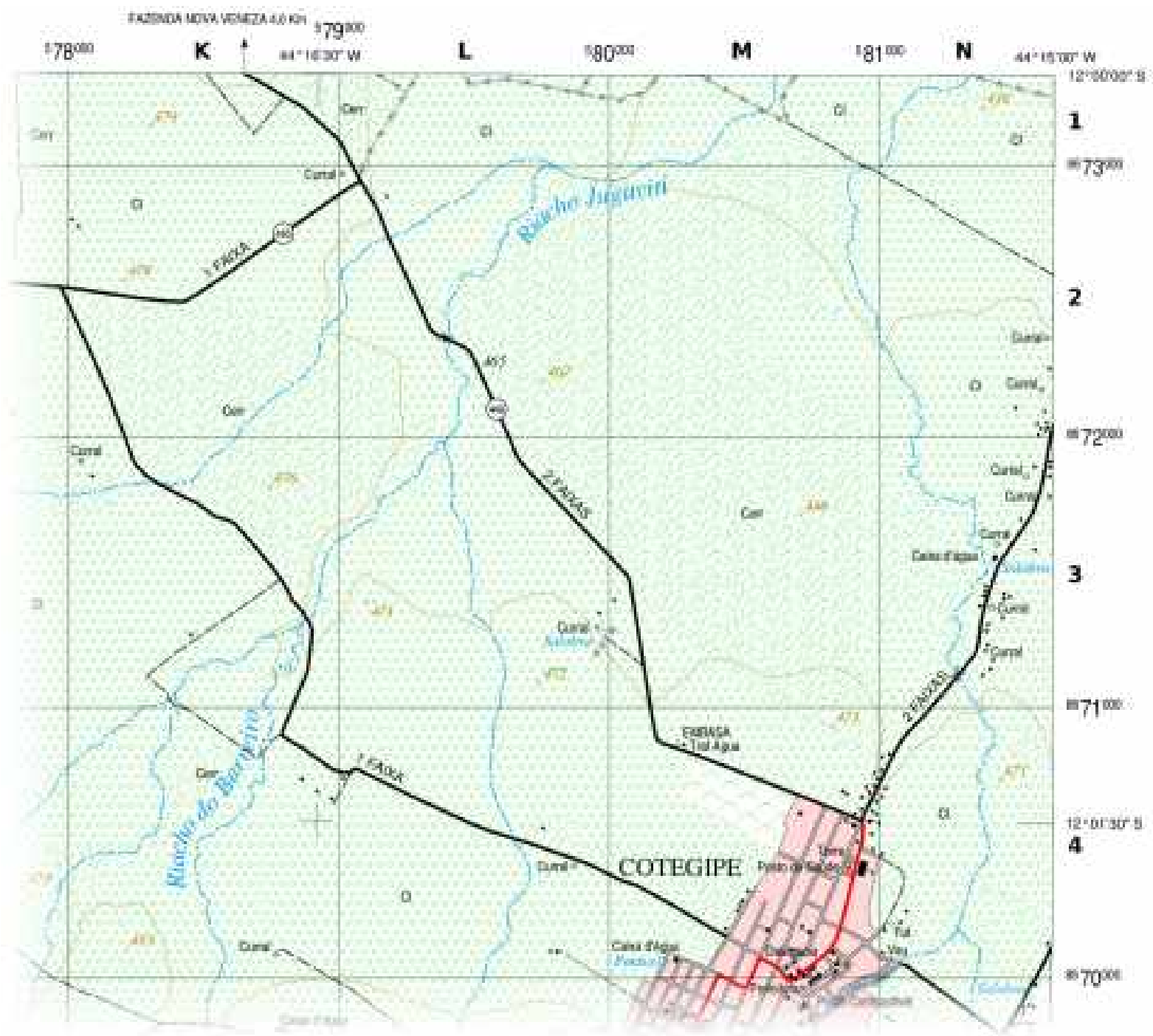

Figura 39: Distribuição amostral

Fonte: DSG (2016b)

da figura 39 a célula M-4 onde deve ser coletado somente um ponto, por exemplo, esquina ou canto de quadra.

\subsubsection{Controle de qualidade posicional no Brasil}

Segundo Cintra e Nero (2015) o Brasil, baseado na normativa americana, formatou oficialmente os parâmetros de exatidão toleráveis para a classificação de produtos da cartografia nacional a partir do decreto número 89.817, de 20 de junho 1984 (BRASIL, 1984). Deste decreto são apresentados na tabela 4 os valores de acuracidade padronizados no Brasil.

Um dos primeiros trabalhos, elaborado no Brasil, de teste estatístico para análise 


\begin{tabular}{c|c|c|c|c}
\hline Classe & PEC-Plan. (mm) & EP-Plan. (mm) & PEC-Alt. (eq) & EP-Alt. (eq) \\
\hline A & 0,5 & 0,3 & $1 / 2$ & $1 / 3$ \\
\hline B & 0,8 & 0,5 & $3 / 5$ & $2 / 5$ \\
\hline C & 1,0 & 0,6 & $3 / 4$ & $1 / 2$ \\
\hline
\end{tabular}

Tabela 4: PEC e Erro padrão (altimétrico e Planimétrico)

Fonte: Decreto 89.817 (BRASIL, 1984)

de erros posicionais (geométricos) em produtos cartográficos foi executado por TOMMASELLI et al. (1988), utilizando a metodologia proposta por Merchant (1982). Como destaca Nero (2005), no processo de avaliação da acurácia cartográfica é necessário realizar uma comparação entre o material a ser avaliado e uma fonte, mais acurada, considerada como padrão de comparação. Os valores desse padrão de comparação podem ser obtidos basicamente a partir do emprego de duas técnicas: levantamento de campo ou coleta sobre um mapa mais acurado. Para esta comparação o produto de referência deve ter características de acurácia no mínimo três vezes melhor em relação ao produto a ser testado (MERCHANT, 1982).

O controle de qualidade utilizando outras fontes (mapas mais acurados) pode ser feita por pontos, como proposto pelo trabalho de Merchant (1982) ou, mais recentemente, utilizando feições lineares (GOODCHILD; HUNTER, 1997; GALO et al., 2001; SANTOS et al. 2015). A escolha de pontos ou feições, na fonte de referência que será utilizada como controle que deve ser feita com atenção a detalhes como precisão e característica da feição, ou ponto, para garantir que este seja bem definido e identificado nas duas fontes. Algumas observações podem ser feitas a este respeito (NERO, 2005, LIMA, 2012):

- Grau de generalização: deve-se ter conhecimento de como foram coletadas as informações e sobre o grau de generalização das feições, coisa que pode afetar a posição de pontos e feições;

- Mudanças temporais entre os produtos: Analisar se houve modificações dos produtos no tempo, ou seja, estar atento para o caso de produtos produzidos em diferentes datas;

Em 2011 surgiu a nova normativa de Especificação Técnica para a Aquisição de Dados Geoespaciais Vetoriais (ET-ADGV), propondo valores para a classificação de PEC em Produtos Cartográficos Digitais (PCD) (ver tabela 5) (DSG, 2016a). 


\begin{tabular}{c|c|c|c|c}
\hline \multirow{2}{*}{$\begin{array}{c}\text { Classe } \\
\text { PCD }\end{array}$} & \multicolumn{2}{|c|}{ Planimetria } & \multicolumn{2}{c}{ Altimetria (c. nível) } \\
\cline { 2 - 5 } & PEC (mm) & EP ( mm) & PEC (eq) & EP (eq) \\
\hline A & 0,28 & 0,17 & $1 / 2$ & $1 / 3$ \\
\hline B & 0,5 & 0,3 & $3 / 5$ & $2 / 5$ \\
\hline C & 0,8 & 0,5 & $3 / 4$ & $1 / 2$ \\
\hline D & 1,0 & 0,6 & 1 & $3 / 5$ \\
\hline
\end{tabular}

Tabela 5: Valores gerais do PEC PCD

Fonte: ET-ADGV (DSG, 2016a)

Embora esta seja somente uma normativa que não tem força de lei, como o decreto de 1984, têm, devido à sua grande especificidade, sido utilizada por diversas instituições que contratam, produzem ou verificam mapeamentos (PENHA et al., 2012; DORNELLES; IESCHECK, 2013; DUARTE; ROMANHOLI, 2017).

Em função dos valores mostrados nas tabelas 4 e 5 pode-se resumir, para escalas pequenas, qual deve ser o erro tolerável para os mapeamentos em questão, conforme apresentado na tabela 6, considerando as escalas 1:25.000 e 1:50.000.

\begin{tabular}{|c|c|c|c|c|c|c|c|c|c|c|c|c|c|c|c|}
\hline \multicolumn{8}{|c|}{$1: 25.000$} & \multicolumn{8}{|c|}{ 1:50.000 } \\
\hline \multicolumn{4}{|c|}{ Planimetria } & \multicolumn{4}{|c|}{ Altimetria (c. nível eq. $10 \mathrm{~m}$ ) } & \multicolumn{4}{|c|}{ Planimetria } & \multicolumn{4}{|c|}{ Altimetria (c. nível eq. $20 \mathrm{~m}$ ) } \\
\hline Classe & Classe & PEC & $\mathrm{EP}$ & Classe & Classe & PEC & $\mathrm{EP}$ & Classe & Classe & PEC & $\mathrm{EP}$ & Classe & Classe & PEC & EP \\
\hline Lei & Norma & $(\mathrm{m})$ & $(\mathrm{m})$ & Lei & Norma & $(\mathrm{m})$ & $(\mathrm{m})$ & Lei & Norma & $(\mathrm{m})$ & $(\mathrm{m})$ & Lei & Norma & $(\mathrm{m})$ & $(\mathrm{m})$ \\
\hline- & A & 7 & 4,25 & A & A & 5 & 3,33 & - & A & 14 & 8,51 & A & A & 10 & 6,67 \\
\hline A & B & 12,5 & 7,5 & B & B & 6 & 4 & A & B & 25 & 15 & B & B & 12 & 8 \\
\hline B & C & 20 & 12,5 & $\mathrm{C}$ & $\mathrm{C}$ & 7,5 & 5 & B & $\mathrm{C}$ & 40 & 25 & C & $\mathrm{C}$ & 15 & 10 \\
\hline C & $\mathrm{D}$ & 25 & 15 & - & D & 10 & 6 & C & D & 50 & 30 & - & D & 20 & 12 \\
\hline
\end{tabular}

Tabela 6: Valores PEC e PEC Digital aplicado as escalas 1:25.000 e 1:50.000

Fonte: ET-ADGV (DSG, 2016a)

Baseado nesta norma o Exército editou a Especificação Técnica para Controle de Qualidade de Dados Geoespaciais (ET-CQDG) que descreve a métrica Erro Médio (EM) em substituição a medida do Padrão de Exatidão (PEC). Os valores a serem aplicados para classificação de qualidade em produtos digitais como, por exemplo, Modelos Digitais de Elevação (MDE) destes os Modelos Digitais de Terreno (MDT) e Modelos Digitais de Superfície (MDS), são apresentados na tabela 7 . 


\begin{tabular}{|c|c|c|c|c|c|c|c|c|}
\hline Tipo & \multicolumn{4}{|c|}{ Planimetria } & \multicolumn{4}{|c|}{ Altimetria (MDE) } \\
\hline Escala & \multicolumn{2}{|c|}{$1: 25.000$} & \multicolumn{2}{|c|}{$1: 50.000$} & \multicolumn{2}{|c|}{ 1:25.000 } & \multicolumn{2}{|c|}{$1: 50.000$} \\
\hline Classe & EM & EP & EM & EP & EM & EP & EM & EP \\
\hline A & 7 & 4,25 & 14 & 8,5 & 2,7 & 1,67 & 5,5 & 3,33 \\
\hline B & 12,5 & 7,5 & 25 & 15 & 5 & 3,33 & 10 & 6,67 \\
\hline $\mathrm{C}$ & 20 & 12,5 & 40 & 25 & 6 & 4 & 12 & 8 \\
\hline $\mathrm{D}$ & 25 & 15 & 50 & 30 & 7,5 & 5 & 15 & 10 \\
\hline
\end{tabular}

Tabela 7: Valores e Erro Médio e Erro Padrão

Fonte: ET-CQDG (DSG, 2016b)

Quando comparados aos da norma de 1984 os valores, listados nas tabelas 7 e 6 , apresentam-se com uma nova classe A de parâmetros mais rígidos. Isso acaba fazendo com que a classificação antiga seja, pela nova norma, seja rebaixada para valores iniciando-se pela classe $\mathrm{B}$.

Utilizando a legislação vigente o decreto 89.817, que não foi revogada, e as demais normativas acaba havendo sobreposição em alguns pontos. Cintra e Nero (2015) destacam que a aplicação dos parâmetros do decreto se aproxima da norma NMAS. Por outro lado, TOMMASELLI et al. (1988), Galo e Camargo (1994) entendem que a legislação permite que seja analisada a acuracidade conforme propõe Merchant (1982). Estes trabalhos não dispunham da instrução normativa, publicada posteriormente, que visa padronizar verificação de acuracidade de produtos geoespaciais, a norma DSG (2016b). Embora elaborada visando atender a Infraestrutura de dados Espaciais (INDE) que é focada em dados vetoriais, a aplicabilidade desta em mapeamentos analógicos não é descartada. Desta forma dispõem-se de uma diretriz normativa que orienta como verificar os parâmetros do decreto 89.817 tanto para produtos digitais quanto para produtos analógicos (cartas topográficas).

Para a primeira normativa brasileira, o decreto 89.817 Brasil (1984), a descrição do erro planimétrico define que no teste, $90 \%$ dos pontos testados deve obedecer (ser inferior) a um valor de Padrão de Exatidão Cartográfico - PEC correspondente à escala. Além disso, Galo e Camargo (1994) os pontos de referência a serem utilizados podem ser determinados por procedimentos na qual o erro não seja superior a 1/3 do Erro Padrã $\complement^{1}$ (EP) esperado para a classe da carta. Não fica claro se estes valores são para cada componente ou sua resultante, mas Cintra e Nero (2015) demonstram que se refere a cada componente

\footnotetext{
${ }^{1}$ Entende-se que a normativa de 1984 considerava equivalente os termos Erro Padrão e Desvio Padrão (GALO; CAMARGO, 1994).
} 
isoladamente 1 . Já a segunda normativa, bem mais recente, a DSG (2016b, tb 21) propõe a comparação com a resultante (da composição das duas componentes horizontais), baseado na norma ISO 19000, segundo descrito na expressão 4.38 ISO, 2003, JAKOBSSON; GIVERSEN, 2007).

$$
E M Q_{H}=\sqrt{\frac{\sum_{i=1}^{n}\left(e_{H i}^{2}\right)}{n}}
$$

Os parâmetros da expressão 4.38 são calculados conforme as expressões 4.39 , sendo que o subscrito $t$ se refere a pontos testados e $r$ aos pontos de referência.

$$
\begin{gathered}
e_{x}=x_{t}-x_{r} \\
e_{y}=y_{t}-y_{r}
\end{gathered}
$$

Neste caso aplicando-se a $e_{H i}$ na expressão 4.38, tem-se o termo apresentado na expressão 4.40 .

$$
e_{H i}=\sqrt{e_{x i}^{2}+e_{y i}^{2}}
$$

Sobre as coordenadas altimétricas, a mesma norma orienta a utilização da expressão 4.41.

$$
E M Q_{Z}=\sqrt{\frac{\sum_{i=1}^{n}\left(e_{Z i}^{2}\right)}{n}}
$$

Os parâmetros da expressão 4.41 são calculados conforme a expressão 4.42, sendo que os sufixos $t$ referem-se aos pontos testados e $r$ aos pontos de referência.

$$
e_{z}=z_{t}-z_{r}
$$

Conforme descrito por SANTOS (2010) a normativa ET-ADGV em 2010 correlacionava a condição de comparação entre o erro médio quadrático² (EMQ) da amostra e o Erro Padrão (EP), de forma a ser um teste de condição, ou seja, caso o EMQ da amostra for menor que o EP proposto pela norma para determinada escala o mapeamento pode

${ }^{1} \mathrm{O}$ que permite detectar tendências por compontente.

${ }^{2}$ A terminologia utilizada no inglês apresenta-se de mais fácil entendimento, pois o termo Root-MeanSquare Error (RMSE), em português seria a raiz do erro médio quadrático. A isso deve-se atentar que as expressões 4.38 e 4.41, onde se utiliza o termo EMQ como equivalente ao RMSE e não a Mean Square Error - MSE em português Erro Quadrático Médio (EQM). 
ser aceito. Desta forma o cálculo de EMQ apresentado pela norma DSG (2016b), propõe a utilização das equações 4.38 e 4.41, de certa forma, fornece uma maior especificação na padronização para a aplicação da legislação e das normativas nacionais. Outra questão da norma DSG (2016b) é a determinação que 90\% dos erros devem estar abaixo de um limite, mas não especifica limite para os $10 \%$ restantes. Caso se suponha uma distribuição normal isso não é necessário.

Sobre a característica de acurácia necessária para o produto de melhor qualidade para comparação, Merchant (1982) propõe como especificação a utilização de pontos coletados em campo ou em bases cartográficas sempre três vezes mais acurado. Nesta base devem ser coletadas coordenadas de pontos homólogos aos do produto cartográfico testado. No Brasil diversos trabalhos utilizaram esta metodologia em diversas cartas topográficas com escalas sistemáticas (TOMMASELLI et al., 1988; GALO; CAMARGO, 1994; NOGUEIRA JÚNIOR, 2003).

\subsubsection{Controle de qualidade qualitativo de seu conteúdo}

Os critérios qualitativos de qualidade surgiram com a chamada cartografia digital, devido ao armazenamento em formato vetorial e em banco de dados. Uma das primeiras iniciativas de análise da qualidade foi a normativa americana Digital Cartographic Data Standards (NCDCDS) que fixou padrões para o armazenamento, classificação, metadados e representação da informação espacial (FEGEAS et al. 1992). Embora estas normas tenham sido desenvolvidas para arquivos digitais, algumas das características analisadas independem do formato (digital ou analógico), conforme se descreve a seguir e podem ser aplicados aos mapeamentos que serão analisados neste trabalho.

Os elementos de qualidade descritos por Guptill e Morrison (2013), Fegeas et al. (1992), ISO (2003) são: linhagem, acurácia de atributos, consistência lógica e completeza. Alguns destes itens podem ser analisados quando se avalia a qualidade de um documento cartográfico analógico (em papel). Com este objetivo alguns deles são descritos a seguir:

- Linhagem - Pode ser descrita como um "histórico" do processamento do dado, no caso dados espaciais. Para isso deve-se incluir uma descrição do material de origem, referências a informações de controle, métodos de derivação, métodos de codificação e todas as transformações matemáticas envolvidas em cada etapa, até a obtenção do produto digital final (MOELLERING, 1988). A linhagem é uma informação do tipo composto, com valores quantitativos e texto descritivo (WEBER et al., 1999). A quantidade e a qualidade das informações de linhagem não são um índice de 
qualidade de dados, mas referem-se a quantidade e a qualidade das informações. São um índice de qualidade dos metadados, ou seja, referem-se a qualidade e a integridade dos dados que descrevem os dados espaciais GUPTILL; MORRISON, 2013). Em produtos analógicos aplica-se, com pequenas adaptações, a produção de cartas topográficas.

- Acurácia de atributos - Em informação geográfica e cartográfica, o termo atributo pode ser definido como características de alguma feição ou conjunto de feições sobre a superfície terrestre. As respostas às questões levantadas (valor dos atributos) podem ser resultado de uma medida com algum tipo de instrumento, tal como a trena; pode ser o resultado da interpretação feita por um observador treinado, tal como o uso da terra presente num mapa ou ainda pode ser consequência de um consenso histórico, ou político, tal como topônimos de um mapa GOODCHILD, 1995, adaptado). Em produtos analógicos aplica-se, com pequenas adaptações, a verificação de topônimos em cartas topográficas.

- Completeza - A completeza ou completude descreve a relação entre os objetos reais representados em um conjunto de dados e o universo abstrato de todos esses objetos, isso é, analisa a quantidade de informação faltante ou acrescida, ou seja, que não deveria estar presente, no total de objetos deste universo (BRASSEL et al. 1995; ÖSTMAN, 1997).

A completitude em informação geoespacial é classificada em dois grandes grupos a completitude conceitual e a de arquivo (armazenada com a informação). No primeiro caso, durante o processo conceitual do projeto, o modelo escolhido pode não ter contemplado todas as possíveis classes, já no segundo caso este é aplicado a informação já consolidada por um modelo, por exemplo, em um banco de dados. Observando a completude, no arquivo já concebido existe a possibilidade de que este atenda ou não ao modelo formalizado, acarretando falha formal de completude. Para exemplificar tome-se o seguinte caso: em um modelo formal (completo) que concebe uma classe de hidrografia (rio) com seu arquivo, assim interpretado e coletado este tipo de feição elas atendem a completude formal. Já se este tem características a serem atributáveis e completas atendem a completude em termos de atributos (BRASSEL et al. 1995).

Pode-se quantificar em taxas ou o grau de completude dos arquivos analisados, tanto em omissões e comissões de feições, ou seja, objetos $\mathrm{L}^{1}$ formalmente representados ou

\footnotetext{
${ }^{1}$ Objetos que não estão representados e deveriam estar, ou ainda aqueles que são representados, mas seu correspondente real não existe.
} 
não. Desta forma Salgé (1995) descreve que isso pode ser representado estatisticamente a partir das taxas de comissão $r^{+}$e de omissão $r^{-}$, conforme apresentam as expressões em 4.43 .

$$
r^{+}=\frac{N^{+}}{\max \left(N, N^{0}\right)} \quad \text { e } \quad r^{-}=\frac{N^{-}}{\max \left(N, N^{0}\right)}
$$

Onde $N^{-}$é o número de ocorrências que existem na realidade e que não foram representados, no caso a omissão propriamente dita. Já $N^{+}$representa o oposto, ou seja, o número de elementos presentes no mapa que não ocorrem na realidade, neste caso a comissão. Já o elemento $N$ representa o número de elementos da amostra e $N^{0}$ o número de ocorrências da realidade. Para calcular o valor de $N$ utiliza-se a expressão 4.44

$$
N=N^{0}+N^{+}-N^{-}
$$




\section{ANÁLISE DOS MATERIAIS UTILIZADOS NOS MAPAS DO IGGSP (1960-1974)}

Este capítulo apresenta o contexto da coleção cartográfica, mais especificamente, a produção das cartas topográficas elaboradas pelo IGGSP entre 1960-1974; presentes no acervo IGCSP (2017). Este conjunto tem como característica o fato de não ter sido finalizado nem publicado. Levando isso em consideração serão apresentados os produtos encontrados nesta Instituição, bem como o contexto de sua elaboração e os principais atores envolvidos.

Como apresentado nos tópicos anteriores muitas instituições fizeram parte da história cartográfica nacional, das quais algumas foram responsáveis pela elaboração dos produtos aqui apresentados. Neste tópico são abordadas, mais em concreto, quais as tecnologias e metodologias utilizadas durante a produção do objeto de estudo. Além disso, serão apresentadas informações sobre a atuação dos envolvidos durante o seu desenvolvimento, além de características até agora inéditas.

Também serão apresentados produtos que se utilizaram desses mapas, dentre os quais se destacam: os mapas municipais e a continuidade das publicações cartográficas no Estado de São Paulo.

\subsection{Contratação e Execução}

O governo estadual paulista tinha e tem interesse em elaborar cartas topográficas para o conhecimento de seus recursos naturais e assim possibilitar os diversos usos e estudos, por exemplo: definição territorial, uso e ocupação do solo, definição de áreas urbanas e rurais, etc... Estas necessidades estavam sendo atendidas com grande dificuldade pelo material produzido pela CGGSP/IGGSP, ou seja, as cartas 1:100.000. Na nova proposta surge a possibilidade de uso da tecnologia do levantamento aerofotogramétrico. O ministério da agricultura teve a iniciativa de iniciar estes levantamentos no início da década 
de 40, porém esses trabalhos foram encerrados em 1947 por não terem características sistemáticas, serem pontuais, não correspondendo às expectativas técnicas 2 , Em 1953, o IGGSP publicou um edita $]^{3}$ que viria a ser uma primeira experiência de concorrência pública para a execução de aerolevantamentos pelo governo do Estado de São Paulo. A área objeto desse edital era de $3.000 \mathrm{~km}^{2}$ situados entre Apiaí e Capão Bonito. Esse projeto foi disputado pela recém criada empresa Viação Aérea São Paulo (VASP) e pela Natividade ambas especializadas em aerofotogrametria, sendo escolhida a proposta da VASP (LEFĖVRE, 1953). Porém, esse processo não foi concluído e, nesse meio tempo a VASP entendeu que seria interessante realizar um levantamento aerofotogramétrico de todo o Estado de São Paulo. Este aerolevantamento visava atender o plano geral cartográfico do estado, que visava produzir cartas topográficas de forma a recobrir o território estadual iniciando-se por áreas até então nunca mapeadas no noroeste paulista (LEFĖVRE, 1963 , pg. 102).

\section{a) Influência da empresa VASP na Contratação}

Em 1956 a VASP articula com o governo estadual, mediante documento 4 , a necessidade de um único projeto de aerolevantamento para evitar as chamadas "sobreposições". O Estado entendendo que a única Instituição que teria competência, pela experiência no assunto, seria o IGGSP (sucessor da CGGSP e fundado em 1938). Assim, foi promulgado o decreto 34.318 de dezembro de 1958 (SÃ PAULO (Estado), 1958). Este atribuiu ao IGGSP, a partir de 1959, a realização e supervisão do levantamento aerofotogramétrico realizado no território do Estado e a execução do trabalho de levantamento topográfico de $40 \%$ do Estado, em escalas que poderiam ser 1:25.000, 1:50.000 e 1:100.000 ${ }^{1}$. Com esta atribuição o IGGSP elaborou o primeiro plano cartográfico geral do Estado, plano que foi descrito por Lefèvre (1963) e, se propunha realizar o mapeamento no prazo de 12 anos através cobertura aerofotogramétrica, apoio de campo e elaboração de cartas topográficas, em todas as áreas do Estado.

\footnotetext{
${ }^{1}$ Lefèvre (1946) descreve que com o auxílio (empréstimo de câmara e restituidores) da Seção de Fotogrametria do Ministério da Agricultura foram executados voos e restituição nas regiões de São Paulo e Iguape durante o ano de 1945.

${ }^{2}$ Notícia publicada no Diário oficial do Estado de São Paulo, 4 de dezembro de 1959.

${ }^{3}$ Notícia publicada no Diário oficial do Estado de São Paulo, 6 de fevereiro de 1953.

${ }^{4}$ Notícia publicada no Diário oficial do Estado de São Paulo, 11 de outubro de 1957.
} 


\subsubsection{Primeiro Levantamento Aerofotogramétrico do Estado de São Paulo}

A primeira proposta de um projeto que executasse um aerolevantamento recobrindo todo o território paulista, partiu da VASP Aerofotogrametria, que se comprometeria a executar o levantamento em escala 1:20.000. Além desta proposta foi apresentada outra pela empresa Cruzeiro Serviços Aerofotogramétricos. A primeira proposta, da VASP, foi impugnada e este levantamento só foi possível pela proposta que formada pelo consórcio entre: a VASP Aerofotogrametria S.A., Serviços Aerofotogramétricos Cruzeiro do Sul e Aeromapa Brasil, que foi contemplado pelo contrato firmado com o IGGSP em 19591. Conforme descrito por Lefèvre (1963) este mapeamento seria executado em escala fotogramétrica de 1:40.000, mas na realidade foi executado com escala 1:25.000 como se explicará. A seguir será descrito como foram separadas as áreas de voo (blocos aerofotogramétricos), com enfoque nas áreas onde foram produzidos os mapeamentos objetos deste estudo. A interessante história das empresas de aerofotogrametria Natividade e VASP pode ser encontrada no Apêndice C.1.2, na página 184.

\section{a) Trabalhos executados no período de 1960-1964}

Os registros originais sobre os voos elaborados entre 1960 e 1964, hoje conhecido como voo de 1962, sobretudo seus negativos estes encontram-se no acervo mantido pela empresa na Base Aerofotogrametria (IDOETA et al. 2004). Uma cópia dos fotos-contatos com seus respectivos foto-índices foram adquiridos pelo Instituto Agronômico de Campinas e hoje encontram-se digitalizados no Instituto Geográfico e Cartográfico - IGCSP. O esquema de organização dos blocos com seu recobrimento e as respectivas executoras do voo pode ser visto na figura 40. Outras empresas como a Cruzeiro do Sul participaram do processo, mas não produziram mapas. Como apontado, o foco deste trabalho está nos mapeamentos, e mais especificamente no Bloco 1 e 7 , pelos motivos que serão descritos no decorrer desta secção.

\footnotetext{
${ }^{1}$ Notícia publicada no Diário oficial do Estado de São Paulo, 22 de março de 1960.
} 


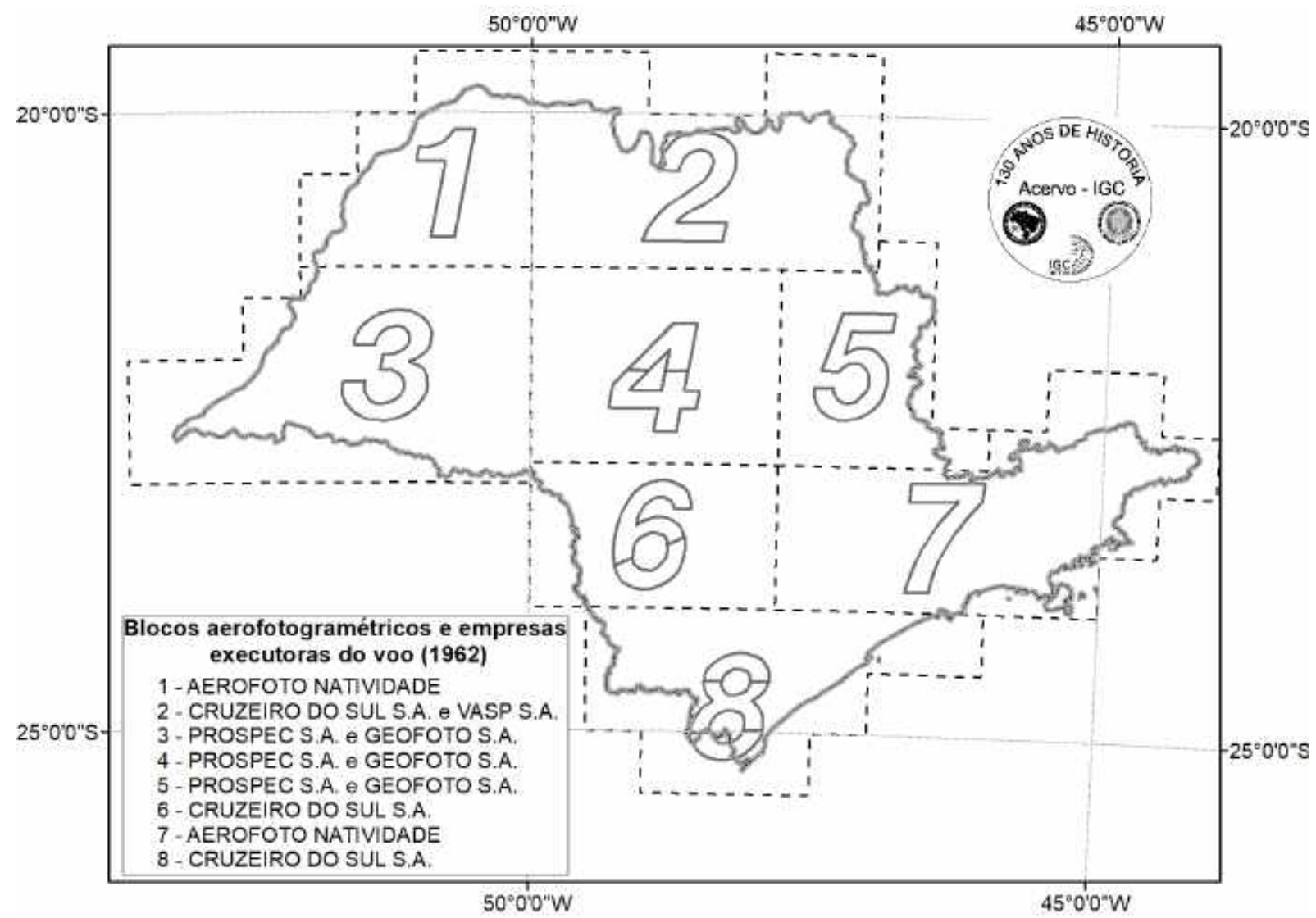

Figura 40: Esquema de blocos do voo de 1962 sobreposto com a área do mapeamento

Fonte: Autor a partir de compilação do acervo IGCSP (2017)

Embora tenha sido importante o voo de 1962 não foi o único realizado no Estado na década de 1960, porém o com maior detalhamento em relação à área total do estado. Em meados de 1965 a United States Air Force - USAF realizou outros dois um em escala 1:20.000 (em algumas poucas cidades) e outro em escala 1:60.000 (em todo o Estado), conforme descrito no Apêndice C.1.1. Em relação às cartas topográficas em escala 1:50.000 elaboradas pelo próprio IGGSP, e outras instituições, estas utilizaram como fonte as fotografias encomendadas pelo Estado (1961-1964). As documentações destes voos bem como as cartas topográficas serão analisadas nos tópicos seguintes.

\subsubsection{Mapeamento 1:25.000 e 1:50.000}

Neste item foram analisados, alguns detalhes técnicos dos mapeamentos produzidos a partir do voo executado de 1961 em diante, sendo os seguintes itens: apoio de campo, aerofotogrametria e das cartas topográficas elaboradas. 


\subsubsection{1 Área de abrangência}

Foram executadas duas licitações, preparadas pelo IGGSP: no primeiro edital, publicado em 1959, sendo objeto desta licitação o mapeamento na região do extremo noroeste do Estadd 1 no segundo outra parte do oeste paulista e a região da capital (grande São Paulo). Os produtos a serem entregues foram as fotografias aéreas (mosaicos) e cartas topográficas (em escala de 1:50.000 ou 1:25.000) feitas por meio de restituição utilizando pares estéreos. A primeira área licitada recobre compreende cerca de 16 mil quilômetros quadrados já o restante do mapeamento, que foi licitado em outubro de $19612^{2}$, recobre área maior com cerca de 37 mil quilômetros quadrados. Essas áreas são apresentadas na figura 41 .

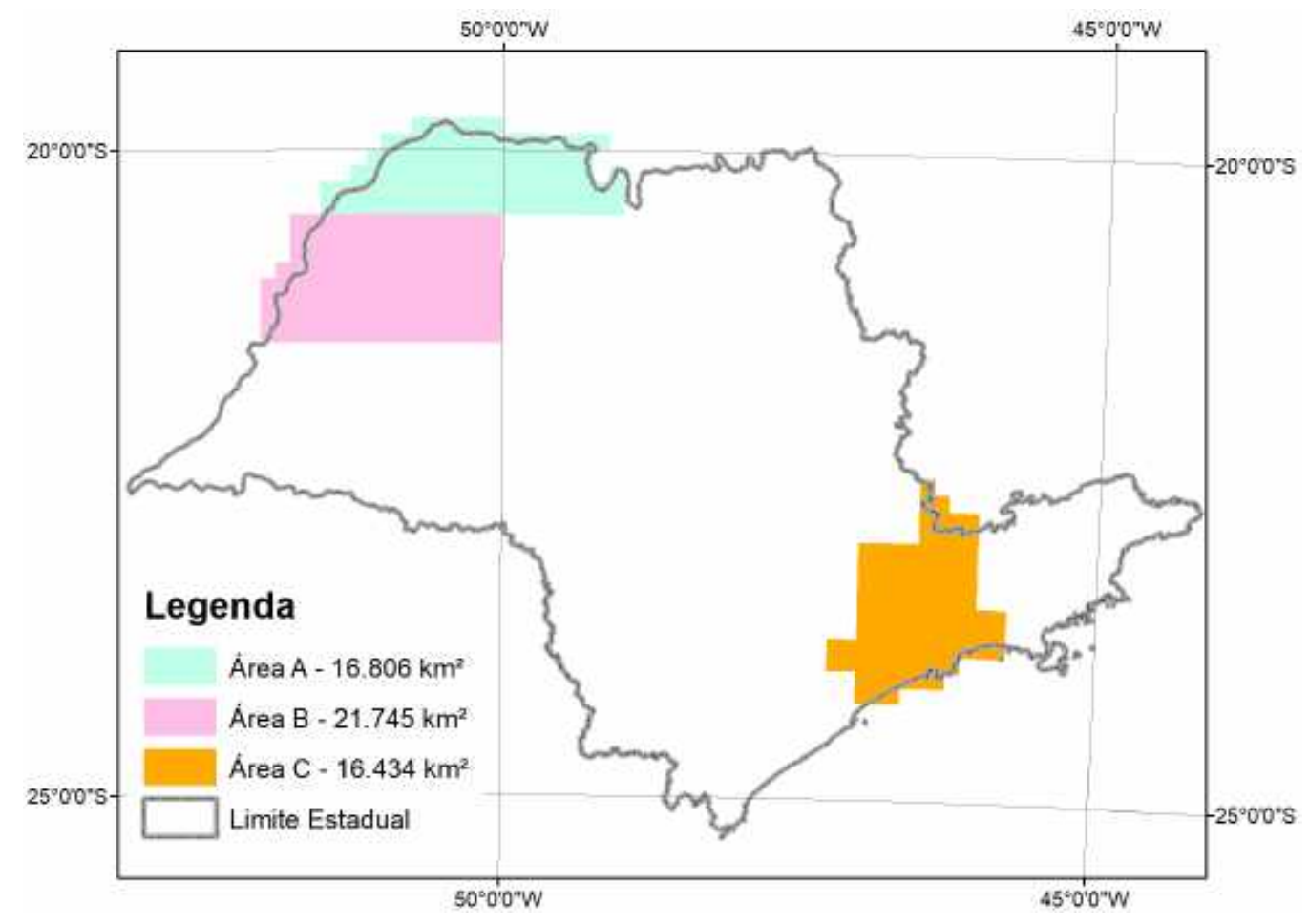

Figura 41: Esquema de áreas do mapeamento 1962/74

Fonte: Autor a partir de compilação do acervo do IGCSP (2017)

\subsubsection{Apoio Terrestre de Campo}

Os únicos trabalhos de campo executados e com resultados publicados o foram em dois boletins do IGGSP. No primeiro, de número 30, Franco (1943) apresenta a rede de triangulação (apoio horizontal) e no segundo elaborado por Colucci (1962), de número 36, aborda o nivelamento (apoio vertical). A seguir descrevem-se os materiais, publicados e

\footnotetext{
${ }^{1}$ Notícia publicada no Diário oficial do Estado de São Paulo, 26 de agosto de 1959.

${ }^{2}$ Diário oficial do Estado de São Paulo, 3 de outubro de 1961.
} 
encontrados, sobre a execução dos levantamentos planimétricos e altimétricos produzidos pelo IGGSP, e utilizados como apoio no mapeamento em análise.

\section{a) Apoio Planimétrico}

Nos trabalhos executados até 1943 os pontos de apoio horizontal se referem à rede que se inicia em Santo Ângelo indo até Capão Bonito conforme pode ser observado na figura 42 . Nesta nota-se que sua abrangência, quando comparada com a das áreas dos mapeamentos, que são objetos de estudo, não contempla as regiões ao oeste e nem mesmo toda a área mais a sudeste. Quanto à precisão de fechamento desta rede de triangulação Franco (1943) informa que os erros, nos diversos cálculos e métodos de controle empregados, visando minimizá-los durante a leitura de ângulos e distâncias, foram em latitude $0^{\circ} 0^{\prime} 11^{\prime \prime}$ (aprox. 340 metros), longitude $0^{\circ} 0^{\prime} 2^{\prime \prime}$ (aprox. 46 metros). Embora estes erros fossem considerados pequenos na época, atualmente com o avanço tecnológico são considerados significativos.

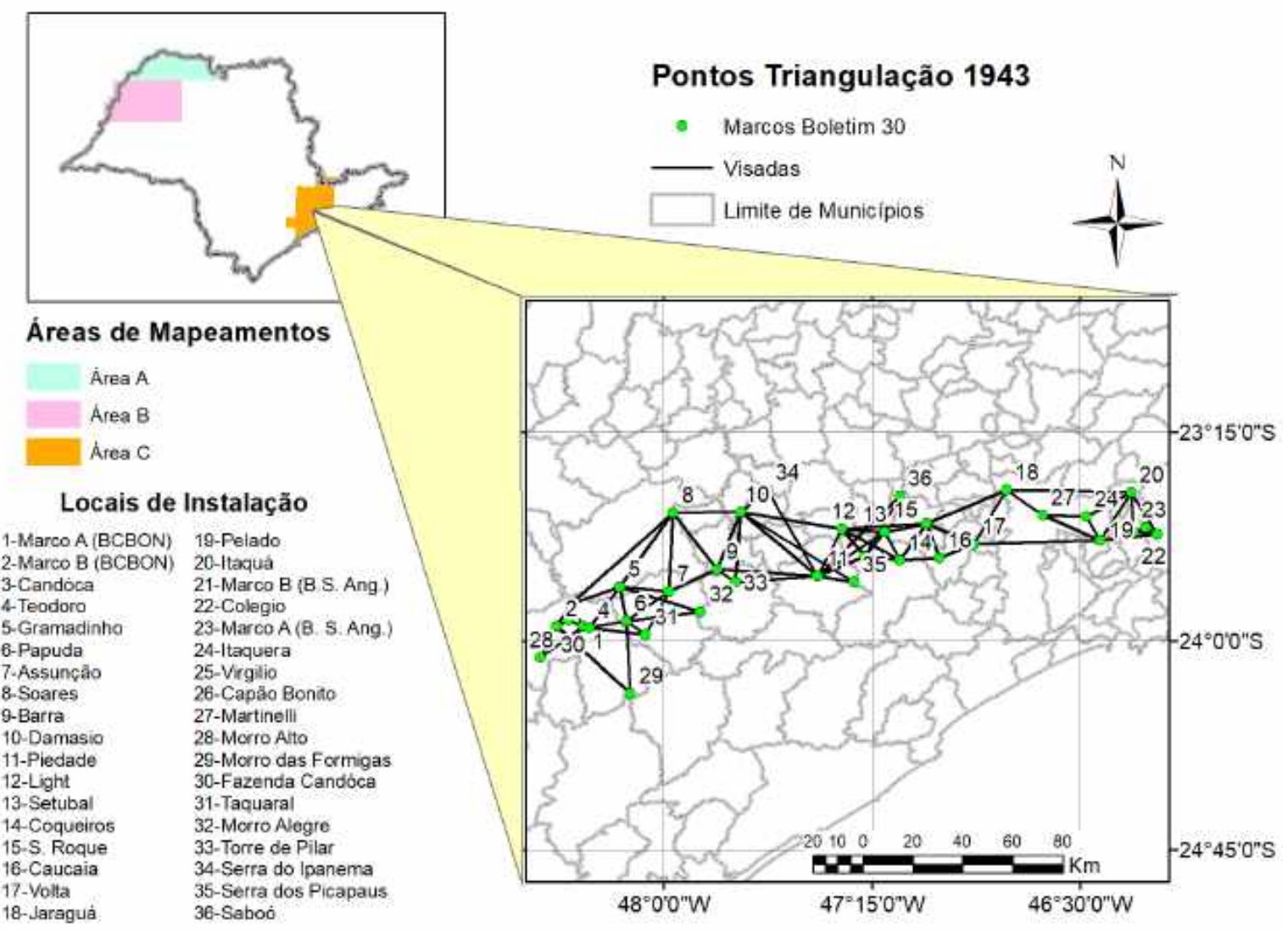

Figura 42: Rede de triangulação entre Santo Ângelo e Capão Bonito

Fonte: Autor em compilação a partir de Franco (1943)

No acervo administrativo do IGGSP (pertencente ao MUGEO-IG) o autor do presente 
trabalho encontrou diversos croquis que ilustravam caminhamentos de redes de triangulação de outro levantamento. Conforme descreve Lefèvre (1963, pg. 102) estes outros levantamentos foram elaborados em apoios planimétricos executados por meio do processo de poligonação utilizando medidas angulares feitas com teodolitos geodésicos e distâncias medidas por telurômetros. Embora estes documentos relatem diversos trabalhos, nenhum cálculo ou tabela de coordenadas foi encontrado nas publicações oficiais do Instituto. Os únicos documentos relativos às coordenadas (cadernetas de campo) encontram-se, não classificados, no Arquivo Público do Estado de São Paulo APESP, que não permite acesso aos mesmos, por estarem em procedimento de restauração.

Em consulta ao acervo do IGCSP (2017) foram encontrados relatórios do IGGSP, elaborados entre 1959 e 1962, que apresentaram dados de um levantamento para apoio horizontal (LEFĖVRE, 1961; LEFĖVRE, 1962). A experiência dos técnicos e a compra do medidor de distância pelo IGGSP (ver Apêndice A página 156), segundo os documentos da época, foram de suma importância para a rápida execução do trabalho que infelizmente, nunca foi publicado. Nova pesquisa permitiu encontrar em rascunhos pertencentes ao acervo do IGCSP (2017) os valores de coordenadas de 139 pontos constantes da tabela 36 (ver página 207 do anexo). A partir destas foram desenhados os vértices dos triângulos representados na figura 43 . Sobrepondo-se estas coordenadas às áreas do mapeamento A, B, e C notasse cobertura compatível.

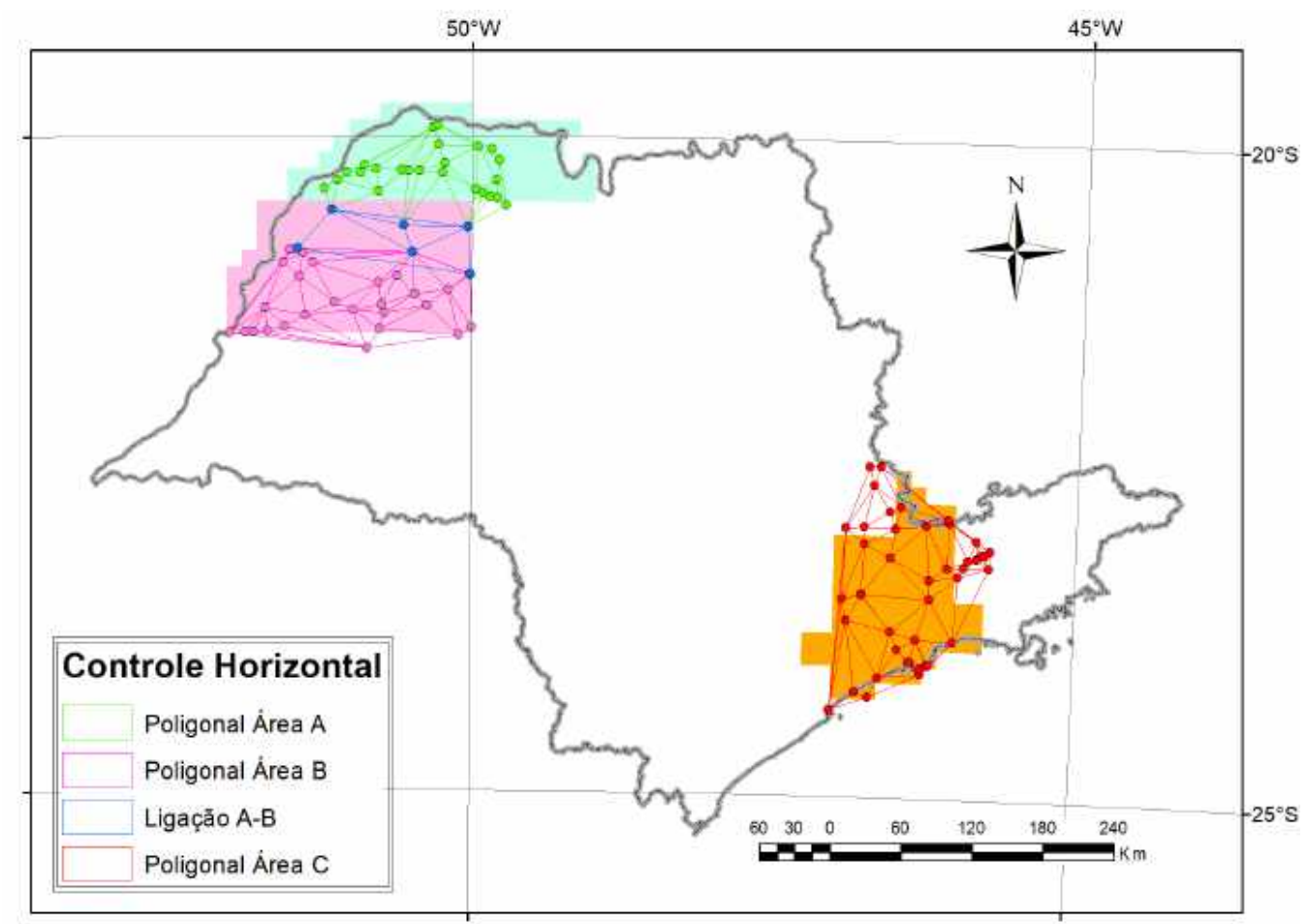

Figura 43: Pontos de controle e representações poligonais do mapeamento 1:25.000 Fonte: Autor a partir de compilação de dados do acervo IGCSP (2017) 


\section{b) Apoio Altimétrico}

O IGGSP elaborou a primeira rede altimétrica do Estado de São Paulo, conforme descreve Franco (1943), os trabalhos de nivelamento desta rede foram referidos ao nível médio dos mares contados a partir do marégrafo do cais da Mortona no Estuário do município de Santos - SP. Esta referência foi utilizada para a $1^{a}$ linha da rede de nivelamento (Santos-Peruíbe) e nas demais, que foram apresentadas na figura 29, repedidas a seguir.

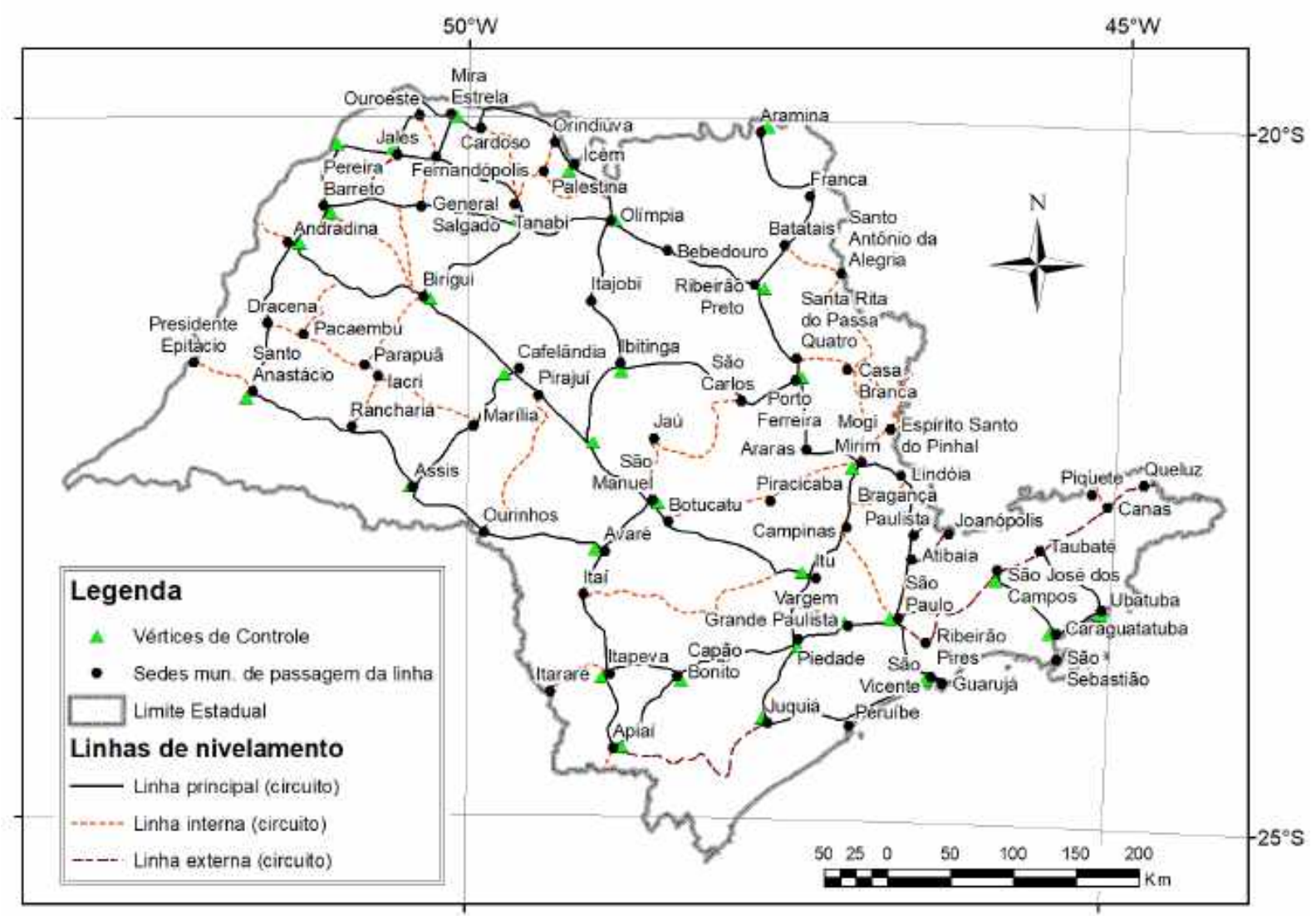

Figura 29: Rede de nivelamento de São Paulo 1940/60 - IGGSP (repetida da página 63) Fonte: Compilação do autor a partir de Colucci (1962)

Nestes trabalhos não houve determinação do desvio da vertical. Ainda sobre os levantamentos verticais, executados durante até o ano de 1961, por vezes foram necessários em lugares onde não era possível realizar o nivelamento geométrico. Nestes locais foram executados trabalhos de levantamento com mais de 200 pontos, utilizando nivelamento barométrico, ainda que com precisão inferior (comparado ao nivelamento geométrico), estes foram incorporados a rede (LEFĖVRE, 1961). 


\subsubsection{Aerofotografias e estereorestituição}

Como todas as fotografias, de 1962, foram tomadas em diversos blocos utilizou-se de foto-índices para localizar as amostras para análise. Estes encontram-se disponíveis no site geoportal do IGCSP, conforme apresentado na figura 45. Sobre a localização de cada fotografia esta foi realizada a partir de coordenadas aproximadas do mesmo site (IGCSP, 2019).

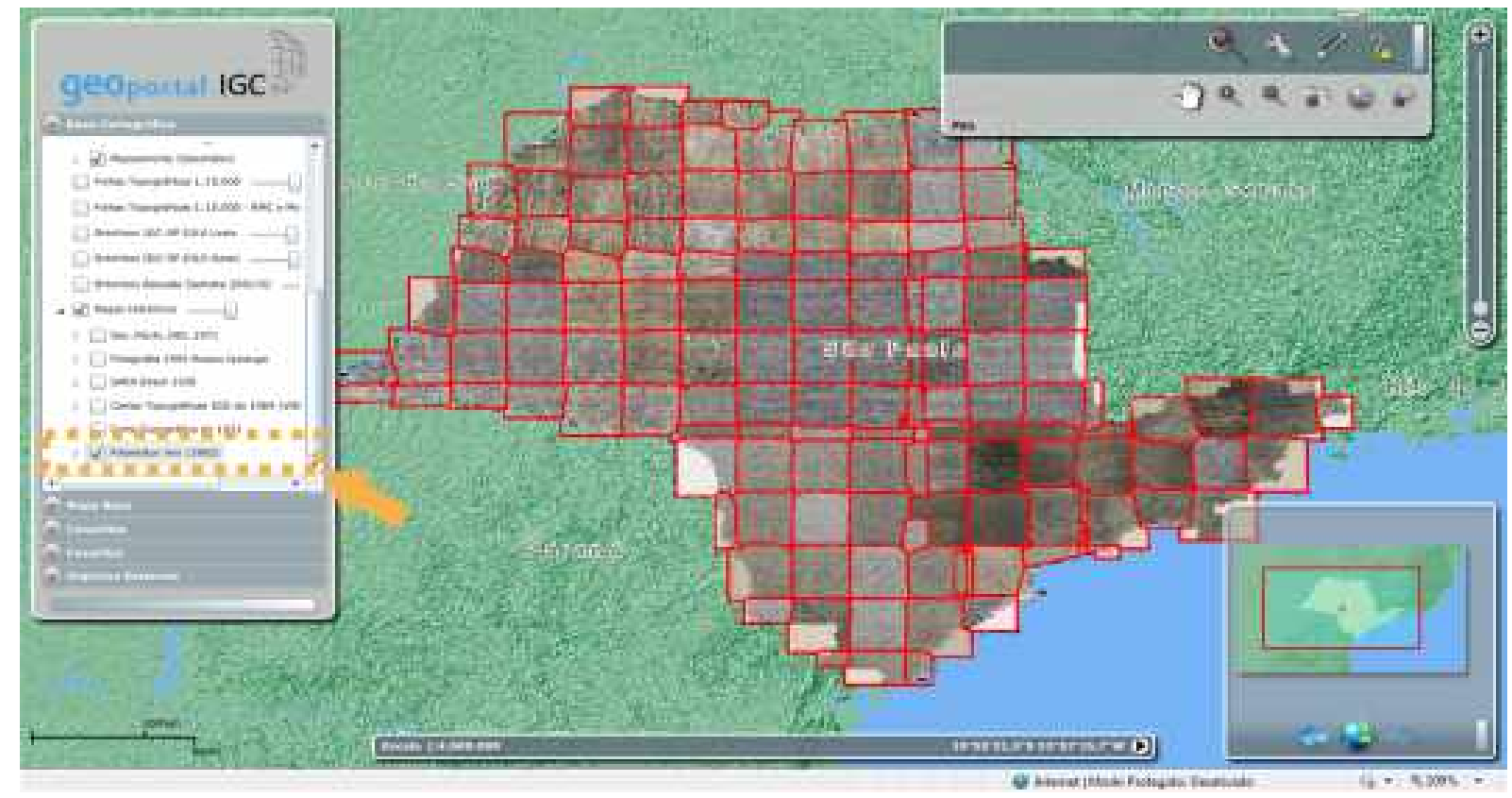

Figura 45: Visualização dos fotoindices no Geoportal IGCSP Fonte: IGCSP (2019)

A partir da pesquisa nestes foto-índices foram selecionadas algumas fotografias, nas áreas de execução dos mapeamentos produzidos entre 1964/74, uma delas reproduzidas na figura 46. Nelas não consta nenhuma informação sobre a câmera, como ocorre em fotos mais recentes: focal, marca/modelo ou mesmo data da tomada das fotografias. A única informação relevante encontra-se no verso: informações sobre a empresa executora (Natividade) e escala aproximada da fotografia. Para tentar resolver estas questões especificamente, examinando os blocos utilizados para a execução do mapeamento (blocos 1 e 7, da figura 40 percebe-se que as fotografias possuem marcas fiduciais do mesmo modelo de câmera de marca FairChild $\square^{1}$ e modelo Cartography, conforme patente de Fairchild (1927a), como se pode observar na comparação das marcas na fotografia e câmera (ver figura 46), não foram encontrados valores de distância focal destas câmaras.

\footnotetext{
${ }^{1}$ Equipamento usado pela primeira vez no Brasil na região do rio Amazonas durante a década de 1920 (FAIRCHILD, 1927a HAMILTON, 1999)
} 

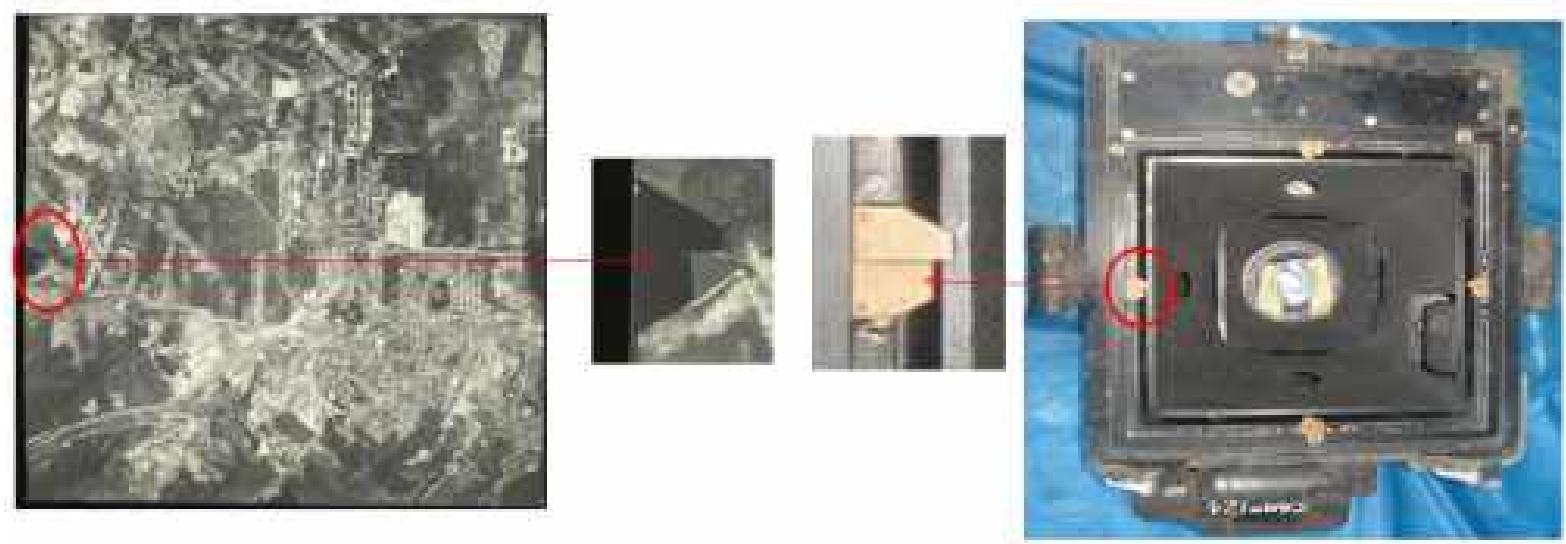

Figura 46: À esquerda fotografia e a direita câmera (detalhe das marcas fiduciais)

Fonte: Autor a partir de compilação do acervo IGCSP (2017)

Outra fonte que corrobora a utilização da câmara do modelo FairChild Cartographic, na área do mapeamento, é a fotografia tirada no aeroporto de Congonhas-SP apresentadas na figura 47 (câmeras laterais em caixas de cores mais escuras) e Wild RC-9 de fabricação Suíça (a câmera do centro da figura 47 em caixa de cor mais clara).

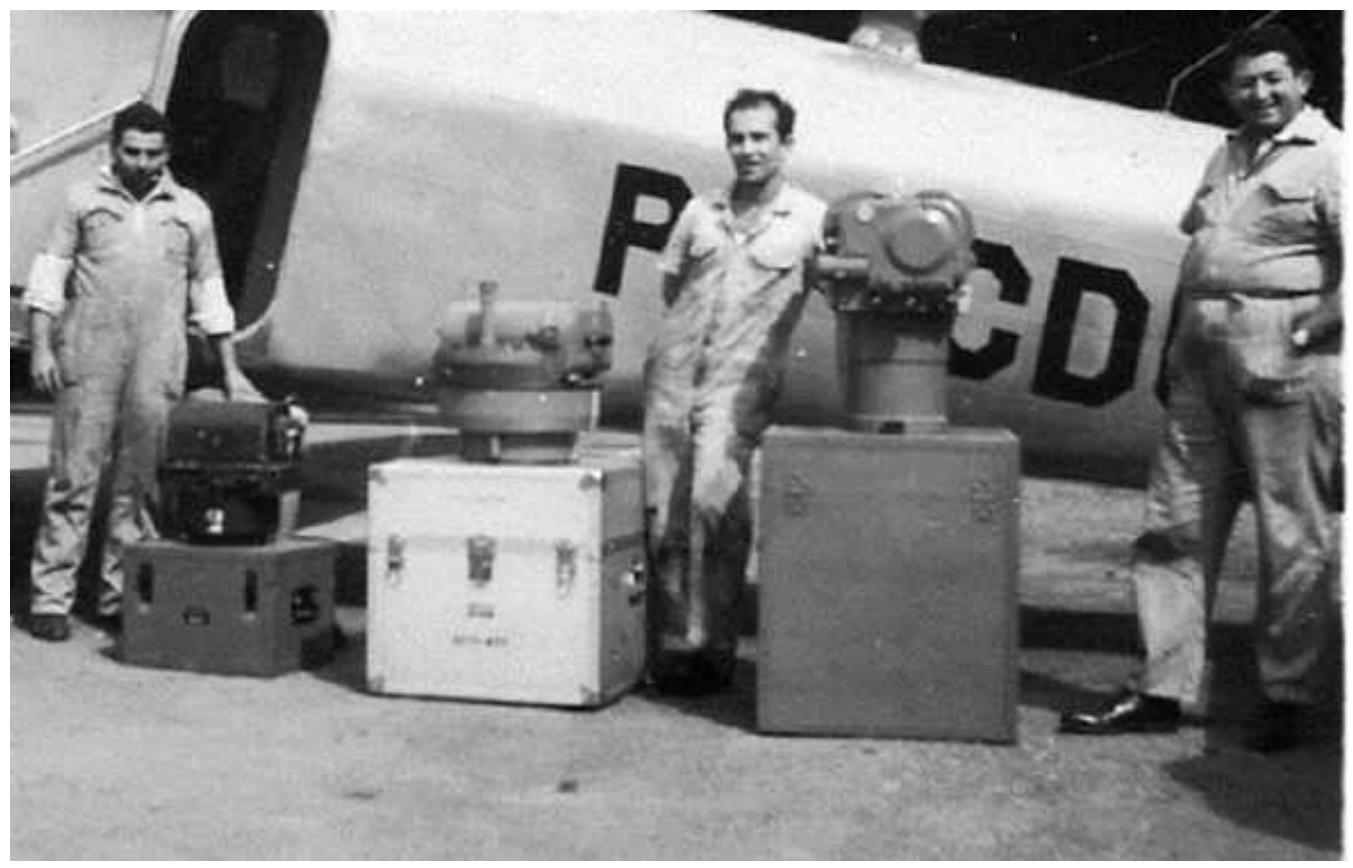

Figura 47: Câmeras FairChild (laterais) e Wild (central) década de 1960 Fonte: Arquivo Pessoal Ruy Natividade

Observa-se que a orientação do primeiro voo (área A da figura 41) não é constante em relação ao norte. Sem equipamentos de orientação precisos, como a tecnologia SHORAN/HIRAN, o controle de voo e a orientação das fotografias foi muito prejudicada. As sobreposições das fotografias são constantes, mas a existência problemas como: nitidez 
e alguns poucos fenômenos de reflexão especular (hotspot ${ }^{1}$.) podem ter atrapalhado na estereorestituição. Já na terceira área (área C da figura 41) a orientação, da maioria dos blocos, em relação ao norte é melhorada, porém, nos blocos da serra do mar a variação de escala da fotografia é maior que o bloco inicial (planície noroeste), como seria de esperar.

Quanto ao processo de restituição das feições, constantes nas plantas disponíveis (mapeamentos 1964/74), os equipamentos utilizados pela empresa Natividade eram os restituidores Galileo Santoni analog stereoplotter modelo III e modelo IV, apresentados na figura 48, cedidos para este trabalho pelo senhor Ruy Natividade.
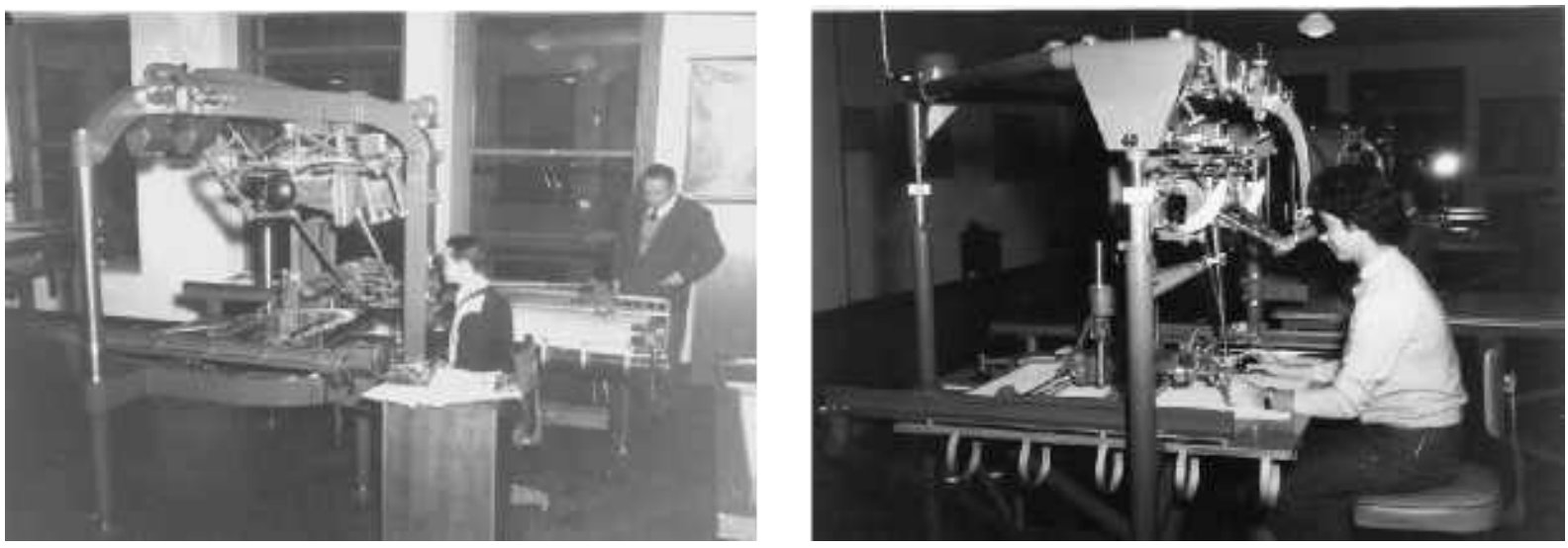

Figura 48: Restituidores Galileo Santoni analog stereoplotter Modelo IV (dir.) e III (esq.)

Fonte: Arquivo Pessoal de Ruy Natividade (disponibilizado para este trabalho)

Sobre a origem e qualidade destes equipamentos Brenni e Giatti (1998) informa que foram desenvolvidos por Ermenegildo Santoni (1896-1970) em 1933 (III) e 1944 (IV), sendo que além destes o inventor criou e aperfeiçoou vários tipos de aparelhos similares até o último modelo em 1963 (V) (MULLEN, 2004, p. 732), a figura 49 ilustra uma propaganda de venda do equipamento na década de 1950.

\section{You can do it better- with a GALILEO-SANTONI STEREOCARTOGRAPH!

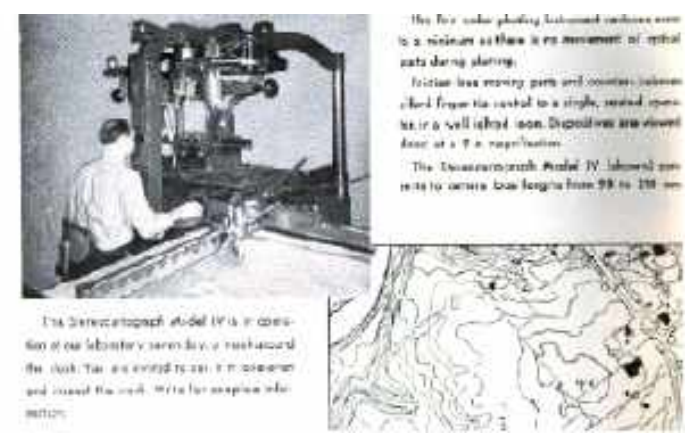

Figura 49: Propaganda do Stereocartograph

Fonte: Eller (1954, p. 416)

\footnotetext{
${ }^{1}$ Áreas que aparecem extraordinariamente claras na fotografia que são resultantes da orientação da câmera em relação ao Sol (JENSEN; EPIPHANIO, 2011, p. 127)
} 
O fator C para o equipamento modelo IV varia de 1500 a 1800 com ampliação da fotografia em no máximo 9 vezes assim, segundo o fabricante, seria possível produzir mapas com curva de nível de intervalo de 6 metros $^{1}$ a partir com fotografias de escala 1:60.000 (HARDY, 1955). Para Brenni e Giatti (1998) essa linha de instrumentos, que são puramente analógicos, foi se aperfeiçoando e estes modelos representam os melhores aparelhos deste tipo, sendo obras-primas da mecânica de precisão da época. Aparentemente se forem utilizadas com boas fotografias estes equipamentos não teriam problemas em realizar a estereorestituição.

\section{a) Datação das aerofotografias}

Constatou-se a ausência de registros precisos sobre esse voo que permitissem verificar a data ou ano de algumas fotografias áreas. Esse dado, no entanto, pode ser avaliado utilizando a documentação histórica da época. Desta forma foram utilizados retratos e relatos de execução de obras notórias que poderiam ter sido fotografadas no voo. Assim, nesta pesquisa foram analisadas as fotografias de construção do MASP no período de 1960 a 1968 e comparadas com a fotografia aérea. Em uma fotografia do prédio em construção, datada de 1964 (foto de jornal), nota-se que a edificação não existia na fotografia do voo. Isso indica que a data de voo de todo o bloco (ver área laranja na figura 41) é anterior a 1964 (ver figura 50).
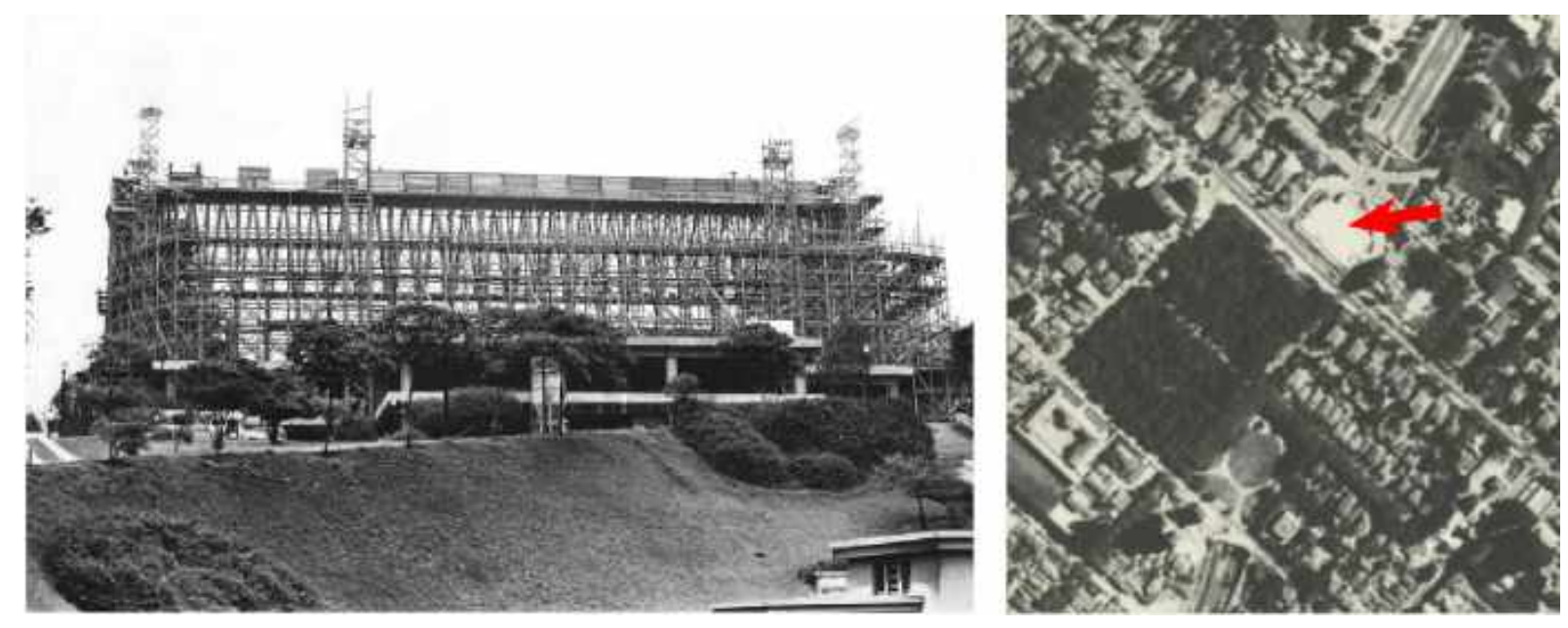

Figura 50: Esq. Foto construção MASP 1964 dir. foto 09240 do voo 1962

Fontes: Esq. Arquivo Jornal Estado de São Paulo dir. IGCSP (2017)

Utilizando a mesma metodologia, porém em outra área, a primeira (ver área A na figura 41), identificou-se um local presente na fotografia que contém a cidade de Votupo-

\footnotetext{
${ }^{1} \mathrm{O}$ equipamento depende de fotografias de qualidade para atender estas especificações.
} 
ranga, mais especificamente sua igreja matriz, e tendo a obra sido fotografada pelo voo (figura 51). Sendo que essa igreja teve a construção de uma das torres iniciada em 1961, especificamente a do lado da Rua Amazonas, segundo documentação da própria Instituição, encontrada no site desta Igreja. Outra confirmação do ano foi dada pela entrevista, concedida para este trabalho, do professor José Bueno Conti que consta no Apêndice D.2 (página 190 que confirma com independência, essa data. Desta forma conclui-se que a foto aérea foi tirada durante o ano de início da construção (1961), detalhe apontado pela seta na figura 51, ou seja, a torre da igreja (VOTUPORANGA, 1961).

\section{Imagem 08/1961}

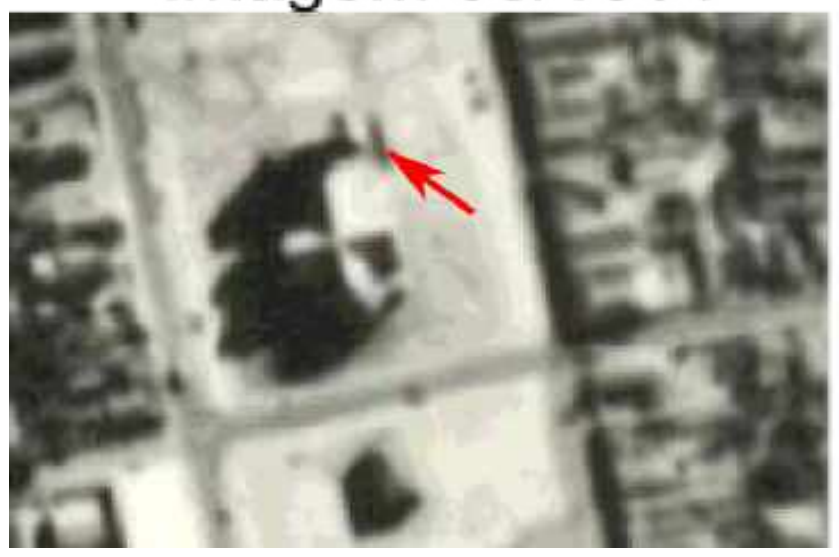

Imagem 04/2010

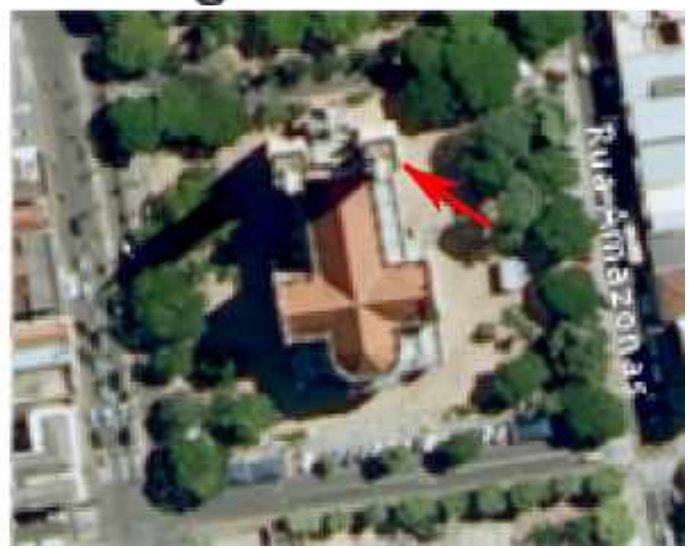

Figura 51: Comparação da imagem de 1961 e 2010 (Igreja Matriz de Votuporanga)

Fonte: Autor em compilação de dados do IGCSP (2017)

\subsubsection{Cartas topográficas}

Segundo a publicação do edital encontrado no diário oficial de $1959^{1}$ nota-se que o mesmo define como escala de produção, descrita pelo termo "matriz", é diferente do que deve constar no final impresso (legenda). Desta forma os valores de escala na impressão era de 1:50.000, já o produto "matriz" seria produzido em escala 25.000. Para entender esse aparente conflito foi analisado o fluxo de trabalho adotado, como montado pelo autor e mostrado na figura 52 .

\footnotetext{
${ }^{1}$ Diário oficial do Estado de São Paulo, 26 de agosto de 1959
} 


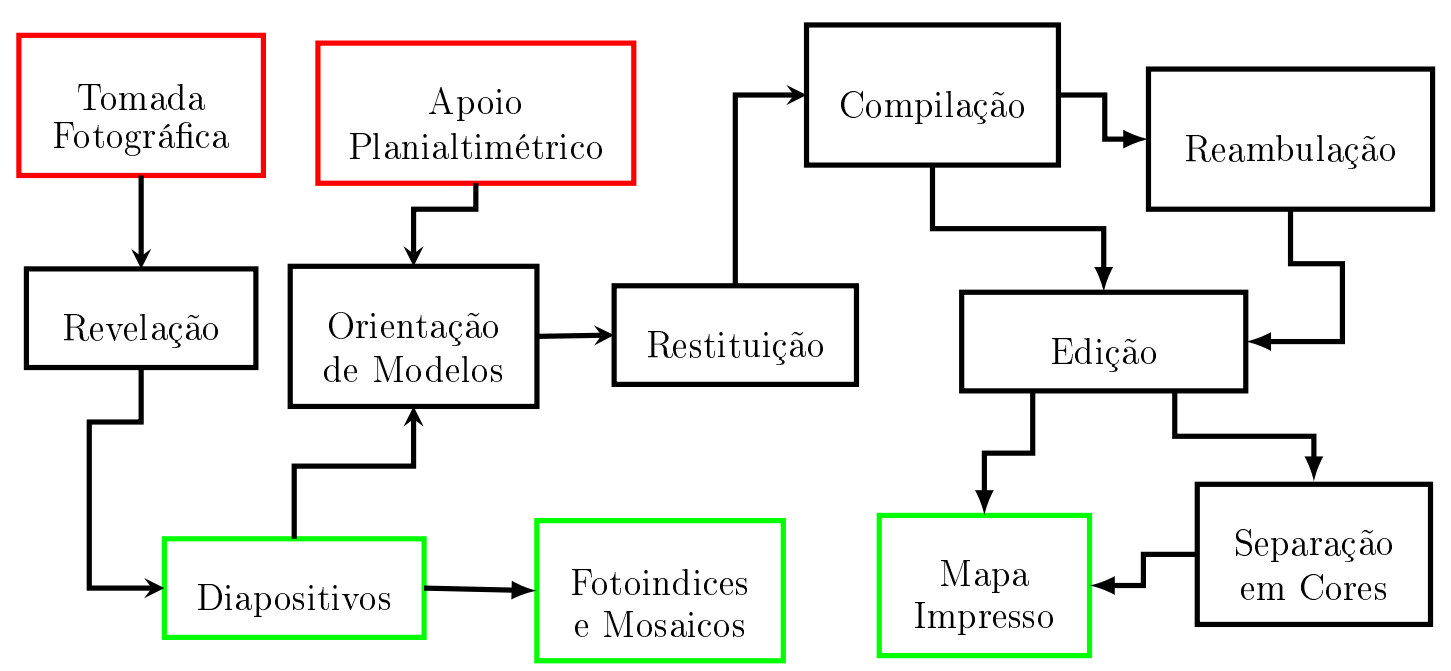

Figura 52: Fluxo de trabalho de produção do mapa

Fonte: Autor baseado em dados do USGS (1990)

Nesse fluxograma os insumos de entrada para a produção do mapa, como a tomada de fotografias e apoio de pontos planialtimétricos, são representados em vermelho, já os produtos finais produzidos, no caso as fotografias (diapositivos, fotoindices e mosaicos) e mapas impressos, são representados em verde. Os mapas impressos encontrados na escala 1:25.000 não apresentam cores e características que o qualificassem como um mapa editado. Ou seja, notam-se edições de feições não terminadas como toponímias e traços com acabamentos primários, quando comparados aos mapas finalizados no mesmo mapeamento. Quanto aos mapas 1:50.000, estes foram todos produzidos em cores, sendo pouco encontrado em no estágio de edição em preto e branco.

Ao se observar algumas cartas topográficas, na escala 1:25.000, veem-se inscrições que passariam a ser incorporadas na carta de escala 1:50.000, carta com legenda e colorida, conforme-se observa na figura 53 em destaque pelo contorno em azul na carta 1:25.000. Outro ponto a ser observado, nesta mesma figura, é que descrição manual com instrução técnica para impressão pelo serviço de mapas do Exército americano, em inglês Army Map Service (AMS) (destacado pelo retângulo amarelo). Isso confirma o processo de separação em cores (figura 52) e o envio para os Estados Unidos, conforme relato da engenheira Zilda (FIGUEIRÔA et al. 1985, pg. 53). 


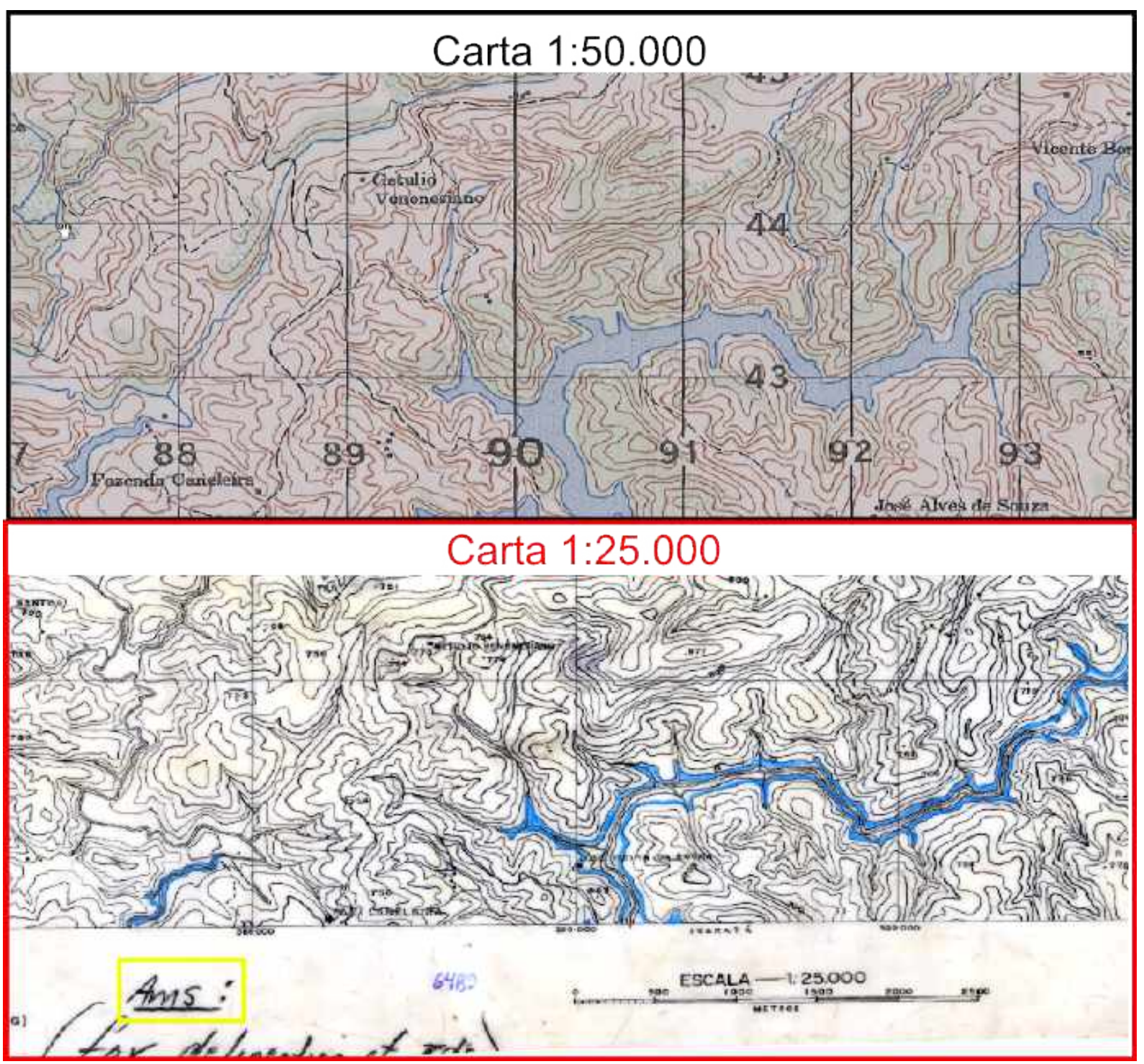

Figura 53: Comparação da coloração dos mapas 1:50.000 e 1:25.000

Comparação da coloração dos mapas 1:50.000 e 1:25.000 Fonte: Autor em compilação de dados do IGCSP (2017)

Outro ponto a ser analisado é a escala de voo, a qual Redweik $(2007)$, em face de câmaras analógicas, optava-se frequentemente por utilizar escalas maiores que as calculadas pela regra empírica de Gruber (conforme visto anteriormente na secção 2.3.1), ou seja, para a carta 1:25.000 era recorrente utilizar fotografias na escala 1:22.000.

Quanto à nomenclatura das cartas, um fato interessante encontrado nos mapas impressos na escala 1:25.000 foi a não conformidade entre o índice de nomenclatura impresso e o baseado na subdivisão das folhas ao milionésimo, que se utiliza nos dias atuais. Esta subdivisão somente foi regulamentada em 196饱. Isto deve ter ocorrido, pois a edição das

${ }^{1}$ Diário Oficial da Uniãc ${\text { decreto }{ }^{o}}_{243}, 28$ de fevereiro de 1967 (BRASIL, 1967). 
folhas (iniciadas com o término do voo em 1962) já estariam em estágio de finalização, porém com nomenclaturas diferentes das normativas utilizados a partir de meados de 1968.

Para às folhas na escala 1:50.000, estas foram praticamente todas finalizadas, restando somente uma pequena área contendo território de Minas Gerais: área C na figura 54 . Todas as áreas e a cobertura dos mapeamentos podem ser vistas na mesma figura, em outras cores. As porcentagens descritas como folhas encontradas representam percentualmente as cartas em relação ao total da área, ou seja, em regiões que foram finalizadas temos $100 \%$ das folhas disponíveis. Ainda nesta figura consta o total de folhas executadas destes mapeamentos (1:50.000 e 1:25.000), presentes no acervo do IGCSP.

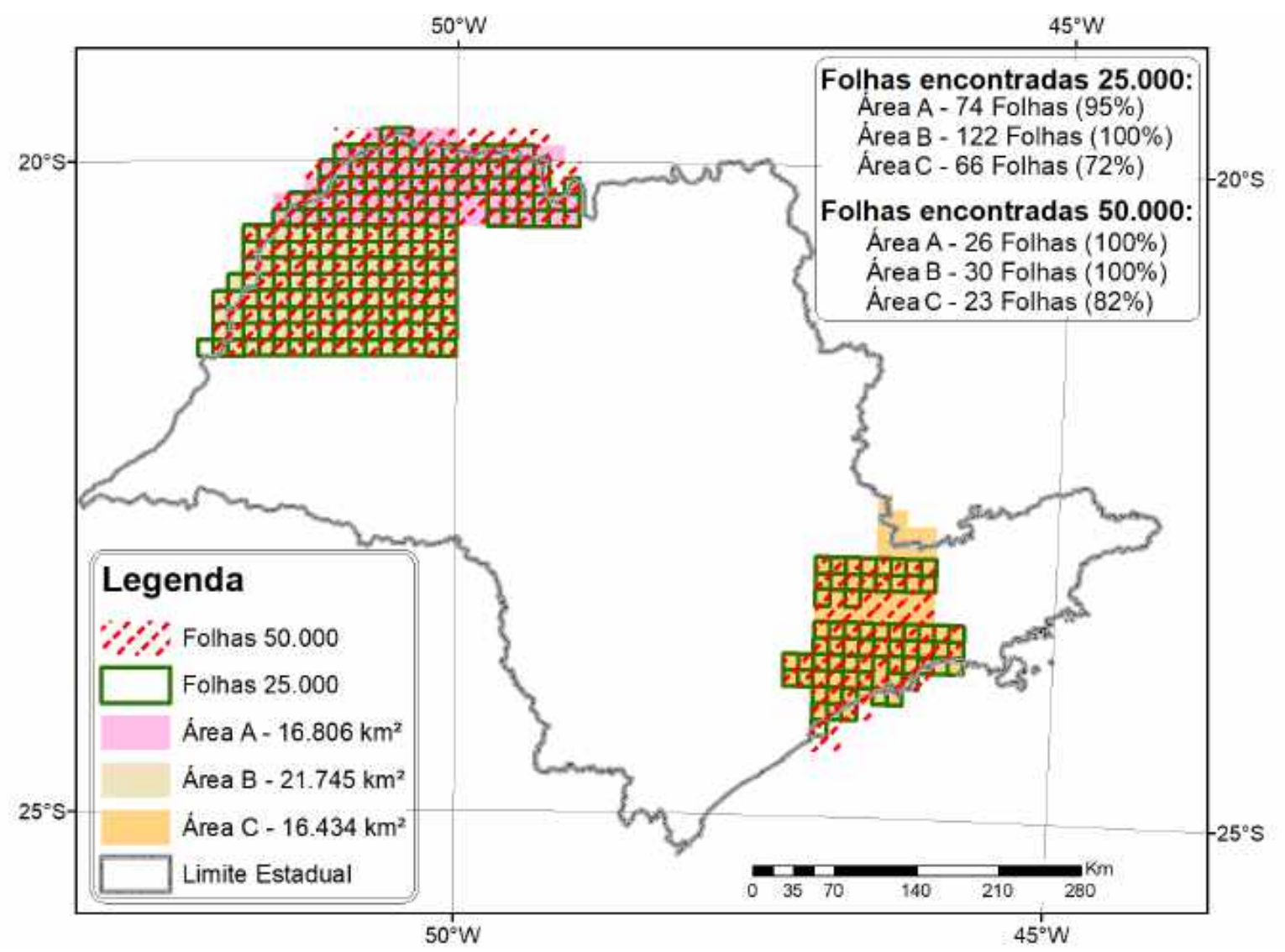

Figura 54: Esquema de áreas do mapeamento 25.000 e 50.000

Fonte: Autor a partir de compilação do acervo do IGCSP (2017)

Como se apontou, os mapeamentos na escala de 1:25.000, mostrados na figura anterior, não foram finalizados. Os motivos que levaram à não conclusão e sua qualidade serão analisados no decorrer desta pesquisa. Para realizar estes trabalhos durante a década de 60 o governo disponibilizou cerca de trezentos e setenta e seis milhões de cruzeiros (conforme descrito em documentos internos), que seriam aproximadamente oitenta e dois 
milhões de reais em valores atualizados por meio do índice IGP-DI $]^{1}$ da Fundação Getúlio Vargas (FGV). Com o objetivo de alocação destes recursos, em 1959, foi criado um fundo orçamentário. O organograma de administração deste fundo é apresentado no Anexo A na (página 207).

\subsection{Continuidade das publicações cartográficas}

As folhas topográficas na escala 1:50.000 produzidas inicialmente em território paulista pelo IGGSP, que serão vistas com mais detalhamento, tiveram sua produção continuada pelo IBGE. Esta informação encontra-se presente na articulação (em formato vetorial) distribuída como índice digital de mapeamentos do IBGE2 A abrangência destas folhas, em território nacional, pode ser vista na figura 55. A seguir está será melhor detalhada no Estado de São Paulo.

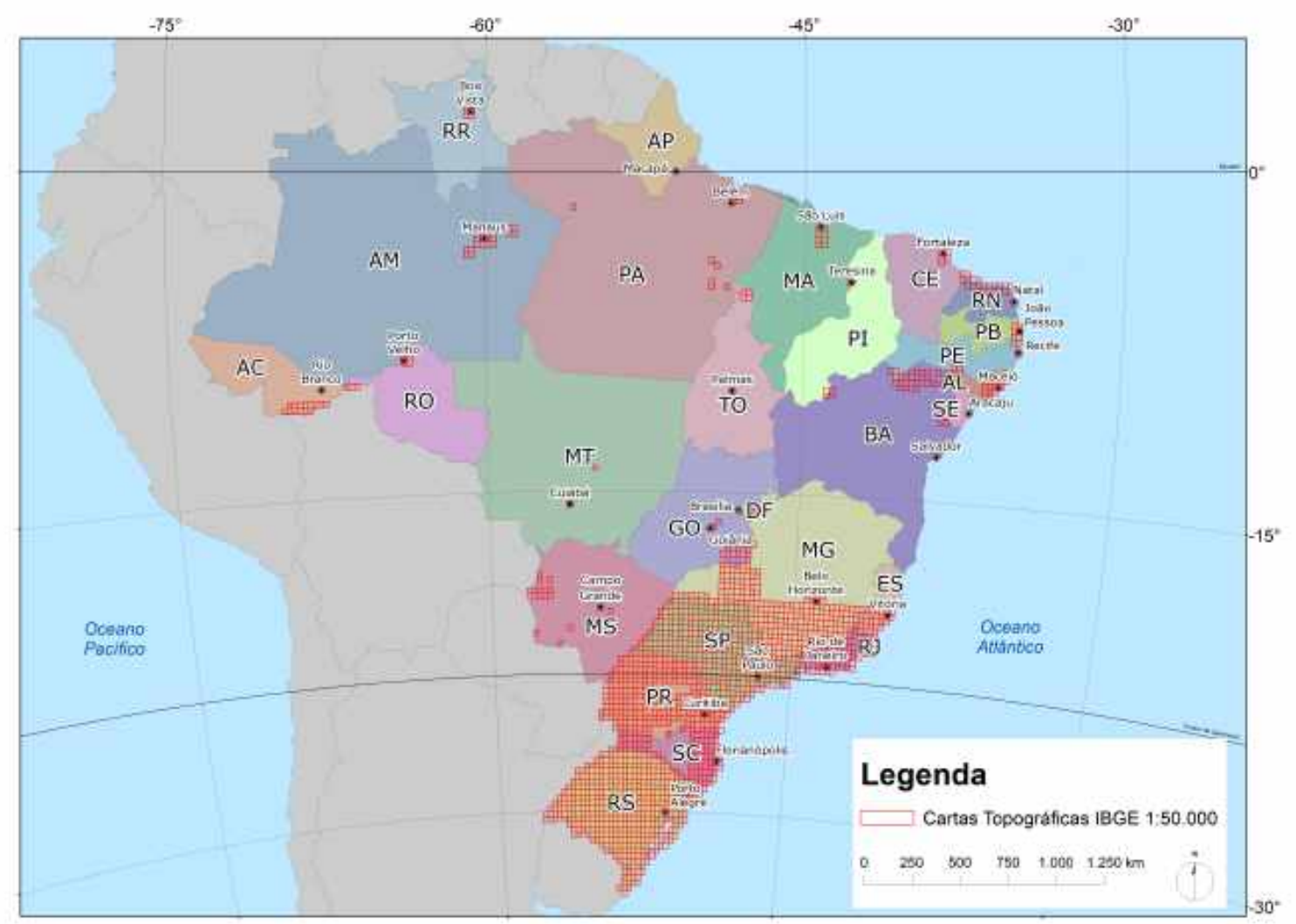

Figura 55: Distribuição das folhas impressas na escala 1:50.000 no Brasil Fonte: Autor a partir de compilação do mapa índice digital do $\mathrm{IBGE}^{1}$

A partir de um cruzamento de dados elaborado em consulta realizada sobre legendas

\footnotetext{
${ }^{1}$ Este cálculo foi efetuado utilizando-se a calculadora do Banco Central do Brasil (BCB, 2018).

${ }^{2}$ Disponível para download no link no site ftp de geociências do IBGE
} 
das cartas, disponíveis no IBGE e no Instituto Geográfico e Cartográfico de São Paulo - IGCSP, o qual foi elaborado na escala 1:50.000, para as 412 folhas do Estado de São Paulo, foi possível constatar que estas cartas foram financiadas e executadas por diversas instituições: IBGE; Instituto Brasileiro do Café - IBC; Diretoria de Serviço Geográfico - DSG; Fundação Instituto de Terras e Cartografia - FITQ1'; Departamento Autônomo de Atividades e Recursos Minerais e Energéticos - DARME e outros. A partir destas informações foi possível catalogar os anos iniciais e finais de publicação das cartas e a quantidade produzida por cada Instituição, como pode ser visto na tabela 8. No qual notase que sempre o IBGE ou a DSG são participantes, com exceção das 80 cartas publicadas pelo IGG. Isso se deu em 1972 com promulgação do Decreto $n^{\circ} 71.262^{2}$, este decreto definia que somente poderiam realizar aerolevantamentos, e trabalhos afins, organizações autorizadas pelo Estado Maior das Forças Armadas - EMFA. Além disso, o mesmo decreto autorizava sem sua permissão que o IBGE e a DSG realizassem trabalhos fotogramétricos, e autorizando também a requisição de material pertinente as empresas que realizavam trabalhos aerofotogramétricos sem a necessidade de anuência da EMFA.

\begin{tabular}{c|c|c|c}
\hline Instituição & Início & Fim & $\mathbf{n}^{o}$ de folhas \\
\hline IGG & 1964 & 1974 & 80 \\
\hline IBGE/IGG & 1971 & 1975 & 65 \\
\hline VASP/IBGE & 1969 & 1988 & 22 \\
\hline IBGE/DAEE & 1971 & 1991 & 100 \\
\hline IBGE & 1969 & 1992 & 149 \\
\hline DSG & 1971 & 1971 & 4 \\
\hline IBGE/IBC $^{2}$ & 1972 & 1975 & 8 \\
\hline DMG/IBGE $^{2}$ & 1970 & 1975 & 5 \\
\hline IBGE/FITC $^{2}$ & 1975 & 1975 & 7 \\
\hline DARME/IBGE & 1975 & 1975 & 6 \\
\hline
\end{tabular}

Tabela 8: Folhas topográficas (1:50.000) do Estado de São Paulo Fonte: Autor a partir de compilação do acervo IGCSP (2017)

Ao analisar as regiões recobertas pelas cartas produzidas por diferentes instituições nota-se que algumas áreas tiveram recobrimento por mais de uma carta, porém produzidas em anos diferentes, ou seja, abrangem regiões sobrepostas, o que deve ser fruto de uma provável atualização, conforme mostra a figura 56. Nesta estão representadas graficamente as folhas topográficas produzidas por diversas instituições e suas sobreposições (notar áreas sobrepostas com diferentes hachuras).

\footnotetext{
${ }^{1}$ Hoje Instituto de Terras, Cartografia e Geologia do Paraná ITCG em folhas de divisa com São Paulo.

${ }^{2}$ Este decreto regulou o Decreto-Lei 71.267 de 1971 (BRASIL, 1972). Atualmente o Decreto-Lei ainda é valido porém, com outro decreto normativo que revogou o de 1972 (BRASIL, 1997).

${ }^{2}$ Folhas entre São Paulo e demais Estados.
} 


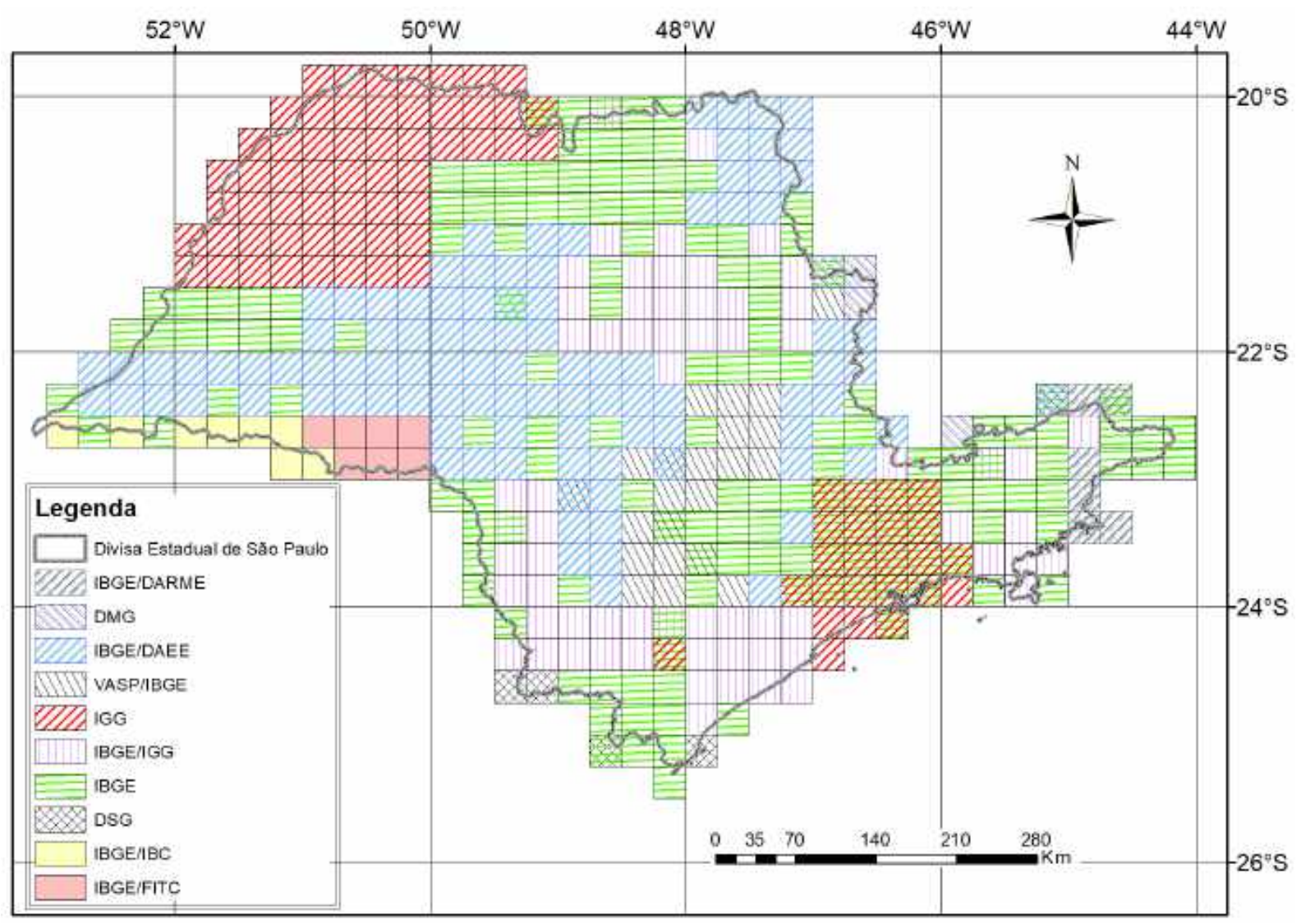

Figura 56: Distribuição das folhas (1:50.000) e seus executores/parceiros

Fonte: Autor a partir de compilação do acervo IGCSP (2017)

\subsubsection{Mapas Municipais}

Outras produções cartográficas do IGGSP, os mapas municipais, já elaborados por meio demarcações territoriais (conforme visto no item 2.1.1.1), eram representações cartográficas que continham, dentre outros elementos, o foco na apresentação da linha de divisa. Esta linha utilizava-se de feições naturais (por exemplo, rios) ou alinhamentos descritos em legislação estadual, mais detalhes sobre os processos de demarcação de divisa e da elaboração de mapas municipais podem ser encontrados no Apêndice B.

Com o fim do IGG, a produção de mapas municipais teve continuidade pela divisão de geografia da Secretaria de Planejamento do Estado de São Paulo, até meados de 1979 quando ficaram a cargo do IGCSP, mais detalhes sobre o fim do IGG estão disponíveis no Apêndice A (página 161). Mesmo com a promulgação da constituição de 1988 não foram modificadas as legislações de criação de municípios, mas sim as incumbências dos entes federativos que deveriam legislar sobre o tema. Desta forma os estados continuaram a

\footnotetext{
${ }^{1}$ Folhas nos limites (entre estados).
} 
produzir, criar e desmembrar municípios e produzir mapas municipais, até o ano de 1995.

A figura 57 mostra graficamente os municípios paulistas que tiveram mapas municipais desenvolvidos pelo IGGSP, bem como os anos que foram promulgadas as leis que os criaram. Como o IGCSP herdou do IGGSP a atribuição de manter a atualização do quadro territorial, continuou produzindo estes mapas até meados de 1996. Quando a emenda constitucional $n^{0} 15^{1}$ alterou a Constituição Federal para que, a partida daí, fosse exigida uma Lei Complementar Federal regulamentando a criação, fusão e desmembramento de municípios (BRASIL, 1996).

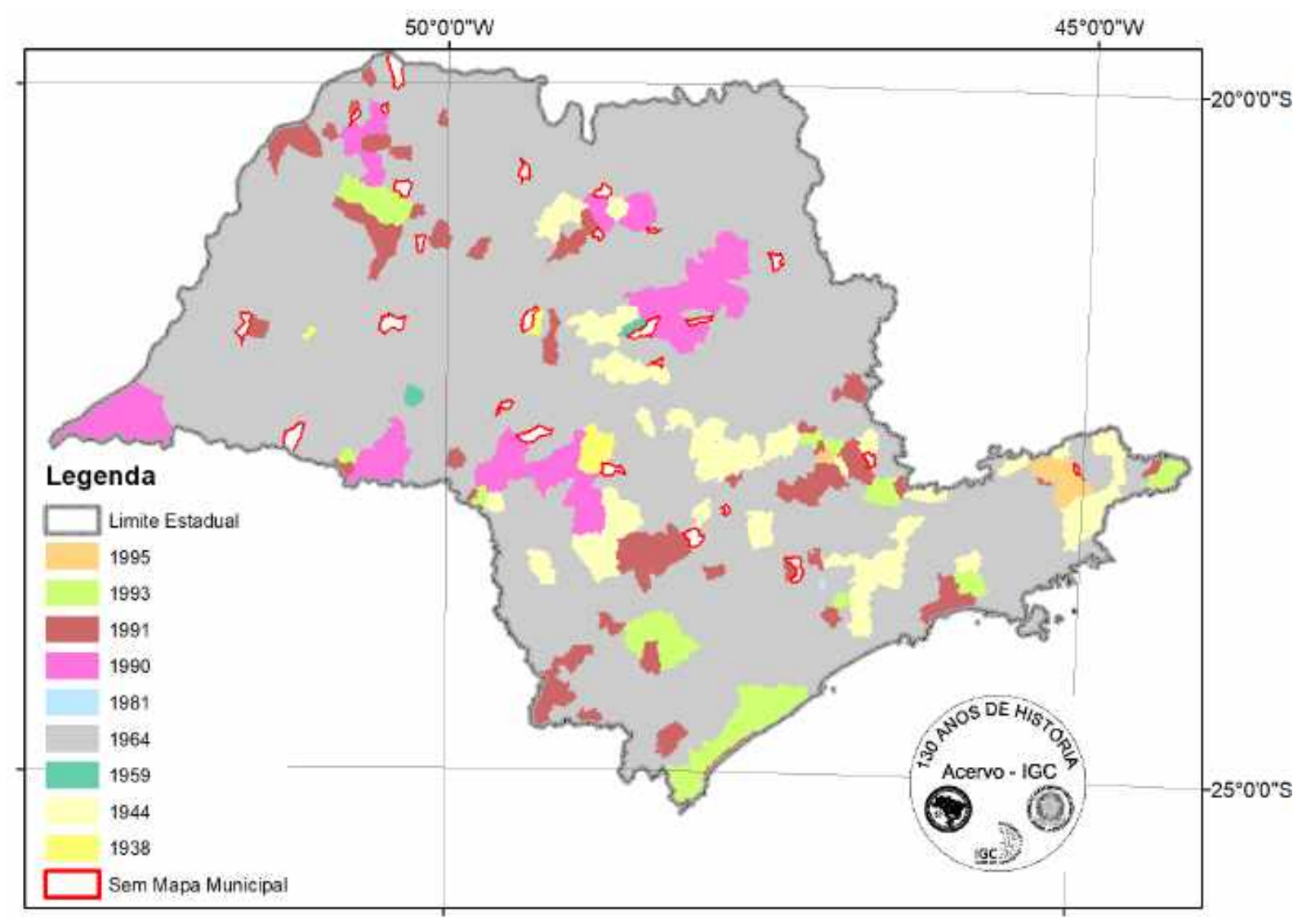

Figura 57: Municípios com mapas municipais e anos de sua criação (leis)

Fonte: Autor em compilação de dados do IGCSP (2017) 


\section{METODOLOGIA DE ANÁLISE DA QUALIDADE DOS MAPAS 1:25.000}

Neste item serão analisadas as qualidades posicionais e qualitativas dos mapeamentos, e seus insumos, produzidos entre 1962 e 1969 pelo IGGSP. Como visto no desenvolvimento dos fundamentos teóricos (capítulo 4 ) para verificar as coordenadas dos mapas (verificação posicional) será necessário calcular os parâmetros de transformação entre os sistemas de referência (VERONEZ, 1998; OLIVEIRA, 2006; PACILÉO NETTO et al., 2003). Como foi apresentado pode-se utilizar transformações matemáticas, como a de Helmert, e um grid de distorções, no caso brasileiro o GRID NTV2 provido por software desenvolvido pelo IBGE (IBGE, 2009). Ao analisar qual seria a melhor metodologia de definição dos parâmetros notou-se a inexistência de trabalhos que realizem uma comparação entre estas formas.

Desta forma foi feita essa comparação: entre a utilização inicial da transformação por três parâmetros, por Helmert e as executadas a partir do GRID NTV2. O resultado apresentado indicou, no presente caso, a técnica mais adequada para realizar essa transformação. Com isso minimiza-se a influência dos erros, ou resíduos, do processo de transformação, permitindo uma melhor comparação entre o mapeamento estudado e base cartográfica mais precisa, durante a análise de qualidade posicional. Na análise qualitativa do mapeamento apresentam-se observações de feições, representadas nos mapas, e comparações destas com elementos encontrados nas fotografias utilizadas no processo de produção destes mapas. Outro processo qualitativo foi a verificação das legendas, dos mapas, de forma a analisar sua propriedade e adequação ao conteúdo necessário comparando-os a mapeamentos de mesma escala produzidos na mesma época por outras entidades executoras. 


\subsection{Transformações entre o Sistema Córrego Alegre e outros SGBs}

Com a crescente utilização de diversas fontes de dados cartográficos posicionadas em referenciais geodésicos diversos, tornou-se necessário o trabalho de compatibilização e com isso quais técnicas de conversão seriam utilizadas. Assim faz-se necessária uma revisão destas técnicas de transformação, tendo em conta a teoria descrita na secção 4. Trabalhos com esta abordagem foram objeto de estudo por diversos autores que utilizam modelos matemáticos para efetuar a transformação entre diferentes sistemas de coordenadas (CASTAÑEDA, 1986; JUNKINS; ERICKSON, 1996; AGUIAR et al., 2002; PACILÉO NETTO et al., 2003: FERNANDES; NOGUEIRA, 2010; MAROTTA; RODRIGUES, 2011).

Para verificar como seria executado o processo de conversão entre os referenciais geodésicos foram analisadas as projeções de referência e do produto testado, que não são iguais. Desta forma, assim como descrito por Marotta e Rodrigues (2011), foi necessária a utilização da transformação de Helmert com sete e três parâmetros, ambas estudadas por diversos autores (VERONEZ, 1998; NETTO et al., 2003). Utilizando como referência para esta transformação, conforme descrito na secção 5.1.2.2 os pontos foram provavelmente coletados pelo IGGSP, onde se concluiu que estes foram os pontos de apoio utilizados na elaboração dos mapeamentos estudados pois, conforme ilustrado pela figura 43, abrangem todas as áreas do mapeamento estudado. Acrescenta-se que estes pontos foram executados por poligonação, e utilizando equipamento medidor eletrônico de distância (Telurômetro), considerou-se que as coordenadas dos vértices calculadas, com lista completa apresentadas no Anexo A (página 207), seriam as mais apropriadas disponíveis para serem utilizadas como parâmetros no cálculo das transformações.

Ao utilizar parte dos pontos, ilustrados pela figura 43, como parâmetros, ou seja, origens no cálculo da transformação, tomou-se como referência o sistema de coordenadas Córrego Alegre. Tendo em vista que o referencial de comparação deve ser um levantamento de melhor precisão, foi utilizado uma ortoimagem com precisão compatível com escala 1:5.000 (IGCSP, 2019). Por se tratar de ortoimagems estas não possuem coordenadas altimétricas, mas para sua produção foi utilizado um Modelo Digital de Terreno que permitiu a correção do relevo nestas imagens (IGCSP, 2017). Além disso, que uma vez que as coordenadas encontradas eram advindas de um processo de poligonação, ou seja, não dispunham da coordenada altimétrica somente coordenadas E e N (ver lista de coordenadas no Anexo A da página 36.

Utilizando a localização aproximada e a descrição de cada ponto listado, dada no 


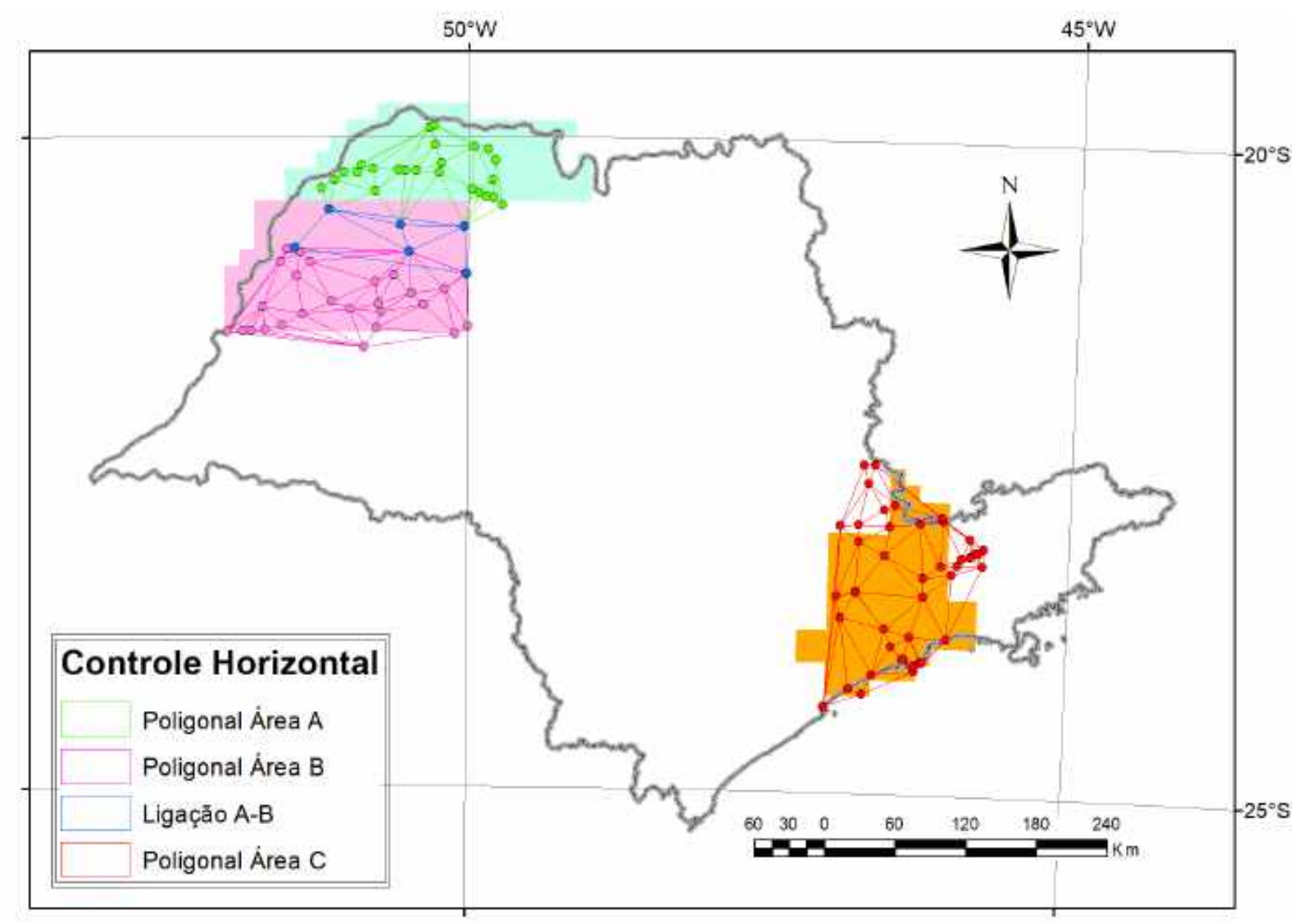

Figura 43: Pontos de controle e representações poligonais do mapeamento 1:25.000 (repetida da página 102

Fonte: Autor a partir de compilação do acervo IGCSP (2017)

documento encontrado com as coordenadas, foram identificados locais onde se confirmou a existência da medição. Isso se deu por relatos de pessoas nos locais em que os pontos foram levantados, ou pela correta identificação (nas ortoimagens) de objetos descritos na lista de coordenadas (ainda presentes nos locais). Com a confirmação destes locais, foi possível realizar a comparação entre as coordenadas em Córrego Alegre (encontradas) com as coordenadas em SIRGAS 2000 (ortoimagens). Estas ortoimagens são as pertencentes ao acervo de mapeamento, realizado entre 2010-2015, do IGCSP e com precisão compatível com escala 1:5.000 (IGCSP, 2017).

Qualquer que seja a técnica utilizada para converter as coordenadas entre os sistemas de referência, ocorrem distorções nestas transformações, ou seja, distorções que são efeitos não modelados por parâmetros de transformação (MAGNA JÚNIOR, 2012). De forma geral faz-se necessário analisar estas distorções de forma que estas não prejudiquem a análise. Como referência destas distorções Magna Júnior (2012) apresenta, na tabela 9. estatísticas sobre as distorções encontradas no sistema Córrego Alegre 61. Esta medição utilizou-se 624 pontos dos quais foram calculadas distorções, isso a partir da transfor- 
mação entre Córrego Alegre 61 e SIRGAS 2000 utilizando-se o ProGrid (NTv2). Magna Júnior (2012) também propõe a avaliação da técnica Thin-Plate Splines (TPS) como alternativa metodológica para a conversão entre referencias geodésicos, porém informa que este método não substitui os procedimentos oficiais efetuados pelo ProGrid, mas podem ser utilizados como critérios para sua avaliação.

\begin{tabular}{l|l|l}
\hline Medidas $(\mathbf{m})$ & Latitude & Longitude \\
\hline Máxima & 7,519 & 12,321 \\
\hline Mínima & $-3,641$ & $-10,880$ \\
\hline Média & 1,035 & 0,118 \\
\hline Média Absoluta & 1,865 & 1,676 \\
\hline RMSE & 2,552 & 2,623 \\
\hline $90 \% \leq$ & 4,728 & 4,376 \\
\hline
\end{tabular}

Tabela 9: Distorções na conversão entre SIRGAS2000 em Córrego 1961 Fonte: Magna Júnior (2012)

De acordo com a tabela 9, o valor médio absoluto das distorções é de 1,865 m em latitude e 1,676 m em longitude, com RMSE (Root Mean Square Error - Raiz do Erro Médio Quadrático) de 2,552 m e 2,623 m em cada componente. Observando-se os valores dessa tabela, mais especificamente a média, e confrontando-os com os valores de erros planimétricos toleráveis na lei do Padrão de Exatidão Cartográfico - PEC, tem-se que a transformação apresenta erros bem a baixo dos necessários para análise do PEC nessa escala (ou seja, em torno de $0.1 \mathrm{~mm}$ na escala). Desta forma, em termos gerais, mostra-se possível a utilização de transformações entre os sistemas Córrego Alegre e SIRGAS 2000. Desta forma conclui-se que as distorções ocasionadas pelo processo de transformação, a partir de dados estabelecidos no ProGriD, sejam pouco relevantes durante o processo de análise da qualidade posicional para mapeamentos em escala 1:25.000.

Para realizar a comparação posicional entre pontos das cartas topográficas (IGGSP) e da ortoimagem (IGCSP), foi necessária a utilização de transformações para compatibilização dos produtos. Visando analisar qual seria a melhor forma de realizar estas transformações foram realizados testes utilizando a transformação por três translações, Helmert e o Grid NTV2 (Progrid). Como parâmetros de referência, para cálculo de Helmert e dos fatores de translação simples (DX,DY,DZ), foram utilizados 7 pontos na área C como observado na figura 59 , sendo estes utilizados como para o cálculo dos parâmetros da transformação por Helmert e simplificado (por três translações). 


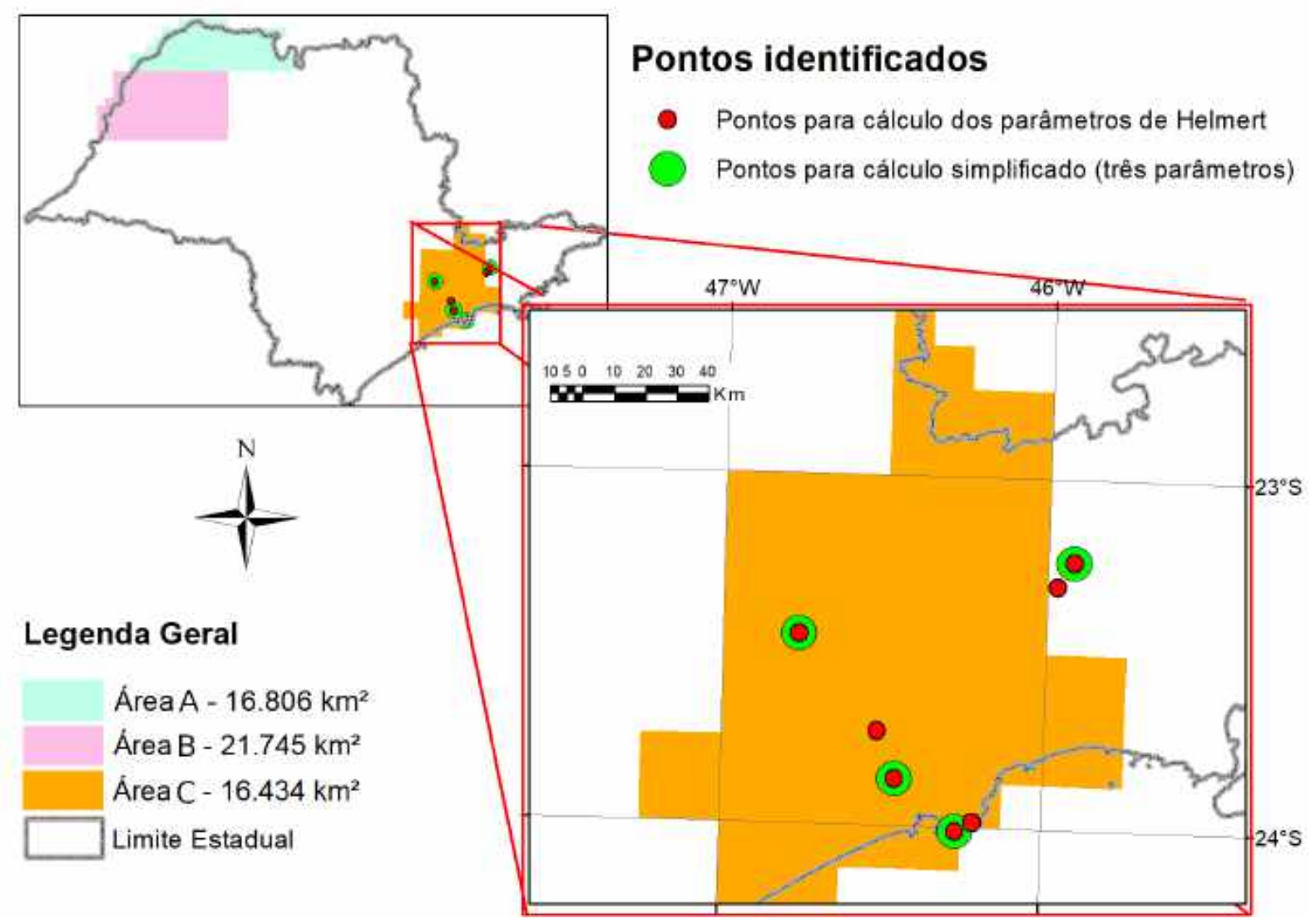

Figura 59: Pontos utilizados no cálculo dos parâmetros de Helmert e de translação

Fonte: Autor em compilação de dados do IGCSP (2017)

O diagrama da figura 60 ilustra, de forma resumida, os passos de transformação e verificação a serem executados nesta análise.

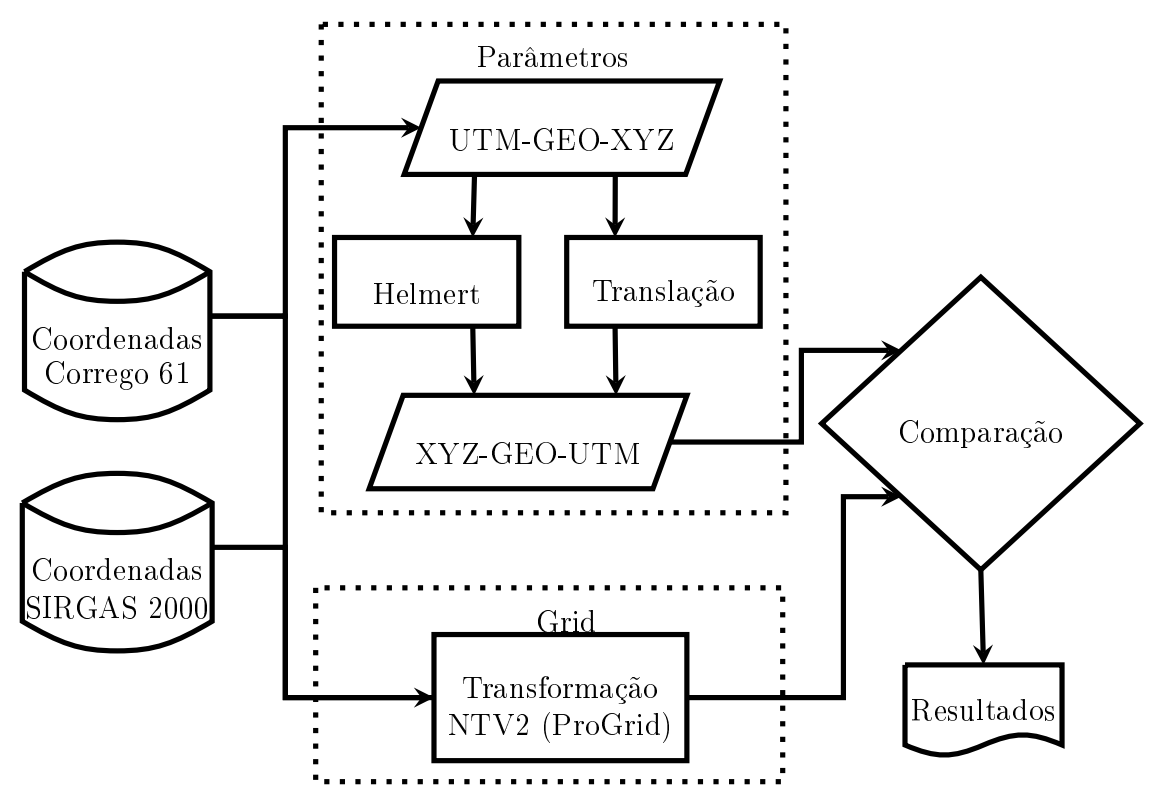

Figura 60: Diagrama das transformações utilizadas nos testes posicionais 
Os próximos itens descrevem como foram realizados os cálculos e quais os parâmetros encontrados. Após a determinação destes parâmetros será apresentada uma comparação de conversão de coordenadas entre estes e o Grid NTV2 (ProGrid). Esta comparação foi realizada, por opção, levando as coordenadas para o sistema de origem do mapeamento (Córrego Alegre) e assim comparadas.

\subsubsection{Transformação pelo modelo Matemático de Helmert}

Para calcular os parâmetros desta transformação foram utilizados como variáveis de entrada as coordenadas dos pontos encontrados em documentos do IGGSP produzidos por levantamentos de poligonação, conforme descrito na página 101. Esta determinação de coordenadas horizontais teve como referência o sistema Córrego Alegre, definido pela CNG, conforme descrito no item 3.1.1. Utilizando o elipsoide de Hayford (1924) com e semi eixo equatorial de 6.378.388m e achatamento $f=1 / 297,00$ (CAMARA et al., 1941).

A partir das coordenadas UTM (E,N), todas no meridiano central (MC) $45^{\circ}$, foram calculadas utilizando as equações 4.1, 4.2 e 4.3 para cálculo das coordenadas geodésicas $(\lambda, \phi, h)$. Utilizando-se estas, foram obtidas as cartesianas (X,Y,Z), a partir das expressões: 4.4 4.6, 4.7 4.8 e 4.9 (estas fórmulas constam na seção 4.1.1.2). O resultado destes cálculos são as coordenadas apresentadas na tabela 10.

\begin{tabular}{|c|c|c|c|c|c|}
\hline Descrição (MC 45) & $\mathrm{E}(\mathrm{m})$ & $\mathbf{N}(\mathbf{m})$ & $\mathrm{X}(\mathrm{m})$ & $\mathrm{Y}(\mathrm{m})$ & $\mathrm{Z}(\mathbf{m})$ \\
\hline Torre da Igreja Rosario Jacarei & 400859,270 & 7422278,430 & 4073664,521 & $-4213915,468$ & $-2507875,452$ \\
\hline Jaraguá- CHG & 319547,810 & 7404626,120 & 4010062,107 & $-4265293,893$ & $-2523372,284$ \\
\hline Caixa d'água Johnsons & 405871,010 & 7430009,450 & 4079418,900 & $-4212580,986$ & $-2500801,504$ \\
\hline Centro caixa d' água Guarujá & 371290,786 & 7343727,357 & 4030114,349 & $-4212184,731$ & $-2579626,524$ \\
\hline Marco 2B Base Guarujá & 376695,860 & 7346906,886 & 4034920,090 & $-4209346,475$ & $-2576764,807$ \\
\hline Montanhão & 345310,010 & 7374724,470 & 4020245,479 & $-4239054,696$ & $-2551044,681$ \\
\hline Mirante Ligth Cubatão & 351445,010 & 7359899,950 & 4020445,670 & $-4230580,132$ & $-2564668,408$ \\
\hline
\end{tabular}

Tabela 10: Coordenadas de pontos Córrego Alegre EN (encontradas) e XYZ (calculadas)

Os valores presentes na tabela 10 serão utilizados para o cálculo ajustado dos parâmetros de Helmert e parte destes no método simplificado, como será descrito nos dois tópicos seguintes. Quanto aos cálculos, estes foram elaborados conforme formulário abordado na revisão bibliográfica (item 4.1.2. No processamento destes cálculos utilizou-se de código, elaborado em linguagem SCILAB! , e disponível no Apêndice E (pg. 192).

${ }_{1}^{1}$ SCILAB. Open source software for numerical computation. 1994-2019. $\quad<$ https://www. scilab.org/> 


\subsubsection{Determinação dos parâmetros de Helmert}

A partir dos pontos determinados no item anterior foi feito o ajustamento dos parâmetros de Helmert (conforme descrito no item 4.1.2.1). Esta sistemática é apresentada, de forma resumida, no diagrama da figura 61. Destaca-se que dada a dificuldade de definição das precisões relacionadas ao sistema Córrego Alegre, que não foram encontradas, por isso foi utilizado o modelo linear para o ajustamento pelo método paramétrico.

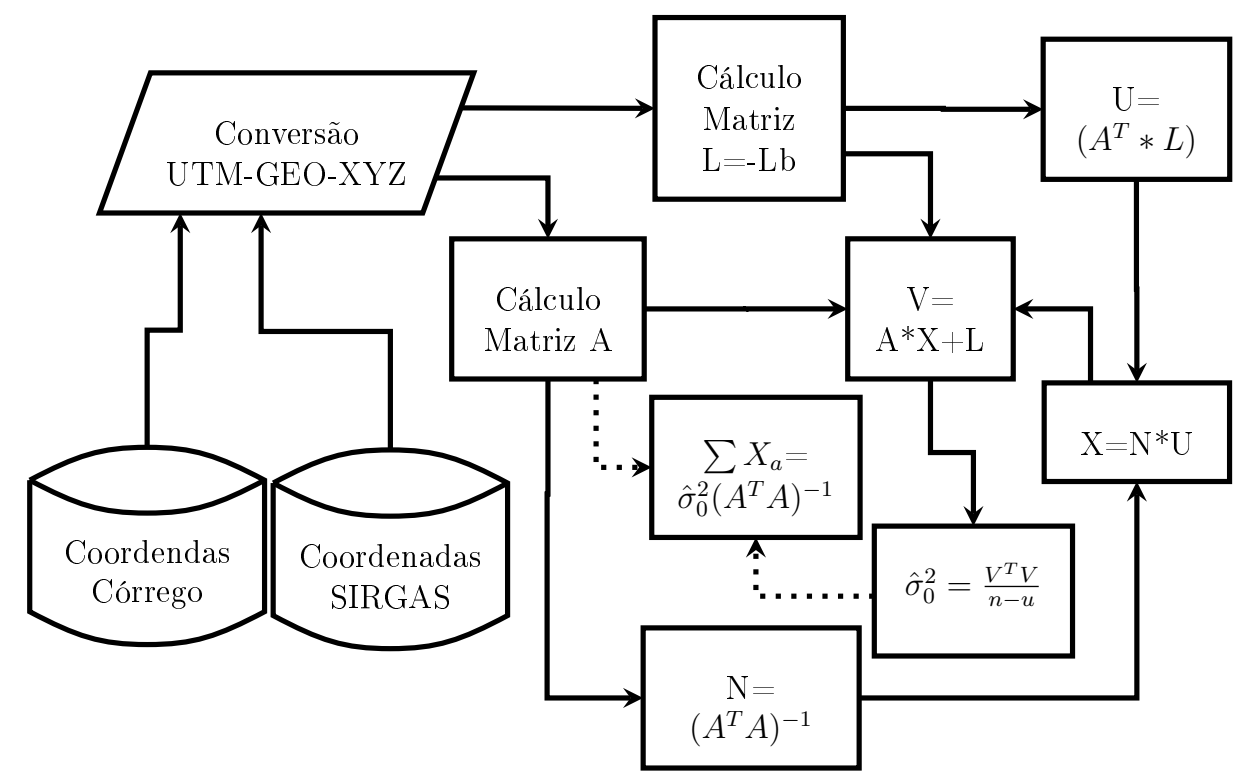

Figura 61: Diagrama representando ajustamento paramétrico (Helmert)

Depois de calculados os parâmetros ajustados, sua matriz variância-covariância e teste estatístico, conforme instruções descritas no item 4.1.2.2. Estes valores são apresentados na tabela 11 .

\begin{tabular}{l|c|c|c}
\hline Parâmetros & Valores & $\boldsymbol{\sigma}_{\text {par }}$ & $\left|\boldsymbol{t}_{\text {par }}\right|$ \\
\hline$T_{X}$ & $-62,338 \mathrm{~m}$ & $70,129 \mathrm{~m}$ & 0,89 \\
\hline$T_{Y}$ & $66,741 \mathrm{~m}$ & $80,699 \mathrm{~m}$ & 0,82 \\
\hline$T_{Z}$ & $-33,516 \mathrm{~m}$ & $74,305 \mathrm{~m}$ & 0,45 \\
\hline $1+\mu$ & 1,0000261 & $8,6543^{-6}$ & 1,31 \\
\hline$\alpha_{1}$ & $0^{\prime \prime}, 53$ & $2^{\prime \prime}, 47$ & 0,21 \\
\hline$\alpha_{2}$ & $1^{\prime \prime}, 33$ & $2^{\prime \prime}, 03$ & 0,65 \\
\hline$\alpha_{3}$ & $-0^{\prime \prime}, 83$ & $2^{\prime \prime}, 73$ & 0,30 \\
\hline
\end{tabular}

Tabela 11: Parâmetros calculados e estatística para transformação entre SIRGAS2000 e Córrego Alegre 
A partir dos valores ajustados para a transformação de Helmert e seus desvios $\left(\sigma_{p a r}\right)$, apresentados na tabela 11, para verificação do seu erro foi calculado o teste estatístico de t-student $\left(\left|t_{\text {par }}\right|\right)$, conforme abordado na secção 4.1.2.3. Utilizando a expressão $4.27 \mathrm{com}$ os graus de liberdade $v=14$ e $1-\alpha=0,95$, temos que: $t_{14 ; 5 \%}=1,76$. Assim tem-se que os valores, apresentados na tabela 11, são menores que o valor teórico desta forma não são aceitos para um nível de significância de $5 \%$.

\subsubsection{Transformação utilizando três translações}

Outra forma de realizar a transformação do sistema SIRGAS para o Córrego Alegre é utilizando três translações (DX,DY e DZ), não havendo rotações nem alteração de escala no processo. Inicialmente tomam-se coordenadas UTM Córrego Alegre (E,N), todas no meridiano central (MC) $45^{\circ}$, que são convertidas para cartesianas (X,Y,Z) conforme apresentado na tabela 12 .

\begin{tabular}{l|c|c|c|c|c}
\hline \multicolumn{1}{c|}{ Descrição $\left(\mathbf{M C} 45^{\circ}\right)$} & $\mathbf{E}(\mathbf{m})$ & $\mathbf{N}(\mathbf{m})$ & $\mathbf{X}(\mathbf{m})$ & $\mathbf{Y}(\mathbf{m})$ & $\mathbf{Z}(\mathbf{m})$ \\
\hline Caixa d' água Johnsons & 405871,010 & 7430009,450 & 4079418,900 & $-4212580,986$ & $-2500801,504$ \\
\hline Jaraguá- CHG & 319547,810 & 7404626,120 & 4010062,107 & $-4265293,893$ & $-2523372,284$ \\
\hline Mirante Ligth Cubatão & 351445,010 & 7359899,950 & 4020445,670 & $-4230580,132$ & $-2564668,408$ \\
\hline Centro Caixa d' água Guarujá & 371290,786 & 7343727,357 & 4030114,349 & $-4212184,731$ & $-2579626,524$ \\
\hline
\end{tabular}

Tabela 12: Coordenadas de pontos Córrego Alegre EN (encontradas) e XYZ (calculadas)

Como no item anterior (para os parâmetros de helmert) foram identificados pontos utilizados como apoio do mapeamento (Córrego Alegre), e apresentados na tabela 12 . sendo estes relacionados com as coordenadas ortoimagem (SIRGAS). Isso foi feito a partir do ajustamento, conforme instruções descritas no item 4.1.2.2. Desta forma, calculados os parâmetros ajustados, sua matriz variância-covariância e teste estatístico, conforme instruções descritas no item 4.1.2.2, os resultados são apresentados na tabela 13 .

\begin{tabular}{l|c|c|l}
\hline Parâmetros & \multicolumn{1}{|c|}{ Valores } & $\boldsymbol{\sigma}_{\text {par }}$ & $\left|\boldsymbol{t}_{\text {par }}\right|$ \\
\hline$T_{X}$ & $-200,692 \mathrm{~m}$ & $0,312 \mathrm{~m}$ & 641 \\
\hline$T_{Y}$ & $167,933 \mathrm{~m}$ & $0,312 \mathrm{~m}$ & 536 \\
\hline$T_{Z}$ & $-4,650 \mathrm{~m}$ & $0,312 \mathrm{~m}$ & 14 \\
\hline
\end{tabular}

Tabela 13: Parâmetros calculados para a transformação de SIRGAS para Córrego utilizando três translações

A partir dos valores ajustados para a transformação de três parâmetros e para a 
verificação de seu erro foi calculado o teste estatístico de t-student a partir do desvio de cada valor, conforme abordado na secção 4.1.2.3. tem-se pela expressão 4.27 com os graus de liberdade $v=9$ e $1-\alpha=0,95\left(t_{9 ; 5 \%}=1,83\right)$. Assim, verifica-se que os valores, apresentados na tabela 11, são maiores que o valor teórico, desta forma são aceitos para um nível de significância de 5\%. Além disso, os valores calculados, e apresentados da tabela 13. são próximos aos descritos por Netto et al. (2003) a diferença, além de fatores não determinados, pode ser atribuída a utilização por parte do autor da transformação entre o sistema de referência WGS84 e Córrego Alegre, diferente do referencial SIRGAS 2000 utilizado no presente trabalho.

\subsection{Resultado da comparação entre as formas de trans- formação}

Procurando realizar uma comparação entre os parâmetros advindos do grid NTV2, da formulação de Helmert e por três parâmetros, realizou-se a transformação entre 21 coordenadas de monografias de campo coletadas em trabalhos posteriores do IGCSP e levantadas por Oliveira (2006). A partir das descrições presentes nas monografias foram coletados pontos homólogos na ortoimagem de melhor escala (IGCSP, 2017). Depois verificaram-se as discrepâncias entre as coordenadas calculadas (a partir dos mesmos pontos) com o ProGrid e analisaram-se os resultados, de modo a validar qual método apresenta melhores resultados para ser utilizado no processo de comparação posicional. Para analisar estas transformações foram utilizadas as coordenadas, todas no meridiano central (MC) $45^{\circ}$, descritas na tabela 14 .

\begin{tabular}{|c|c|c|c|c|c|c|c|}
\hline $\mathbf{n}^{o}$ & $\operatorname{Marco}\left(\mathrm{MC} 45^{\circ}\right)$ & $\mathbf{N}(\mathbf{m})$ & $\mathbf{E}(\mathbf{m})$ & $\mathbf{n}^{o}$ & $\operatorname{Marco}\left(\mathrm{MC} 45^{\circ}\right)$ & $\mathbf{N}(\mathbf{m})$ & $\mathbf{E}(\mathbf{m})$ \\
\hline 1 & V2022 & 7394766,790 & 338292,110 & 12 & V3516 & 7400609,050 & 329754,110 \\
\hline 2 & V2060 & 7395130,890 & 359892,270 & 13 & V3519 & 7396423,980 & 324944,910 \\
\hline 3 & V3021 & 7393084,080 & 342419,140 & 14 & V3526 & 7400543,070 & 348002,300 \\
\hline 4 & V3031 & 7386674,760 & 344865,400 & 15 & V3542 & 7393148,830 & 337003,780 \\
\hline 5 & V3043 & 7378212,550 & 326586,980 & 16 & Mongagua 3.pdf & 7333991,410 & 334898,230 \\
\hline 6 & V3070 & 7394341,360 & 353413,720 & 17 & Embu.pdf & 7383222,540 & 307780,530 \\
\hline 7 & V3142 & 7368063,720 & 316638,570 & 18 & Barueri.pdf & 7401179,700 & 303641,110 \\
\hline 8 & V3148 & 7358563,270 & 318065,250 & 19 & Atibaia.pdf & 7436763,530 & 343733,070 \\
\hline 9 & V3173 & 7366466,490 & 327831,690 & 20 & Bertioga 2.pdf & 7372431,480 & 412905,260 \\
\hline 10 & V3247 & 7410241,820 & 322047,560 & 21 & Pedra Bela.pdf & 7479519,320 & 350768,700 \\
\hline 11 & V3279 & 7408032,620 & 354197,970 & - & - & - & - \\
\hline
\end{tabular}

Tabela 14: Coordenadas de Monografias em Córrego Alegre utilizadas na comparação Fonte: Autor em compilação de dados de Oliveira (2006) e do acervo IGCSP (2017)

\footnotetext{
${ }^{1}$ Valores calculados por Netto et al. (2003 p.52) foram $\mathrm{TX}=204,173 \mathrm{~m}$; $\mathrm{TY}=-170,358 \mathrm{~m}$; $\mathrm{TZ}=6,34 \mathrm{~m}$.
} 
A partir das monografias dos pontos, apresentados na tabela 14, foram verificados, em termos planimétricos, os respectivos locais em base cartográfica mais precisa (ortofoto do IGC). A distribuição destes pontos é ilustrada na figura 62, que contempla a Área C. Os pontos com nomes iniciados por $V$ foram coletados para mapeamentos realizados na Região Metropolitana de São Paulo; já os finalizados por .pdf foram utilizados por mapeamentos realizados pelo IGCSP (OLIVEIRA, 2006, IGCSP, 2017). Em relação às outras áreas (A e B) não foram encontrados pontos de qualidade compatível que permitisse tal verificação.

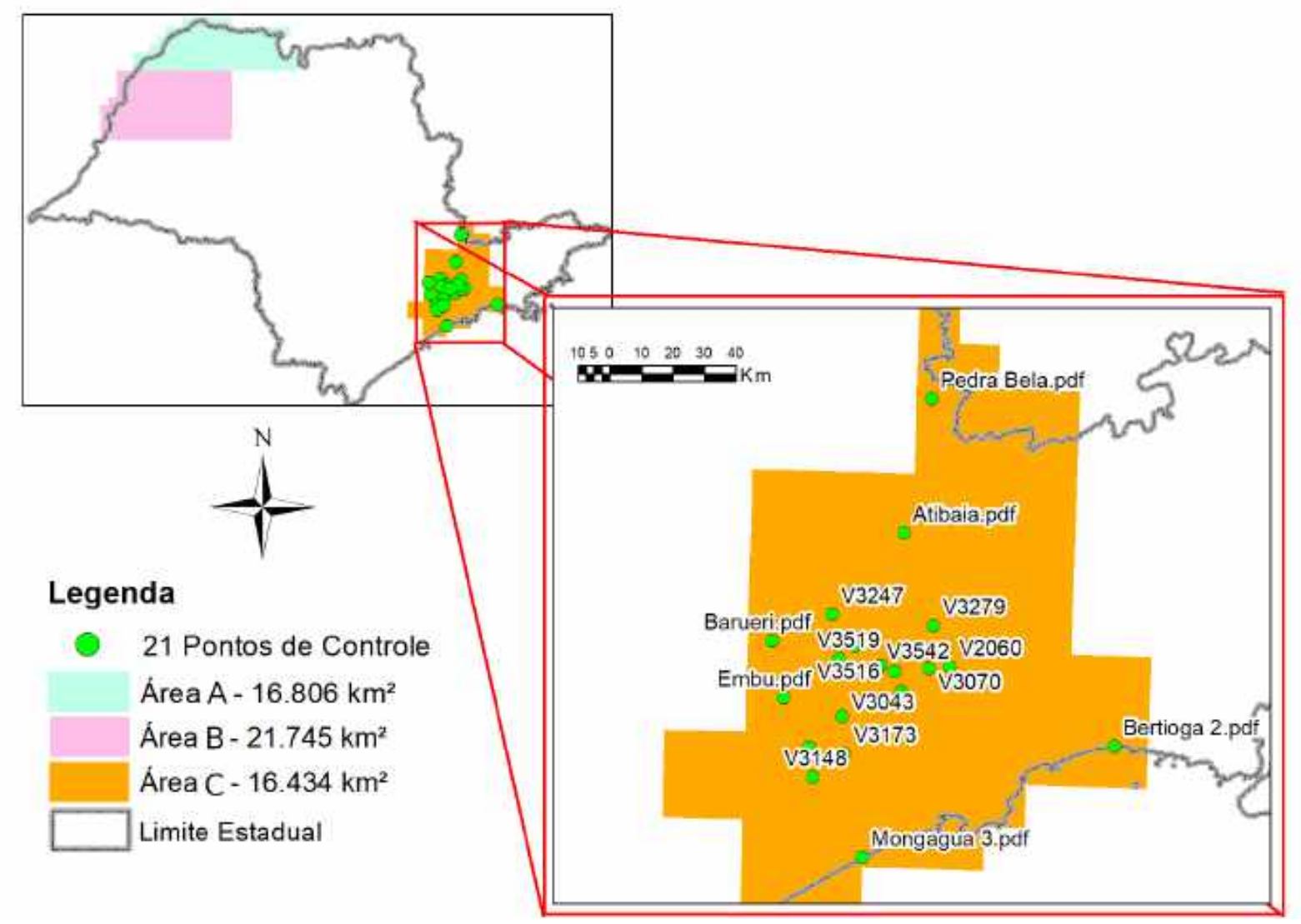

Figura 62: Pontos utilizados no cálculo dos parâmetros de Helmert e translação

Utilizando os valores da tabela 14 e as descrições presentes nas monografias foi possível a identificação destes locais na Ortoimagem, sendo esta de qualidade posicional (planimétrica) compatível com escala 1:5.000 e estimada ser 5 vezes mais precisa que o mapeamento 1:25.000 feito com a tecnologia dos anos 60. Os valores das coordenadas em SIRGAS 2000 dos respectivos pontos estão apresentados na tabela 15 .

\begin{tabular}{l|l|c|c|c|l|l|c}
\hline $\mathbf{n}^{o}$ & Marco $(\mathbf{M C 4 5})$ & $\mathbf{E}(\mathbf{m})$ & $\mathbf{N}(\mathbf{m})$ & $\mathbf{n}^{o}$ & Marco $\left(\mathbf{M C} 45^{\circ}\right)$ & $\mathbf{E}(\mathbf{m})$ & $\mathbf{N}(\mathbf{m})$ \\
\hline 1 & V2022 & 338264,517 & 7394757,136 & 12 & $\mathrm{~V} 3516$ & 329730,209 & 7400598,964 \\
\hline 2 & V2060 & 359865,444 & 7395121,676 & 13 & $\mathrm{~V} 3519$ & 324921,017 & 7396413,346 \\
\hline 3 & V3021 & 342396,260 & 7393074,549 & 14 & $\mathrm{~V} 3526$ & 347976,445 & 7400533,594 \\
\hline
\end{tabular}


continuando tabela da página anterior

\begin{tabular}{l|l|l|l|l|l|l|l}
\hline $\mathbf{n}^{o}$ & Marco $\left(\mathbf{M C 4 5 ^ { \circ }}\right)$ & $\mathbf{N}(\mathbf{m})$ & $\mathbf{E}(\mathbf{m})$ & $\mathbf{n}^{o}$ & Marco $\left(\mathbf{M C} 45^{\circ}\right)$ & $\mathbf{N}(\mathbf{m})$ & $\mathbf{E}(\mathbf{m})$ \\
\hline 4 & V3031 & 344840,964 & 7386664,062 & 15 & V3542 & 336980,753 & 7393139,220 \\
\hline 5 & V3043 & 326562,252 & 7378202,210 & 16 & Mongagua 3.pdf & 334872,588 & 7333980,705 \\
\hline 6 & V3070 & 353389,376 & 7394330,655 & 17 & Embu.pdf & 307755,924 & 7383211,603 \\
\hline 7 & V3142 & 316614,520 & 7368053,611 & 18 & Barueri.pdf & 303615,867 & 7401168,751 \\
\hline 8 & V3148 & 318040,970 & 7358554,643 & 19 & Atibaia.pdf & 343708,752 & 7436751,875 \\
\hline 9 & V3173 & 327804,386 & 7366456,623 & 20 & Bertioga 2.pdf & 412880,440 & 7372420,198 \\
\hline 10 & V3247 & 322026,009 & 7410230,928 & 21 & Pedra Bela.pdf & 350738,791 & 7479510,208 \\
\hline 11 & V3279 & 354173,207 & 7408021,673 & - & - & - & - \\
\hline
\end{tabular}

Tabela 15: Coordenadas de Monografias em SIRGAS 2000 utilizadas na comparação

Para efetuar a comparação de qual seria a forma mais adequada de conversão optou-se em converter as coordenadas planimétricas do sistema SIRGAS, apresentadas na tabela 15. para o sistema Córrego Alegre. Isso se deu utilizando as coordenadas apresentados na tabela 15, porém convertidas de UTM para geodésica (item 4.1.1.1) e para o referencial cartesiano (item 4.1.1.2, foram calculadas as respectivas coordenadas no sistema Córrego Alegre utilizando as seguintes formas: a da transformação de Helmert (item 6.1.1.1), a da transformação por três parâmetros (item 6.1.2) e com software Progrid (item 4.1.3). Na tabela 16 apresentam-se os valores de coordenadas calculadas, no sistema Córrego Alegre e na projeção UTM, para cada uma destas três formas de transformação.

\begin{tabular}{l|l|c|c|c|c|c|c}
\hline \multirow{2}{*}{$\mathrm{n}^{o}$} & \multirow{2}{*}{ Marco $\left(\mathbf{M C} 45^{\circ}\right)$} & \multicolumn{2}{|c|}{ GRID (PROGRID) } & \multicolumn{2}{c|}{ Helmert } & \multicolumn{2}{c}{ Três translações } \\
\cline { 3 - 7 } & & $\mathbf{E}(\mathbf{m})$ & $\mathbf{N}(\mathbf{m})$ & $\mathbf{E} \mathbf{( m )}$ & $\mathbf{N} \mathbf{( m )}$ & $\mathbf{E} \mathbf{( m )}$ & $\mathbf{N}(\mathbf{m})$ \\
\hline 1 & V2022 & 338289,149 & 7394767,491 & 338287,627 & 7394764,373 & 338287,652 & 7394764,403 \\
\hline 2 & V2060 & 359889,820 & 7395131,842 & 359889,113 & 7395128,942 & 359888,617 & 7395129,009 \\
\hline 3 & V3021 & 342420,843 & 7393084,863 & 342419,478 & 7393081,747 & 342419,470 & 7393081,889 \\
\hline 4 & V3031 & 344865,536 & 7386674,356 & 344864,252 & 7386671,095 & 344864,163 & 7386671,394 \\
\hline 5 & V3043 & 326587,059 & 7378212,706 & 326585,073 & 7378209,007 & 326585,434 & 7378209,550 \\
\hline 6 & V3070 & 353413,790 & 7394340,850 & 353412,878 & 7394337,895 & 353412,566 & 7394337,990 \\
\hline 7 & V3142 & 316639,472 & 7368064,197 & 316637,092 & 7368060,135 & 316637,639 & 7368060,908 \\
\hline 8 & V3148 & 318066,116 & 7358565,262 & 318063,587 & 7358560,922 & 318064,124 & 7358561,990 \\
\hline 9 & V3173 & 327829,383 & 7366467,151 & 327827,249 & 7366463,116 & 327827,590 & 7366463,864 \\
\hline 10 & V3247 & 322050,503 & 7410241,322 & 322048,683 & 7410238,551 & 322049,183 & 7410238,173 \\
\hline 11 & V3279 & 354197,595 & 7408031,858 & 354196,717 & 7408029,270 & 354196,366 & 7408028,913 \\
\hline 12 & V3516 & 329754,820 & 7400609,350 & 329753,091 & 7400606,345 & 329753,390 & 7400606,244 \\
\hline 13 & V3519 & 324945,676 & 7396423,774 & 324943,779 & 7396420,614 & 324944,177 & 7396420,676 \\
\hline 14 & V3526 & 348000,927 & 7400543,843 & 347999,801 & 7400540,990 & 347999,617 & 7400540,828 \\
\hline 15 & V3542 & 337005,401 & 7393149,586 & 337003,830 & 7393146,414 & 337003,928 & 7393146,462 \\
\hline 16 & Mongagua 3.pdf & 334898,397 & 7333991,328 & 334895,664 & 7333986,361 & 334895,708 & 7333988,018 \\
\hline 17 & Embu.pdf & 307780,566 & 7383222,157 & 307778,252 & 7383218,513 & 307779,103 & 7383218,857 \\
\hline 18 & Barueri.pdf & 303640,433 & 7401179,220 & 303638,071 & 7401176,122 & 303639,018 & 7401175,996 \\
\hline 19 & Atibaia.pdf & 343732,889 & 7436762,061 & 343731,963 & 7436760,208 & 343731,932 & 7436759,195 \\
\hline 20 & Bertioga 2.pdf & 412905,621 & 7372430,410 & 412905,510 & 7372426,923 & 412903,567 & 7372427,459 \\
\hline 21 & Pedra Bela.pdf & 350764,719 & 7479519,215 & 350762,143 & 7479519,658 & 350761,982 & 7479517,471 \\
\hline & & & & &
\end{tabular}

Tabela 16: Coordenadas de Monografias em SIRGAS 2000 utilizadas na comparação 
A transformação de Helmert utiliza os valores lineares de transformação $\left(T_{X}, T_{Y}, T_{Z}\right)$ e os parâmetros de escala e rotação $(\mu, R)$, com base na expressão 4.10 (item 4.1.2.1). Por outro lado a transformação por três translações utilizou os parâmetros lineares $\left(T_{X}, T_{Y}, T_{Z}\right)$ advindos da aplicação da expressão 4.15 (item 4.1.2.2). Ao comparar os valores das monografias (tabela 14), com os coletados na ortoimagem IGC em coordenadas SIRGAS transformadas para Córrego Alegre (tabela 16), têm-se as discrepâncias destas e seus valores estatísticos apresentados na tabela 17.

\begin{tabular}{|c|c|c|c|c|c|c|c|}
\hline \multirow[t]{2}{*}{$\mathrm{n}^{o}$} & \multirow{2}{*}{ Marco } & \multicolumn{2}{|c|}{ ProGrid } & \multicolumn{2}{|c|}{ Helmert } & \multicolumn{2}{|c|}{ Três translações } \\
\hline & & $\Delta \mathbf{N}(\mathbf{m})$ & $\Delta \mathrm{E}(\mathbf{m})$ & $\Delta \mathbf{N}(\mathbf{m})$ & $\Delta \mathbf{E}(\mathbf{m})$ & $\Delta \mathrm{N}(\mathbf{m})$ & $\Delta \mathrm{E}(\mathbf{m})$ \\
\hline 1 & V2022 & 0,701 & $-2,961$ & $-2,417$ & $-4,483$ & $-4,458$ & $-2,387$ \\
\hline 2 & V2060 & 0,952 & $-2,450$ & $-1,948$ & $-3,157$ & $-3,653$ & $-1,881$ \\
\hline 3 & V3021 & 0,783 & 1,703 & $-2,333$ & 0,338 & 0,330 & $-2,191$ \\
\hline 4 & V3031 & $-0,404$ & 0,136 & $-3,665$ & $-1,148$ & $-1,237$ & $-3,366$ \\
\hline 5 & V3043 & 0,156 & 0,079 & $-3,543$ & $-1,907$ & $-1,546$ & $-3,000$ \\
\hline 6 & V3070 & $-0,510$ & 0,070 & $-3,465$ & $-0,842$ & $-1,154$ & $-3,370$ \\
\hline 7 & V3142 & 0,477 & 0,902 & $-3,585$ & $-1,478$ & $-0,931$ & $-2,812$ \\
\hline 8 & V3148 & 1,992 & 0,866 & $-2,348$ & $-1,663$ & $-1,126$ & $-1,280$ \\
\hline 9 & V3173 & 0,661 & $-2,307$ & $-3,374$ & $-4,441$ & $-4,100$ & $-2,626$ \\
\hline 10 & V3247 & $-0,498$ & 2,943 & $-3,269$ & 1,123 & 1,623 & $-3,647$ \\
\hline 11 & V3279 & $-0,762$ & $-0,375$ & $-3,350$ & $-1,253$ & $-1,604$ & $-3,707$ \\
\hline 12 & V3516 & 0,300 & 0,710 & $-2,705$ & $-1,019$ & $-0,720$ & $-2,806$ \\
\hline 13 & V3519 & $-0,206$ & 0,766 & $-3,366$ & $-1,131$ & $-0,733$ & $-3,304$ \\
\hline 14 & V3526 & 0,773 & $-1,373$ & $-2,080$ & $-2,499$ & $-2,683$ & $-2,242$ \\
\hline 15 & V3542 & 0,756 & 1,621 & $-2,416$ & 0,050 & 0,148 & $-2,368$ \\
\hline 16 & Mongagua 3.pdf & $-0,082$ & 0,167 & $-5,049$ & $-2,566$ & $-2,522$ & $-3,392$ \\
\hline 17 & Embu.pdf & $-0,383$ & 0,036 & $-4,027$ & $-2,278$ & $-1,427$ & $-3,683$ \\
\hline 18 & Barueri.pdf & $-0,480$ & $-0,677$ & $-3,578$ & $-3,039$ & $-2,092$ & $-3,704$ \\
\hline 19 & Atibaia.pdf & $-1,469$ & $-0,181$ & $-3,322$ & $-1,107$ & $-1,138$ & $-4,335$ \\
\hline 20 & Bertioga 2.pdf & $-1,070$ & 0,361 & $-4,557$ & 0,250 & $-1,693$ & $-4,021$ \\
\hline 21 & Pedra Bela.pdf & $-0,105$ & $-3,981$ & 0,338 & $-6,557$ & $-6,718$ & $-1,849$ \\
\hline
\end{tabular}

Tabela 17: Discrepâncias entre coordenadas transformadas e das monografias 15

Com os valores apresentados na tabela 17, das discrepâncias $(\Delta E$ e $\Delta N)$, sobre estes foram calculadas estatísticas, conforme descritos na tabela 18. Na qual apresentam-se os seguintes cálculos estatísticos: média, desvio padrão, tendência (item 85), de assimetria e curtose. A partir dos dados de média e do desvio padrão, da tabela 18 , conclui-se que, ao menos na área C, a utilização do ProGrid apresenta valores de transformação estatisticamente melhores. Uma das hipóteses para este fato, além do desconhecimento 
dos valores de desvios das coordenadas utilizadas para o cálculo das transformações, é abordagem de transformação utilizada pelo ProGrid. Isso pois, além de realizar a transformação pelo método de Helmert, também utiliza um grid que permite a modelagem das distorções entre os sistemas de referência envolvidos, fruto das diferenças entre suas materializações (COSTA, 1999b; SANTOS et al., 2012).

\begin{tabular}{l|c|c|c|c|c|c}
\hline Transformação & \multicolumn{2}{|c|}{ Progrid } & \multicolumn{2}{c|}{ Helmert } & \multicolumn{2}{c}{ 3 Translações } \\
\hline Ordenada & $\Delta \mathrm{N}$ & $\Delta \mathrm{E}$ & $\Delta \mathrm{N}$ & $\Delta \mathrm{E}$ & $\Delta \mathrm{N}$ & $\Delta \mathrm{E}$ \\
\hline Média (m) & 0,075 & $-0,188$ & $-3,050$ & $-1,848$ & 2,951 & 1,782 \\
\hline Desvio Padrão (m) & 0,800 & 1,655 & 1,108 & 1,810 & 0,803 & 1,821 \\
\hline$t$ (teórico) & 1,725 & 1,725 & 1,725 & 1,725 & 1,725 & 1,725 \\
\hline$t_{20 ; 5 \%}(\mathbf{c a l c})$ & 0,726 & 1,690 & 21,322 & 12,784 & 26,179 & 6,912 \\
\hline Resultado & sem tendência & com tendência & \multicolumn{2}{c}{ com tendência } \\
\hline Assimetria & 0,288 & $-0,623$ & 1,188 & $-0,831$ & $-0,287$ & 0,909 \\
\hline Curtose & 0,352 & 0,442 & 3,545 & 1,066 & $-0,652$ & 1,761 \\
\hline
\end{tabular}

Tabela 18: Medidas estatísticas para discrepâncias apresentadas na tabela 17

Ainda na tabela 18, observa-se que embora exista equivalência entre a transformação por três parâmetros e o progrid, dada pelos valores aproximados de desvio padrão. A única transformação aprovada no teste de tendência $(\mathrm{t})$ e que apresentou melhores valores de assimetria foi a utilizando Progrid. Em suma foi a transformação considerada mais adequada para a análise, sendo compatível com a precisão requerida para escala 1:25.000. Esse resultado corrobora os estudos realizados por Garnero (2014) que concluiu que a utilização de GRIDs para a conversão entre sistema fornece resultados compatíveis e acurados quando comparados às transformações matemáticas, como Helmert ou Molodensky. Desta forma apresenta-se, na próxima secção, a verificação posicional da área C do mapeamento, objeto material deste estudo, utilizando o ProGrid como método de transformação entre os sistemas.

Notari (1972) apresenta que os erros máximos toleráveis, na época do mapeamento, para o apoio de campo, em um mapeamento de escala 1:25.000 era de 3,125m $(0,125 \mathrm{~mm}$ x denominador da escala). Ao compará-los com a média dos erros encontrados, na tabela 18, temos que os métodos de transformação, três parâmetros e Helmert, embora tenham apresentados valores maiores que o ProGrid, indicam que as coordenadas dos pontos encontrados (tabela 10) apresentam erros compatíveis, para a época. Desta forma, pode- 
se concluir que as coordenadas destes pontos foram realmente as utilizadas, na década de 1960, para apoio de campo ao mapeamento de escala 1:25.000 abordado neste estudo.

\section{3 Área de estudo e análises posicional e qualitativa}

Com o objetivo de determinar a acurácia absoluta de parte do mapeamento 1:25.000 foi definido, a título de amostragem, que seriam analisadas cartas pertencentes a região $\mathrm{C}$ do mapeamento, pelos motivos apontados (disponibilidade de pontos bem identificados). A figura 63 apresenta as folhas sobre os quais serão desenvolvidas as análises descritas nos tópicos a seguir.

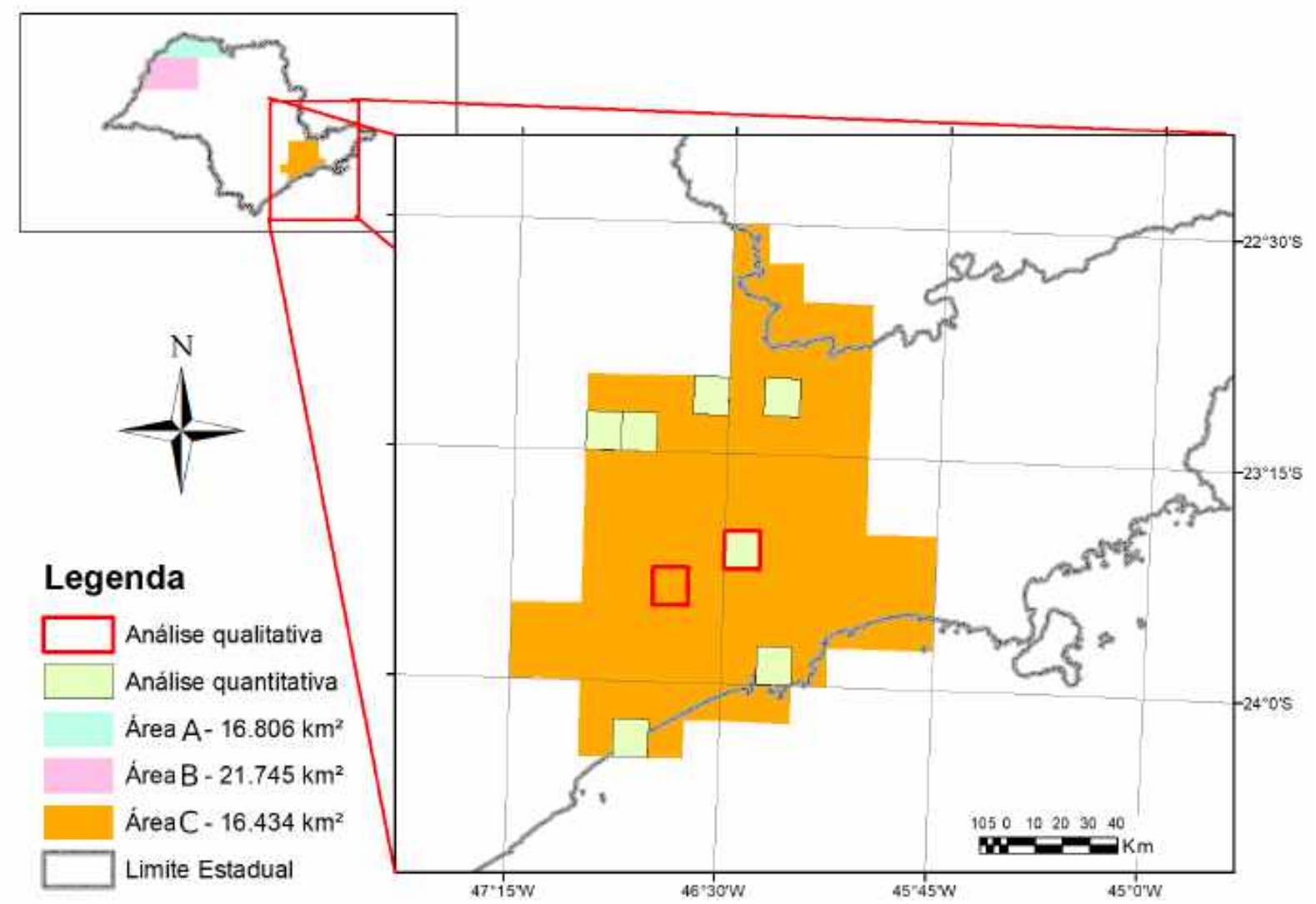

Figura 63: Folhas escolhidas para as análises de qualidade

Durante o processo de verificação foram selecionadas folhas que contêm feições de quadra (um dos níveis representados nas cartas) ainda existentes para comparar com mapeamentos mais precisos e atuais, isso para minimizar custos de trabalhos, sem a necessidade de coletas de coordenadas em campo. Quanto a altimetria esta foi coletada observando-se locais em que o terreno não sofreu modificações. 


\subsubsection{Análise posicional}

Segundo Merchant (1982), e mais recentemente pela Especificação Técnica para controle de Qualidade de Dados Geoespaciais (ET-CQDG) elaborada pelo Exército Brasileiro, mais especificamente pelo seu Departamento de Ciência e Tecnologia - DSG (2016b), para realizar a análise posicional de produtos cartográficos faz-se necessário comparar o produto testado com uma base mais acurada.

Visando atender à metodologia de análise posicional proposta pela ET-CQDG, elaborada pela DSG (2016b), nas folhas encontradas de escala 1:25.000, do mapeamento objeto de estudo. A partir de um ponto deste será identificado seu homólogo no mapeamento de referência, conforme se descreve no próximo tópico.

\subsubsection{Definição de pontos homólogos}

Com o objetivo de encontrar pontos identificáveis e homólogos entre o mapeamento de 1969 e a ortoimagem de 2010 foi adotada a seguinte metodologia: comparando-se a fotografia de 1962 com uma fotografia mais atual (IGCSP-2010), foram localizadas as quadras aonde existiam, em ambas as imagens, edificações, de mesma forma presentes em esquinas (DUARTE; CINTRA, 2017). Isso é um indicativo de que não houve modificação dos cantos da quadra. Quanto os pontos de altimetria foram coletadas as altitudes de pontos cotados no mapeamento de 1969 que não sofreram modificação, ou seja, foi observado se os picos de morros com pontos cotados não continham vegetação alta nem foram modificados (por exemplo, terraplanagem) entre o voo de 1962 e 2010.

Para coleta dos pontos de verificação planimétrica apresenta-se, como exemplo, o ponto ilustrado pela figura 64. Os pontos verdes/setas vermelhas indicam um canto de quadra do centro Histórico da cidade de Santos, mas especificamente o museu do café inaugurado em 1922, a direita: na carta topográfica, nas fotos aéreas (1962 e 2010); e a esquerda: ortofoto 2010 e na foto do Street View da Google (2018). A partir da identificação inicial nas fotografias aéreas foi analisado cada local (pelo street view) onde identificou-se a existência da mesma edificação, ou seja, este local não sofreu alterações significativas desde a realização do mapeamento (1962) até fonte de comparação (2010). Desta mesma forma, foi possível identificar outros cantos de quadras presentes nas cartas onde foram coletadas as amostras (já apresentadas na figura 63) assim, a partir da coleta e comparação das coordenadas destes locais, foi realizada a verificação quantitativa da qualidade posicional. 

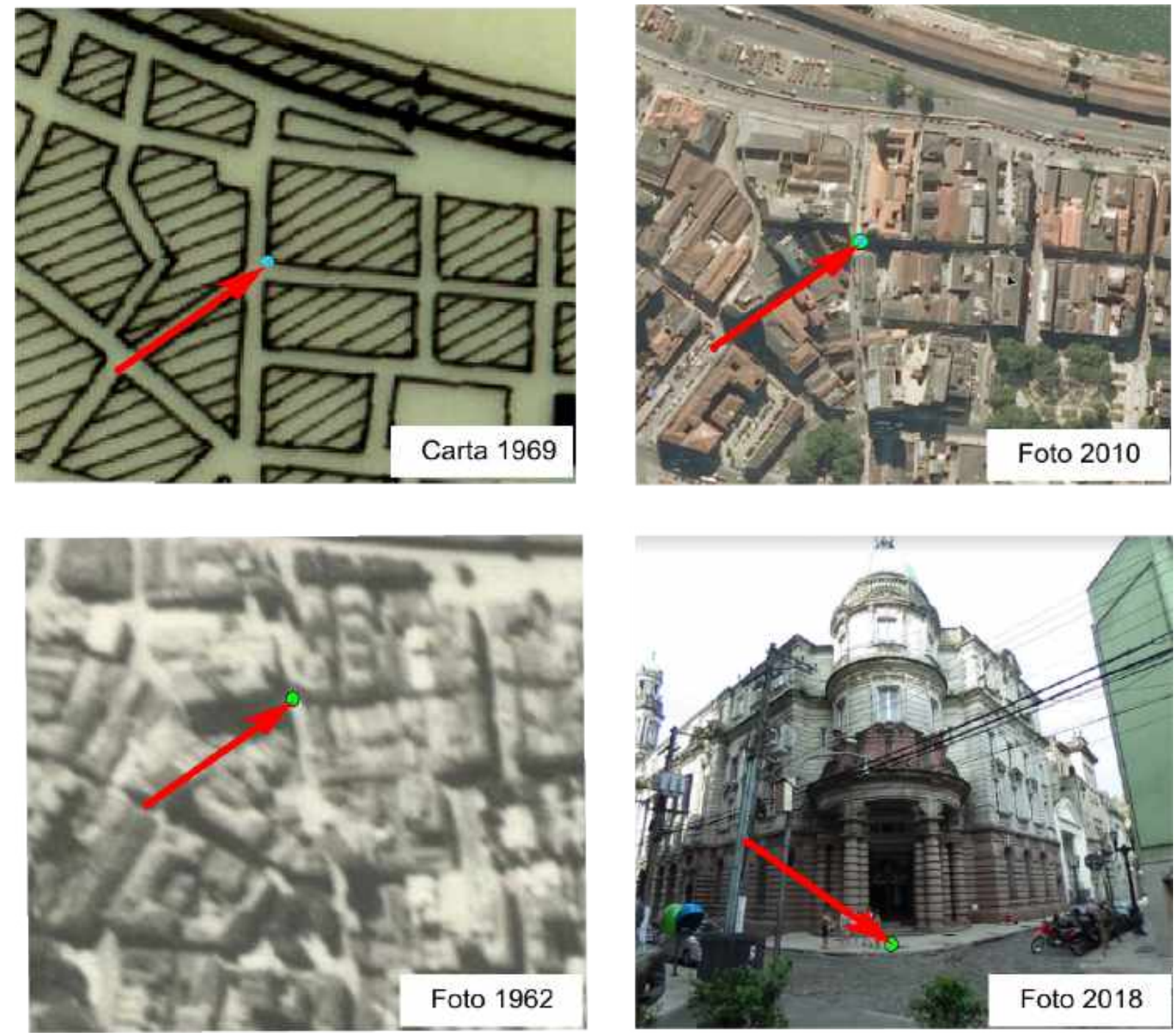

Figura 64: Metodologia de escolha dos pontos homólogos

Utilizando esta metodologia foram iniciados os processos de leitura das coordenadas na região $\mathrm{C}$, conforme descrito na secção 6.3.1. Nesta coleta procurou-se considerar a distribuição proposta pelo DSG (2016b), descrita na secção 4.2.1.2, embora muitas quadras encontradas estivessem concentradas em poucas áreas do mapeamento.

Com a metodologia definida foram medidas coordenadas métricas em UTM (metros) para cada dupla de pontos homólogos escolhidos. Nestes foram considerados separadamento os eixos Norte e Este, e foram calculadas as estatísticas para análise, conforme será apresentado no tópico a seguir.

\subsubsection{Análise estatística}

Uma das primeiras variáveis estatísticas é o tamanho da amostra. Para análises de cartas topográficas Merchant (1982) propõe a utilização de 20 pontos, como amostra. 
Outra definição importante é a da quantidade de produtos a serem testados, no nosso caso as folhas topográficas no mapeamento 1:25.000. Para a norma DSG (2016b) a unidade lote é utilizada para representar cada elemento, neste caso uma folha topográfica. Ainda para a norma, os elementos representados nesta folha são considerados itens. Como contabilizar cada um dos itens disponíveis em cada folha seria inviável trabalhou-se somente com o total de lotes (folhas) encontradas na área C no caso $66(N=66)$.

Tendo como referência o tamanho do lote (quantidade de folhas) $N=66$ e tomando como nível geral de inspeção I tem-se que são necessárias verificações em no mínimo 5 folhas para um nível de aceitação (qualidade aceitável) de 10\%, assim foram observadas 7 folhas (ISO, 2013). Estas encontram-se distribuídas conforme ilustra a figura 65 .

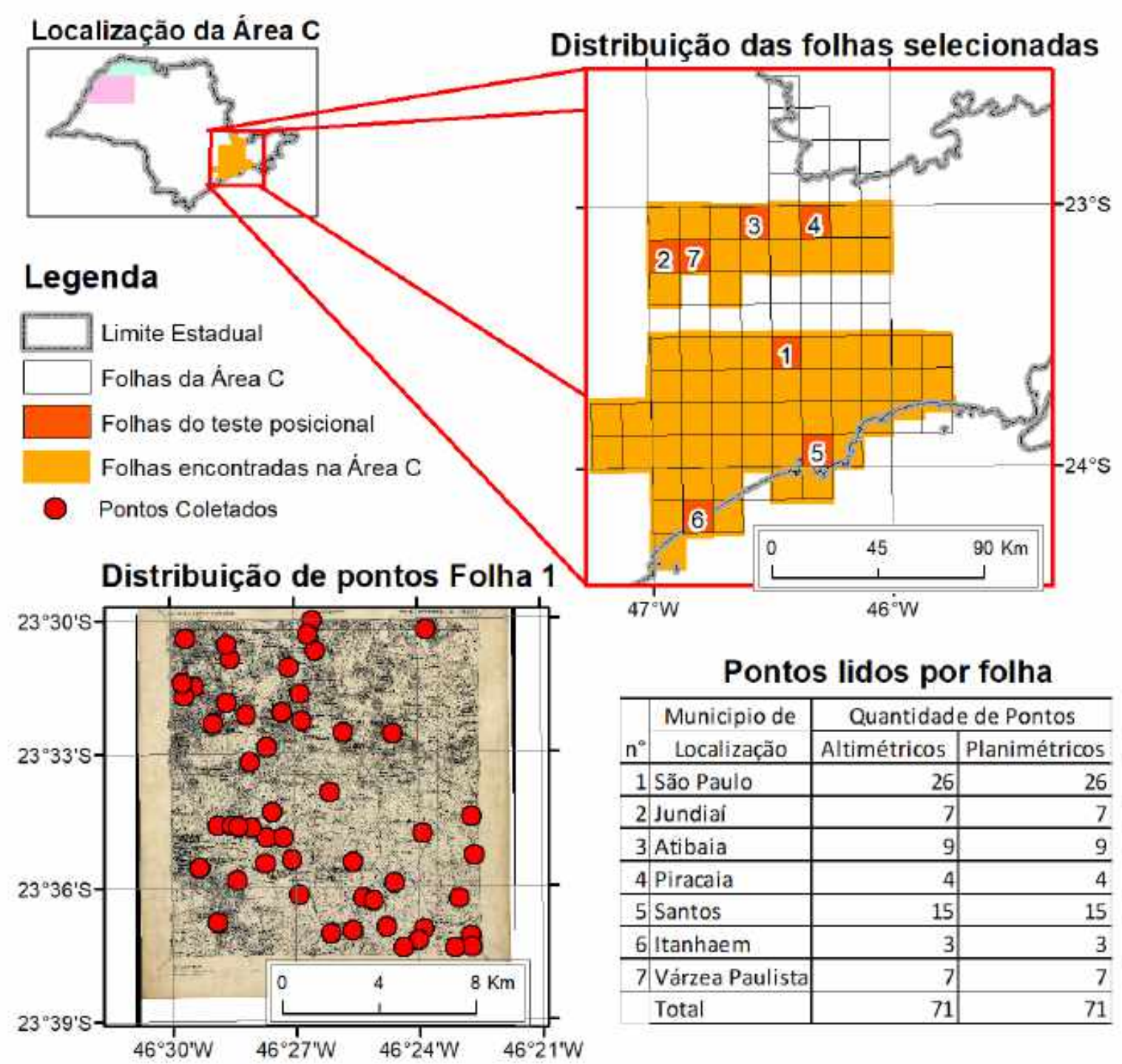

Figura 65: Distribuição dos pontos coletados para análise posicional 
Quando aos itens observados, como no exemplo da folha 1 da figura 65, o ideal é que todos os elementos das folhas selecionadas fossem testados porém, como já foi visto, a questão temporal só permitiu o teste de alguns elementos imutáveis, na prática esquinas de quadras (planimetria) e locais cotados sem alteração no terreno (altimetria). Levandose em consideração estas limitações foram coletadas coordenadas de 71 pontos, nas cartas do IGG e na ortofoto IGC (tabela da figura 65). Mais detalhes sobre as coordenadas de cada ponto são listadas no Apêndice F, tabela 30 (página 198.

A norma ET-CQDG especifica que a escolha da amostra deve obedecer a certa distribuição espacial. Para garantir a homogeneidade descrita a norma utiliza um grid disposto nas folhas para este fim. No caso da análise deste trabalho, aplicado a mapeamentos antigos, não foi possível seguir estas orientações, pois foram muitas as diferenças encontradas devido ao grande intervalo de tempo entre os produtos e a falta de disponibilidade em fontes mais precisas. Por estes motivos a distribuição da amostra não pode seguir totalmente as recomendações da DSG (2016b), como mostrado na folha 1 da figura 65. mas foi o melhor que se pode fazer.

Como as coordenadas se encontram em diferentes data, foi necessária sua transformação antes de realizar a comparação. Como observado na secção 6.1 verificou-se que a utilização do GRID NTv2 apresenta melhores resultados para esta transformação e, desta forma, foi a metodologia utilizada. Com esses pressupostos foram calculadas as discrepâncias das coordenadas de ambas as fontes.

Após o cálculo das discrepâncias, foram eliminados os considerados erros grosseiros da amostra, maior que $3 \sigma$ conforme visto na secção 4.2.1, o que diminuiu as coordenadas de 71 pontos planialtimétricos para 66 pontos de coordenadas planimétricas e 68 de altimétricas. As medidas estatísticas das discrepâncias destas coordenadas são apresentadas na tabela 19. Para detalhes das discrepâncias e as coordenadas de cada ponto solicita-se o leitor pode consultar o apêndice $\mathrm{F}$ na tabela 32 da página 200 .

\begin{tabular}{l|c|c|c}
\hline \multicolumn{1}{c|}{ Medida Estatística } & $\Delta \mathrm{E}$ & $\Delta \mathrm{N}$ & $\Delta \mathrm{H}$ \\
\hline Média (m) & $-0,89$ & 3,31 & $-3,23$ \\
\hline Erro Padrão (m) & 0,99 & 2,21 & 0,86 \\
\hline Mediana (m) & $-1,75$ & 8,21 & $-3,40$ \\
\hline EMQ (m) & 7,99 & 18,10 & 7,36 \\
\hline Curtose & 0,99 & $-0,08$ & 0,12 \\
\hline Assimetria & 0,84 & $-0,25$ & 0,43 \\
\hline Desvio padrão (m) & 8,00 & 17,94 & 7,09 \\
\hline
\end{tabular}


continuando Tabela 19 da página anterior

\begin{tabular}{l|c|c|c}
\hline \multicolumn{1}{c|}{ Medida Estatística } & $\Delta \mathrm{E}$ & $\Delta \mathrm{N}$ & $\Delta \mathrm{H}$ \\
\hline Mínimo (m) & $-14,54$ & $-41,21$ & $-17,16$ \\
\hline Máximo (m) & 20,74 & 47,44 & 18,27 \\
\hline Tamanho da amostra & 66 & 66 & 68 \\
\hline$t$ (amostral) & 1,216 & 1,919 & 3,707 \\
\hline$t_{65 ; 5 \%}^{E N}$ ou $t_{67 ; 5 \%}^{H}($ teórico) & 1,668 & 1,668 & 1,667 \\
\hline Resultado teste $\mathbf{t}$ & Sem tendência & Com tendência & Com tendência \\
\hline
\end{tabular}

Tabela 19: Medidas estatísticas para os valores de discrepâncias observados

Os valores expressos na tabela 32 são apresentados, na figura 66 , em forma de gráficos (histograma e curva normal) para cada uma das diferenças entre as coordenadas: $\Delta \mathrm{E}$ (DE) $\Delta \mathrm{N}(\mathrm{DN})$ e $\Delta \mathrm{H}(\mathrm{DZ})$.
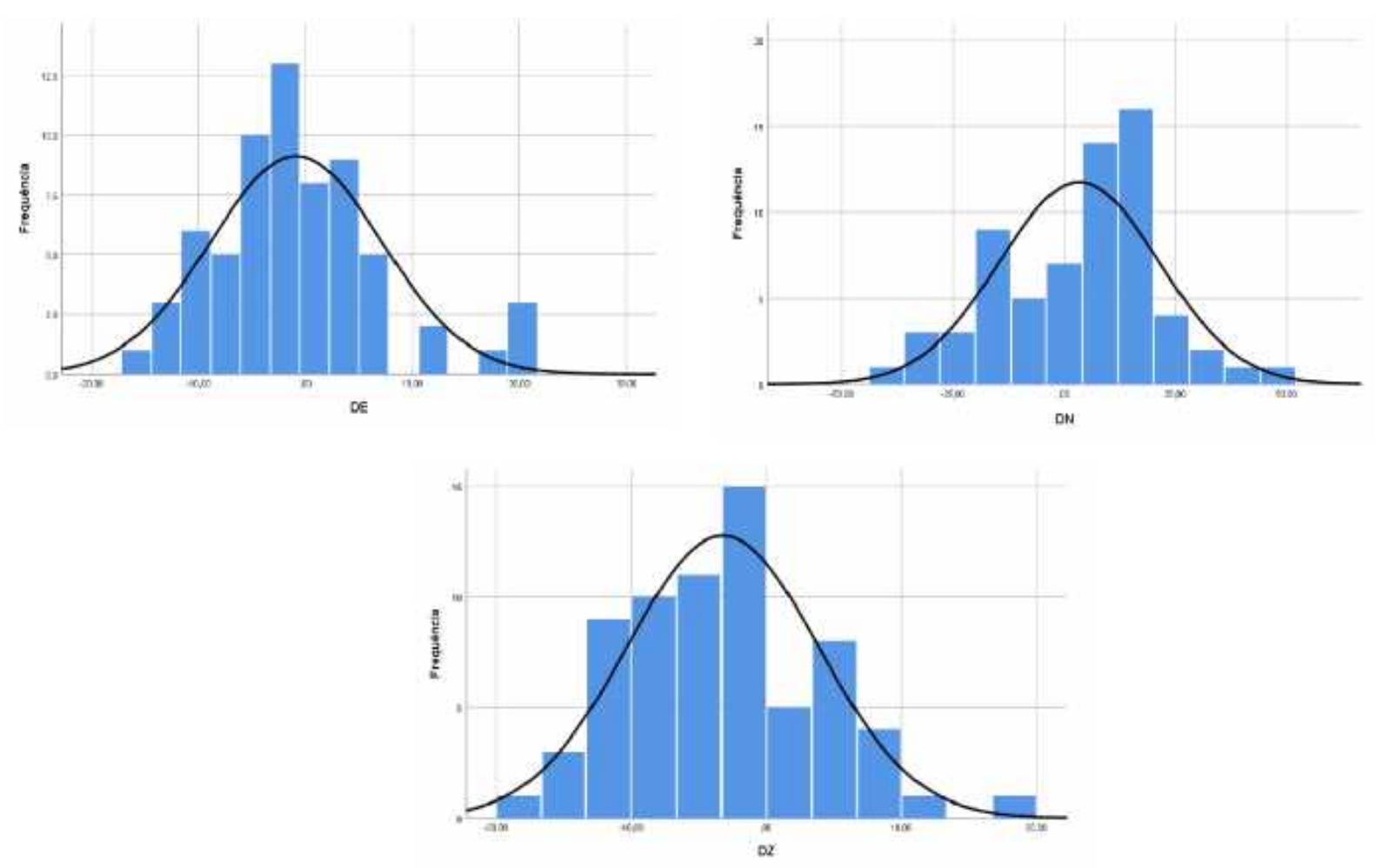

Figura 66: Histograma de valores estatísticos para das diferenças DE,DN e DZ

\subsubsection{Análise posicional segundo normativas brasileiras}

Em meados de 1970 quando foram elaboradas as últimas versões deste mapeamento não existiam normatizações nacionais que fornecessem parâmetros para a avaliação po- 
sicional de mapeamentos. Posteriormente foram estipuladas normas 1 utilizando-se de parâmetros estatísticos, que propunham analisar a acuracidade posicional para bases cartográficas. Conforme visto na secção 4.2.1.3 foram utilizadas bases com coordenadas planimétricas para a comparação com acurácia compatível na escala 1:5.000 e para coordenadas altimétricas estas foram obtidas a partir de modelos digitais do terreno na escala 1:10.000 (IGCSP, 2017). Isso pois não se dispunha de base altimétrica na mesma escala da planimétrica (1:5.000) para toda região analisada.

Em termos práticos para realizar o teste de verificação posicional do mapeamento de acordo com a legislação de 1984 , foram utilizados trabalhos como os elaborados por TOMMASELLI et al. (1988), Galo e Camargo (1994), Nero (2005).

A primeira etapa desta análise foi a definição da amostra a ser utilizada, estas foram as coordenadas já apresentadas na tabela 32 e cálculos estatísticos sobre suas discrepâncias (item 6.3.1.2). A partir destas amostras foram calculadas discrepâncias em milímetros para escala do produto analógicd ${ }^{3}$. Estes valores e as coordenadas dos pontos em Córrego Alegre - UTM são apresentados a seguir, na tabela 20.

\begin{tabular}{|c|c|c|c|c|c|c|}
\hline \multirow[t]{2}{*}{$\mathrm{n}^{o}$} & \multicolumn{2}{|c|}{ Ponto Ortofoto } & \multicolumn{2}{|c|}{ Ponto Monografia } & \multicolumn{2}{|c|}{ Discrepâncias (1:25.000) } \\
\hline & $\mathbf{E}(\mathbf{m})$ & $\mathbf{N}(\mathbf{m})$ & $\mathbf{E}(\mathbf{m})$ & $\mathbf{N}(\mathbf{m})$ & $\Delta \mathbf{E}(\mathbf{m m})$ & $\Delta \mathbf{N}(\mathbf{m m})$ \\
\hline 1 & 309719,517 & 7435000,999 & 309723,503 & 7435021,228 & $-0,159$ & $-0,809$ \\
\hline 2 & 309044,242 & 7434656,485 & 309041,548 & 7434675,414 & 0,108 & $-0,757$ \\
\hline 3 & 308265,13 & 7435214,115 & 308269,741 & 7435226,667 & $-0,184$ & $-0,502$ \\
\hline 4 & 308521,127 & 7434546,186 & 308517,549 & 7434555,821 & 0,143 & $-0,385$ \\
\hline 5 & 310096,581 & 7435039,133 & 310095,781 & 7435057,403 & 0,032 & $-0,731$ \\
\hline 6 & 309497,94 & 7432382,382 & 309497,734 & 7432400,028 & 0,008 & $-0,706$ \\
\hline 7 & 306503,988 & 7435288,959 & 306515,022 & 7435317,221 & $-0,441$ & $-1,13$ \\
\hline 8 & 306404,252 & 7434999,824 & 306418,291 & 7435030,191 & $-0,562$ & $-1,215$ \\
\hline 9 & 306708,439 & 7434150,284 & 306710,293 & 7434181,039 & $-0,074$ & $-1,23$ \\
\hline 10 & 305890,06 & 7433966,677 & 305894,52 & 7434007,882 & $-0,178$ & $-1,648$ \\
\hline 11 & 307419,596 & 7434540,51 & 307433,141 & 7434563,385 & $-0,542$ & $-0,915$ \\
\hline 12 & 307344,535 & 7431860,798 & 307344,472 & 7431863,506 & 0,003 & $-0,108$ \\
\hline 13 & 306471,993 & 7435807,878 & 306486,533 & 7435835,241 & $-0,582$ & $-1,095$ \\
\hline 14 & 340602,822 & 7442841,326 & 340608,336 & 7442855,747 & $-0,221$ & $-0,577$ \\
\hline 15 & 340550,628 & 7443102,685 & 340553,954 & 7443118,942 & $-0,133$ & $-0,65$ \\
\hline 16 & 341353,74 & 7442808,224 & 341357,89 & 7442823,762 & $-0,166$ & $-0,622$ \\
\hline 17 & 341127,157 & 7442954,404 & 341132,248 & 7442966,11 & $-0,204$ & $-0,468$ \\
\hline
\end{tabular}

\footnotetext{
${ }^{1}$ Cabe ressaltar que a norma americana $N M A S$ já era utilizada desde a década de 1950 (USBB, 1947); mas não se encontrou registro de sua utilização durante a produção do mapeamento estudado.

${ }^{2}$ Decreto lei número 89.817 de 20 de junho de 1984 (BRASIL, 1984).

${ }^{3}$ Conforme determina a legislação federal mas especificamente o artigo 9 do decreto 89.817 de 20 de junho de 1984 (BRASIL, 1984).
} 
continuando Tabela 20 da página anterior

\begin{tabular}{|c|c|c|c|c|c|c|}
\hline \multirow[t]{2}{*}{$\mathrm{n}^{o}$} & \multicolumn{2}{|c|}{ Ponto Ortofoto } & \multicolumn{2}{|c|}{ Ponto Monografia } & \multicolumn{2}{|c|}{ Discrepâncias (1:25.000) } \\
\hline & $\mathbf{E}(\mathbf{m})$ & $\mathbf{N}(\mathbf{m})$ & $E(\mathbf{m})$ & $\mathbf{N}(\mathbf{m})$ & $\Delta \mathrm{E}(\mathrm{mm})$ & $\Delta \mathrm{N}(\mathrm{mm})$ \\
\hline 18 & 339722,841 & 7442557,704 & 339723,852 & 7442568,455 & $-0,04$ & $-0,43$ \\
\hline 19 & 339821,637 & 7442085,181 & 339823,741 & 7442097,105 & $-0,084$ & $-0,477$ \\
\hline 20 & 337663,322 & 7442633,516 & 337666,445 & 7442648,268 & $-0,125$ & $-0,59$ \\
\hline 21 & 341822,713 & 7442828,382 & 341816,483 & 7442842,184 & 0,249 & $-0,552$ \\
\hline 22 & 360655,707 & 7449878,398 & 360637,225 & 7449869,892 & 0,739 & 0,34 \\
\hline 23 & 361084,241 & 7449924,054 & 361063,499 & 7449922,895 & 0,83 & 0,046 \\
\hline 24 & 361051,4 & 7449790,725 & 361030,866 & 7449789,282 & 0,821 & 0,058 \\
\hline 25 & 349310,938 & 7398714,313 & 349318,006 & 7398693,017 & $-0,283$ & 0,852 \\
\hline 26 & 349175,95 & 7396881,913 & 349178,44 & 7396873,76 & $-0,1$ & 0,326 \\
\hline 27 & 349984,254 & 7396384,768 & 349985,905 & 7396370,387 & $-0,066$ & 0,575 \\
\hline 28 & 353469,425 & 7393182,683 & 353465,14 & 7393151,547 & 0,171 & 1,245 \\
\hline 29 & 348817,025 & 7391758,206 & 348815,688 & 7391749,509 & 0,053 & 0,348 \\
\hline 30 & 348095,744 & 7390043,215 & 348088,601 & 7390031,979 & 0,286 & 0,449 \\
\hline 31 & 349645,611 & 7389518,792 & 349633,953 & 7389505,339 & 0,466 & 0,538 \\
\hline 32 & 348805,139 & 7387760,072 & 348797,462 & 7387745,671 & 0,307 & 0,576 \\
\hline 33 & 350816,68 & 7395037,179 & 350821,302 & 7395021,613 & $-0,185$ & 0,623 \\
\hline 34 & 350120,133 & 7394427,331 & 350119,721 & 7394410,034 & 0,016 & 0,692 \\
\hline 35 & 352265,09 & 7396130,693 & 352265,36 & 7396117,49 & $-0,011$ & 0,528 \\
\hline 36 & 351453,315 & 7396482,49 & 351454,684 & 7396471,77 & $-0,055$ & 0,429 \\
\hline 37 & 352197,497 & 7397283,43 & 352206,254 & 7397268,283 & $-0,35$ & 0,606 \\
\hline 38 & 352815,408 & 7399086,569 & 352823,047 & 7399064,33 & $-0,306$ & 0,89 \\
\hline 39 & 347804,255 & 7397536,716 & 347806,382 & 7397528,444 & $-0,085$ & 0,331 \\
\hline 40 & 352712,122 & 7400314,204 & 352719,42 & 7400296,298 & $-0,292$ & 0,716 \\
\hline 41 & 352489,947 & 7399698,806 & 352498,68 & 7399693,315 & $-0,349$ & 0,22 \\
\hline 42 & 349154,285 & 7399293,028 & 349164,951 & 7399271,456 & $-0,427$ & 0,863 \\
\hline 43 & 351730,022 & 7398356,709 & 351729,029 & 7398342,196 & 0,04 & 0,581 \\
\hline 44 & 353989,339 & 7395673,041 & 353983,442 & 7395656,528 & 0,236 & 0,661 \\
\hline 45 & 347422,696 & 7397162,711 & 347419,697 & 7397147,493 & 0,12 & 0,609 \\
\hline 46 & 347333,986 & 7397700,915 & 347321,901 & 7397672,521 & 0,483 & 1,136 \\
\hline 47 & 347456,188 & 7399526,848 & 347456,507 & 7399512,602 & $-0,013$ & 0,57 \\
\hline 48 & 348627,43 & 7396008,508 & 348628,582 & 7395992,105 & $-0,046$ & 0,656 \\
\hline 49 & 356071,468 & 7395657,187 & 356068,185 & 7395635,093 & 0,131 & 0,884 \\
\hline 50 & 357401,46 & 7399948,215 & 357403,699 & 7399933,643 & $-0,09$ & 0,583 \\
\hline 51 & 368232,743 & 7346641,902 & 368242,637 & 7346647,513 & $-0,396$ & $-0,224$ \\
\hline 52 & 367009,67 & 7346306,888 & 367015,423 & 7346305,796 & $-0,23$ & 0,044 \\
\hline 53 & 371700,212 & 7345398,155 & 371712,951 & 7345400,525 & $-0,51$ & $-0,095$ \\
\hline 54 & 367676,195 & 7351625,976 & 367671,745 & 7351613,39 & 0,178 & 0,503 \\
\hline 55 & 360952,206 & 7348451,993 & 360956,77 & 7348444,109 & $-0,183$ & 0,315 \\
\hline 56 & 360631,301 & 7350738,96 & 360642,494 & 7350727,321 & $-0,448$ & 0,466 \\
\hline
\end{tabular}


continuando Tabela 20 da página anterior

\begin{tabular}{|c|c|c|c|c|c|c|}
\hline \multirow[t]{2}{*}{$\mathrm{n}^{o}$} & \multicolumn{2}{|c|}{ Ponto Ortofoto } & \multicolumn{2}{|c|}{ Ponto Monografia } & \multicolumn{2}{|c|}{ Discrepâncias (1:25.000) } \\
\hline & $\mathbf{E}(\mathbf{m})$ & $\mathbf{N}(\mathbf{m})$ & $E(\mathbf{m})$ & $\mathbf{N}(\mathbf{m})$ & $\Delta \mathbf{E}(\mathbf{m m})$ & $\Delta \mathbf{N}(\mathbf{m m})$ \\
\hline 57 & 368085,586 & 7348041,523 & 368082,317 & 7348038,041 & 0,131 & 0,139 \\
\hline 58 & 364621,984 & 7352598,461 & 364631,611 & 7352586,995 & $-0,385$ & 0,459 \\
\hline 59 & 362795,167 & 7348692,062 & 362789,228 & 7348685,561 & 0,238 & 0,26 \\
\hline 60 & 364942,097 & 7352498,812 & 364937,843 & 7352478,993 & 0,17 & 0,793 \\
\hline 61 & 361961,919 & 7353105,018 & 361972,288 & 7353093,639 & $-0,415$ & 0,455 \\
\hline 62 & 366025,978 & 7351877,955 & 366023,193 & 7351868,18 & 0,111 & 0,391 \\
\hline 63 & 365283,765 & 7348195,609 & 365287,934 & 7348190,82 & $-0,167$ & 0,192 \\
\hline 64 & 369082,117 & 7346094,152 & 369084,44 & 7346091,718 & $-0,093$ & 0,097 \\
\hline 65 & 317406,306 & 7323467,354 & 317407,204 & 7323424,501 & $-0,036$ & 1,714 \\
\hline 66 & 318673,3 & 7324771,238 & 318653,427 & 7324723,794 & 0,795 & 1,898 \\
\hline & & & & Média & $-0,035$ & 0,132 \\
\hline & & & & Desvio Padrão & 0,320 & 0,717 \\
\hline
\end{tabular}

Tabela 20: Coordenadas Planimétricas e discrepâncias em milímetros para cálculo do PEC

Para o cálculo dos parâmetros definidos no PEC utilizou-se como variável a escala do mapeamento (1:25.000), ou seja, para cálculo dos estimadores: Padrão de Exatidão Cartográfica - PEC e Erro Padrão - EP foi utilizada como referência a escala 1:25.000. Sendo estes apresentados na tabela 21.

\begin{tabular}{l|c|c|c|c|c|c}
\hline Classe & Limite 1:25.000 & \multicolumn{2}{|c|}{ Valores acima do intervalo } & \multicolumn{2}{|c|}{ Porcentagem acima } & Resultado \\
\cline { 2 - 6 } 1984 & PEC $(\mathrm{mm})$ & Qtd $\mathrm{E}>$ limite & Qtd N >limite & $\% \mathrm{E}$ & $\% \mathrm{~N}$ & Atende ? \\
\hline $\mathrm{A}$ & 0,5 & 8 & 40 & 12,12 & 60,61 & Não \\
\hline $\mathrm{B}$ & 0,8 & 2 & 15 & 3,03 & 22,73 & Não \\
\hline $\mathrm{C}$ & 1 & 0 & 8 & 0 & 12,12 & Não \\
\hline
\end{tabular}

Tabela 21: Valores de PEC calculados

Conforme apresentado na tabela 21 os valores da ordenada N são superiores ao limite tolerável do PEC, ou seja, não foi possível atender o PEC em nenhuma das classes, para escala 1:25.000. Da mesma forma foram calculados os valores para o Erro Padrão, apresentados na tabela 22. Nesta os erros para o teste $\chi^{2}$ são maiores quando comparados aos calculados como limites das classes, desta forma os resultado corrobora o apresentado na tabela 21 no não atendimento a nenhuma classe planimétrica para o PEC na mesma escala $(1: 25.000)$. 


\begin{tabular}{l|c|c|c|c|c|c}
\hline Classe & Limite 1:25.000 & \multirow{2}{*}{$\sigma \mathrm{X}$} & \multicolumn{2}{|c|}{ Teste $\chi^{2}$ com 90\% de confiança } & Resultado \\
\cline { 4 - 5 } 1984 & $\mathrm{EP}(\mathrm{mm})$ & & $\chi^{2}$ E calc. & $\chi^{2} \mathrm{~N}$ calc. & $\chi_{65 ; 10 \%}^{2}$ tab. & Atende ? \\
\hline $\mathrm{A}$ & 0,3 & 0,21 & 150,33 & 754,91 & & Não \\
\hline $\mathrm{B}$ & 0,5 & 0,35 & 54,12 & 271,77 & \multirow{2}{*}{79,97} & Não \\
\hline $\mathrm{C}$ & 0,6 & 0,42 & 37,58 & 188,73 & & Não \\
\hline
\end{tabular}

Tabela 22: Valores de Erro Padrão (EP) calculados

Para a avaliação das medidas de coordenadas altimétricas, ainda conforme a normativa brasileira, os valores devem ser analisados utilizando a equidistância, em metros, no dado em questão no valor de 20 metros, neste caso $1 / 3 * 20 \mathrm{~m}=6,7 \mathrm{~m}$. As observações já coletadas (item 6.3.1.2 nas quais calculadas: as discrepâncias entre a referência e carta topográfica. O detalhe de cada diferença das coordenadas altimétricas também pode ser consultado no Apêndice F página 199 (tabela 31). Estas ainda necessitam de uma conversão planimétrica para que as coordenadas comparadas tivessem o mesmo sistema de referência planimétrico, isso garantiu a melhor proximidade possível ao ponto em relação as ordenadas E e N para coleta de altitude e posterior comparação. Da mesma forma como apresentado para o cálculo planimétrico, a tabela 23 apresenta os valores de PEC calculado a partir das diferenças encontradas.

\begin{tabular}{l|c|c|c|c}
\hline Classe & Limite eq 20m & Valores acima & Porcentagem acima & $\begin{array}{c}\text { Resultado } \\
\text { Atende ? }\end{array}$ \\
\cline { 2 - 5 } 1984 & PEC $(\mathrm{m})$ & Qtd H >limite & $\% \mathrm{H}$ & Não \\
\hline $\mathrm{A}$ & 10 & 14 & 20,59 & Sim \\
\hline $\mathrm{B}$ & 12 & 6 & 8,82 & Sim \\
\hline $\mathrm{C}$ & 15 & 2 & 2,94 & \\
\hline
\end{tabular}

Tabela 23: Valores calculados para o PEC altimétrico

Com os resultados apresentados na tabela 23 temos uma indicação inicial que em termos altimétricos o mapeamento seria classificado segundo a lei como classe B, pois tem-se erros menores que $10 \%$ nesta classe. Quanto ao erro padrão (EP), os valores deste são apresentado na tabela 24. Nesta análise observando os valores EP temos que o parâmetro foi atendido para a equidistância de 20 metros. 


\begin{tabular}{l|c|c|c|c|c}
\hline Classe & Limite eq 20m & $\sigma \mathrm{X}$ & \multicolumn{2}{|c|}{ Teste $\chi^{2}-90 \%$} & Resultado \\
\cline { 2 - 5 } 1984 & $\mathrm{EP}(\mathrm{m})$ & & $\chi^{2} \mathrm{H}$ calc. & $\chi_{67 ; 10 \%}^{2}$ tab. & Atende \\
\hline $\mathrm{A}$ & 6,67 & 4,72 & 153,67 & & Não \\
\hline $\mathrm{B}$ & 8 & 5,66 & 106,82 & 82,19 & Não \\
\hline $\mathrm{C}$ & 10 & 7,07 & 68,36 & & Sim \\
\hline
\end{tabular}

Tabela 24: Valores calculados para Erro Padrão (EP) altimétrico

Observando o resultado anterior tem-se que, em termos altimétricos, o mapeamento testado atende a classe $\mathrm{C}$ da referida lei. Temos que equidistância de 20 metros testada se refere a escala 1:50.000 na norma DSG (2016b). Com esta observação cabe se analisar este mapeamento com este parâmetro, porém ao se observar a lei de 1984! é clara em exigir a escala do mapa temos que esta não pode ser aplicada. É possível utilizar a norma da DSG (2016b pg. 4-12) para a análise de cartas topográficas, conforme exemplo da secção 4.2.1.2, porém como esta norma é mais exigente sendo assim não atenderia os parâmetros para escala 1:25.000 na planimetria e na altimetria.

\section{a) Análise posicional na escala 1:50.000}

Além da equidistância e os erros outra evidência que corrobora com a hipótese de este mapeamento já foi considerado para época de escala final 1:50.000. Esta evidência são inscrições encontradas escritas a mão, em algumas folhas, da coleção 1:25.000 conforme ilustra a figura 67.

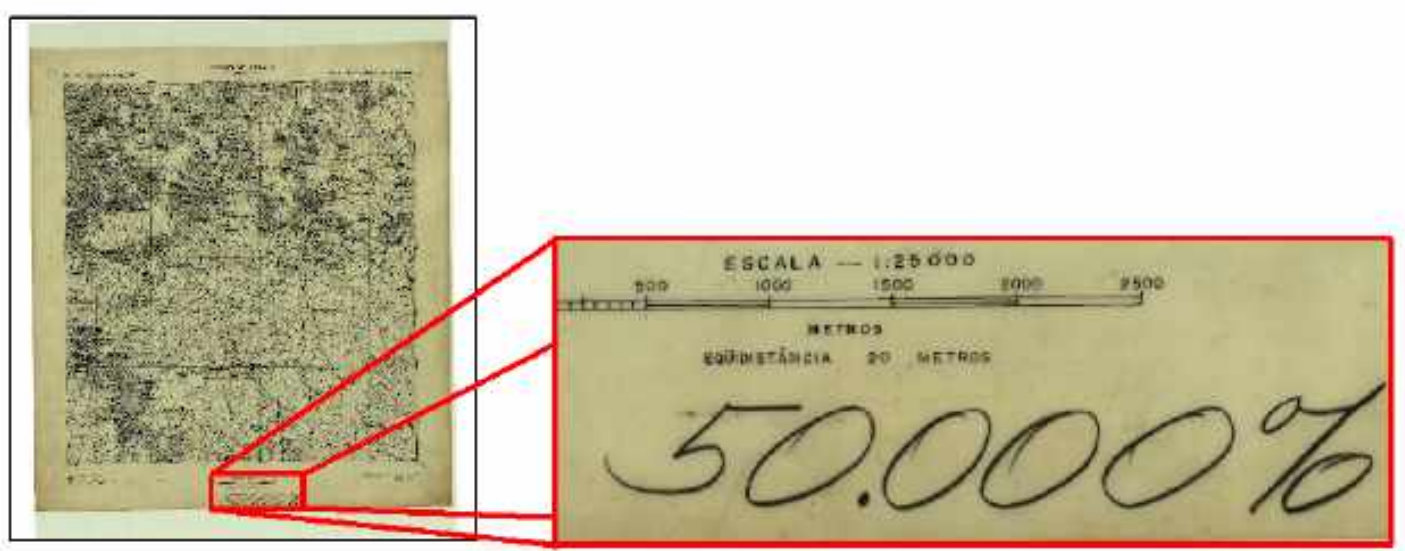

Figura 67: Anotação 50.000 na legenda da carta de escala 1:25.000

Fonte: Autor em compilação de dados do acervo IGCSP (2017)

\footnotetext{
${ }^{1}$ Conforme determina a legislação federal, mas especificamente o artigo 9 do decreto 89.817 de 20 de junho de 1984 (BRASIL, 1984).
} 
Embora estes fatos sejam somente hipóteses fato que todas as folhas 1:50.000 produzidas contem, ao menos em parte, muitos elementos representados que constam nas cartas 1:25.000, conforme visto no item 5.1.2.4. Estes elementos reforçam a hipótese das folhas 1:50.000 terem sido geradas a partir das restituições das folhas 1:25.000, ou seja, por algum APAGAR processo de redução (generalização).

Estes fatos permitem analisar, ao menos em hipótese, se em termos posicionais o mapa 1:25.000 atende a escala 1:50.000. Para isso foram aplicados testes posicionais planimétricos utilizando-se as mesmas observações do teste aplicado a escala 1:25.000 (tabela 20), porém com valores em milímetros calculados para a escala 1:50.000. Embora exista a imposição, descrita na norma, que vincula a escala do produto (carta topográfica 1:25.000) ao cálculo do PEC. Neste teste, a título experimental, aplicou-se a transformação em milímetros utilizando o fator de escala 1:50.000. Os resultados estão presentes na tabela 25, os valores apresentados, pelo menos em hipótese, atenderiam ao PEC para escala 1:50.000 para a Classe B na planimetria.

\begin{tabular}{l|c|c|c|c|c|c}
\hline \multirow{2}{*}{$\begin{array}{l}\text { Classe } \\
1984\end{array}$} & Limite 1:50.000 & \multicolumn{2}{|c|}{ Valores acima do intervalo } & \multicolumn{2}{|c|}{ Porcentagem acima } & Resultado \\
\cline { 2 - 7 } & PEC $(\mathrm{mm})$ & Qtd $\mathrm{E}>$ limite & Qtd N $>$ limite & $\% \mathrm{E}$ & $\% \mathrm{~N}$ & Atende ? \\
\hline $\mathrm{A}$ & 0,5 & 0 & 9 & 0 & 13,63 & Não \\
\hline $\mathrm{B}$ & 0,8 & 0 & 3 & 0 & 4,54 & Sim \\
\hline $\mathrm{C}$ & 1 & 0 & 0 & 0 & 0 & Sim \\
\hline
\end{tabular}

Tabela 25: Valores de PEC calculados

\subsubsection{Análise qualitativa}

Para classificar alguns parâmetros relativos e a fidelidade dos elementos representados nos mapeamentos serão analisadas as quantidades de feições encontradas e os atributos dos topônimos. A linhagem, a técnica e a origem produtiva que já foram apresentados em tópicos anteriores.

\subsubsection{Análise da escala de voo}

Com o objetivo de calcular a escala de uma fotografia, de modo a verificar a escala do voo, realizou-se uma medida direta da distância de feição na fotografia que foi comparada com uma medida no terreno. Tendo medido uma distância sobre a fotografia 09240 do bloco 7 (1962), pertencente a área C do mapeamento 1:25.000 (1969) (ver figura 40), a mesma foi medida também na ortofoto, disponível no site geoportal IGCSP (2019), 
conforme pode ser observado na figura 68 .
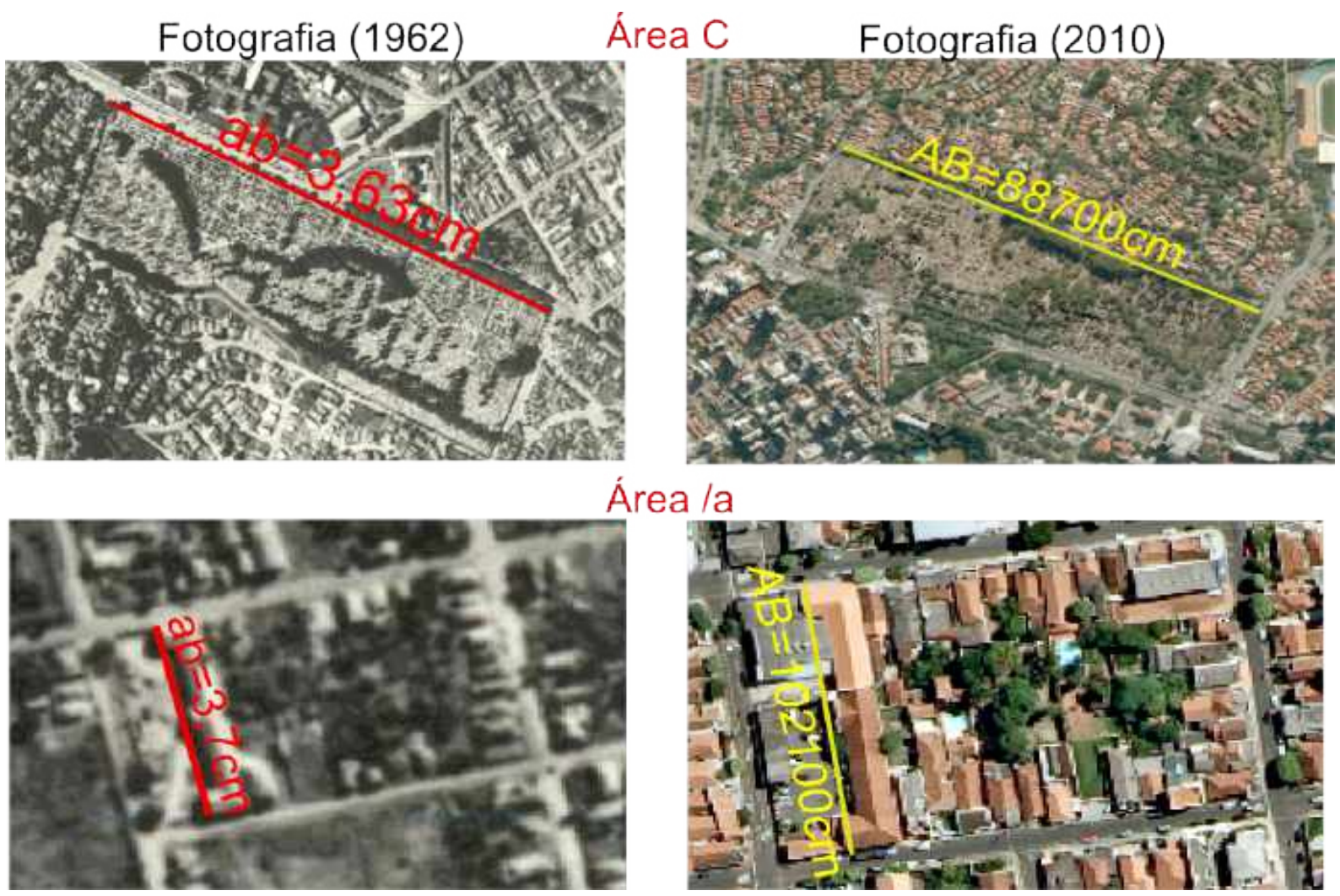

Figura 68: Feições medidas em fotografias de 1961 (esq. p/b) e 2010 (dir. col.)

Para analisar a escala (E) destas fotografias foram utilizados os valores de distância coletados em locais imutáveis, conforme descrito por Jensen e Epiphanio (2011, p. 157), nas áreas $\mathrm{C}$ e $\mathrm{A}$ do mapeamento e em ortofotos (fotografias aéreas com correção do relevo). As feições correspondentes foram apresentadas na figura 68, já os cálculos de escala (proporção) são vistos na expressão 6.1.

$$
\begin{gathered}
E_{\text {area } \mathrm{C}}=\frac{a b}{A B}=\frac{3,61 \mathrm{~cm}}{88700,00 \mathrm{~cm}} \approx \frac{1}{25.000} \\
E_{\text {area A }}=\frac{a b}{A B}=\frac{3,7 \mathrm{~cm}}{102100,00 \mathrm{~cm}} \approx \frac{1}{27.000}
\end{gathered}
$$

\subsubsection{Análise de sobreposições aerofotográficas}

Para garantir a sobreposição de $60 \%$ segundo Fairchild (1927b) as câmeras da marca Fairchild utilizadas no voo deste mapeamento já continham medidores de intervalo, porém este depende da velocidade de voo ser constante. Como descrito na secção 2.3.1 esta sobreposição garante uma maior área para a correta restituição sem dificuldades para visão tridimensional e coleta das feições. Adicionalmente foram analisadas as amostras 
aerofotográficas de todos os blocos dos mapeamentos (blocos 1, 2 e 7), e foram encontrados os valores mostrados na tabela 26 .

\begin{tabular}{c|c|c}
\hline Bloco & Média de sobreposição & Qtd \\
\hline 7 & $54,3 \%$ & 30 \\
\hline 1 & $59,2 \%$ & 30 \\
\hline 2 & $52,7 \%$ & 30 \\
\hline
\end{tabular}

Tabela 26: Análise de sobreposição das aerofotografias

Os valores apresentados na tabela 26 mostram que a sobreposição foi, em geral, mais próxima de $50 \%$, o que se considera como o mínimo teórico de sobreposição.

\subsubsection{Análise de completude de feições (integridade)}

Utilizando as medidas estatísticas, abordadas na teoria (item 4.2.2), foram contabilizadas a completude das feições de quadras presentes nas folhas 1:25.000 (SF-23-Y-CVI-1-SO e SF-23-Y-C-VI-1-NO). Depois observando a fotografia aérea de 1962, que foi utilizada durante a restituição para a elaboração destas folhas, e comparando com locais identificados nas folhas topográficas, verificou-se quais quadras não haviam sido coletadas (omissões) ou que foram feitas incorretamente (comissões). Os valores foram calculados de acordo com a expressão 4.44 e os resultados são mostrados na tabela 27.

\begin{tabular}{l|c|c}
\hline Escala & \multicolumn{2}{|c}{$\mathbf{1 : 2 5 . 0 0 0}$} \\
\hline Folha & SF-23-Y-C-VI-1-SO & SF-23-Y-C-VI-1-NO \\
\hline$N^{0}$ & 6186 & 2205 \\
\hline$N^{+}$ & 484 & 191 \\
\hline$N^{-}$ & 191 & 501 \\
\hline$N$ & 6479 & 1895 \\
\hline Porc.Erro & $+4,73 \%$ & $-14,05 \%$ \\
\hline
\end{tabular}

Tabela 27: Comissões e omissões de quadras das folhas analisadas

Nos valores apresentados na tabela 27 notasse diversas omissões e comissões na representação das feições de quadra. Isso denota uma completitude ruim considerando a escala 1:25.000, principalmente com omissões contabilizadas em 14\%.

Quanto à completude de topônimos não foram encontrados documentos cartográficos com escala de maior detalhe que pudesse ser tomado como referência para estas nomencla- 
turas. Além disso, não foram encontrados topônimos em grande parte das cartas 1:25.000, isso demonstra que estes topônimos poderiam ter sido inseridos em outra fase do projeto, o que se supõem que pelo fato da não finalização destas cartas.

\subsubsection{Análise de legenda e topônimos (atributos)}

Durante a análise dos mapeamentos foi verificada a existência de legendas somente nas cartas de escala 1:50.000. Não se tem informação sobre a ausência das mesmas nas cartas topográficas 1:25.000 ou se foram produzidas com a intenção de não as conter. Em comparação com cartas produzidas pela USGS nos Estados Unidos em escala compatível (1:24.000) estas não possuem legenda agregada a carta, mais sim uma documentação a parte com tal informação, o que poderia, ao menos em tese, ser aplicado as cartas 1:25.000 do IGGSP mas não foi encontrado documento à parte com essa informação. Sobre a legenda encontrada nas cartas produzidas pelo IGGSP (1:50.000) a partir de 1964, quando comparadas com as de mesma escala elaboradas pelo Exército Brasileird 1 na região de limite com Argentina (1950), notou-se que não dispunham dos mesmos símbolos de representação em suas legendas. Ao procurar outras fontes que contivessem alguma semelhança na simbologia, estas foram encontradas em cartas produzidas pela Força Aérea Real Canadense, como parte de um levantamento executado em 1931. As cartas produzidas a partir desse levantamento foram elaboradas em 1939 pelo Departamento de Minas e Recursos DMR, do Canadá, em escala 1:63.360². Estes símbolos foram normatizados para escalas 1:50.000 pela Army Map Services - AMS na década de 1950 (ARMY, 1952).

Aos elementos da legenda do produto cartografado pelo Exército tem como interesse fornecer aos usuários elementos práticos com enfoque nas aplicações militares. Como exemplo, temos em suas legendas feições hidrográficas onde que registram símbolos para a passagem sobre estes rios, sistemas viários detalhando tipos de caminhos especificando se nestes seria possível passagem de veículo ou somente caminhando ${ }^{3}$, Quanto ao mapeamento de escala 1:25.000, embora tenha sido produzido aparentemente para fins civis, tem alguns elementos militares (quarteis) que foram assinalados para serem removidos como observado na carta de Carapicuíba - SP, figura 69.

\footnotetext{
${ }^{1}$ Cartas encontradas no acervo da biblioteca Mário de Andrade - SP.

${ }^{2}$ Arquivos disponíveis para download no acervo do site da Universidade de Ontário (Canadá) https://ocul.on.ca/topomaps/maps/map04/.

${ }^{3}$ Ressalta-se que estes detalhes de legenda foram encontrados nas cartas produzidas pelo Exército nos limítrofes entre o Brasil e a Argentina.
} 


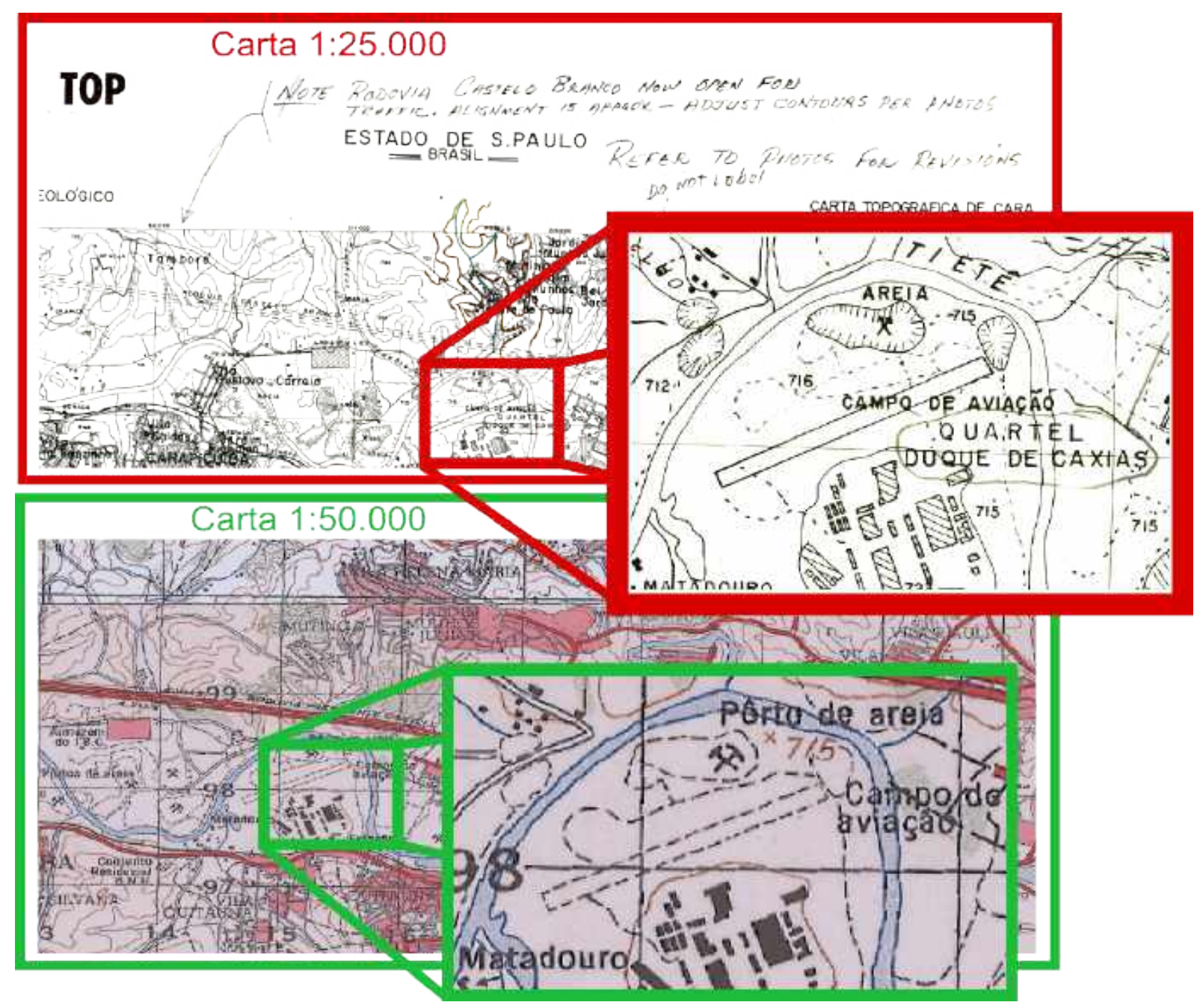

Figura 69: Notas feitas na carta 1:25.000 e omitidas nas 1:50.000

Fonte: Autor em compilação dos dados do IGCSP (2017)

Existem outros elementos ilustrados, como o ilustrado na figura 69. A existência destes demonstra alguma preocupação com a edição posterior da matriz restituída. A omissão destes elementos nas cartas de escala 1:50.000 do IGG, conforme ilustra a mesma figura, indica que questões ligados a defesa também estavam sendo consideradas. Como estas informações eram repassadas, para serem impressas (conforme abordado na secção 5.1.2.4, pelo Exército norte-americano demonstra o alinhamento dos atores envolvidos na produção deste mapeamento. Outros detalhes sobre a atuação do Exército americano em levantamentos aerofotogramétricos, executados em território nacional/paulista, podem ser consultados no apêndice-secção C.1.1. 


\section{CONCLUSÕES}

Para concluir este trabalho apresenta-se proposta de metologia para análise de qualidade em mapeamentos antigos. Como aplicação prática desta metodologia discuti-se seu resultado nas cartas topográficas analisadas. Além disso, são apresentadas considerações sobre a importância deste e outros trabalhos cartográficos, executados pelo IGGSP. Por fim, são apresentadas algumas sugestões com vista a trabalhos futuros.

\section{a) Proposta metodológica avaliação e sua aplicação nos mapeamentos estu- dados}

Apresentam-se como critérios a serem levantados, em uma análise de série cartográfica, o levantamento de suas características técnicas, conforme os itens listados a seguir:

- História da Instituição que o produziu e a produção propriamente dita, época e contexto tecnológico. É importante não julgar com rigor indevido, através da utilização de critérios atuais;

- Os métodos de levantamento de campo (triangulação, astronomia de posição, ...) e técnicas de gabinete (aerofotogrametria da época; etc);

- Os parâmetros cartográficos utilizados para a avaliação da produção final, dos quais destacam-se:

- Datum: esferóide ou elipsóide e outros parâmetros, exemplo: sistema de projeção (Policônica, UTM, ...);

- Processo de aferição da qualidade geométrica: escolha de referência de coordenada para comparação com maior acurácia (coletado em campo ou mapeamento de maior detalhe); compatibilização de sistemas (e escolha da transformação a ser empregada e sua verificação), escolha e coleta de pontos homólogos, cálculo das diferenças e análises estatísticas (erros grosseiros, curtose, 
assimetria, teste de tendência e precisão), escolha de normas (parâmetros de comparação);

- Avaliação de outros itens de qualidade (completeza, linhagem, topônimos, legenda, etc.).

A partir da utilização da metodologia descrita é possível classificar melhor os itens de qualidade e, além isso, descrever melhor as características técnicas do levantamento. Isso beneficia a descrição dos metadados, do produto analisado, de forma que contenham informações relevantes aos utilizadores destes produtos.

Especificamente sobre as análises posicionais e qualitativas, do mapeamento 1:25.000 produzido pelo IGGSP, foram analisadas as referências geodésicas utilizadas, e para a comparação com base mais precisa, foram estudas as formas de transformação entre coordenadas de diferentes sistemas (conforme abordado na secção 6.1). Esta análise auxiliou na utilização dos métodos de transformação e, ao compará-los, foi possível definir que o método mais adequado é o que utiliza o Grid NTv2 do ProGrid. Ou seja, levando-se em consideração a escala e os pontos de controle, disponíveis este experimento, e ao utilizar a transformação do ProGrid esta apresentou resultado mais acurado quando comparado aos obtidos a partir das outras metodologias testadas.

A partir da comparação de coordenadas entre pontos homólogos e outras observações foram efetuados testes posicionais e qualitativos. Os testes posicionais, descritos na secção 6.3. foram realizados a partir de base mais acurada e precisa, ortomoisaicos produzidas pelo IGCSP do voo de 2010 (IGCSP, 2019). Cabe ressaltar que a grande diferença temporal, entre a base mais acurada e os mapas topográficos analisados dificultou, mas não impossibilitou, a identificação de pontos homólogos. Assim a partir das coordenadas destes pontos foi possível utilizar a transformação do ProGrid, desta forma os valores foram unificados em um único sistema. Por fim, utilizou-se estes valores onde foram efetuados calculos de discrepâncias entre estas das coordenadas, a fins de se realizar um teste de análise posicional.

Sobre a análise posicional das feições restituídas, no mapeamentos do IGGSP, estas foram passíveis de serem testadas. Embora deva-se considerar que foram encontrados erros, entende-se que fatores como as limitações tecnológicas da época e a falta de pessoal por parte do Instituto (mais detalhes no Apêndice A item A.2 tiveram grande influência. Apesar disso, os resultados foram considerados qualitativamente aceitáveis. Quanto a classificação das análises posicionais, realizadas sobre nos mapas de escala 1:25.000, conclui-se que os valores de erros encontrados, apresentados na secção 6.3.1, ilustram que parte dos 
produtos publicados, utilizado parâmetros estipulados posteriormente $\bigsqcup^{1}$ não atendem classes de qualidade para escala 1:25.000. Porém, os resultados são compatíveis com a classe de qualidade C para a escala 1:50.000 do Padrão de Exatidão Cartográfico (BRASIL, 1984). Deve-se atentar que, além dos mapeamentos, existem ainda outros trabalhos positivos que devem ser considerados, tais como: a rede de nivelamento do IGGSP, fotografias aéreas, levantamentos para mapas municipais e uso pioneiro dos medidores eletrônicos de distância.

Acredita-se que motivo do mapeamento de escala 1:25.000 não ser classificado como aceitável, para os padrões normativos do PEC, pode ter sido ocasionado por diversos fatores. Mas o principal estaria relacionado com a escala de voo, que deveria ter sido escolhida uma escala maior (de maior detalhe), conforme abordado na secção 5.1.2.4. Isso poderia, ao menos em tese ajudar, pois, conforme descrito na secção 5.1.2.3, as fotografias utilizadas durante este trabalho estão, em alguns casos, desfocadas por motivos não determinados, assim este fator pode ter levado aos resultados encontrados. Desta forma, conclui-se que esse foi o principal fator que ocasionou uma menor qualidade posicional destas folhas, o que poderia, ao menos em tese, explicar a não finalização das folhas topográficas na escala 1:25.000 e pela escolha da produção das folhas na escala 1:50.000.

Quanto ao resultado geral obtido na aplicação da análise metodológica, aplicada sobre os mapeamentos do IGGSP, apesar de terem ocorrido dificuldades, como a localização de pontos homólogos, devida a grande diferença temporal, e o não de acesso a algumas fontes, como documentos da empresa VASP. Mesmo assim, todas as verificações foram executadas, dentro das limitações descritas, e desta forma constatou-se que a aplicação da metodologia se mostrou satisfatória.

\section{b) Importância da produção cartográfica do IGGSP}

Os primeiros estudos e mapeamentos efetuados pela CGGSP mostraram importantes resultados para o conhecimento do território paulista. Em continuidade a estes trabalhos o IGGSP trabalhou desenvolvendo diversas campanhas de mapeamento, as quais implicaram em consideráveis investimentos governamentais. Neste sentido o presente estudo apresentou o IGGSP, desde sua criação até o fim de suas atividades, com foco em sua produção cartográfica. Sobre esta mostrou-se especificamente a atuação do IGGSP nos mapeamentos de escala 1:25.000 (produzidos na década de 1970) nos quais o instituto

\footnotetext{
${ }^{1}$ Os valores de PEC foram definidos 20 anos depois da execução do mapeamento pelo decreto ${ }^{o}$ 89.817 (BRASIL, 1984).
} 
participou de forma direta como executor e fiscalizador de processos contratados.

Os mapas e os levantamentos topográficos produzidos pelo IGGSP foram subsídios para diversos trabalhos técnicos, as vezes internos do próprio Instituto como a elaboração de mapas municipais e as vezes externos, como a utilização de cartas topográficas na área de meio ambiente (ROSSETTO, 1969; CASTRO et al., 2003; SILVA et al., 2006). Além dos mapeamentos, as fotografias, principalmente do voo de 1962, foram ferramentas utilizadas por diversos trabalhos científico, dos quais pode-se citar: geomorfológicos (CARNEIRO; SOUZA, 2003; ORTIZ; FREITAS, 2005; NASCIMENTO JÚNIOR et al., 2008, PINHEIRO, 2009, SOUZA; OLIVEIRA, 2012), hidrográficos (TESSLER; FURTADO, 1983: SOUZA et al. 2009, SANTOS; FURLAN, 2010), questões ambientais (SOUZA; LUNA, 2010; RIBEIRO et al., 2013), dentre outros. Isso mostra a importância desses produtos cartográficos.

Os investimentos governamentais, mais especificamente do Estado de São Paulo, foram considerados importantes para a elaboração dos produtos cartográficos até meados da década de 70. Porém, a descontinuidade na formação de recursos humanos e o aproveitamento de conhecimento desenvolvido pelos técnicos do IGGSP no quesito cartográfico levou a decadência da instituição; para se ter uma ideia, somente um técnico foi reconhecido pelo governo, em 1982, como sendo um pesquisador nesta área, o engenheiro Adhemar Colucci ${ }^{1}$, e isso somente depois de um pedido feito por um grupo de engenheiros agrimensores $\mathrm{S}^{2}$ informando a importância dos trabalhos realizados no campo do nivelamento do Estado (ver tópico 3.2.1.1 na página 62).

Com o fim do IGGSP (1974) criou-se a Divisão de Geografia da Secretaria de Planejamento que ficou encarregada de elaborar parte dos trabalhos (entre 1974 e 1979), sendo que estes atualmente são executados pela Divisão Administrativa e Territorial (D.A.T.) do IGCSP (a partir de 1979), oriunda da "divisão de assuntos geográficos" do IGGSP sendo esta que se sobressaiu em relação às demais. Porém quando se observa o gráfico de produção técnico e cientifica do IGGSP, abordados no item 2.1.1.1, vê-se a importância dos lentamentos topográficos e posteriormente dos levantamentos fotogramétricos para a elaboração dos mapas que viriam estabelecer limites territoriais. A aparente importância política e econômica da empresa VASP aerofotogrametria fez com que o Estado de São Paulo apoiasse fortemente a empresa, com sua estatização e fortalecendo-a em relação a outras concorrentes dando mais tarde origem a Terra Fotg ${ }^{3}$.

\footnotetext{
${ }^{1}$ Publicado no Diário Oficial do Estado o decreto $\mathrm{n}^{\circ} 19.718,20$ de outubro de 1982 que aposenta como pesquisador o engenheiro Adhemar Colucci (SÄO PAULO (Estado), 1982).

${ }^{2}$ Documento solicitando reconhecimento de Adhemar Colucci como pesquisador - Acervo MUGEO.

${ }^{3}$ Decreto n. 8.451, de 1 de setembro de 1976 (São Paulo,SP)
} 


\section{c) Recomendações e trabalhos futuros}

No levantamento inicial dos mapas de escala 1:100.000 descobriu-se que diversos deles não foram finalizados pelo IGGSP, e procuramos saber se as cadernetas de campo foram utilizadas em trabalhos executados entre os anos de 1940 e 1960, porém não foram localizadas mais informações sobre o tema. Numa consulta feita ao arquivo do Estado, que ficou responsável por armazenar tais documentos, houve a informação de que o Acervo correspondente se encontra em processo de restauração. Um trabalho importante seria este levantamento, pois pode-se encontrar indicações importantes nestes documentos, como os estudos feitos em mapas mais antigos (CINTRA; SILVA, 2001; SANTOS; CARLOS, 2017).

Seria importante continuar avaliando o Progrid principalmente em mapeamentos de escalas maiores (de maior detalhe) e em outras áreas, pois acredita-se que seu desempenho pode ser diferente e talvez pior que outros métodos ou uma confirmação de ser o melhor método.

Ademais são convenientes estudos focados em mapas produzidos para a elaboração de limites de municípios, conhecidos como mapas municipais, bem como suas descrições em forma de lei sendo estas utilizando elementos geográficos e sua comparação novas técnicas (FURTADO, 2007; MACEDO et al., 2013, BORGES, 2014).

Os mapas produzidos pelo Instituto ainda são os únicos, até hoje, disponíveis em escala 1:50.000 na região noroeste paulista sendo que estes mapas foram pioneiros no sentido de serem produzidos, de forma sistemática, por órgão estadual no Brasil. Porém parte destes, os produzidos na região leste paulista, foram sobrepostos por mapeamentos feitos pelo IBGE, alguns com somente 10 anos de diferença, por exemplo o caso da folha SF-23-Y-D-IV-3. Este fato poderia ser estudado, inclusive se existiu ou não alguma comunicação entre as instituições. Ainda sobre a relação entre o IBGE e o IGGSP notase a participação do engenheiro e então diretor do Instituto (Valdemar Lèfreve) na CNG (entre 1940 e 1970). Seria interessante saber se existiu alguma troca de experiências entre estas duas instituições, e em que consistiu.

Sobre as folhas de escala 1:50.000, de responsabilidade do IBGE, são muito utilizadas por contemplar diversas regiões do Brasil, inclusive no território paulista, ainda que necessitam de verificações quanto à sua qualidade, de forma a beneficiar os usuários que muitas vezes a utilizam por serem de fácil acesso e disponibilizadas gratuitamente no site do IBGE. Quanto ao material cartográfico do Exército, que embora tenha um portal pró- 
prio, não foram encontradas as cartas mencionadas no presente trabalho. Mesmo depois de efetuar o cadastro de usuário e contatos por e-mail, em seu geoportal, não houve disponibilização em meio digital. Porém estes podem ser, em parte, encontrados no acervo, em papel, da biblioteca Mário de Andrade, em São Paulo-SP. Conforme se destacou na comparação das legendas das cartas topográficas do IGGSP e outras cartas (seção 6.3.2.4) um estudo interessante seria aquele voltado aos níveis (itens da legenda) cartografados: acredita-se que o foco de produção da carta topográfica produzida pela DSG mostrouse, por meio de sua legenda (conforme abordado na secção 6.3.2.4), ser produzido para aplicações militares. Quanto às cartas produzidas pelo IGGSP estas teriam caráter mais civil para levantamento de recursos naturais e outras aplicações. Considera-se importante desenvolver estudos que verifiquem quais os fundamentos e características que levaram à elaboração de determinadas cartas topográficas e os compare com as aplicações mais usuais destes documentos. Isso tanto posicionalmente quanto qualitativamente, pois tais fatores podem influenciar nos resultados encontrados durante a utilização destes produtos cartográficos.

Personalidades importantes para a área da cartografia foram encontradas neste trabalho, dais quais se destacam: Nestor Natividade e Zilda de Almeida Sampaio, dentre outros. Estudos que se aprofundassem melhor a bibliografia destes personagens seriam importantes, como os elaborados para Theodoro Sampaio e João Pedro de Cardoso COSTA, 2003: LUCIO, 2014).

É importante ressaltar que, embora se tenha avançado muito no entendimento da questão cartográfica presente no IGGSP, muitos documentos e relatórios foram perdidos o que, de certa forma, dificultou a análise de alguns pontos como por exemplo questões relacionadas à VASP. Esforços adicionais, como consulta aos acervos: do Estado no Arquivo Público, da Fazenda e de prefeituras permitiriam reconstruir alguns acontecimentos ocorridos ainda não estudados, como por exemplo mapeamentos municipais. 


\section{APÊNDICE A - HISTÓRIA DO IGGSP E DE SUA PREDECESSORA, A CGGSP}

Em se tratando das ciências cartográficas pode-se dizer que a CGGSP produziu muito através de diversas cartas e explorações de rios. A figura 70 que mostra o oeste do território paulista, reforçando a ideia de terrenos despovoados (IGCSP, 2017). Quanto a outras regiões, consideradas mais desenvolvidas do Estado, estas foram mapeadas em escala 1:100.000, resultando no mapeamento que seria usado até a década de 1970 (CINTRA; SILVA, 2002).

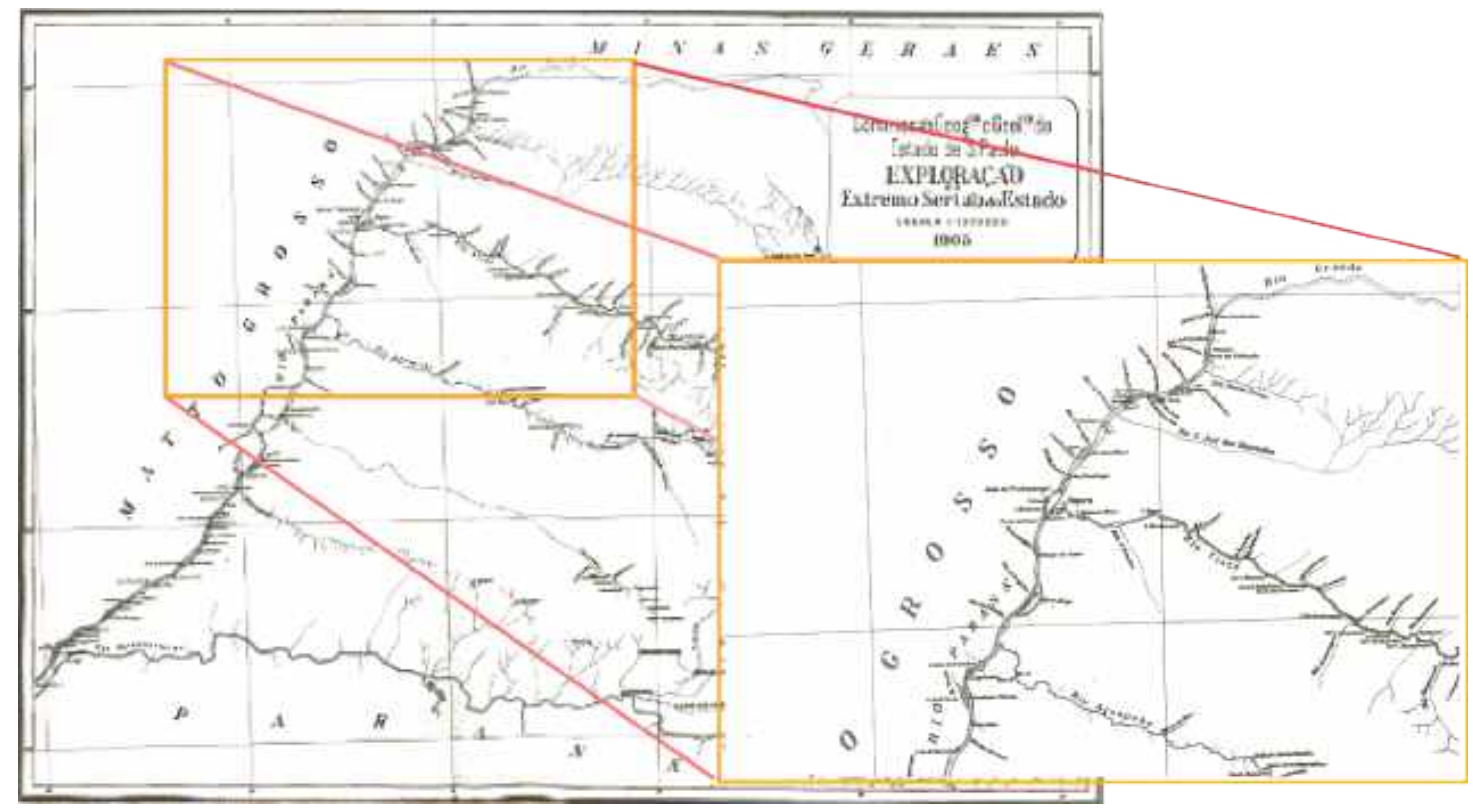

Figura 70: Exploração CGGSP - Rio do Peixe São Paulo (1905)

Fonte: Acervo IGCSP (2017)

Durante a sua existência, a CGGSP produziu farto material, contabilizado por Moi et al. (2005, p.48-49) como sendo: 33 relatórios, 22 boletins, 70 mapas e cartas, 30 fitas 
cinematográficas (desaparecidas), cerca de 1.200 fotografias, além de documentação administrativa e científica. A comissão teve dois diretores: Orville Adalbert Derby (1886-1905) e João Pedro de Cardoso (1905-1931). A administração de Derby foi criticada por Carlos Botelho, então secretário da agricultura, quando advoga pela conveniência de parar os levantamentos da zona povoada (estudos realizados pelo então diretor) e iniciar-se a exploração do sertã Ṭ $^{1}$ isso significou a saída de Derby e a reorientação dos trabalhos da CGGSP. O relatório do ano seguinte (1905), denota a mudança já pelo título "Comissão Exploradora do Extremo Sertão Paulista" FIGUEIRÔA, 1987, p. 71). Sob a direção de Cardoso os trabalhos técnicos voltaram-se ao campo da geodésia visando uma rápida resposta às demandas cartográficas. Como descreve Lucio (2014):

O material publicado pela CGGSP, sobre as pesquisas geológicas e sobre as ciências naturais (botânica, zoologia) ultrapassam em quantidade o material sobre os levantamentos topográficos e contribuem para embasar a hipótese de que Derby imprimiu uma feição de pesquisa voltada, em primeiro lugar, para o conhecimento científico teórico, ao invés de orientar esse conhecimento às aplicações de caráter prático tão demandadas por interesses de fazendeiros e empresários [...] (LUCIO, 2014).

Em termos políticos logo após assumir (1905), Cardoso responde ao apoio a ele concedido e envia, durante a sua direção, cerca de 30 ofícios à assembleia legislativa do Estado de São Paulo com cartas topográficas e relatórios e responde prontamente às requisições de descrições geográficas para a elaboração de divisas entre os municípios paulistas. Sendo estes últimos requisitados por meio da comissão legislativa de estatística, divisão civil e judiciária. Importante destacar que a execução e impressão deste material começou em 1911, e que o custo desses trabalhos foi possivelmente financiado pelos lucros obtidos no Programa de Valorização do Café iniciado em 1907 (CALDEIRA, 2017, p.573).

Mais adiante, após a gestão de João Pedro de Cardoso, em meados de 1935 a CGGSP teve as suas atribuições repassadas ao Departamento Geográfico e Geológico. Tais alterações introduzem profundas mudanças em pouco tempo, o que descaracterizou a Instituição(FIGUEIRÔA, 2008, p. 115-118). Essas mudanças constantes podem ser observadas pelos seguintes decretos estaduais produzidos após 1931, já na era Vargas:

- Decreto $n^{0} 5.153$ de 08/08/1931 - Transferência da CGGSP para a secretaria de Viação e Obras Públicas (SÃO PAULO (Estado), 1931a);

- Decreto n ${ }^{\circ} 5.161$ de 12/08/1931 - Absorção da CGGSP pela Inspetoria de Serviços Públicos, transformando-a em Diretoria de Serviços Públicos e da Carta Geral do

${ }^{1}$ enfatizando que a região já era conhecida e o sertão desconhecido 
Estado. Por esse decreto, extinguiu-se o cargo de Chefe da CGGSP, e os seus objetivos resumiam-se ao estudo para o aproveitamento das forças hidráulicas do Estado (SÃO PAULO (Estado), 1931b);

- Decreto n ${ }^{\circ} 5.174$ de 27/08/1931 - O Serviço de Apatita ficou subordinado à Secretaria da Agricultura, Indústria e Comércio (SÃO PAULO (Estado), 1931c);

- Decreto $\mathrm{n}^{\circ} 5.320$ de 30/12/1931 - Promulgado pelo interventor federal Coronel Manuel Rabelo, criou o Instituto Agronômico e Geográfico e incorporou parte da Diretoria de Serviços Públicos e da Carta Geral do Estado ao Serviço Meteorológico Estadual (SÃO PAULO (Estado), 1931d);

- Decreto $n^{\circ} 7.309$ de 05/07/1935 - Promulgado no governo de Armando Salles (eleito pela Assembleia Constituinte paulista) que decidiu extinguir o Instituto Agronômico e Geográfico, sendo incorporado em parte pelo Instituto Astronômico e Geofísico e em parte pelo Departamento Geográfico e Geológico - DGG, sendo que herdou o corpo técnico da extinta CGGSP (SÃO PAULO (Estado), 1935).

Por tudo isso, a CGGSP deixou de funcionar, na prática, em meados de 1932. Porém, só foi oficialmente extinta pela Lei $\mathrm{n}^{\circ} 12.621$ de 2007 que revoga a leis provinciais especificamente $\mathrm{n}^{\circ}$ 9, de 27 de março de 1886 (SÃO PAULO (Estado), 2007). Pode-se ressaltar que o fim do seu funcionamento ocorreu no governo Vargas, sendo uma represália a São Paulo, que se posicionava contra essa ditadura. Em qualquer caso, essa ação se acentuou após o período definido como Estado Novo (1937), que reorganizou o país de forma a centralizar diversas atribuições, por exemplo, demarcações territoriais e recenseamento. Durante este período também foi criada uma Instituição para garantir o atendimento deste objetivo, o Instituto Brasileiro de Geografia e Estatística - IBGE (MESQUITA; SANDES, 2014). Uma ramificação do IBGE que se encarregou de produzir as diretrizes da cartografia nacional foi o Conselho Nacional de Geografia (CNG), muito embora tinha como atribuição inicial somente o CENSO de 1940, tendo que ser modificado para atender à finalidade cartográfica (MATTOS, 1943).

\section{A.1 A criação e as atribuições do IGGSP}

O decreto estadual $n^{\circ}$ 9.871, de 28 de dezembro de 1938 modificou as atribuições e o nome do Departamento Geográfico e Geológico passando a se denominar Instituto Geográfico e Geológico (IGGSP) do Estado de São Paulo (SÃO PAULO (Estado), 1938b). 
Conforme publicações no Diário Oficial do Estado de São Pauld 11 os primeiros técnicos foram nomeados em janeiro de 1939 e seu primeiro diretor técnico foi o Geólogo Annibal Alves Bastos. Essa legislação descreve alguns serviços, a serem executados pelas seguintes divisões técnicas; com os respetivos técnicos nesse início:

- Divisão de Geodésia - Área responsável pelas definições de coordenadas geográficas e a implantação de marcos para o cálculo de triangulação. Engenheiros: Ludovico Taliberti (Chefe), Gastão Cesar Bierrenbach de Lima, Adhemar Colucci, Zilda Sampaio Perroni, José de Oliveira Quintão;

- Divisão de Topografia - Área responsável pelos levantamentos topográficos diversos, tais como: demarcação de divisas municipais e estaduais, levantamentos taqueométricos, confecção de mapas municipais. Engenheiros: Aristides Bueno (Chefe), Eduardo Bernardes de Oliveira (assistente);

- Divisão de Climatologia e Hidrografia - Área responsável por boletins meteorológicos, mapas pluviométricos e pela implementação e manutenção de estações meteorológicas. Engenheiros: Valdemar Lefèvre (Chefe), Silvano Wendel, Nestor Aratangy;

- Divisão de Geologia Geral e Econômica - Área responsável pela perfuração de poços, levantamentos geológicos, petrografia, análises de jazidas. Engenheiros: Estevam Aires Pinto (Chefe), Theodoro Knech, Plinio de Lima, Osmar Mesquita, Alfredo Borges, Jesuíno Felicíssimo Júnior, Newton da Costa Silveira, Cyro Alves Rocha. O Departamento Laboratorial dava subsídio a esta divisão para a análise de solos e rochas;

Com a publicação da lei que regulava a criação de municípios em $1932^{2}$ ao recém criado IGGSP foi atribuída a tarefa de elaborar, em conjunto com os municípios, os mapas municipais do Estado.

\section{A.1.1 Estrutura administrativa}

O organograma desta estrutura e a organização administrativa da Instituição, vigente até 1969, pode ser observada no Anexo A (pg 202). Outro relato sobre a estrutura é feito

${ }^{1}$ Publicação do dia 25 de janeiro de 1939 definindo atribuições do decreto $n^{o} 9.871$ (SÃO PAULO (Estado), 1938b).

${ }^{2}$ Decreto-lei $\mathrm{n}^{\circ} 311$ de 2 de março de 1938 (BRASIL, 1938) 
por documento internd ${ }^{1}$, editado entre as décadas de 50 e 60, descrevendo que o Instituto chegou a ter, somente em assuntos ligados a geodésia e topografia, cerca de 46 técnicos dentre engenheiros, auxiliares, desenhistas e fototécnicos. O documento original que apresenta a estrutura da organização e informações sobre junta deliberativa do IGGSP somente foi oficialmente publicada em 1967 (Anexo A, pg 207). Isso ocorreu, provavelmente, porque a Instituição passava por mais um processo de reestruturação.

\section{a) Trabalhos executados pelo Serviço de Geodésia}

A divisão de Geodésia foi incumbida da execução de levantamentos de triangulação geodésica, coordenadas geográficas e nivelamento de precisão. A determinação destes pontos de referência permitiram a execução de levantamentos topográficos secção de Serviços de Topografia do Instituto. Como exemplo, em parte destes trabalhos, conforme registro de documentos internos datados da década de 40 e 50, podem ser apresentados os seguintes:

- Determinação de coordenadas geográficas - Foram efetuados cálculos e observações de latitude através de observações de alturas zenitais em 399 localidades do território paulista (1939-58) conforme consta em parte no Boletim n ${ }^{o} 28$ do Lima e Colucci (1940) e continuado por registros internos do mesmo Instituto;

- Triangulação geodésica - Foram levantados 122 vértices (1939-57) utilizando bases calculadas astronomicamente (pontos de primeira ordem) pelo método Sterneck, como ilustrado pela caderneta de campo não preenchida da figura 71. Isso seguindo as normas definidas na II reunião pan-americana de consulta sobre geografia e cartografia (ARCHELA, 2007).

${ }^{1}$ IGGSP. Segunda reunião brasileira de consulta sobre cartografia. In: ACERVO INSTITUTO GEOLÓGICO (MUGEO). Curitiba - PR: Instituto Geográfico Geológico de São Paulo, 1959. p. 1-6. 


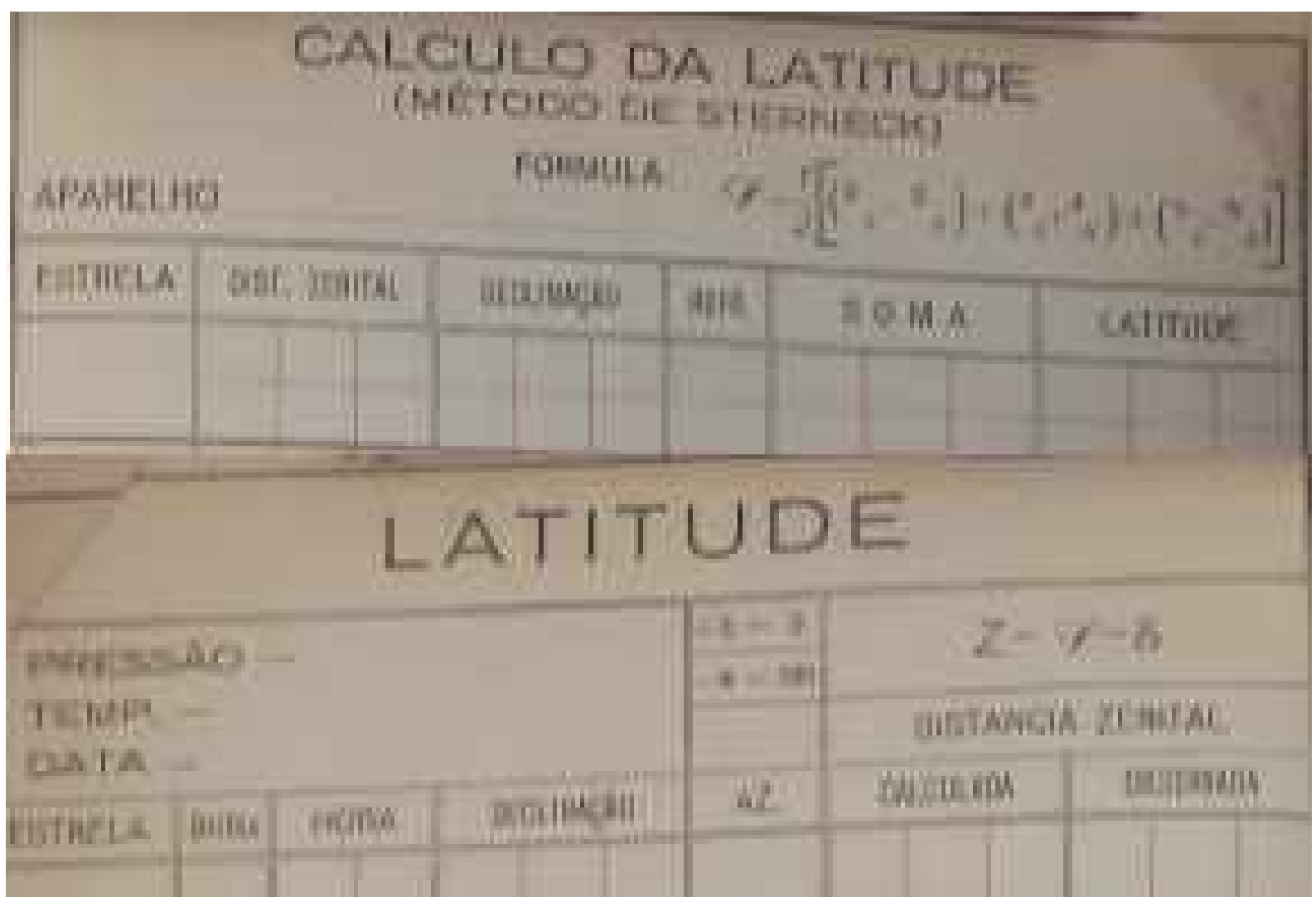

Figura 71: Caderneta de Campo com calculo de Latitude e Sterneck Fonte: Autor, foto tirada no MUGEO-IG

Já na década de 60 o Instituto adquiriu um telurômetro, ver figura 72 , que proporcionou maior rendimento no trabalho de medição de bases e distâncias, quando comparado com o método clássico de medir bases, propiciando assim uma simplificação operacional de levantamento geodésico (CARVALHO, 1983);

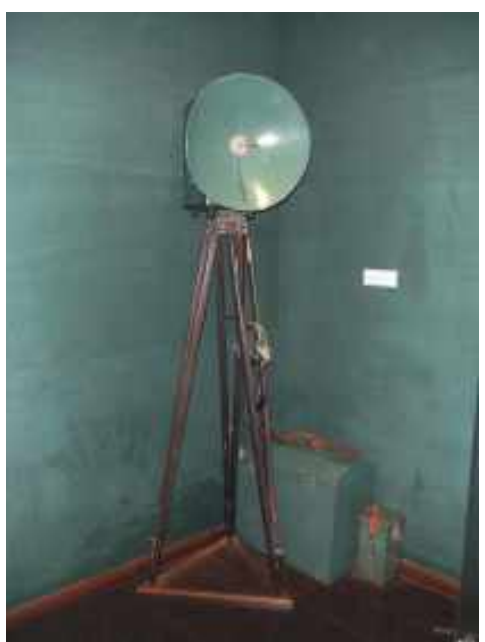

Figura 72: Telurômetro utilizado pelo IGGSP

Fonte: Autor, foto tirada no MUGEO-IG 
- Rede de nivelamento - Esta rede foi levantada no período de 1940-58, incluindo $8393 \mathrm{~km}$ de linhas, com cerca de 1660 marcos de referência de nível (RN's). Trabalhos para o Departamento de Águas e Esgoto de São Paulo também foram realizados. A rede paulista de nivelamento do IGGSP foi objeto de diversos estudos, que analisaram ou utilizaram pontos da mesma, dos quais podemos citar: Alencar (1968), Luz e Guimarães (2001), Arana (2005), Oliveira (2006).

\section{b) Trabalhos executados pelos Serviços de Topografia}

A Divisão de Serviços de Topografia do Instituto executou levantamentos topográficos para a elaboração de folhas topográficas de modo a, principalmente, representar divisas municipais e estaduais. Um exemplo disso é um documento interno, datado de 1944, que descreve o trabalho de demarcação das divisas de 305 municípios e 668 distritos. Sobre os levantamentos topográficos eram feitas coletas de nomes e feições, medindo-se ângulos (rumos/azimutes) e distâncias sobre caminhamentos e visadas em feições hidrográficas e relevo (por exemplo, espigões). Estas feições eram calculadas e depois desenhadas em escala, normalmente 1:20.000, e reduzidas a outras escalas como 1:50.000 e 1:100.000, técnica esta já empregada desde os tempos de Theodoro Sampaio (1886).

\section{c) Secção de estudos geográficos}

Esta seç̧ão não fazia parte da organização inicial do IGGSP e foi criada em janeiro de 1947. Nasceu da necessidade de organizar e informar sobre assuntos de cunho geográfico tendo como base as cartas topográficas produzidas pela CGGSP e por levantamentos topográficos feitos entre 1940 e 1942. Segundo documentos do Instituto esta secção foi responsável pela coordenação e organização de informações geográficas municipais e estaduais. Para isso, foram efetuados estudos sobre o relevo, uso e ocupação do solo do Estado de São Paulo, incluindo estudos pioneiros realizados pelo professor Pierre Monbeig da Universidade de São Paulo (MONBEIG et al., 1984). Isso, além de plantas de municípios, e outras de documentações cartográficas estaduaiș (ROCHA, 1947).

Teve como chefe desde a sua fundação até a sua aposentadoria (1966) a engenheira Zilda Sampaio Perroni a qual descreveu os trabalhos desempenhados, em entrevista da qual reproduzimos o trecho a seguir (FIGUEIRÔA et al., 1985).

[...]Depois, criaram a Secção de Estudos Geográficos. Foi em 1947 e

\footnotetext{
${ }^{1}$ Notícia publicada no Diário Oficial do Estado de São Paulo 16 de março de 1965
} 
eu fui designada para chefiá-la. Na chefia da Secção, correu tudo bem. Uma vez, para cuidar da revisão territorial, fizeram uma comissão. A comissão se reunia, mas não fazia nada. Até que depois de um tempo, alguém levantou e disse: "mas se uma das finalidades da Secção é esta também, porque nós temos que ficar... ela cuida sozinha." E olhe que não tínhamos mapa! Da primeira vez, ali do nortẹ do Estado de São Paulo não havia nada, nada. Mas meu pai havia trabalhado muito por lá e então, nas férias eu o ajudava. De forma que tinha este trabalho e podia tirar dali algum auxílio. Não com exatidão mas era alguma coisa e por aí foi feita a primeira revisão (1938). Tinha muito erro; mais tarde, com os levantamentos aéreos, dava para rever as divisas com mais exatidão, além dos dados oficiais: tudo o que saía publicado sobre divisas, recortávamos e púnhamos numa pasta. Era uma para cada município. Depois, marcávamos no mapa. Quando chegava a época de fazer a próxima revisão territorial, estava tudo pronto![...]

\section{A.1.2 Personalidades de destaque do IGGSP}

Neste tópico apresentam-se algumas personalidades importantes que fizeram parte do corpo de colaboradores do IGGSP, muitos deles ex-funcionários da CGGSP, e suas áreas de atuação:

- Valdemar Lefèvre - Formado em engenharia civil pela Escola Politécnica, sendo que na época não havia ainda a USP. Era natural de São Paulo, onde nasceu em 15 de julho de 1903. Foi transferido do antigo Departamento Geográfico e Geológico - DGG (onde era assistente) para o IGGSP como engenheiro chefe da Seção de Climatologia e Hidrografia, tendo assumido em 1939. Depois, com a saída do diretor Annibal Alves Bastos do IGGSP (1941) assumiu o cargo de chefia até sua aposentadoria (1967). Dentre outras atividades, foi membro da comissão de Limites São Paulo-Rio de Janeiro; membro do convênio celebrado em 1958 entre São Paulo e Minas Gerais para definições dos limites; membro do conselho Estadual de Águas e Energia Elétrica, membro da Seção Brasileira do Instituto Pan-americano de Geografia e História, consultor técnico do Diretório Regional de Geografia no Estado de São Paulo, diretor da revista técnica "O I.G.G.", membro da comissão de Limites São Paulo-Paraná e do Conselho de Política da Agricultura. Foi autor dos trabalhos "Instruções Meteorológicas"; "Súmula Referente ao Serviço Geográfico de São Paulo"; a "Sinopse climatológica", "Manual Bibliográfico da Geografia Paulista",

\footnotetext{
${ }^{1}$ Em depoimento Zilda de Sampaio Perroni conta que quando jovem foi moradora da Cidade de Araraquara e que seu pai o senhor Antônio de Sampaio Peixoto era engenheiro (ALTIMEYER, 2016, pg. 67).
} 
além de estudos e artigos publicados na revista técnica "O I.G.G.". Representou o Estado de São Paulo em diversos Congressos técnicos e culturais sobre Cartografia, Geografia e Geologia. Faleceu em São Paulo em 17 de julho de 1975 (PMSP, 2009).

- Gastão Cesar Bierrenbach de Lima - Engenheiro Civil nasceu em 1885; formou no Mackenzie College em 1910. Iniciou sua atuação como engenheiro na empresa The São Paulo Tramway, Light and Power Company. Transferiu-se em 1914 para o Departamento de Obras da Prefeitura de São Paulo onde trabalhou até 1919. Depois de trabalhar autonomamente, em 1926 entrou para a Comissão Geográfica e Geológica, sob a então direção de João Pedro Cardoso. Extinta a Comissão, foi transferido para o Departamento Geográfico e Geológico (DGG) e depois para o IGGSP, em 1938, onde desenvolveu diversos trabalhos de levantamentos topográficos no Estado de São Paulo, elaborando cerca de 20 artigos, na sua maioria na própria revista do IGGSP. Faleceu em São Paulo em 7 de fevereiro de 1968 (BASTOS, 1968).

- Sérgio Mezzalira - Geólogo e Paleontólogo, natural de Campinas-SP (1920), formado pela Universidade do Rio de Janeiro. Em maio de 1942, a convite de Paulo Erichsen de Oliveira, começou a trabalhar na Seção de Paleontologia da Divisão de Geologia e Mineralogia do Departamento Nacional de Produção Mineral. Foi admitido no então IGGSP, na época dirigido por Valdemar Lefèvre, em maio de 1946; desenvolveu pesquisas paleontológicas, levantamentos geológicos e hidrogeológicos. Na década de 1950 passou à categoria de pesquisador, o primeiro do IGGSP em tempo integral. A contribuição de Sérgio Mezzalira à Paleontologia e Geologia é muito grande, tendo publicado dezenas de trabalhos sobre os mais variados assuntos. Sua "Bibliografia Analítica da Paleontologia do Estado de São Paulo" é indispensável para todos aqueles que desejam estudar os fósseis do Estado. Faleceu, no dia 5 de junho de 2009 (GEOLÓGICO, 2009).

- Zilda de Sampaio Perroni - Arquiteta, Engenheira Civil e Bibliotecária, nascida em Portugal (1905). Sua formação deu-se na universidade Mackenzie. Formada em 1925 sendo aluna bolsista de arquitetura, inicia sua vida profissional dando aulas no Colégio Mackenzie; entrou para a função pública na Repartição de Águas do Estado como desenhista, na DGG (1933). Durante esse trabalho cursou engenharia e biblioteconomia e foi admitida como estagiaria de engenharia. Sendo efetivada como engenheira padrão em 1938, no IGGSP, trabalhou na Instituição por 32 anos até se aposentar em 1966. Faleceu no mês janeiro de 2000 em São Paulo ALTIMEYER, 2016). 


\section{A.1.3 Publicações Científicas de Cartografia do IGGSP}

Pode-se destacar como publicações do IGGSP, incluindo a CGGSP, diversos documentos: 6 notas prévias, 88 boletins, 20 revistas, 12 relatórios, 48 mapas, 1193 mapas municipais, carta dos excursionistas na escala 1:200.000, 20 cartas topográficas na escala 1:250.000, 74 cartas topográficas em escala 1:100.000, 80 cartas topográficas em escala 1:50.000, 262 cartas topográficas em escala 1:25.000 (não publicadas), 4 folhas (1:12.500), 11 folhas geológicas, 11 mapas gerais do Estado, 37 cartas gerais do Estado e 11 cartas diversas.

Dentro do material cartográfico a destacar estão alguns boletins e diversos mapas, mais especificamente as cartas topográficas sistemáticas, nas escalas: 1:250.000, 1:100.000, 1:50.000, 1:25.000 e alguns mapas na escala 1:12.500. Para documentar e disponibilizar parte das determinações de coordenadas há alguns boletins de importância, como os seguintes (PERIS, 1981, p.70):

- Boletim $\mathbf{n}^{o} 28$ - O boletim Coordenadas Geográficas e Geodésicas, publicado pelo Serviço de Geodesia do Instituto no ano de 1940, apresenta os resultados de trabalhos realizados em anos anteriores na determinação (feita com técnica menos precisa) de 84 coordenadas geográficas, medidas em diferentes municípios, e uma breve descrição sobre as medições de coordenadas geodésicas e o cálculo de suas diferenças (LIMA; COLUCCI, 1940);

- Boletim $\mathbf{n}^{o} 29$ - O boletim Determinação do meridiano por uma estrela em elongação, com o uso de tabelas para as latitudes de $20^{\circ}$ a $25^{\circ}$ foi elaborado pelo Serviço de Geodesia do Instituto, em 1942, descrevendo também a utilização desta técnica (BIERRENBACH; TALIBERTI, 1942);

- Boletim $\mathbf{n}^{o} 30$ - Compensação dos erros no trabalho de triangulação elaborado no ano de 1943 (FRANCO, 1943). Neste boletim descreve-se como foi empregado o método prático e o dos mínimos quadrados (MMQ) nas determinações dos ângulos dos triângulos;

- Boletim $\mathbf{n}^{o} 34$ - O boletim Coordenadas geográficas de locais do Estado de São Paulo é uma continuação do boletim 28 apresentando as coordenadas geográficas de 324 pontos, medidos em diferentes municípios do Estado, durante 14 anos pelo Instituto (LUDOVICO, 1953).

- Boletim $\mathbf{n}^{o} 36$ - O boletim Nivelamento Geral do Estado - Altitudes de Precisão, 
elaborado 1962, apresenta o resultado dos nivelamentos executados pelo serviço de geodésica desde 1940 (COLUCCI, 1962);

- Boletim $\mathbf{n}^{o} 37$ - O boletim Aerotriangulação Espacial elaborado em 1962 e escrito pelo capitão Alberto do Santos Franco, apresenta conceitos de aerotriangulação como, por exemplo, a orientação relativa (numérica e gráfica) (FRANCO, 1962). Apresenta também trabalhos baseados em propostas elaboradas pelo Institut Géographique Militaire, da França, como a compensação de medidas utilizando a técnica dos mínimos quadrados por Verdin e Moreau (FRANCO, 1963).

- Boletim $\mathbf{n}^{o} 38$ - O boletim Azimutes por Circum-Elongações em Função de Diferenças de Distancias Zenitais de 1962 apresenta uma alternativa ao método das circum-elongações QUINTÃO, 1962);

- Boletim $\mathbf{n}^{o} 46$ - O boletim Tabela de determinação do Meridiano verdadeiro, por meio de estrelas em elongação, nas latitudes $-1^{\circ}$ a $-40^{\circ}$ elaborado em 1966, por Adhemar Colluci, mostra como foram realizados os cálculos de azimutes por meio de determinações astronômicas (COLUCCI, 1966).

Os trabalhos do IGGSP tomaram como base os trabalhos da CGGSP, que foram pioneiros no Brasil, do ponto de vista da Cartografia sistemática, como se pode ver na citação a seguir, que começa referindo-se à base geodésica inicial da triangulação.

Essa base, por ter sido a pioneira [para este fim], constitui-se num marco da história da nossa cartografia e deu origem à primeira triangulação e ao primeiro protótipo (Estampa III), que serviu de modelo e inspirou a série cartográfica que Alberto Ribeiro Lamego, em 1956, avaliava assim: "ao exonerar-se da CGGSP, em 1905, Orville Derby legava ao Brasil, pela primeira vez uma grande área cartografada, em folhas na escala 1:100.000, publicadas a partir de 1899, e ainda hoje fundamentais"(CINTRA, 2003).

\section{A.2 Fim do IGGSP e órgãos que receberam suas atri- buições}

Já na década de 40, mais precisamente em 1941, os serviços da secção inicial de Climatologia foi desmembrada e encampada pelo governo federal e em 1951 os serviços de hidrografia foram anexados ao Departamento de Águas e Energia Elétrica - DAEE 
(IGGSP, 1959). Entre as décadas de 50 e 70 muitos dos técnicos das áreas de topografia e geodésia foram aposentados ou faleceram. E, em 1962 segundo relato da engenheira Zilda, foram admitidos, em substituição a estes, seis geógrafos para a seção de estudos geográficos, porém sem processo de seleção (hoje conhecido como concurso), o que (segundo a mesma) afetava a qualidade dos trabalho\$ ${ }^{1}$. Em 1967 foi promulgado um decretd que dispôs sobre a estrutura funcional e medidas para a reforma administrativa da Secretaria de Estado dos Negócios da Agricultura na qual ficou criada a Coordenadoria de Pesquisa de Recursos Naturais, ficando o Instituto Geográfico e Geológico e outros Institutos da Secretaria, dentro dessa Coordenadoria da Secretaria de Agricultura (SÃO PAULO (Estado), 1967). Segundo Sergio Mezzalira em entrevista concedida a Figueirôa et al. (1985, p.59) tal coordenadoria teria influenciado no poder político e autonomia dos Institutos, impossibilitando diversas ações.

Já com poucos técnicos em 1968, a junta deliberativa do Instituto, comandada pelo então diretor, o engenheiro Jesuíno Felicíssimo Jr. (1966-1971), tentava mostrar ao governo a importância da Instituição por meio de sua forte ligação com organizações governamentais e privadas. Para mais detalhes ver o organograma presente no Anexo A (pg. 207). Ainda em 1971 uma nova sede foi anunciada (na rua Antônio de Godoy, no centro de São Paulo) com a mudança das atribuições do Instituto, de modo que, aparentemente, a área de geologia, diferente do enfoque dos diretores anteriores, passaria a ter mais importância para a Instituição (BASTOS, 1968, p. 165, grifo nosso).

\footnotetext{
"Discordamos levemente sobre os efeitos de nossos sucessores, brilhantes sob todos os aspectos, mas não queremos viver sob os louros de tão cara e gloriosa tradição [...] que eles souberam manter no passado, se não nos faltarem recursos e apoio."
}

Aparentemente os trabalhos iniciados nos anos de 1960 foram interrompidos nessa mesma década. Realizando algumas verificações destes materiais cartográficos, provavelmente devido à falta de pessoal e recursos financeiros, os trabalhos se viram afetados, e desta forma, por exemplo, as cartas 1:25.000 não foram finalizadas.

Em 1969 um decreto estadual sem número de 4 de novembro de 1969 $9^{3}$ com a justificativa de tornar a organização do Instituto mais "maleável", alterou a antiga organização da Instituição criando uma Divisão de Geografia, com seis Secções Técnicas e uma Divisão de Geologia, também com seis Seções Técnicas (SÃO PAULO (Estado), 1969). Essa estru-

\footnotetext{
${ }^{1}$ Documento administrativo interno do IGGSP - Acervo MUGEO Instituto Geográfico.

${ }^{2}$ Estado de São Paulo decreto ${ }^{\circ}$ 48.133, 20 de junho de 1967 (SÃO PAULO (Estado) 1967)

${ }^{3}$ Estado de São Paulo decreto $n^{\circ}$ de 4 de novembro de 1969 (SÄO PAULO (Estado), 1969).
} 
tura que seria sua última forma, pode ser observada na figura 73 . Segundo relatos ${ }^{1}$ houve a tentativa de dar continuidade aos trabalhos das seções fechadas, por meio do engenheiro Juvenal Felicíssimo, que foi chamado em 1972 para ser lotado na seção de fotogrametria, porém sem sucesso, provocando sua saída muito pouco tempo depois.

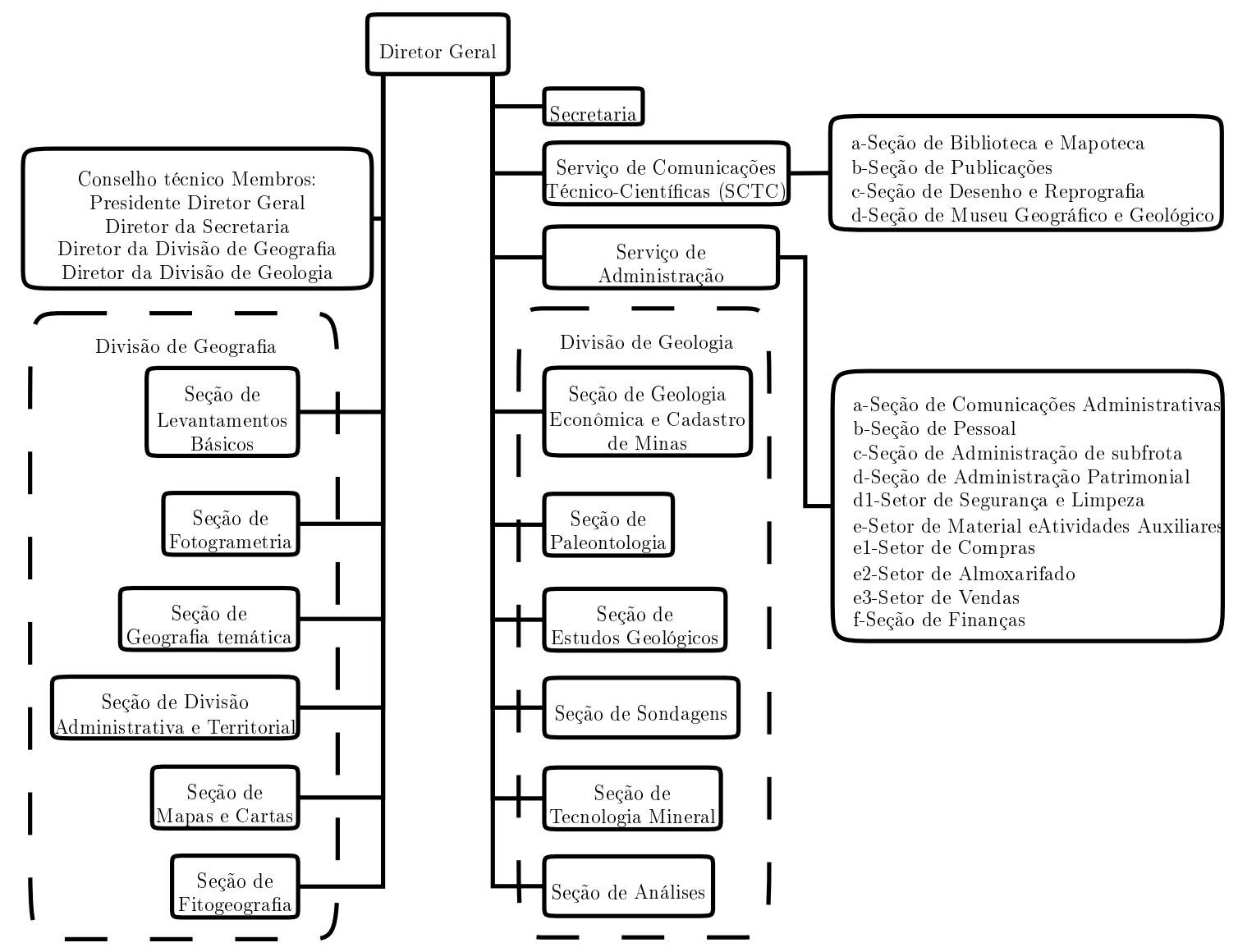

Figura 73: Última organização institucional do IGG (1969/74)

Em 1974 foi criado um grupo de trabalho para definir a situação institucional do IGGSP ${ }^{2}$ o qual mapeou ${ }^{3}$ todas as contribuições ou sobreposições de serviços executados pelo IGGSP e outras instituições tais como: DAEE, VASP, IPT, etc... Este grupo em vez de unir a Instituição fez com que em 1975 o IGGSP fosse desmembrado pelo decreto número 6822 que criou o Instituto Geológico - IG e a Divisão de Geografia da Secretaria de Planejamentd 4 SÃO PAULO (Estado), 1975). Esse decreto, conforme descrito por Figueirôa et al. (1985, p.64), foi o resultado de um acordo entre a Secretaria de Economia e Planejamento e a da Agricultura. A Secretaria de Planejamento tinha interesse na secção

\footnotetext{
${ }^{1}$ Entrevista telefônica de Jesuíno Felicíssimo Neto (sobrinho de Juvenal Felicíssimo e filho de Jesuíno Felicíssimo Júnior).

${ }^{2}$ Estado de São Paulo decreto $n^{o} 3.535$, de 9 de abril de 1974 (SÃO PAULO (Estado), 1974$)$.

${ }^{3}$ Reunião do Grupo de Trabalho sobre a definição institucional do IGGSP 27/05/1974 - Fonte: Acervo MUGEO Instituto Geográfico.

${ }^{4}$ Diário oficial do Estado de São Paulo 26 de setembro de 1975 (SÃO PAULO (Estado), 1975 ).
} 
de geografia, e assim definiu que seriam de responsabilidade desta todas as atribuições que fossem pertinentes à de divisa de municípios. Desta forma a atividade de delimitação de divisas utilizando cartas topográficas, que antes eram de responsabilidade do IGGSP, passariam a ser de responsabilidade desta nova secção. Além disso, definiu também que atividades ligadas à elaboração das cartas topográficas atribuídas a profissionais do ramo da engenharia (aerofotogrametria, cartografia e geodésia) seriam removidas da divisão de geografia e repassadas para a empresa VASP Aerofotogrametria, incluindo alguns equipamentos, como o da figura 74 . Já a Secretaria de Agricultura ficou com o restante, sendo nela criado para isso o Instituto Geológico - IG, com uma estrutura organizacional própria (FIGUEIRÔA et al., 1985, p.74).

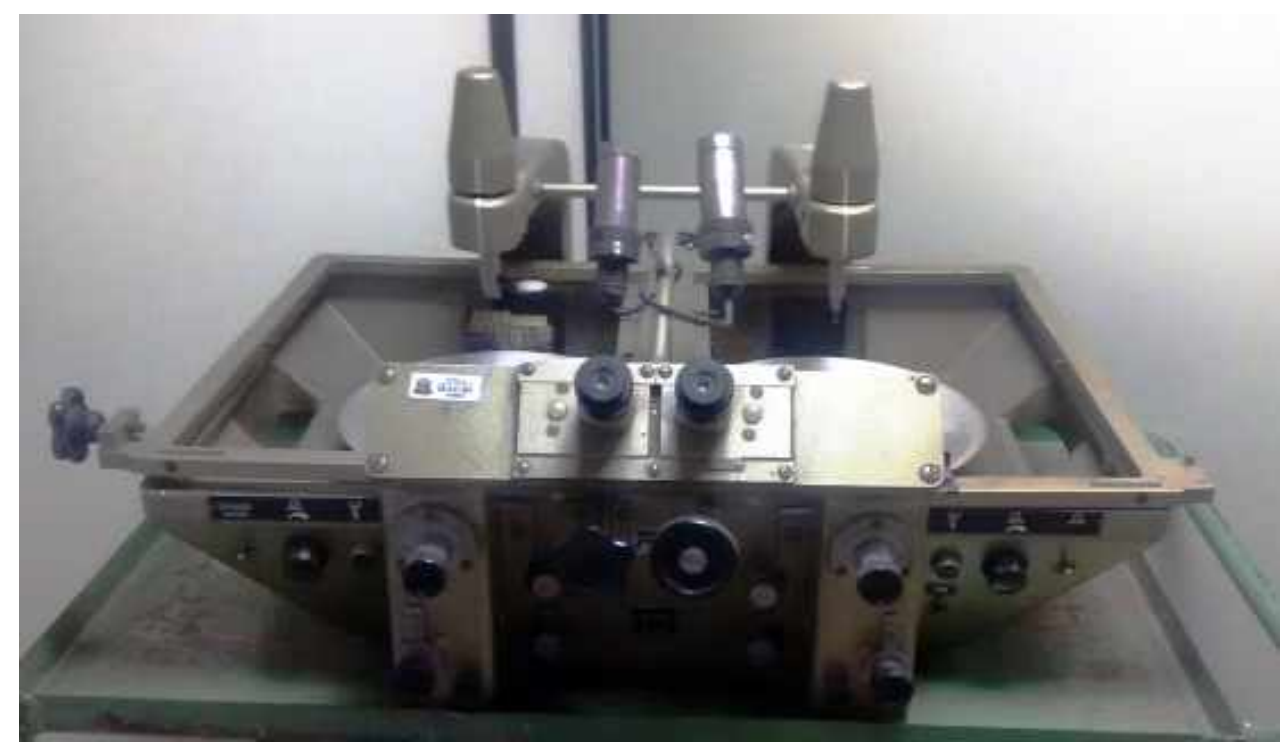

Figura 74: Wild PUG 4 (perfurador de fotografias)

Fonte: Autor em visita ao acervo IGCSP (2017)

As demais atribuições do IGGSP no que se referiam à geologia e a outras atividades administrativas (por exemplo recursos humanos) foram absorvidas pelo recém-criado IG. Sobre esta divisão pode-se ler a seguir o relado da engenheira Zilda, sobre a falta de pessoal (FIGUEIRÔA et al. 1985, p. 50).

"Entr. - A senhora acompanhou o a divisão do Geográfico e do Geológico? Acompanhou de fora só ?

Zilda - Minha filha foi um desastre!. Você sabe a união faz a força. Agora esta lá Geográfico fraquinho e Geológico idem [...] Mas deve ter tido algo por trás; quem sabe?

Entr. - A senhora sabe?

Zilda - É acho que sei. Mas não vou falar. Quem estava lá que fale! Eu me bati pela entrada dos geógrafos. Tinha muito serviço para geógrafos, era uma Secção de assuntos geográficos. Eu consegui [...]. Mas depois foram saindo [...]" 
A documentação relativa à divisão municipal ficou sob a responsabilidade da Divisão de Geografia da Secretaria de Planejamento (futuro Instituto Geográfico e Cartográfico - IGCSP) e o restante das atribuições do IGGSP ficaram com o IG. Os departamentos ligados às áreas de levantamentos somente foram reintegradas a divisão de geografia em meados de 1979 quando foi criado o IGCSP pelo decreto 13.413 1 , que o criou com quatro divisões: Cartografia, Geografia, Divisão de Apoio Técnico à "Divisão Administrativa e Territorial" e Serviço de documentação técnico científica; para mais detalhes ver Anexo A (pg. 203). De forma resumida a criação e a linhagem das áreas técnicas do IGGSP e do IGCSP desde 1938 até 2018 estão na tabela 28.

\begin{tabular}{|c|c|c|c|}
\hline IGG 1938/1969 & IGG 1969/1974 & IGC $1979 / 2005$ & IGC $2005 / 2018$ \\
\hline Serviço de geodésia & \multirow{3}{*}{ Seção de Levantamentos básicos } & Seção de levantamentos básicos & Desativada \\
\hline \multirow{2}{*}{ Serviço de topografia } & & Seção de cartografia sistemática & Subgerencia de cartografia sistemática \\
\hline & & Seção de cartografia temática & Subgerencia de cartografia temática \\
\hline Desenho fototécnia & Seção de Fotogrametria & $\begin{array}{l}\text { Seção de aerofotogrametria } \\
\text { Setor de desenho de mapas } \\
\text { Setor de comunicação visual }\end{array}$ & Desativada \\
\hline \multirow{3}{*}{ Secção de estudos geográficos } & \multirow{3}{*}{ Seção de divisão administrativa e territorial } & Seção de limites, divisas e demarcações & Subgerencia de limites, divisas e demarcações \\
\hline & & Seção de fornecimento de doc. técnica & Subgerencia de fornecimento de doc. técnica \\
\hline & & Seção de Mapas municipais & Desativada \\
\hline \multirow{3}{*}{ Não existia } & \multirow{3}{*}{ Seção de fitogeografia } & Seção de geografia física & Desativada \\
\hline & & Seção de geografia regional & Subgerência de geografia regional \\
\hline & & Seção de geografia humana & Subgerência de geografia humana \\
\hline Mapoteca & Seção de mapas e cartas & $\begin{array}{c}\text { Seção de mapoteca e fototeca } \\
\text { Seção de biblioteca } \\
\text { Setor de reprografia }\end{array}$ & Subgerência de documentação técnico-científica \\
\hline
\end{tabular}

Tabela 28: Tabela do histórico de áreas técnicas entre IGG e IGC (1938-2018)

\footnotetext{
${ }^{1}$ Diário oficial do Estado de São Paulo 13 de março de 1979 (SÃO PAULO (Estado), 1979).
} 


\section{APÊNDICE B - HISTÓRICO SOBRE AS DEMARCAÇÕES TERRITORIAIS PAULISTAS}

A delimitação do que tornariam as terras brasileiras teve seus primeiros mapas elaborados por Portugal período colonial. Estes mapas trazem as delimitações das capitanias hereditárias, cujos limites geométricos foram estudados por Cintra (2013), foram produzidos entre 1534-36. O processo de interiorização dos colonizadores, formando as primeiras vilas, se deu principalmente ao longo dos dois primeiros séculos, como ilustrado por Cintra (2017) e apresentado na figura 75.

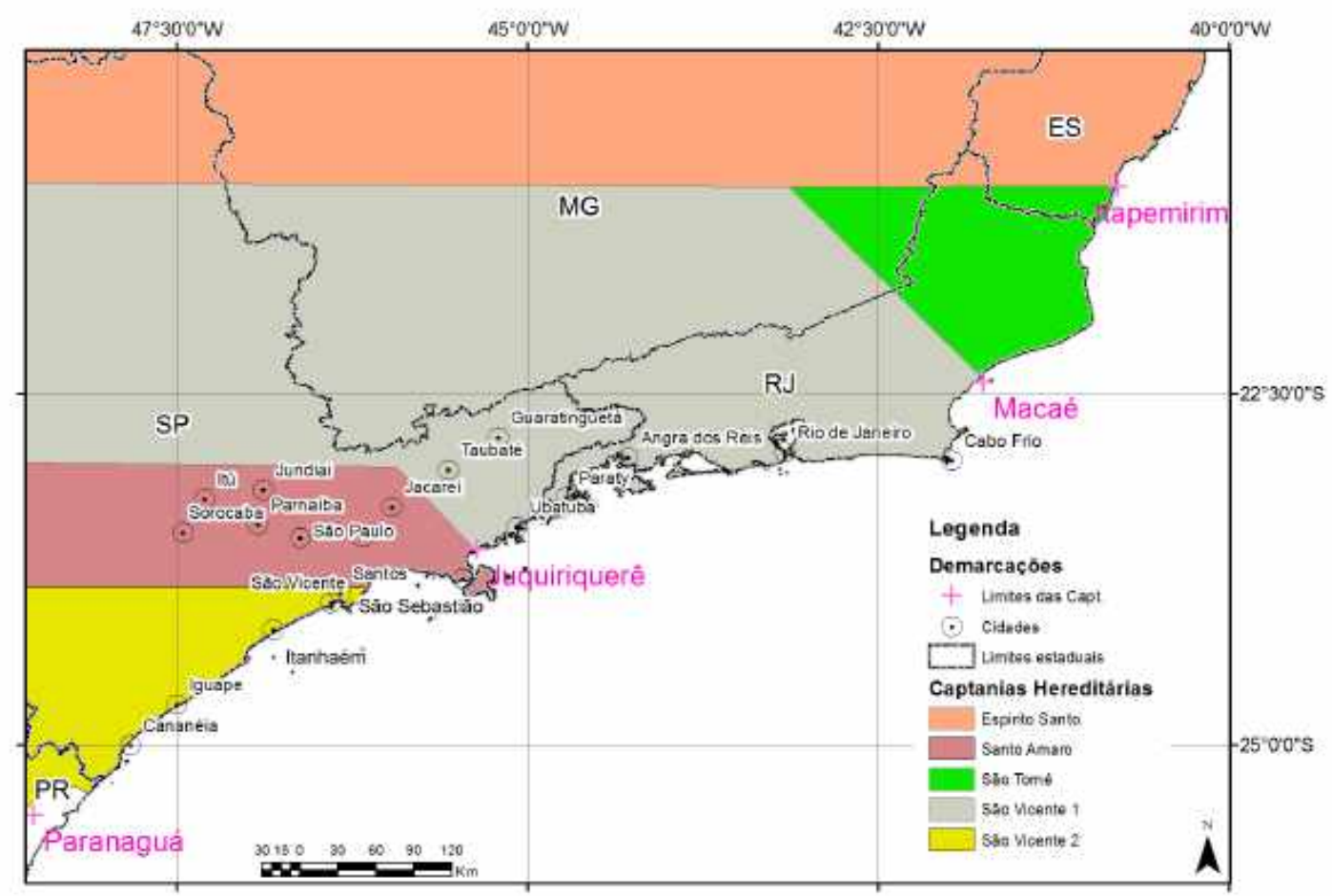

Figura 75: Cidades e capitanias na região sudeste de 1532-1700

Fonte: Cintra (2017) 
O conceito de território e sua demarcação, utilizando-se de equipamentos e técnicas de medição, surgiu bem depois (ALLIÈS, 1980, CINTRA, 2017). A importância do local definia a necessidade da sua demarcação. No Brasil, durante o período colonial, o grau de importância de um local variava, podendo ser classificado como: cidades, cidades reais, vilas, freguesias (ANDRADE, 2016). As primeiras descrições de limites ocorreram em áreas que sofreram desmembramento dos primeiros locais constituídos. Neste contexto Bueno (2009) destaca que o conceito de território com contornos precisos e definidos é socialmente construída no século XVIII. Como exemplo desta descrição temos a divisa territorial do que hoje é o município de São Sebastião, antes na categoria de vila, descrito por José Tomás Nabuco de Araújo (1813-1878) em 1852 (ALMEIDA, 1958):

"dividindo-se para o sul com o município de Santos, pelo rio Saí, em distância de 10 léguas; para o norte pelo rio Juqueriquerê, em distância de 2 e meia léguas, com Caraguatatuba"(ALMEIDA, 1958, crifo nosso).

Pode-se observar, na descrição de Nabuco, que durante a definição dos limites utilizou elementos naturais (rios), distâncias e locais conhecidos. Isso mostra que era comum a utilização do conhecimento geográfico da região para a descrição dos limites. Muitos outros locais foram demarcados utilizando os mesmos tipos de descrição. Esta foi a forma de delimitar as regiões e, até então, a utilização de mapas nunca foi uma exigência da administração Imperial. Para Cigolini (2014) esta organização se iniciou no período republicano, a partir de 1890, e foi sendo modificado durante todo o século XX.

Outra questões relativas a território ocorridas durante o início da república foram as dos limites internacionais e estaduais brasileiros. Sobre os internacionais destacam-se os mapas publicados em 1920 pelo engenheiro Everardo Backheuser (MENEZES, 2006). Estas fronteiras internacionais, com os outros países sul-americanos, se consolidaram no século XX por acordos finalizados na década de 1970, já a fronteira marítima foi consolidada quando o Brasil aderiu ao tratado da convenção da Jamaica de 1982 (BORBA, 2013). Sobre limites estaduais, se iniciam com a proclamação da república na constituição de 1891 (BARBOZA, 2017). Quanto a definição dos limites estaduais foram consolidadas, na sua maioria, durante a primeira metade do século XX. Porém houve casos em que esta divisão não foi pacífica, como descreve Rodrigues (1991). Destas, notabilizou-se a que envolveu o estado de Santa Catarina e Paraná, julgada em 1910, que acabou, de certa forma, influenciando o início da Guerra do Contestado (SILVA, 2017b). Porém, a maioria dos limites foram aceitos sem grandes conflitos e assim, logo que possível, eram providenciadas suas demarcações. Sendo estas realizadas principalmente pela utilização de cartas topográficas e com a implantação de marcos em pontos geográficos notáveis como, por 
exemplo, entre as divisas de Santa Cataria e Paraná na Foz do Rio Iguassu CAMARGO, 1920).

\section{B.1 Limites estaduais paulistas}

Durante no período conhecido como velha república, mais especificamente nos primeiros anos do século XX, foram publicadas diversas leis estaduais que fomentavam estudos para a demarcação de limites entre São Paulo e outros estados (SÃO PAULO (Estado), 1905). Estes estudos utilizaram como fontes primárias de informação relatos históricos da ocupação, ou passagem de colonizadores desde o início do século XVII. As divisas do território paulista foram em parte litigiosas e acordadas como, por exemplo, com o estado de Minas Gerais (1936) e Rio de Janeiro (1921-1950); já que outras que tiveram árbitro judicial como as divisas com Paraná (1921).

A primeira linha divisória fixada foi a entre São Paulo e Paraná, definida por meio de laudo proferido pelo então Presidente da República Epitácio Pessoa SÃO PAULO (Estado), 1921). Conforme descreve Lefèvre (1966) esta demarcação não teve um acordo direto e foi intermediada pelo Presidente que fez uso dos pareceres de ambas comissões estaduais para proferir a decisão que ambos aceitaram.

Já a divisa entre São Paulo e Rio de Janeiro foi iniciada por um acordo em 1921, mas por questões políticas somente foi ratificada em 1950 (S̃̃O PAULO (Estado), 1950). Em relatório publicado pelo IGGSP em 1950 é descrito como foi realizado o processo de demarcação, primeiro utilizando descrições geográficas sucintas, advindas do acordo de 1921, porém com maior detalhamento. Este foi realizado através de novos levantamentos, inclusive com a utilização de marcos e as suas coordenadas geodésicas (GUEDES et al. 1950).

Morato (1937) descreve a demarcação do limite entre São Paulo e Minas Gerais. Este processo, ocorrido até o ano de 1936, foi executado por meio de um acordo elaborado por uma comissão mista composta de engenheiros paulistas e mineiros, o qual resolveu questões históricas entre os estados. Neste caso, para a definição da linha limítrofe, foram utilizadas descrições geográficas, as quais também definem os limites entre municípios como se descreve no próximo tópico. 


\section{B.2 Divisas municipais a partir de 1938}

Antes da existência de uma divisão territorial municipal já existiam, desde o século XIX, descrições sobre dos perímetros de localidades da província de São Paulo, por exemplo, a divisa entre município de Santo Amard ${ }^{1}$ e freguesia de São Bernardo (S̃̃̃O PAULO (Estado), 1842). Porém a sistematização do conhecimento territorial municipal foi somente proposto pelo Decreto federal $\mathrm{n}^{\circ} 1527$ em 1937. Nesta primeira iniciativa, desde o início da república, foi criada uma ordenação territorial válida em todo o território nacional, utilizando parte do conhecimento geográfico e cartográfico (BRASIL, 1937). Para regular esta função, neste decreto, o governo criou o Conselho Nacional de Geografia CNG (Ligado ao Instituto Nacional de Estatística - INE), orgão que ficou incumbido de normatizar, por meio de resoluções e normas, a sistemática do conhecimento geográfico para este fim. Durante sua existência o CNG publicou a "Revista Brasileira de Geografia", sendo esta responsável por divulgar suas resoluções e normativas além de trabalhos técnicos. Em sua primeira edição definiu as regras para sistematização territorial estabelecendo normas que para elaboração de mapas municipais, contendo a representação do município e dos seus vizinhos (DEFFONTAINES, 1939). Até então, as divisas municipais eram regulamentadas apenas por memoriais descritivos contendo elementos geográficos da paisagem (ex. rios, morros, etc...).

Utilizando-se de conceitos da geografia física foram apresentados os primeiros trabalhos publicados inicialmente pela CNG (DEFFONTAINES, 1939). Com as definições descritas na revista, normalizaram-se as formas de definição e representação dos limites municipais a serem executados por profissionais das áreas de geodésia, topografia e cartografia. Esta estrutura foi concebida com a participação de geógrafos, como o doutor em geografia Pierre Deffontaines ${ }^{2}$.

A descrição do limite territorial passava assim a utilizar elementos geográficos, como era executado em demarcações anteriores, porém utilizando de descrições mais detalhadas e representadas em mapas. Para atingir este detalhamento foram utilizados conceitos da geografia física, que permitiram descrever melhor as linhas limítrofes. Esta forma de observação era conhecida como análise geomorfológica, iniciada a partir dos anos de 1870 e difundida pela escola alemã de geografia (SACK, 2002, WIENS et al., 2007). O número de profissionais atuando em geografia durante o início do século XX era pequeno, o curso

\footnotetext{
${ }^{1}$ Território atualmente incorporado ao município de São Paulo

${ }^{2} \mathrm{O}$ geógrafo francês Pierre Deffontaines foi membro de duas missões universitárias francesas enviadas ao Brasil nos anos 30, uma delas deu origem à criação dos cursos de história e geografia da Universidade de São Paulo (USP) e outras universidades em diversos países (FERREIRA, 1998).
} 
de geografia só foi criado na Universidade de São Paulo em 1934 (SÃO PAULO (Estado), 1934). No entanto, conforme descrito por Cintra e Silva (2001) profissionais de engenharia, pelo menos em território paulista, já executavam levantamentos topográficos desde o início do século, atividade prevista no processo de elaboração das representações e descrições de limites municipais. Para isso forma, os profissionais que definir os limites entre municípios e estados, eram os formados em engenhariat. Pereira (2009) destaca a década de 1940 como sendo de grande importância na questão cartográfica brasileira:

A década de 1940 é marcante logo no seu primeiro ano no campo da cartografia, pois pela primeira vez na história da Estatística Brasileira, os dados de coleta e tabulações do censo são referenciados a uma base cartográfica sistematizada, organizado quanto às categorias administrativas: Municipais e Distritais - Cidades e Vilas, e assegurando o georreferenciamento das estatísticas brasileiras. (PEREIRA, 2009, p. 29)

A forte atuação de profissionais formados em geografia, na parte de mapeamentos municipais, somente ocorreu em meados da década de 1960, conforme consta no depoimento da engenheira Zilda de Sampaio Perroni, funcionária do IGGSP, que indicou profissionais formados em geografia para auxiliar no processo de identificação das divisas (FIGUEIRÔA et al. 1985, p. 50). Antes deste fato o IGGSP não contava com profissionais formados em geografia, o que reforça este entendimento.

"[...] bati pela entrada dos geógrafos. Tinha muito serviço para geógrafos, era uma Secção de assuntos geográficos. Eu consegui [...]"

Quando se observa a sistematização na descrição da paisagem, utilizando geomorfologia, verifica-se que esta é um ramo da geografia, confirmando a indicação da engenheira (WIENS et al., 2007). A área de concentração da geografia, com abordagem mais física, somente fez parte do currículo dos cursos de geografia, no Brasil, a partir da década de 1940 (SILVA; FERREIRA, 2011, p. 291). Já os profissionais de engenharia no Brasil, que já eram formados anteriormente em número maior, tinham conceitos de geomorfologia em disciplinas da sua formação (OLIVEIRA, 2008).

\section{B.2.1 Os primeiros Mapas Municipais}

Com a promulgação da lei 311 de 1938 se tornou obrigatório que todas as prefeituras do Brasil, para que fossem reconhecidas, deveriam realizar a confecção de seu mapa, no intuito de dirimir dúvidas quanto os seus limites territoriais (BRASIL, 1938). A

\footnotetext{
${ }^{1}$ No século XX a formação de engenheiros incluía disciplinas sobre limites (MACKENZIE, 1913).
} 
sua execução foi financiada pela União e os primeiros profissionais a produzirem mapas municipais foram engenheiros de organizações estaduais, conhecidas como Departamentos de Serviço Geográfico, especificamente de Minas Gerais e São Paulo. Esta produção era contratada pela prefeitura interessada que solicitava este serviço à instituição executora (DEFFONTAINES, 1939). Embora os padrões de convenção cartográfica e levantamentos tenham sido estabelecidos o texto de descrição das divisas, que seria apresentado na lei de criação/alteração do município, nunca foi regulamentada (CASTRO, 1939). A diferença técnica entre os poucos mapas produzidos pelo exército e estes inúmeros mapas municipais são descritas por Pereira (2009):

"[...] Mas, a diferença mais significativa destes mapas, naquela época, para àqueles produzidos pelo Exército, encontrava-se na precisão das informações. No Exército, usava-se tanto o método geodésico (o da triangulação) e/ou astronômico (calculando-se a latitude e a longitude). Já os mapas municipais, realizados pelas prefeituras, se pautavam nas ementas das divisas municipais, que não raro traziam sobreposição de informações com ementas de outros municípios. [...]"

Ao que tudo indica os trabalhos que foram executados de forma sistemática a adoção de critérios rigorosos, utilizando o método clássico, não foram eficientes dada a grande demanda de municípios em um vasto território. Desta forma, os engenheiros utilizaram técnicas de geomorfologia descritiva e, quando disponíveis, mapas topográficos em escalas 1:100.000 para elaborar estes mapas e descrever estas leis. Sobre a experiência adquirida pelos engenheiros em desenvolver os mapas e as descrições de divisas, apresenta-se trecho do depoimento de José Bueno Conti, funcionário do IGGSP na década de 1960 (a íntegra consta no Apêndice D.2 pg. 190:

"Entr. - Como eram transcritas estas demarcações ?;

Conti - Nossa parte era a de conferir os textos e mapas conforme o que havíamos observado em campo. A forma que estes eram escritos era passado a nós pela engenheira Zilda. A forma da escrita e os termos empregados já eram utilizados anteriormente pelos engenheiros e técnicos; Entr. - A representação desta linha era dada pelo Mapa Municipal? O senhor participava desta elaboração ?;

Conti - Não executei nenhuma elaboração destes mapas, eu e meus colegas somente os conferíamos conforme o texto proposto. Para isso utilizávamos as cartas topográficas 100.000 e quando cheguei, no noroeste do estado, utilizávamos fotografias aéreas;[...]

Entr. - Quando saiu do IGGSP outros técnicos continuaram fazendo este trabalho ?;

Conti - Eu e meus colegas geógrafos que executávamos estes trabalhos não nos motivamos muito pela função, pois já existiam profissionais engenheiros que elaboravam muito bem os mapas e descreviam as demarcações. Realizávamos o trabalho de conferência[...]" 
O papel do Instituto Geográfico e Geológico de São Paulo - IGGSP foi de suma importância para este crescimento, sendo criados/demarcados /desmembrados/re-demarcados, durante a sua existência, 561 municípios com seus respectivos mapas municipais, últimas versões produzidas e respetivos anos, conforme ilustrado na figura 7 .

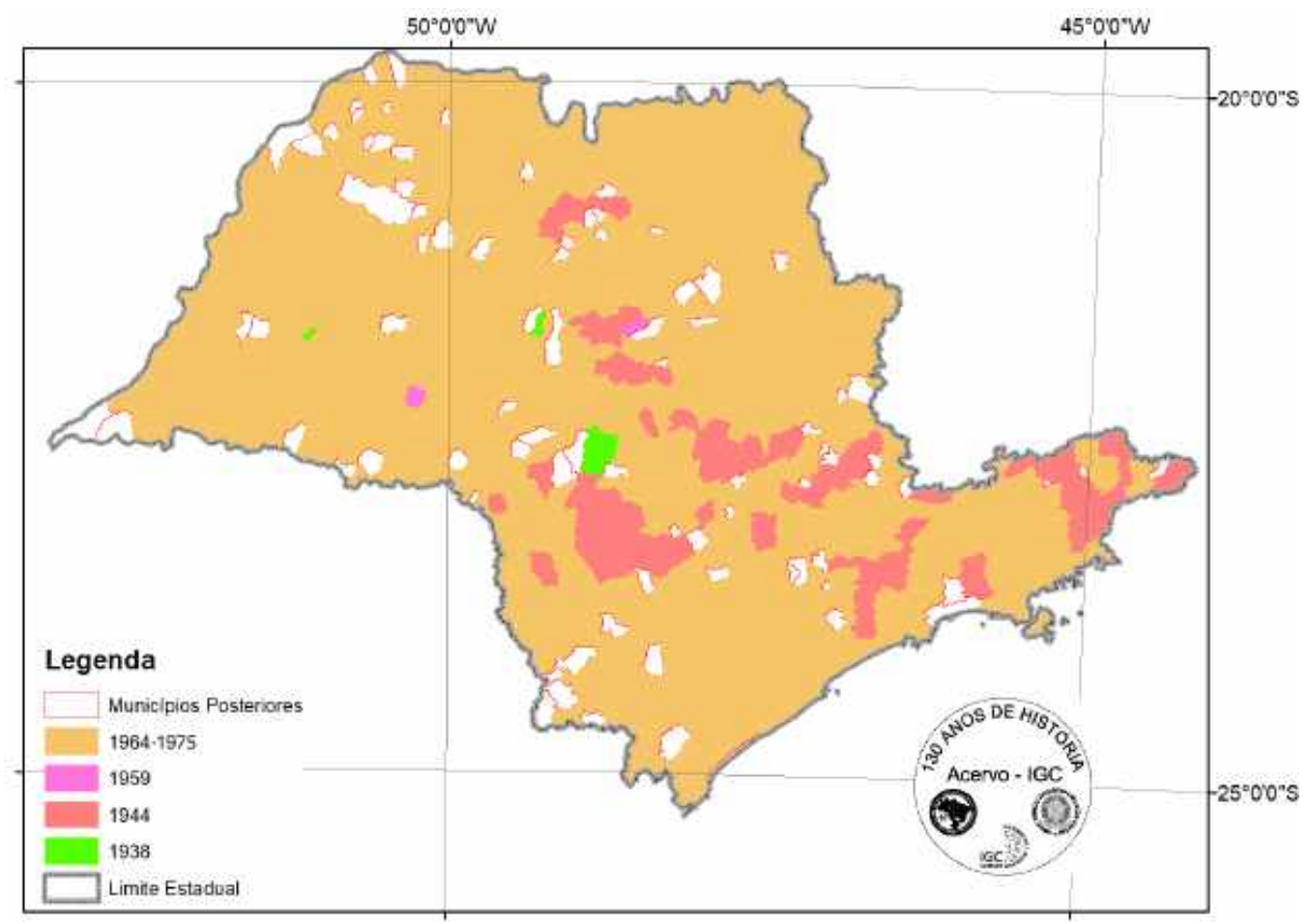

Figura 7. Municípios e mapas municipais produzidos pelo IGG (repetida da página 32 ) Fonte: Compilação do autor de IGCSP 2017)

A continuidade desta produção nos anos seguintes foi diminuída. Pois, conforme relato do depoimento (Apêndice D.2), outras ofertas de trabalho com mais apelo para profissionais da geografia, dificultaram encontrar aqueles que se dispuserem trabalhar com divisas territoriais em São Paulo na década de 1960. E não foram encontradas contratações informações sobre a contratação de mais engenheiros nos anos posteriores.

\section{B.2.2 Descrição de demarcações das divisas municipais}

Conforme descrito o processo de demarcação das divisas de municípios paulistas foi intensificado após a legislação de 1938 (BRASIL, 1937). Sobre o processo de descrição dos limites, que deram origem a leis de criação/desmem-bramento, existe publicação do IGGSP: Lima (1945) que descreve a utilização de termos da geografia física, mais especificamente geomorfológicos que estavam vigentes durante a sua elaboração (MARTONNE, 1934, LONGWELL et al., 1939, LOBECK, 1939, MARTONNE, 1939; ENGELN, 1941). 
Cabe ressaltar a obra do professor Emmanuel de Martonne, catedrático de geografia física da Sorbonne (Universidade de Paris), que em 1937 lecionou como professor visitante na Universidade de São Paulo - USP (USP, 1937). Aproveitou para estudar a morfologia brasileira, em especial a paulista, e para isso utilizou cartas da CGG na escala 1:100.000 (MARTONNE, 1939). Sendo especialista em descrever a paisagem, Martonne propunha desde sua tese de doutorado contornar as dificuldades impostas pela falta de cartografia utilizando de observações da paisagem e desenhos, representando levantamentos expeditos a prancheta (MARTONNE, 1902 apud RIBEIRO, 1973).

Pode-se entender parte do problema da demarcação de divisas no início do século XX a partir da necessidade de definir a localização da linha de divisa, da melhor maneira possível. Tendo em vista que o número de municípios só crescia e levando em consideração a falta de cartografia precisa, optou-se por utilizar-se, inicialmente, os mapeamentos em escala 1:100.000 e levantamentos expeditos. Porém, já na década de 1950, em algumas regiões foram utilizadas fotografias aéreas, para um maior detalhamento físico geográfico, e geomorfológico, quando comparados a levantamentos na escala 1:100.000.

A evolução do processo descritivo pode ser observada nas leis paulistas. A utilização de termos como: contraforte, espigão, divisor, etc... antes não utilizados, com a adoção da teoria geomorfológica passaram a ser empregados. Alguns destes termos, conforme descreve Lima (1945), são apresentados a seguir:

- Contraforte - É uma ramificação mais ou menos elevada de uma montanha ou cordilheira, em direção transversal à mesma. Seu contrário ou complementar é o talvegue, como ilustra a figura 77 .

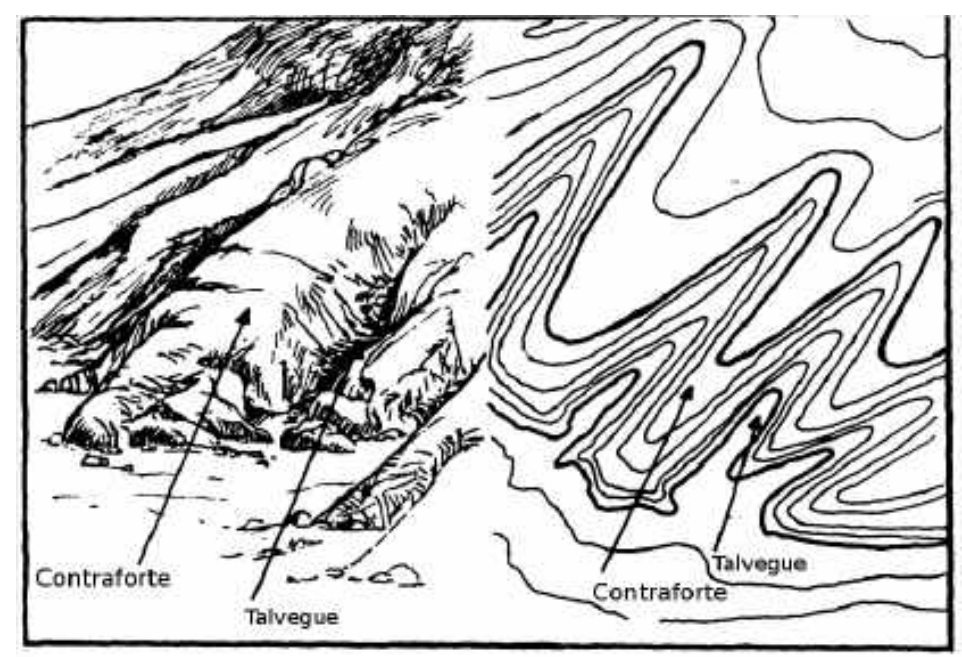

Figura 77: Ilustração de contraforte e talvegue à esquerda e a direita por curvas de nível Fonte: Lucariello (1987) 
- Divisor - Linha que separa a direção para onde correm as águas pluviais, ou bacias de drenagem, conforme ilustra a figura 78

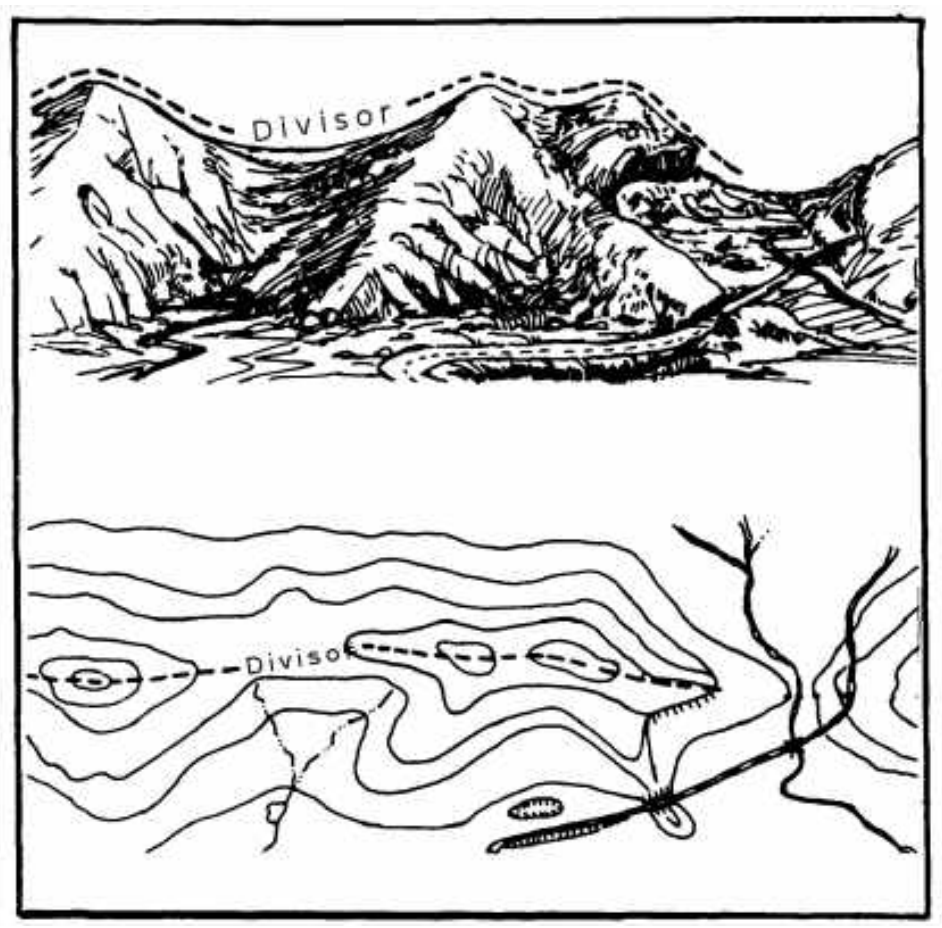

Figura 78: Ilustração de divisor de águas acima e perspectiva abaixo em curvas de nível Fonte: Lucariello (1987)

- Morro - Elevação do terreno, como fortes declives para todos os lados, sobressaindo dos terrenos que lhe são adjacentes. A figura 79 ilustra o elemento físico e sua representação em carta topográfica em curvas de nível;

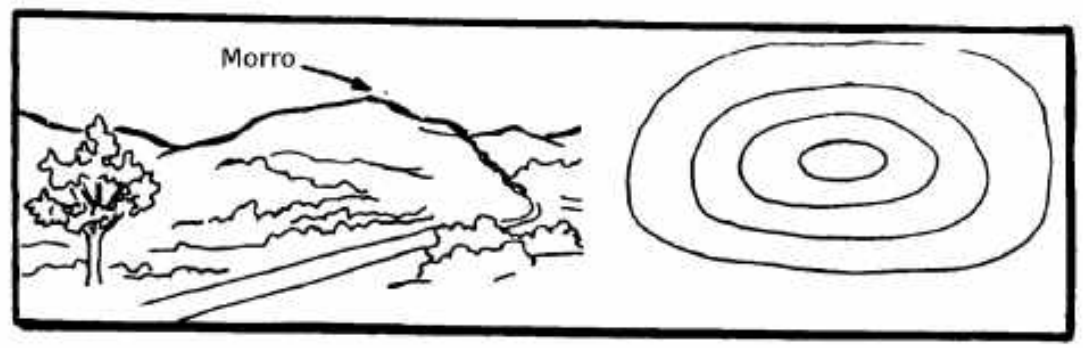

Figura 79: Ilustração de morro à esquerda e à direita em curvas de nível Fonte: Lucariello 1987)

Conforme descreve Donnelly (2012) a identificação destes elementos naturais, utilizados como divisa, podem ser dificultadas por variações na interpretação das evidencias de sua localização. Principalmente nestes casos, não é incomum o arbítrio judiciário e/ou a 
participação do poder público com variadas proposições 1 técnicas e legislativas (BORGES, 2014; FELIX, 2015; ETGES; PEREIRA, 2017).

A partir deste processo de descrição utilizando feições geográficas foram elaboradas diversas leis e mapas municipais. O resumo das alterações ocorridas nas legislações do quadro territorial paulista, entre 1938 a 1995, pode ser observado no mapa da figura 80 .

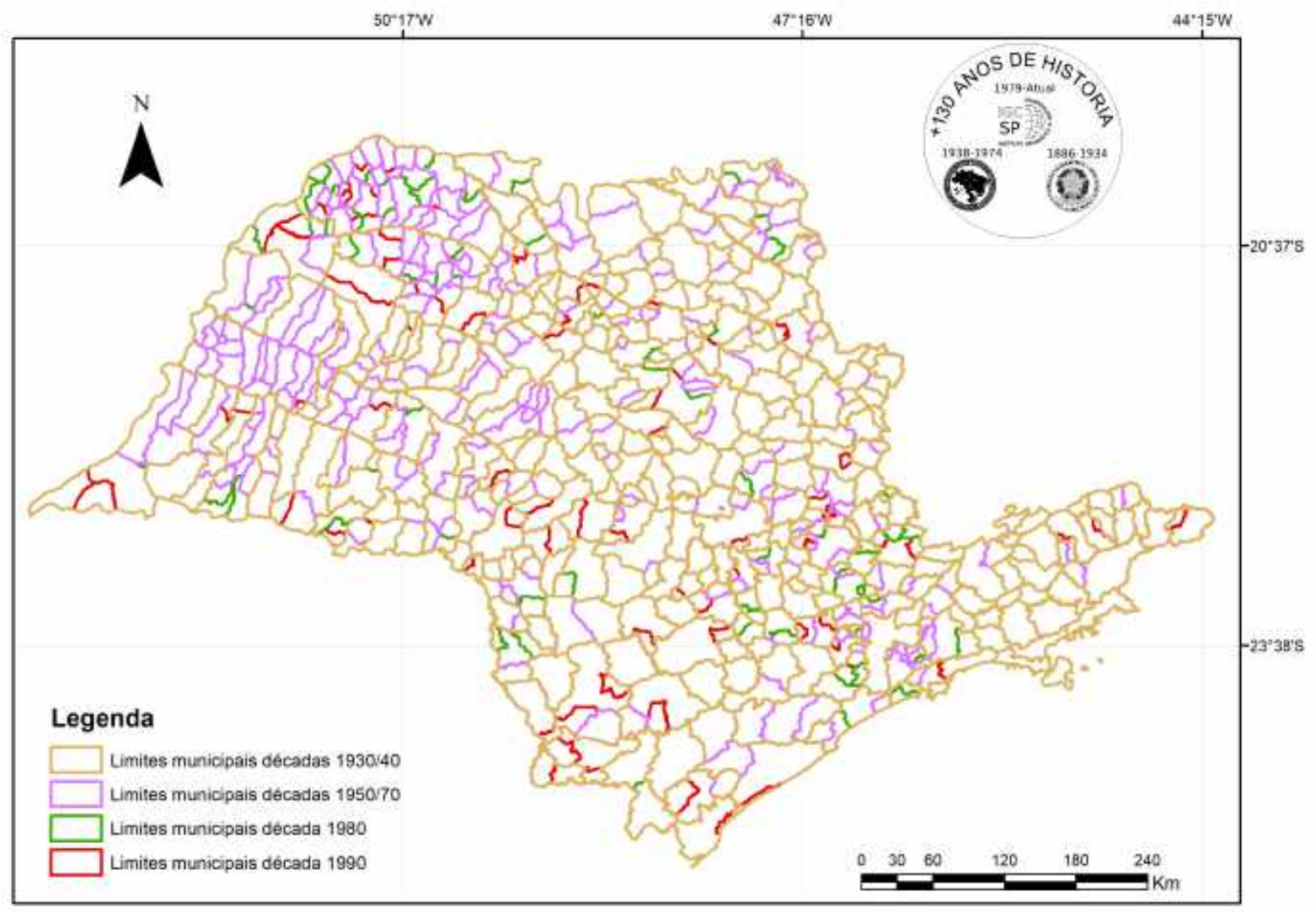

Figura 80: Resumo da evolução do quadro territorial paulista entre 1938 e 1997 Fonte: Compilação do autor a partir de dados IGCSP e SEADE

A figura anterior ilustra que no início da década de 1930/40 onde o estado contava com 245 e após 60 anos, na década de 1990, passou a possuir um total de 645 municípios (FAVERO, 2004). Parte deste total 561 tiveram seus traçados e mapas criados/modificados pelo IGGSP, até a metade da década de 1970, o que, para esta evolução, foi de grande consideração. Cabe ressaltar que a partir de 1997 não foram efetuadas modificações no quadro territorial devido à publicação da emenda Constitucional $n^{\circ} 15$, de 12 de novembro de 1996 (BRASIL, 1996).

\footnotetext{
${ }^{1}$ De acordo com a Emenda Constitucional ${ }^{o} 15$, de 12 de novembro de 1996, estão suspensos alterações no quadro territorial brasileiro, até que seja formulada Lei Complementar Federal que disponha sobre o assunto (BRASIL, 1996).
} 


\section{APÊNDICE C - RESUMO HISTÓRICO DA AEROFOTOGRAMETRIA}

Embora o foco principal desta secção seja o destaque na história da aerofotogrametria no Brasil/São Paulo é importante ressaltar alguns acontecimentos externos que tiveram influência direta no início desta história. Como por exemplo, o final da primeira guerra que impulsionou o desenvolvimento da aerofotogrametria. Também destaca-se os empreendimentos civis como a invenção de câmaras, por exemplo, a do norte-americano Sherman Fairchild em 1917, ou o aerocartógrafo (DOYLE, 1964). Todos estes avanços tecnológicos foram muito importantes para o impulsionamento da fotografia aérea vertical.

Segundo Smith (1979) os primeiros testes de mapeamento utilizando câmeras acopladas a aviões foram iniciados pela divisão norte-americana de levantamento costeiro e geodésico (do inglês US Coast and Geodesic Survey) em 1919, com a invenção das câmeras de grande formato e montagem em blocos destas fotografias. Estes inventos proporcionam, principalmente durante a década de 1930, avanços em aplicações que auxiliaram o levantamento aerofotogramétrico (LI et al., 2002; RANGO; HAVSTAD, 2003).

Ainda na década de 1920 diversos países passaram a elaborar, inicialmente em partes, cartas topográficas utilizando fotografias aéreas. O que começou como técnica complementar, a fotogrametria, entre a década de 1930 e 1940, acabou se tornando a principal forma de produção das cartas topográficas, superando as técnicas convencionais (MACEK, 2017). Confirmando esta mudança metodológica a figura 81 apresenta as descrições presentes em três legendas de mapeamentos efetuados, entre a década de 1920 e 1940, por serviços geológicos norte-americanos. 


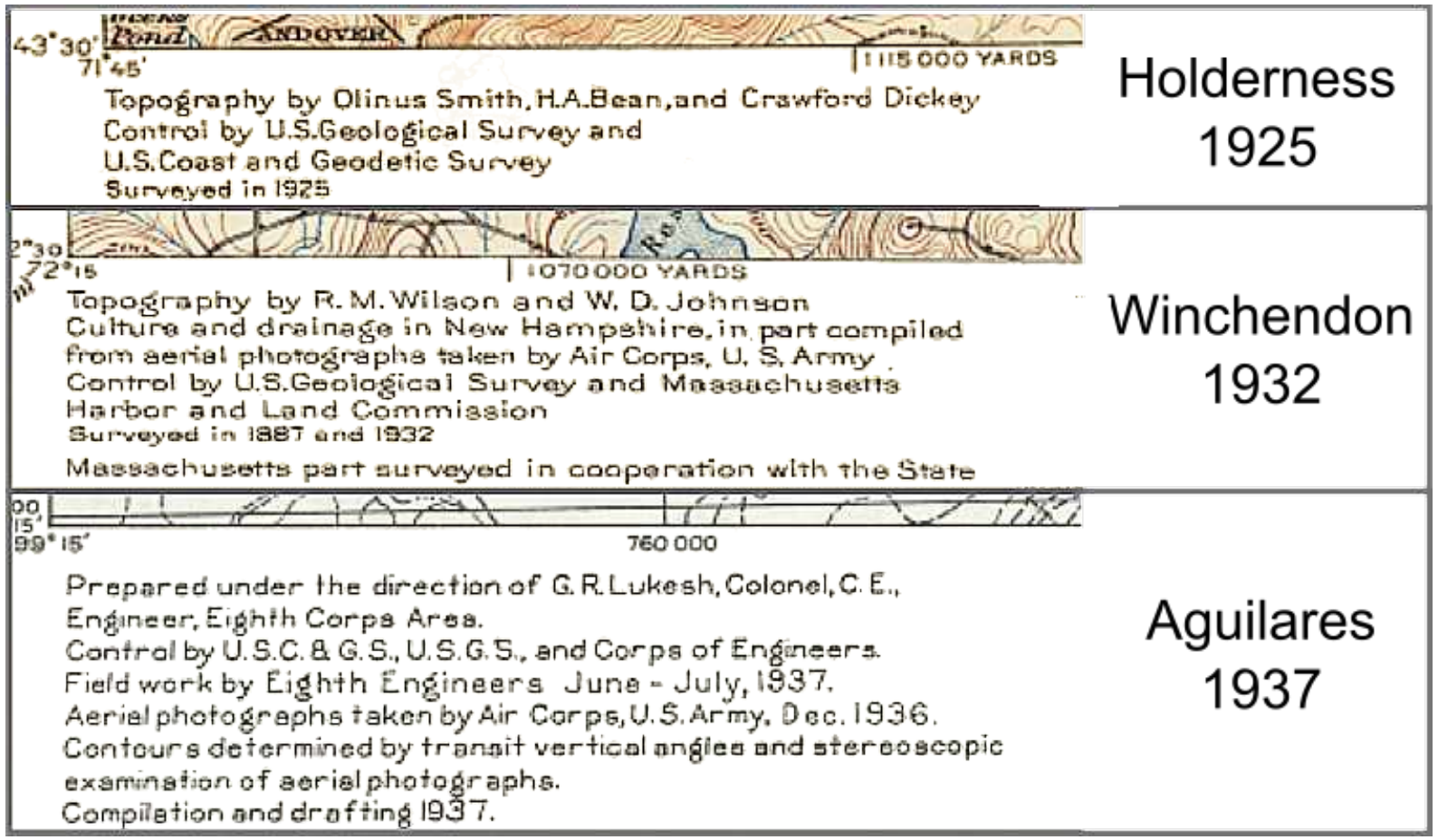

Figura 81: Detalhes de legendas folhas topográficas do Texas (E.U.A.)

Fonte: Autor, em compilação de cartas do Acervo da Universidade do Texas ${ }^{1}$

\section{C.1 Aerofotogrametria no Brasil}

Ao tratarmos dos aerolevantamentos feitos para a elaboração de cartas topográficas em escalas sistemáticas no Brasil, o pioneirismo correspondem ao Serviço Geographico Militar, no então Distrito Federal (Rio de Janeiro). Os voos foram executados para auxiliar na elaboração da primeira carta a utilizar fotografias (SILVA, 2011). O voo foi realizado com aeronaves Caudron e uma câmara aerofotogramétrica Heyde de formato 12 X 12 centímetros; o percurso foi de $748 \mathrm{~km}$ e a altura de voo foi $2.500 \mathrm{~m}$ sendo tomadas 948 chapas fotográficas e a carta topográfica elaborada na escala 1:50.000 está disponível no acervo da biblioteca naciona $]^{1}$ e pode ser vista ta figura 82 .

\footnotetext{
${ }^{1}$ Cartas disponíveis para download no acervo da Universidade do Texas http://legacy.lib.utexas.edu/maps/topo/topo_us.html.

${ }^{1}$ Biblioteca Nacional acervo digital Carta do Distrito Federal Escala 1:50.000
} 


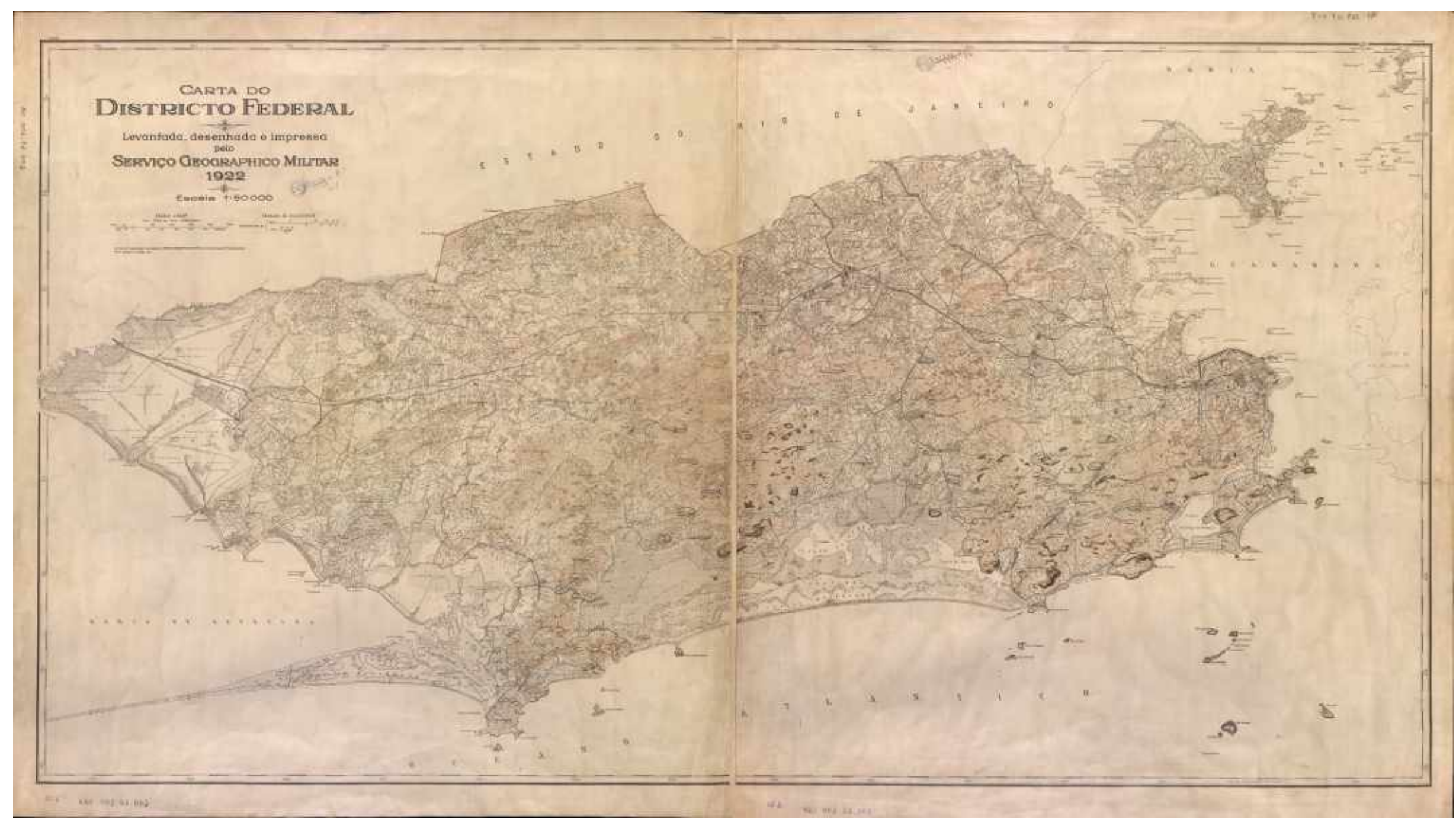

Figura 82: Carta Topográfica do Rio de Janeiro 1922 
A primeira legislação que regulava a execução de voos que fossem tiradas photographias é o decreto 16.983 de 1925, desde que aprovadas pelo então Ministro da Viação e Obras Publicas, não afetou a elaboração do levantamento pioneiro SARA (da prefeitura de São Paulo) e outros no inicio da década de 1930 (LIMA, 2012). Este fato, em conjunto com a posterior criação da Comissão Nacional de Geografia (CNG) acabou incentivando que diversas empresas começassem a pleitear, junto com as prefeituras, a autorização, para a elaboração de mapas cadastrais. Esse fato aconteceu por exemplo em voos de 1938 na cidade de Araraquara e 1939 em Bauru ambos pela Sociedade Paulista de Photographias Aereas Ltda 1 .

De forma sistemática a primeira organização nacional (federal) brasileira a executar levantamentos topográficos sistemático por aerofotogrametria foi o exército brasileiro, porém somente com trabalhos executada a partir de 1927 o Serviço Geográfico Militar (SGM) adquiriu duas câmeras automáticas, que contribuíram significativamente para a melhoria das coberturas aéreas. Porém os mapeamentos continuaram mistos até 1936 quando ocorreu uma renovação da técnica com o uso de estereógrafo Wol:2 e as folhas de Bagé e São Borja (RS) e Campo Grande (MT), que foram elaboradas pelo método exclusivamente aerofotogramétrico (PEREIRA, 2009). Destacam-se mapeamentos sistemáticos posteriores de Ponta Grossa (escala 1:25.000), e de 1955 na região de fronteira com a Argentina (escala 1:50.000 e 1:100.000). Ambos foram executados por levantamentos topográficos e impressos pela recém criada segunda Diretoria de Serviço Geográfico (DSG) do Ministério da Guerra. Acredita-se que a recém criada segunda Diretoria de Serviço Geográfico (1946) que ficava em Ponta Grossa-PR influenciou para que os primeiros trabalhos fossem nessa região. Esta diretoria foi transferida em 1972 para o distrito federal em Brasília-DF (EVANGELISTA, 2002).

Outra instituição relevante nos processos de mapeamento sistemático federal foi a CNG. Criada como um departamento do IBGE, promoveu uma política de demarcação territorial. Como se pode observar em resolução promulgada pelo governo federal em 20 de julho de 1938 ( $n^{\circ}$ 35), que determinou ao Diretório Central da CNG "o estudo de um plano de intensificação no país dos levantamentos territoriais, sobretudo com os recursos modernos da aerofotogrametria" (SANTOS; CASTIGLIONE, 2014).

A necessidade de conhecer os recursos naturais e garantir o desenvolvimento urbano

1 LEVANTAMENTO Aerophotographico em Bauru e Araquara. Jornal Estado de São Paulo, p. 4-1, 1938-39.

${ }^{2}$ Emíle Wolf, criou no Brasil, um aparelho restituidor de simples aplicação e de baixo custo, o Estereógrafo Wolf, mais tarde aperfeiçoado pelo General Benjamim Arcoverde e que recebeu o nome de Auto-estereógráfo (SILVA, 2011). 
do Brasil protagonizado pelos grandes êxodos rurais que se iniciaram na década de 40, proporcionaram a intensificação dos levantamentos aerofotogramétricos (ALVES; MARRA, 2009). Para atender a estas necessidades paulistas o recém criado IGG tinha as atribuições de realizar levantamentos topográficos e geodésicos, maiores detalhes no Apêndice A.1. Porém, o desafio de conhecer um território muito extenso como o paulista só se mostrava exequível com o uso da metodologia aerofotogramétrica, conforme descrito na resolução n ${ }^{\circ} 35$ da CNG.

\section{C.1.1 Aerofotogrametria da Força Aérea Americana no Brasil}

Para o governo americano o fim da segunda gerra mundial e a necessidade de conhecer os recursos naturais motivaram em abril de 1946 a criação do Inter American Geodetic Survey - IAGS. Este programa ficou sob a responsabilidade das forças armadas americanas, sendo a estas atribuída a tarefa da elaboração do mapeamento de áreas das Américas em conjunto com os diversos países das Américas do Sul, Central e Antilhas. Para realizar esta tarefa, em convênio com cada país, o IAGS criou em 1952 a Escola de Cartografia em Fort Clayton no Panamá. E, em sua criação (1972), já tinha treinado (em espanhol) mais de 3500 técnicos entre civis e militares (WOOD, 1974).

Conforme relatado por Granicher (1972), a cooperação técnico-científica entre instituições de países da América, o IAGS forneceu treinamento a diversos técnicos; estes treinamentos foram muito importantes para a formação do corpo técnico que foi aproveitado por diversas instituições dos países de origem. A estrutura de cooperação/treinamento era dividida em grandes áreas como: estabelecimento de rede geodésica, utilização de aerofotogrametria e posteriormente (1974) mapeamento utilizando imagens de satélite do projeto SKYLAB (STAPLES, 1974).

Embora os acordos para levantamento só fossem assinados em 1946, a necessidade da utilização de bases aéreas em pontos estratégicos no final da segunda guerra mundial fez com que o governo norte americano, em 1941, iniciasse a construção de bases aéreas na Região Nordeste do Brasil (SHELE et al. 2011). O trânsito intenso de aeronaves durante o final da segunda guerra permitiu o recobrimento aerofotogramétrico desta região pelo sistema Trimetrogon e o estabelecimento de pontos de apoio astronômico, efetivados em 1942 e anos subsequentes. Esses trabalhos foram realizados pela Força Aérea Norte Americana, proporcionando um rápido reconhecimento de territórios. No Brasil foram fotografadas áreas, de grande extensão, que não haviam sido mapeadas na região do nordeste, utilizando a tecnologia do Trimetron. Essas regiões são ilustradas na área mais 
escura do mapa da figura 83 (CORRÊA FILHO, 1987, p. 32).

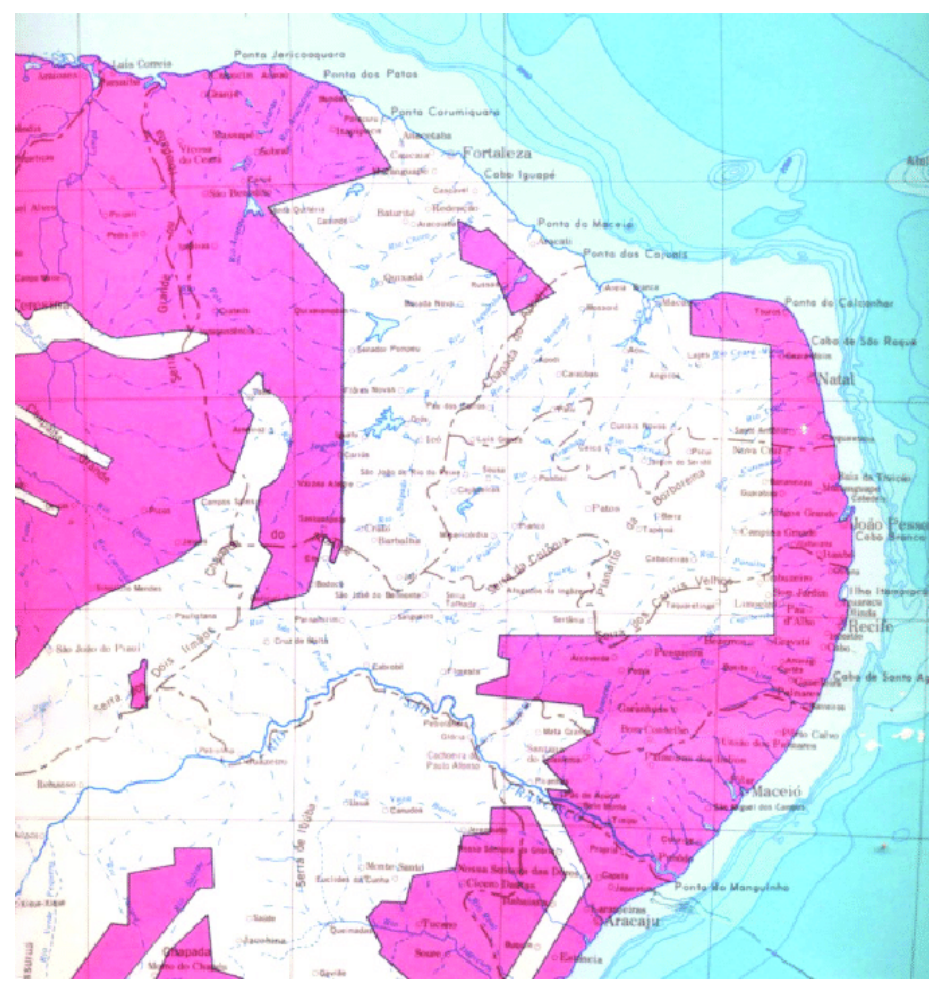

Figura 83: Áreas de levantamento Trimetron na região nordeste do Brasil (1943 a 1945) Fonte: SUDENE (1968)

Com a publicação do decreto-lei $n^{\circ} 9.210^{1}$ ficaram atribuídas à CNG as definições normativas para a cartografia nacional (BRASIL, 1946). As primeiras aplicações destas normas em mapeamentos sistemáticos foram materializadas por folhas topográficas elaboradas pela CNG, utilizando levantamentos americanos em Trimetron e publicadas em 19492, uma delas para a o desenho da região da cachoeira de Paulo Afonso - BA a qual viria a se tornar barragem/represa seis anos depois. Já em 1953 (no governo Vargas 51-54) foi promulgado o decreto 33.044 de 15 de julho de 1953 que, dentre outras normatizações, estabeleceu um processo de cooperação na produção de mapas e cartas topográficas ${ }^{3}$, tendo como base tecnológica para determinação de coordenadas horizontais, as técnicas de rádio posicionamento, descritas em Brasil (1953). A execução destes trabalhos só foi iniciada na década de 60 com o primeiro presidente do regime militar, Castelo Branco, que estabeleceu um grupo de trabalho para definir as Diretrizes e Bases da Política Cartográfica Nacional, que culminou no Acordo Brasil - Estados Unidos Sobre Serviços Cartográficos, a chamada Comissão Mista Executora do Acordo Brasil Estados Unidos Sobre Serviços Cartográficos - CMEABEUSC. Isso foi estabelecido pelo decreto

\footnotetext{
${ }^{1}$ Decreto-lei número 9.210, de 29 de abril de 1946 (BRASIL, 1946).

${ }^{2}$ Informação disponível na carta 1:250.000 (SC-24-NE-3) elabora da pela CNG em 1949.

${ }^{3}$ Mapas no Brasil custaram 4 milhões de dólares - Jornal o Correio da Manhã 19 de junho de 1954 (BRASIL, 1953).
} 
57.814 1 Mesmo antes dos acordos, o exército americano já executava os voos em território brasileiro, a cargo de sua Força Aérea 2 , sendo conhecido como acordo United States Air Force de 1965 (USAF-1965) e a equipe dessa força aérea norte americana ficou conhecida como Aerial Survey Teams 10 - AST10 (LEAL, 2007, p.123). A equipe e o avião estão retratados na figura 84 .

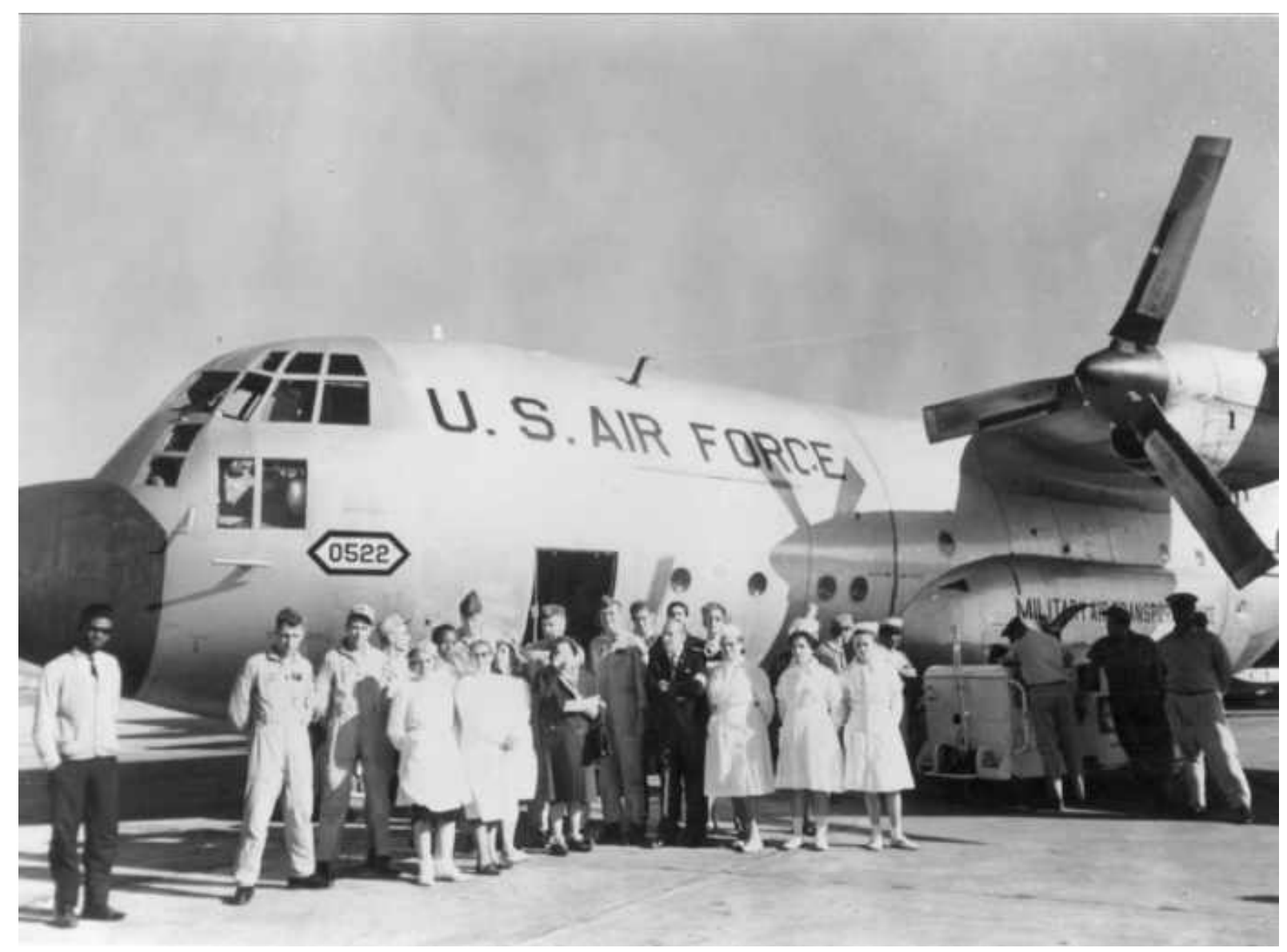

Figura 84: Avião e equipe da USAF Missão AST10

Fonte: Kingsbury (1966)

Para a realização do recobrimento fotogramétrico da USAF foram escolhidas as escalas do voo de 1:60.000 e 1:20.000, sendo utilizada a câmera Fairchild KC-1B. A Força Aérea Americana e a comissão (CMEABEUSC) estudaram e planejaram dividir a área do Brasil em dois grandes projetos: AF 63-32 e AF 63-32A. O projeto AF63-32 foi subdividido em áreas de 1 a 8 e o projeto AF 63-32A, em áreas de 9 a 14 como pode ser observado no mapa da direita na figura 85. O tempo de execução do projeto foi de 1964 a 1967 LEAL, 2007, p. 126).

${ }^{1}$ Decreto $\mathrm{n}^{\circ}$ 57.814, de 15 de Fevereiro de 1966 (BRASIL, 1966).

${ }^{2}$ Documentos da força aérea Americana relatam que em 1962 as triangulações HIRAN 


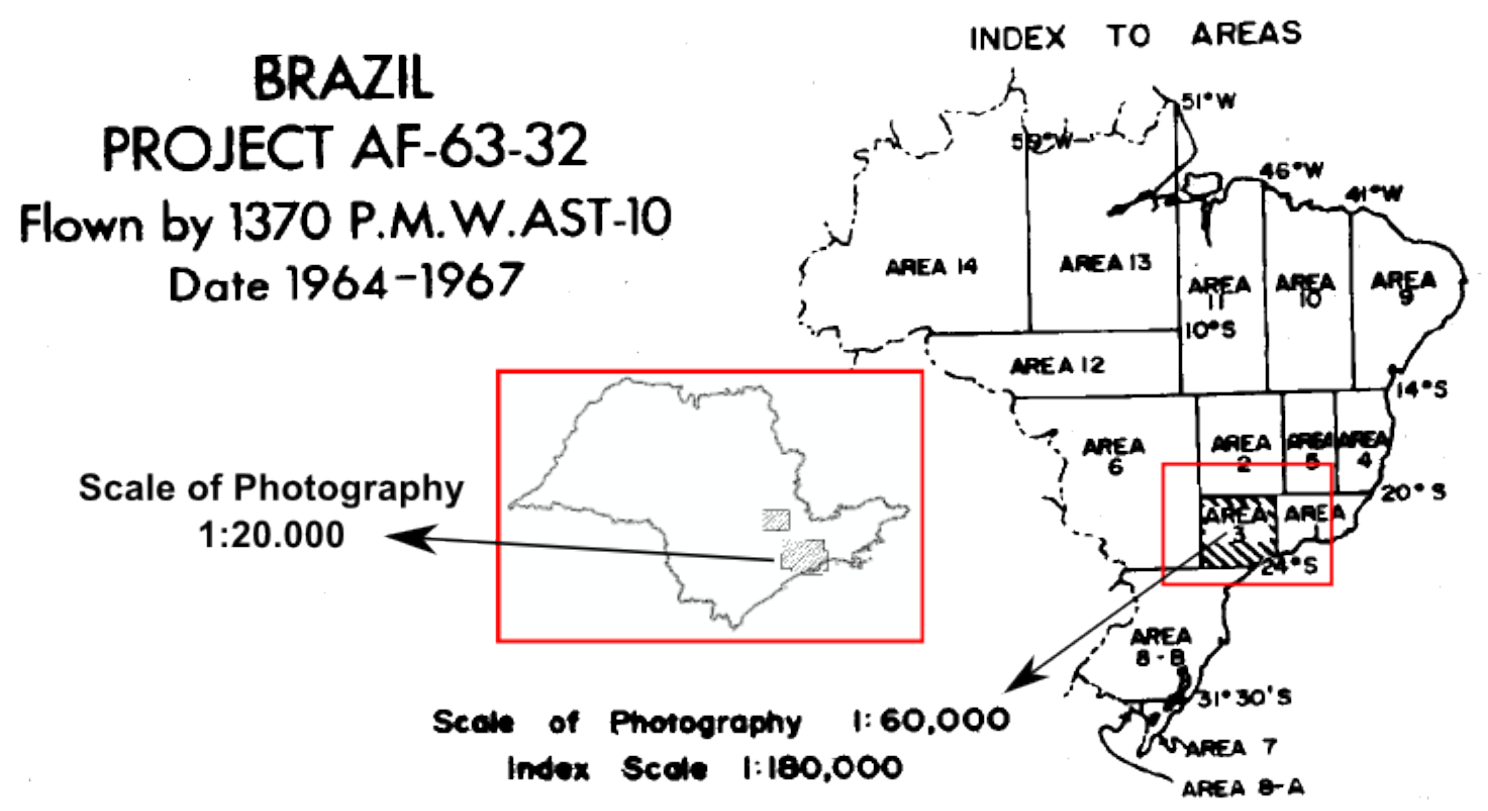

Figura 85: Informações de legenda de um fotoindice (São Paulo) do voo da USAF Fonte: Autor a partir de compilação do acervo IGCSP (2017)

A principal técnica utilizada no voo da USAF foi o levantamento geodésico aéreo SHORAN/HIRAN, que consistia na determinação de coordenadas a partir de dispositivos eletrônicos embarcados em aeronaves. Este método exige a utilização de duas estações terrestres (em posições conhecidas) e depois voar em planos seccionados abrangidos por estas bases. O equipamento no avião envia sinais de rádio e depois de alguns cálculos determina de maneira precisa as distâncias entre as duas estações (já conhecidas) calibrando cálculos. Uma terceira estação terrestre podia então ser adicionada, sua distância aos dois primeiros pontos calculadas, e assim por diante, formando uma rede de triângulos em constante expansão. Como cada lado do segmento em solo poderia ter até 805 quilômetros de comprimento, o método HIRAN era indicado pois realizava medições rápidas e precisas da distância, quando comparado a técnicas anteriores, principalmente sobre o oceano, selva, gelo polar e outras grandes áreas que não podiam ser mapeadas por equipes de levantamento topográfico de solo e desta forma diminuía custos e aumentava a produtividade (LAURILA, 1957). Um sistema com funcionamento parecido é o descrito por Thompson (1966); este foi utilizado para a elaboração dos mapas topográficos da United States Geological Survey (USGS).

Já a disponibilização das fotografias do voo AST-10 seria pública e irrestrita, conforme descrevem documentos do governo norte americano. Mas a pressão de empresas brasileiras, do ramo da aerofotogrametria, fizeram que fossem recomendadas restrições ao acesso de tais informações (IAGS1965, 1965a). 
Os contatos e intercâmbios técnicos foram intensificados já durante o voo AST-10; um exemplo foi a execução no sudeste Brasileiro quando diversas autoridades incluindo civis como o Diretor do IGGSP, o senhor engenheiro Waldemar Lefreve, acompanharam alguns procedimentos (IAGS1965, 1965b). Este alinhamento proporcionou trabalhos em conjunto, como a elaboração de cartas 1:250.000 pelo governo americano e a Diretoria de Serviço Geográfico ${ }^{1}$ e trabalhos específicos como a elaboração da carta 1:12.500 da cidade de São Paulo e regiões próximas (FIGUEIRÔA et al., 1985, pg. 53). Além de trabalhos em conjunto, a força aérea americana proporcionou treinamentos pelo Inter American Geodetic Survey (IAGS). Estes foram concedidos a funcionários do IBGE, que foram enviados ao Panamá para efetuar os cursos de produção cartográfica².

\section{C.1.2 Empresas Paulistas de Aerofotogrametria (1945-1969)}

\section{Empresa Natividade Aerofotogrametria}

Para Nestor Henrique Moraes Natividade piloto e instrutor de voo, bacharel em Letras e fundador da empresa com seu sobrenome (Natividade) apontava o comprometimento desta com a aerofotogrametria e principalmente com levantamentos realizados no Estado de São Paulo. Sabe-se que em março de 1939, esse profissional já atuava como diretor técnico do novo Aeroclube de Poços de Caldas, iniciativa presidida por Walter Moreira Salles?. Segundo depoimento, para o presente trabalho, de Ruy Natividade $\bigsqcup^{4}$ ele informalmente fundou a Sociedade Construtora Aeronaútica Itapema Ltda em 1940, e oficialmente em 1942, para construir planadores e um avião tipo Piper Club de dois lugares. Na área de fotogrametria, em 1946, fundou a empresa Natividade de Levantamentos Aéreos; depois em 1950 fundou a Aeromapa Brasil, especializada em serviços de aerofotogrametria. Esta tendo como sócios: os italianos Enrico Landi e Carlo Baldini e o engenheiro Brasileiro Raul de Moraes Natividad£5. Outra atividade executada entre 1945 e 1953 foi a criação de uma empresa de táxi aéreo, atuando também como piloto particular de Assis Chateubriand dos Diários Associados. Os trabalhos realizados pela empresa Natividade, no Estado de São Paulo, foram: Levantamento Aerofotogramétrico para as indústrias Matarazzo em Campos do Jordão (1946), Levantamento Aerofotogramétrico para a companhia Moura

\footnotetext{
${ }^{1}$ Informações que constam na legendas de cartas do Brasil disponibilizadas pela USGS.

${ }^{2}$ Autorização para viagem oficial de servidores do IBGE para o Panamá publicada no Diário Oficial da União (DOU) de 2 de fevereiro de 1971 pg.21 Seção 1.

${ }^{3}$ Atividades do Aeroclube de Poços de Caldas. Folha da Manhã, São Paulo, 16 de março de 1939, página 4.

${ }^{4}$ Depoimento pessoal sobre seu pai. Filho de Nestor Henrique Moraes Natividade, São Paulo, 16 de julho de 2017.

${ }^{5}$ Diario Oficial do Estado de Sâo Paulo 30 de setembro de 1953
} 
Andrade nos municípios de Bebedouro e Pitangueiras (1948) e os trabalhos realizados para o IGG descritos a seguir.

Os primeiros voos fotogramétricos da empresa Natividade para o IGG são registrados em documentos internos do Instituto, são datados do ano de 1946. Segundo Rocha (1947) este voo foi feito com uma câmera Farchild modelo T5 (f. $152 \mathrm{~mm}$, chapa de $24 \times 24 \mathrm{~cm}$, na escala 1:20.000) de propriedade do então Departamento de Águas do Ministério da Agricultura. A lista de locais pode ser observada na tabela 29, Os levantamentos foram feitos de forma linear e recobriram feições hidrográficas específicas, muito diferente dos voos feitos posteriormente que abrangem áreas mais retangulares, ou seja, não somente faixas correspondendo a rios.

\begin{tabular}{c|c|c|c}
\hline Rios & $\mathbf{k m}$. Linear & $\mathbf{k m}^{2}$. Área & $\mathbf{k m}$. larg. Média \\
\hline Paranapanema & 650 & 2367 & 3,64 \\
\hline Tiete & 405 & 892 & 2,20 \\
\hline Taquarí & 70 & 283 & 4,04 \\
\hline Batalha & 90 & 499 & 5,54 \\
\hline Barra Mansa & 95 & 418 & 4,40 \\
\hline Paraná & 325 & 1759 & 5,41 \\
\hline Itararé & 100 & 456 & 4,56 \\
\hline Total & 1735 & 6664 &
\end{tabular}

Tabela 29: Tabela de levantamentos de 1947 feitos pela Natividade Fonte: Rocha (1947)

Em 1954 foi registrada a empresa Aerofoto Natividade Ltda que em 1967, havendo uma mudança na constituição da empresa, adotou a designação Aerofoto Natividade S/A Nessa época a empresa mantinha um hangar em Congonhas e escritórios com equipamentos aerofotogramétricos. Como ilustra a figura 86 foram utilizados dois aviões para a realização de diversos aerolevantamentos, entre 1954 e 1967. Outros equipamentos essenciais para este trabalho destaca-se a compra da câmera Wild RC9 importada dos Estados Unidos e os estéreo restituidores Galileo Santoni analog stereoplotter modelo III e modelo IV, já apresentados na página 106 .

\footnotetext{
${ }^{1}$ Notícia publicada no Diário oficial do Estado de São Paulo 08 de dezembro de 1967
} 

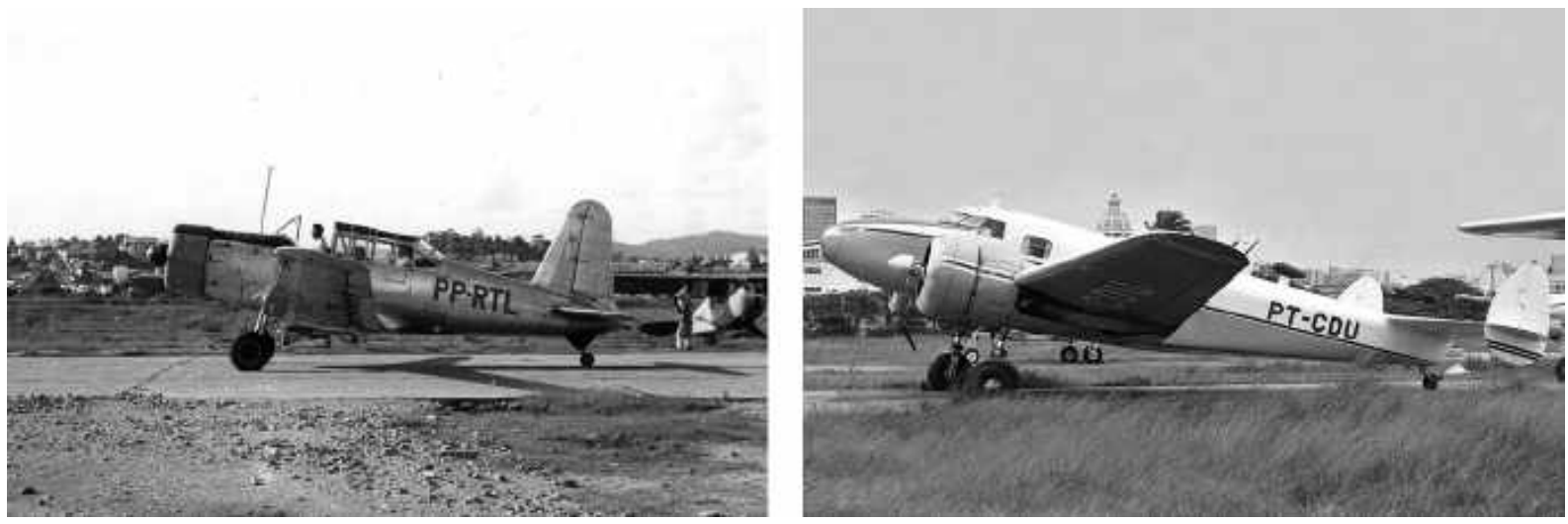

Figura 86: Aviões da Natividade Vultee BT-13A (PP-RTL) e Lockheed (PT-CDU)

Fonte: Autor a partir de compilação do acervo pessoal de Ruy Natividade

As atividades da empresa foram encerradas com a venda das empresas Natividade e Aeromapa, como descrito no depoimento a seguir, no início da década de 1970 (IDOETA et al. 2004). Segundo relatos de seu filho Ruy Natividade existia uma certa "indicação" por parte do regime para que a empresa tivesse participação de membros militares o que teria sido consolidado com a venda.

"No inicio da década de 70 a Aerofoto Cruzeiro do Sul comprou a Aerofoto Natividade e a Aeromapa Brasil (ambas empresas do meu pai) e propôs a compra da Geotel a Antonio Cobo Neto e Irineu Idoeta, condicionando a compra a que esses dois profissionais juntamente com seus dois sócios mais recentes, Cel. Divaldo Galvão de Lima e Lyrio Silva de Paula, assumissem a diretoria da Aeromapa que incorporaria a Aerofoto Natividade e a Geotel.[...]" (IDOETA et al. 2004 , p. 17, grifo nosso)

Esta influência é confirmada por outros testemunhos da época, como em entrevista concedida para esta dissertação pelo engenheiro Antônio Cobo Neto. Este, um dos fundadores da empresa Base Aerofotogrametria em 1974, relembra alguns dos fatos ocorridos durante a década de 1960, a transcrição dessa entrevista encontra-se no Apêndice D.1 (página 189).

\section{Empresa VASP Aerofotogrametria}

A empresa Viação Aérea São Paulo (VASP), foi fundada em meados de 1933, sendo privatizada pelo governo paulista por contrato firmado em 19351. Isso garantia aportes do governo estadual visando a execução de voos principalmente entre São Paulo e a então

\footnotetext{
${ }^{1}$ Notícia publicada no Diário oficial do Estado de São Paulo 08 de outubro de 1935
} 
Capital federal, o Rio de Janeiro. O braço de fotogrametria da empresa, a VASP aerofotogrametria foi fundada em maio de 1952. Com o objetivo de especializar-se, firmou contrato para transferência de conhecimento, com Instituto romano "Instituto Fotogramétrico Relevatori Methodo Nistri". Além do suporte com o investimento estadual, tentou financiamento junto à prefeitura de São Paulo para construir um departamento especializado no Estadd 1 . Outros trabalhos eram efetuados como o de aerolevantamentos para CESP (projetos de linha de transmissão) e COSIPA (Cálculo de volume de rejeito) (NOTARI, 1972).

Em 1955 diversas instituições estaduais, por exemplo: IGG, DER, DAEE..., já haviam sido criadas e para subsidiar seus trabalhos contratavam voos fotogramétricos, cada um por sua conta. A VASP, por sua vez, entendeu que tais voos, executados por diversas empresas e sem nenhuma coordenação, gerava "sobreposição" de trabalhos. Para mudar esta realidade e tentar garantir estes recursos a VASP entrega, através de seu presidente, um relatório ao governador do Estado de São Paulo, o senhor Jânio Quadros, mostrando que esses órgãos estavam comprando imagens de forma repetida. Com este argumento a VASP propõem uma cobertura aerofotogramétrica de todo o Estado em escala 1:20.000 de forma "vantajosa" ao governd22. Outro fato acontecido ainda em 1955 foi a participação da VASP Aerofotogrametria no processo licitatório, com voo aerofotogramétrico (escala 1:2.000), que segundo Maniçoba e Oliveira (2015), serviram de base para os estudos realizados pela empresa americana Donald Belcher \& Associates para definir os locais para a instalação da futura Capital federal. Do processo licitatório participaram também as empresas GEOFOTO e Serviços Aerofotogramétricos Cruzeiro do Sul, sendo esta última a vencedora e executora do projeto ALBUQUERQUE et al., 2013; MANIÇOBA; OLIVEIRA, 2015).

Em 7 de outubro de 1957 foi assinado entre o IGG e a VASP Aerofotogrametria um contrato de voo para todo o Estado de São Pauld? O valor do contrato foi de 21 milhões de cruzeiros, que convertidos para valores atuais (2019) seriam aproximadamente 8 milhões de reais utilizando o índice IGP-DI (FGV). Este valor, considerado alto na época, acabou por suspender o contrato, dois dias depois de sua assinatura, pelo governador. Isso ocorreu pelo fato do mesmo ter sido informado pelo Deputado oposicionista Hilário Torloni, por meio da assembleia legislativa do Estado, que o preço cobrado pela VASP era acima do valor de mercado. O que motivou esse acontecimento, por sua vez, foi o recebimento de

\footnotetext{
${ }^{1}$ Notícia publicada no Diário Oficial do Estado de São Paulo,, 03 de novembro de 1951 .

${ }^{2}$ Notícia publicada no Diário oficial do Estado de São Paulo, 11 de outubro de 1957.

${ }^{3}$ Notícia publicada no Diário oficial do Estado de São Paulo, 05 de outubro de 1957
} 
telegrama da empresa concorrente (Serviços Aerofotogramétricos Cruzeiro do Sul S.A.)ำ Esta atividade foi retomada somente em 1959 (2 anos depois), já em forma de consórcio (entre as empresas VASP Aerofotogrametria S.A., Serviços Aerofotogramétricos Cruzeiro do Sul S.A. e Aeromapa LTDA) autorizado pelo governador e sem nenhuma objeção pela assembleia administrativa, porém agora com custo superior de 26 milhões e 640 mil cruzeiroł $2^{2}$, que atualizados (2019) atingiriam valores próximos a 10 milhões de reais ao se aplicar o índice IGP-DI (FGV). Disso se conclui, salvo maiores esclarecimentos, que o preço anterior era menor e que o Estado teria feito um melhor negócio se não fosse impugnado o contrato. Outro fato interessante foi a promulgação da Lei $n^{o} 5.447^{3}$ (proposta pelo deputado Henrique Turner) beneficiando a VASP e a Cruzeiro com isenção de impostos para adquirir aviões e equipamentos (BRASIL, 1968). Sobre os equipamentos que a VASP possuía, durante o voo de 1962, segundo Notari (1972) eram 12 restituidores Wild de modelos como os B8 e A7.

\footnotetext{
${ }^{1}$ Notícia publicada no Diário oficial do Estado de São Paulo, 09 de outubro de 1957

${ }^{2}$ Notícia publicada no Diário oficial do Estado de São Paulo, 29 de novembro de 1959.

${ }^{3}$ Brasil - Lei Federal $n^{o} 5.4474$ de junho de 1968 (BRASIL, 1968).
} 


\section{APÊNDICE D - ENTREVISTAS}

\section{D.1 Antônio Cobo Neto}

O entrevistado foi, um dos fundadores da empresa Base Aerofotogrametria em 1974, o piloto e engenheiro formado pelo exército brasileiro no início da década de 1960, o sr. Antônio Cobo Neto. Perguntado sobre os fatos ocorridos durante a década de 1960, em relação a aerofotogrametria, no trecho a seguir relata alguns acontecimentos:

Entr. - O que o senhor sabe sobre a venda da empresa Aerofoto Natividade?;

Cobo - Em 1967 eu e o Sr. Irineu montamos a empresa Geotel, e vendemos ela em 1970 para a Cruzeiro do Sul. O mesmo, na mesma época, aconteceu com a Aerofoto Natividade;

Entr. - O senhor conheceu o Nestor Henrique Natividade ?;

Cobo - Sim, claro. Convivia sempre com ele no hangar da Natividade no aeroporto de Congonhas;

Entr. - Quanto à descrição feita no livro escrito pelo senhor Idoeta sobre a compra da Aeromapa, condicionando a sociedade com alguns militares, o senhor acredita que existia realmente algum interesse nestas atividades por parte do regime?;

Cobo - Com o golpe de 1964, a atividade de aerolevantamento era considerada de interesse do Estado, tanto que qualquer acontecimento considerado de segurança nacional, por exemplo os aviões das empresas deveriam estar à disposição da força aérea brasileira. Um exemplo de militar em empresa de fotogrametria foi a diretoria da VASP ter sido ocupada nesta época pelo coronel Fleury e seu diretor técnico o Major Monteiro. Como neste exemplo, todas as empresas sofreram intervenção militar. Quando as empresas eram pequenas estas eram compradas pela Cruzeiro;

Entr. - Como estudavam as pessoas da época e qual a sua formação ?; Cobo - Sou engenheiro formado pelo exército em 1961 como a maioria dos engenheiros da época; comecei na aeronáutica, somente depois fui fazer meu curso superior no Instituto Militar de Engenharia - IME. O curso tinha disciplinas de astronomia e geodesia. Depois tive a experiência em trabalhos de aeroportos nas fronteiras do Brasil;

Entr. - O senhor conheceu algum membro do IGG? Saberia dizer algo sobre os voos executados para o IGG; 
Cobo - Sim conheci a Zilda, o Quintão e o Taliberti. Porém eles já estavam aposentados. O grande responsável desde a década de 1940 pelos voos executados para o IGG foi o sr. Nestor Natividade;

Entr. - O senhor acha que ocorreu na década de 1960 uma grande influencia dos norte americanos nesta área?;

Cobo - Sim, por sinal no governo João Goulart já havia um acordo para a realização de voo em todo o território nacional que depois se concretizou com o AST10. Engana-se quem acredita que o Jango era comunista.

\section{D.2 José Bueno Conti}

Entrevista a um dos professores da Faculdade de Filosofia, Letras e Ciências Humanas (FFLCH) da Universidade de São Paulo (USP) ao geógrafo e professor titular José Bueno Conti. Focalizando nos fatos ocorridos durante a década de 1960, em relação ao IGG, onde trabalhou durante 3 anos. No trecho a seguir o professor Conti conta alguns acontecimentos durante seu trabalho no instituto:

Entr. - Quando o senhor se formou em geografia e quais foram suas experiências profissionais?;

Conti - Em 1958 me formei no curso de Geografia pela Universidade de São Paulo, iniciei trabalhando na rede estadual de ensino. Fui convidado para trabalhar como contratado no Instituto Geográfico e Geológico em 1960, aceitei pois o ordenado era maior que ao pago como professor fiquei até 1963 e depois sai quando fui convidado a trabalhar na Faculdade de Geografia da USP;

Entr. - Como o senhor ficou sabendo da vaga?;

Conti - No departamento de Geografia da USP. O diretor do IGG ligou para lá e ofereceu vaga. Eu mais três colegas nos interessamos;

Entr. - Quais foram os trabalhos para que foram contratados e qual era seu superior no Instituto?;

Conti - Trabalhava na seção de assuntos geográficos. Minha chefe era a engenheira Zilda de Sampaio Perroni. Eu e meus colegas desenvolvíamos estudos geográficos que auxiliavam na demarcação de divisas;

Entr. - Estas demarcações como funcionavam ?;

Conti - Dado o interesse em determinar onde passava a divisa nos dirigíamos a campo e realizávamos consultas com a população local de forma a definir onde estava localizada a linha divisória;

Entr. - Como eram transcritas estas demarcações ?;

Conti - Nossa parte era a de conferir os textos e mapas conforme o que havíamos observado em campo. A forma que estes eram escritos era passado a nós pela engenheira Zilda. A forma da escrita e os termos empregados já eram utilizados anteriormente pelos engenheiros e técnicos; Entr. - A representação desta linha era dada pelo Mapa Municipal? O senhor participava desta elaboração ?;

Conti - Não executei nenhuma elaboração destes mapas; eu e meus 
colegas somente os conferíamos conforme o texto proposto. Para isso utilizávamos as cartas topográficas 100.000 e quando cheguei, no noroeste do estado, utilizávamos fotografias aéreas;

Entr. - Esta conferência por meio das fotografias era feita utilizando informações recentes?;

Conti - Quando em 1961 foram disponibilizadas as recentes fotografias do noroeste do estado de São Paulo, estas passaram a auxiliara a interpretação, principalmente para definir os divisores de águas em regiões que não tinham mapeamento 100.000 ;

Entr. - Como o senhor interpretava as fotografias?;

Conti - Utilizando técnicas de fotointerpretação conforme apreendíamos na USP, que contava com algumas fotografias, durante a graduação, com as aulas do professor Aziz Nacib Ab Saber;

Entr. - Ficou sabendo sobre os trabalhos de implementação dos marcos municipais?;

Conti - Em alguns casos solicitávamos a implementação de marcos em regiões específicas, mas não me recordo em que situações estes eram implementados;

Entr. - Quando saiu do IGG outros técnicos continuaram fazendo este trabalho?;

Conti - Eu e meus colegas geógrafos que executávamos estes trabalhos não nos motivamos muito pela função, pois já existiam profissionais engenheiros que elaboravam os mapas e descreviam as demarcações. Realizávamos o trabalho de conferência, o que não nos proporcionava muito protagonismo e assim todos acabaram saindo;

Entr. - Teve contato com alguém do IGG depois de sair ?;

Conti - Somente com a engenheira Zilda minha chefe, mas pouco tempo depois de sair ela acabou se aposentando;

Entr. - Como ficou sabendo do fim do IGG ?;

Conti - Eu já estava na Universidade, bem distante dos trabalhos do instituto, por isso fiquei sabendo muito tempo depois de seu fim. Na época pensei que foi uma pena, pois os trabalhos de elaboração da cartografia do estado e das demarcações de divisa eram muito bem executados pelos engenheiros do instituto. Sabe, acredito que são aqueles equívocos governamentais, mas pelo que sei os trabalhos de divisa agora são elaborados pelo Instituto Geográfico e Cartográfico. 


\section{APÊNDICE E - SCRIPT PARA CÁLCULO DO AJUSTAMENTO}

\section{E.1 Cálculo dos parâmetros de Herlmert}

clear ;

$/ / \mathrm{Xk}-\mathrm{SAD}$

$/ / \mathrm{X}$-OORREGO

$\mathrm{X} 1=\quad 4073664.5207377800$;

$\mathrm{X} 2=\quad 4010062.1065499100$;

$\mathrm{X} 3=\quad 4079418.8999666200 ;$

$\mathrm{X} 4=\quad 4030114.3491197900$;

$\mathrm{X} 5=\quad 4034920.0895789100 ;$

$\mathrm{X} 6=\quad 4020245.4788487200 ;$

$\mathrm{X} 7=\quad 4020445.6701426900$;

$\mathrm{Y} 1=\quad-4213915.4683267400 ;$

$\mathrm{Y} 2=\quad-4265293.8933748600$;

$\mathrm{Y} 3=\quad-4212580.9861558300$;

$\mathrm{Y} 4=\quad-4212184.7306441100$;

$\mathrm{Y} 5=\quad-4209346.4748664300 ;$

$\mathrm{Y} 6=\quad-4239054.6955613600 ;$

$\mathrm{Y} 7=\quad-4230580.1315328600 ;$

$\mathrm{Z} 1=\quad-2507875.4517445700$;

$\mathrm{Z} 2=\quad-2523372.2841696900$;

$\mathrm{Z} 3=\quad-2500801.5036608700$;

$\mathrm{Z} 4=\quad-2579626.5235106600$;

$\mathrm{Z} 5=\quad-2576764.8069038300$; 


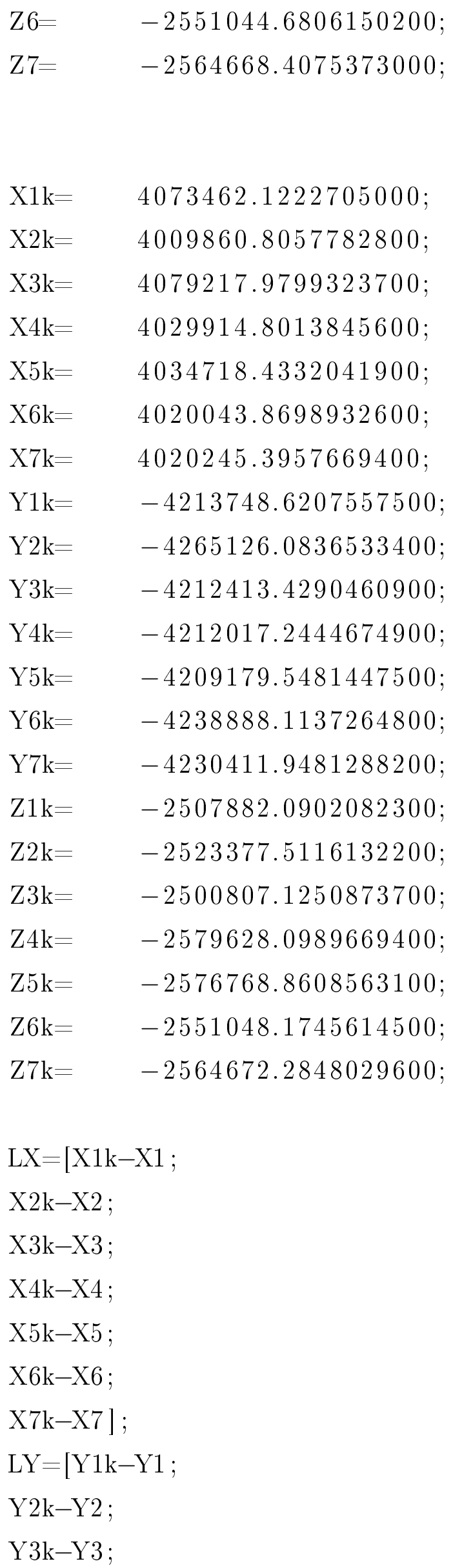


$\mathrm{Y} 4 \mathrm{k}-\mathrm{Y} 4$;

$\mathrm{Y} 5 \mathrm{k}-\mathrm{Y} 5$;

$\mathrm{Y} 6 \mathrm{k}-\mathrm{Y} 6$;

$\mathrm{Y} 7 \mathrm{k}-\mathrm{Y} 7]$;

$\mathrm{LZ}=[\mathrm{Z} 1 \mathrm{k}-\mathrm{Z} 1$;

$\mathrm{Z} 2 \mathrm{k}-\mathrm{Z} 2$;

$\mathrm{Z} 3 \mathrm{k}-\mathrm{Z} 3$;

$\mathrm{Z} 4 \mathrm{k}-\mathrm{Z} 4$;

$\mathrm{Z} 5 \mathrm{k}-\mathrm{Z} 5$;

$\mathrm{Z} 6 \mathrm{k}-\mathrm{Z} 6$;

$\mathrm{Z7k}-\mathrm{Z7}$ ] ;

$\mathrm{L}=[\mathrm{X} 1 \mathrm{k}-\mathrm{X} 1$;

$\mathrm{Y} 1 \mathrm{k}-\mathrm{Y} 1$;

$\mathrm{Z1k}-\mathrm{Z} 1$;

$\mathrm{X} 2 \mathrm{k}-\mathrm{X} 2$;

$\mathrm{Y} 2 \mathrm{k}-\mathrm{Y} 2$;

$\mathrm{Z} 2 \mathrm{k}-\mathrm{Z} 2$;

$\mathrm{X} 3 \mathrm{k}-\mathrm{X} 3$;

$\mathrm{Y} 3 \mathrm{k}-\mathrm{Y} 3$;

$\mathrm{Z} 3 \mathrm{k}-\mathrm{Z} 3$;

$\mathrm{X} 4 \mathrm{k}-\mathrm{X} 4$;

$\mathrm{Y} 4 \mathrm{k}-\mathrm{Y} 4$;

Z4k-Z4;

$\mathrm{X} 5 \mathrm{k}-\mathrm{X} 5$;

$\mathrm{Y} 5 \mathrm{k}-\mathrm{Y} 5$;

Z5k-Z5;

$\mathrm{X} 6 \mathrm{k}-\mathrm{X} 6$;

$\mathrm{Y} 6 \mathrm{k}-\mathrm{Y} 6$;

$\mathrm{Z} 6 \mathrm{k}-\mathrm{Z} 6$;

$\mathrm{X} 7 \mathrm{k}-\mathrm{X} 7$;

$\mathrm{Y} 7 \mathrm{k}-\mathrm{Y} 7$;

$\mathrm{Z7k}-\mathrm{Z7}$; ] ;

$\mathrm{A}=[1,0,0, \mathrm{X} 1,0,-\mathrm{Z} 1, \mathrm{Y} 1$;

$0,1,0, \mathrm{Y} 1, \mathrm{Z} 1,0,-\mathrm{X} 1$;

$0,0,1, \mathrm{Z} 1,-\mathrm{Y} 1, \mathrm{X} 1,0$;

$1,0,0, \mathrm{X} 2,0,-\mathrm{Z} 2, \mathrm{Y} 2$; 


$$
\begin{aligned}
& 0,1,0, \mathrm{Y} 2, \mathrm{Z} 2,0,-\mathrm{X} 2 ; \\
& 0,0,1, \mathrm{Z} 2,-\mathrm{Y} 2, \mathrm{X} 2,0 ; \\
& 1,0,0, \mathrm{X} 3,0,-\mathrm{Z} 3, \mathrm{Y} 3 ; \\
& 0,1,0, \mathrm{Y} 3, \mathrm{Z} 3,0,-\mathrm{X} 3 ; \\
& 0,0,1, \mathrm{Z} 3,-\mathrm{Y} 3, \mathrm{X} 3,0 ; \\
& 1,0,0, \mathrm{X} 4,0,-\mathrm{Z} 4, \mathrm{Y} 4 ; \\
& 0,1,0, \mathrm{Y} 4, \mathrm{Z} 4,0,-\mathrm{X} 4 ; \\
& 0,0,1, \mathrm{Z} 4,-\mathrm{Y} 4, \mathrm{X} 4,0 ; \\
& 1,0,0, \mathrm{X} 5,0,-\mathrm{Z} 5, \mathrm{Y} 5 ; \\
& 0,1,0, \mathrm{Y} 5, \mathrm{Z} 5,0,-\mathrm{X} 5 ; \\
& 0,0,1, \mathrm{Z} 5,-\mathrm{Y} 5, \mathrm{X} 5,0 ; \\
& 1,0,0, \mathrm{X} 6,0,-\mathrm{Z} 6, \mathrm{Y} 6 ; \\
& 0,1,0, \mathrm{Y} 6, \mathrm{Z} 6,0,-\mathrm{X} 6 ; \\
& 0,0,1, \mathrm{Z} 6,-\mathrm{Y} 6, \mathrm{X} 6,0 ; \\
& 1,0,0, \mathrm{X} 7,0,-\mathrm{Z} 7, \mathrm{Y} 7 ; \\
& 0,1,0, \mathrm{Y} 7, \mathrm{Z} 7,0,-\mathrm{X} 7 ; \\
& 0,0,1, \mathrm{Z} 7,-\mathrm{Y} 7, \mathrm{X} 7,0 ;
\end{aligned}
$$$$
\text { ]; }
$$$$
\mathrm{U}=\left(\mathrm{A}^{\prime} * \mathrm{~L}\right) \text {; }
$$$$
\mathrm{N}=\left(\operatorname{inv}\left(\mathrm{A}^{\prime} * \mathrm{~A}\right)\right) \text {; }
$$

$\mathrm{X}=\mathrm{N} * \mathrm{U}$;

$\mathrm{V}=\mathrm{A} * \mathrm{X}-\mathrm{L}$;

$\operatorname{sigma}=\left(\mathrm{V}^{\prime} * \mathrm{~V}\right) / 14$;

$\mathrm{MvcXa}=\operatorname{sigma} * \mathrm{~N}$;

raizMvc $=(\operatorname{sqrt}(\operatorname{MvcXa}))$

diagonal_raiz $=\operatorname{diag}(\operatorname{raizMvc})$

$\mathrm{Xdiag}=\mathrm{X} . / \operatorname{diag}($ raizMvc)

$[\mathrm{T}]=\mathrm{cdft}(" \mathrm{~T} ", 14,0.95,0.05)$

\section{E.2 Cálculo por três parâmetros}

clear ;

$/ / \mathrm{Xk}$-SIRGAS

$/ / \mathrm{X}$-OORREGO 


$\begin{array}{ll}\mathrm{X} 1= & 4079418.8999666200 ; \\ \mathrm{X} 2= & 4010062.1065499100 ; \\ \mathrm{X} 3= & 4020445.6701426900 ; \\ \mathrm{X} 4= & 4020445.6701426900 ; \\ \mathrm{Y} 1= & -4212580.9861558300 ; \\ \mathrm{Y} 2= & -4265293.8933748600 ; \\ \mathrm{Y} 3= & -4230580.1315328600 ; \\ \mathrm{Y} 4= & -4230580.1315328600 ; \\ \mathrm{Z} 1= & -2500801.5036608700 ; \\ \mathrm{Z} 2= & -2523372.2841696900 ; \\ \mathrm{Z} 3= & -2564668.4075373000 ; \\ \mathrm{Z} 4= & -2564668.4075373000 ;\end{array}$

$\mathrm{X} 1 \mathrm{k}=\quad 4079217.9799323700$;

$\mathrm{X} 2 \mathrm{k}=\quad 4009860.8057782800$;

$\mathrm{X} 3 \mathrm{k}=\quad 4020245.3957669400$;

$\mathrm{X} 4 \mathrm{k}=\quad 4020245.3957669400$;

$\mathrm{Y} 1 \mathrm{k}=\quad-4212413.4290460900 ;$

$\mathrm{Y} 2 \mathrm{k}=\quad-4265126.0836533400 ;$

$\mathrm{Y} 3 \mathrm{k}=\quad-4230411.9481288200$;

$\mathrm{Y} 4 \mathrm{k}=\quad-4230411.9481288200 ;$

$\mathrm{Z1k}=\quad-2500807.1250873700$;

$\mathrm{Z} 2 \mathrm{k}=\quad-2523377.5116132200$;

$\mathrm{Z} 3 \mathrm{k}=\quad-2564672.2848029600$;

$\mathrm{Z} 4 \mathrm{k}=\quad-2564672.2848029600$;

$\mathrm{L}=[\mathrm{X} 1 \mathrm{k}-\mathrm{X} 1$;

$\mathrm{Y} 1 \mathrm{k}-\mathrm{Y} 1$;

$\mathrm{Z} 1 \mathrm{k}-\mathrm{Z1}$;

$\mathrm{X} 2 \mathrm{k}-\mathrm{X} 2$;

$\mathrm{Y} 2 \mathrm{k}-\mathrm{Y} 2$;

$\mathrm{Z} 2 \mathrm{k}-\mathrm{Z} 2$;

$\mathrm{X} 3 \mathrm{k}-\mathrm{X} 3$;

$\mathrm{Y} 3 \mathrm{k}-\mathrm{Y} 3$;

$\mathrm{Z} 3 \mathrm{k}-\mathrm{Z} 3$; 
$\mathrm{X} 4 \mathrm{k}-\mathrm{X} 4$;

$\mathrm{Y} 4 \mathrm{k}-\mathrm{Y} 4$;

$\mathrm{Z} 4 \mathrm{k}-\mathrm{Z} 4$; ] ;

$\mathrm{A}=[1,0,0 ;$

$0,1,0$;

$0,0,1$;

$1,0,0$;

$0,1,0$;

$0,0,1$;

$1,0,0$;

$0,1,0$;

$0,0,1$;

$1,0,0$;

$0,1,0$;

$0,0,1$;

];

$\mathrm{U}=\left(\mathrm{A}^{\prime} * \mathrm{~L}\right)$;

$\mathrm{N}=\left(\operatorname{inv}\left(\mathrm{A}^{\prime} * \mathrm{~A}\right)\right)$;

$\mathrm{X}=\mathrm{N} * \mathrm{U}$;

$\mathrm{V}=\mathrm{A} * \mathrm{X}-\mathrm{L}$;

$\operatorname{sigma}=\left(\mathrm{V}^{\prime} * \mathrm{~V}\right) / 9$;

$\mathrm{MvcXa}=\operatorname{sigma} * \mathrm{~N}$;

$\operatorname{raizMvc}=(\operatorname{sqrt}(\operatorname{MvcXa}))$

diagonal_raiz $=$ diag $($ raizMvc)

$\mathrm{Xdiag}=\mathrm{X} . / \operatorname{diag}(\operatorname{raizMvc})$

$\mathrm{T}=\mathrm{cdft}($ "T" , $9,0.95,0.05)$ 


\section{APÊNDICE F - TABELAS DE COORDENADAS E CÁLCULOS POSICIONAIS}

Tabela 30: Coordenadas coletadas na área C para avaliação posicional

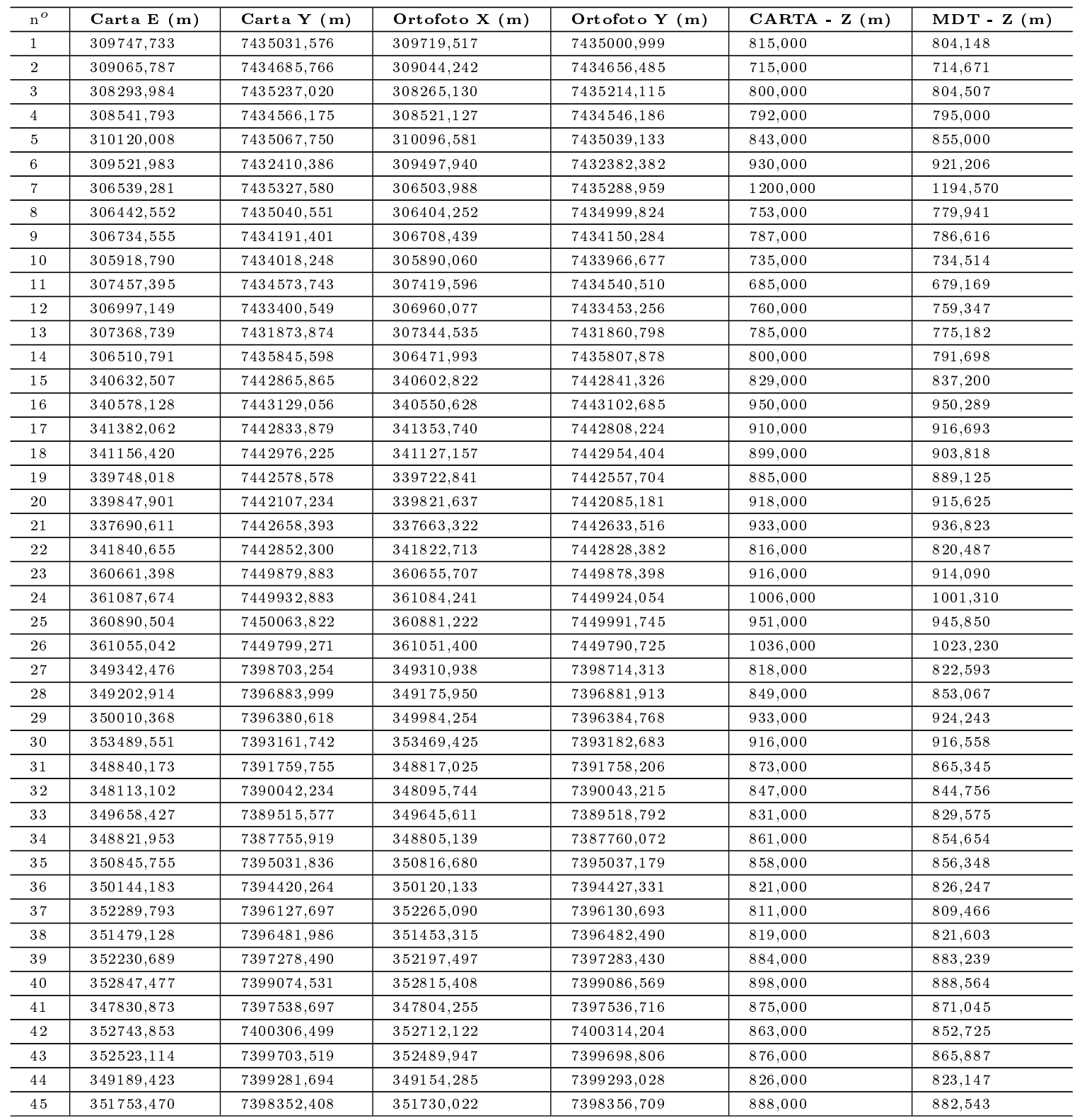


Continuando Tabela 30 da página anterior

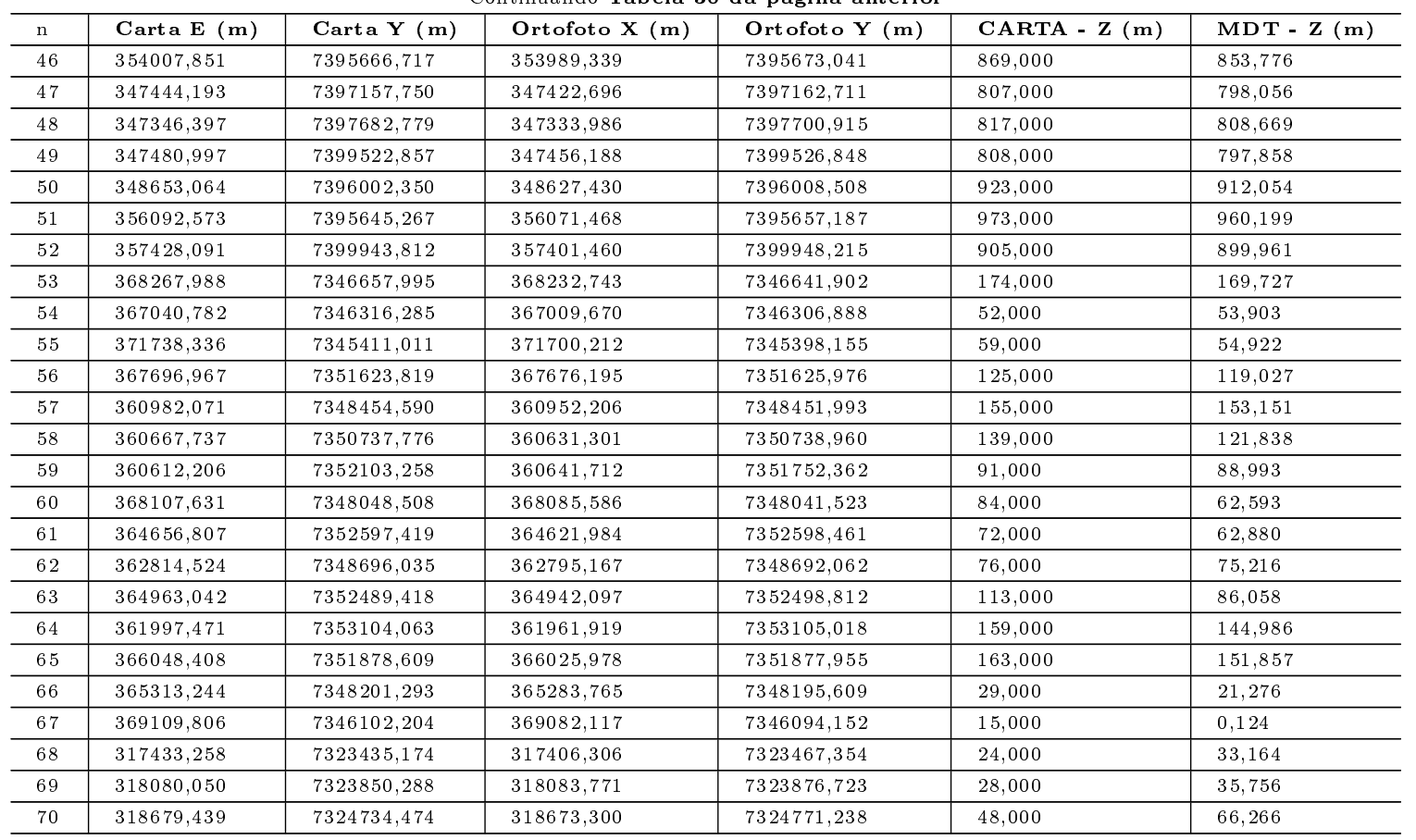

Tabela 31: Coordenadas altimétricas e suas discrepâncias para verificação posicional

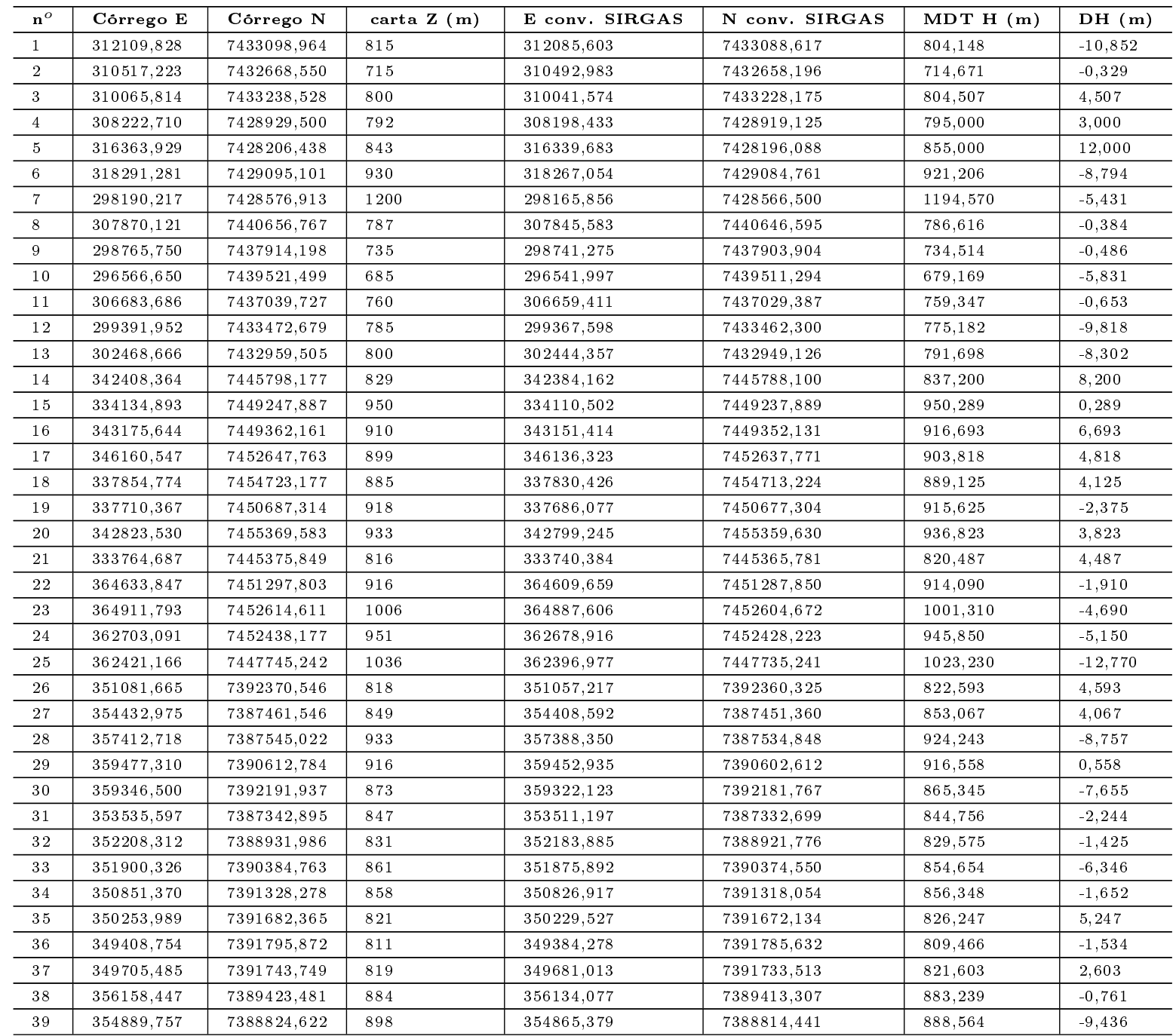


Continuando Tabela 31 da página anterior

\begin{tabular}{|c|c|c|c|c|c|c|c|}
\hline $\mathbf{n}^{O}$ & Córrego $\mathbf{E}$ & Cörrego N & Carta H (m) & E conv. SIRGAS & N conv. SIRGAS & MDT H (m) & DH (m) \\
\hline 40 & 355299,332 & 7388699,738 & 875 & 355274,963 & 7388689,562 & 871,045 & $-3,955$ \\
\hline 41 & 354448,629 & 7390293,062 & 863 & 354424,240 & 7390282,877 & 852,725 & $-10,275$ \\
\hline 42 & 351562,548 & 7391299,363 & 876 & 351538,108 & 7391289,146 & 865,887 & $-10,113$ \\
\hline 44 & 358841,370 & 7388817,421 & 888 & 358816,996 & 7388807,248 & 882,543 & $-5,457$ \\
\hline 45 & 357330,180 & 7391492,870 & 869 & 357305,804 & 7391482,697 & 853,776 & $-15,224$ \\
\hline 48 & 358696,028 & 7386741,850 & 808 & 358671,658 & 7386731,675 & 797,858 & $-10,142$ \\
\hline 49 & 357173,613 & 7387059,351 & 923 & 357149,247 & 7387049,177 & 912,054 & $-10,946$ \\
\hline 50 & 356535,437 & 7386751,375 & 973 & 356511,073 & 7386741,201 & 960,199 & $-12,801$ \\
\hline 51 & 355840,110 & 7387616,565 & 905 & 355815,746 & 7387606,391 & 899,961 & $-5,039$ \\
\hline 52 & 361227,802 & 7348900,688 & 174 & 361202,512 & 7348890,213 & 169,727 & $-4,273$ \\
\hline 57 & 361773,791 & 7350414,292 & 139 & 361748,539 & 7350403,836 & 121,838 & $-17,162$ \\
\hline 58 & 365836,947 & 7345239,240 & 91 & 365811,561 & 7345228,735 & 88,993 & $-2,007$ \\
\hline 59 & 371642,438 & 7346858,501 & 84 & 371617,091 & 7346848,030 & 72,593 & $-11,407$ \\
\hline 60 & 371713,876 & 7346873,582 & 72 & 371688,529 & 7346863,112 & 62,880 & $-9,120$ \\
\hline 61 & 362422,572 & 7351374,541 & 76 & 362397,345 & 7351364,097 & 75,216 & $-0,784$ \\
\hline 62 & 362055,297 & 7350258,273 & 159 & 361820,779 & 7351169,526 & 144,986 & $-14,014$ \\
\hline 63 & 365648,013 & 7358701,331 & 163 & 362030,041 & 7350247,816 & 151,857 & $-11,143$ \\
\hline 64 & 369219,776 & 7355022,028 & 29 & 365622,974 & 7358690,978 & 21,276 & $-7,724$ \\
\hline 65 & 366268,205 & 7358854,423 & 15 & 369194,642 & 7355011,640 & 0,124 & $-14,876$ \\
\hline 66 & 316439,436 & 7322432,453 & 24 & 366243,171 & 7358844,073 & 33,164 & 9,164 \\
\hline 67 & 316653,485 & 7322560,159 & 28 & 316413,349 & 7322421,785 & 35,756 & 7,756 \\
\hline
\end{tabular}

Tabela 32: Pontos Planimétricos e Altimétricos da comparação e suas diferenças

\begin{tabular}{|c|c|c|c|c|c|c|c|c|c|}
\hline & \multicolumn{2}{|c|}{ Ortofoto } & \multicolumn{2}{|c|}{ Ponto Corrego Conv. Progrid } & \multicolumn{2}{|c|}{ Cotas } & \multicolumn{3}{|c|}{ Diferenças } \\
\hline $\mathbf{n}^{\circ}$ & SIRGAS X (m) & SIRGAS Y (m) & Progrid X (m) & Progrid Y (m) & carta Z (m) & mdt $Z(m)$ & DE (m) & DN (m) & $\mathrm{DZ}(\mathrm{m})$ \\
\hline 1 & 309719,517 & 7435000,999 & 309723,503 & 7435021,228 & 815 & 804,148 & $-3,986$ & $-20,229$ & $-10,852$ \\
\hline 2 & 309044,242 & 7434656,485 & 309041,548 & 7434675,414 & 715 & 714,671 & 2,694 & $-18,929$ & $-0,329$ \\
\hline 3 & 308265,13 & 7435214,115 & 308269,741 & 7435226,667 & 800 & 804,507 & $-4,611$ & $-12,552$ & 4,507 \\
\hline 4 & 308521,127 & 7434546,186 & 308517,549 & 7434555,821 & 792 & 795 & 3,578 & $-9,635$ & 3,000 \\
\hline 5 & 310096,581 & 7435039,133 & 310095,781 & 7435057,403 & 843 & 855 & 0,8 & $-18,27$ & 12,000 \\
\hline 6 & 309497,94 & 7432382,382 & 309497,734 & 7432400,028 & 930 & 921,206 & 0,206 & $-17,646$ & $-8,794$ \\
\hline 7 & 306503,988 & 7435288,959 & 306515,022 & 7435317,221 & 1200 & 1194,57 & $-11,034$ & $-28,262$ & $-5,431$ \\
\hline 8 & 306404,252 & 7434999,824 & 306418,291 & 7435030,191 & 787 & 786,616 & $-14,039$ & $-30,367$ & $-0,384$ \\
\hline 9 & 306708,439 & 7434150,284 & 306710,293 & 7434181,039 & 735 & 734,514 & $-1,854$ & $-30,755$ & $-0,486$ \\
\hline 10 & 305890,06 & 7433966,677 & 305894,52 & 7434007,882 & 685 & 679,169 & $-4,46$ & $-41,205$ & $-5,831$ \\
\hline 11 & 307419,596 & 7434540,51 & 307433,141 & 7434563,385 & 760 & 759,347 & $-13,545$ & $-22,875$ & $-0,653$ \\
\hline 12 & 307344,535 & 7431860,798 & 307344,472 & 7431863,506 & 785 & 775,182 & 0,063 & $-2,708$ & $-9,818$ \\
\hline 13 & 306471,993 & 7435807,878 & 306486,533 & 7435835,241 & 800 & 791,698 & $-14,54$ & $-27,363$ & $-8,302$ \\
\hline 14 & 340602,822 & 7442841,326 & 340608,336 & 7442855,747 & 829 & 837,2 & $-5,514$ & $-14,421$ & 8,200 \\
\hline 15 & 340550,628 & 7443102,685 & 340553,954 & 7443118,942 & 950 & 950,289 & $-3,326$ & $-16,257$ & 0,289 \\
\hline 16 & 341353,74 & 7442808,224 & 341357,89 & 7442823,762 & 910 & 916,693 & $-4,15$ & $-15,538$ & 6,693 \\
\hline 17 & 341127,157 & 7442954,404 & 341132,248 & 7442966,11 & 899 & 903,818 & $-5,091$ & $-11,706$ & 4,818 \\
\hline 18 & 339722,841 & 7442557,704 & 339723,852 & 7442568,455 & 885 & 889,125 & $-1,011$ & $-10,751$ & 4,125 \\
\hline 19 & 339821,637 & 7442085,181 & 339823,741 & 7442097,105 & 918 & 915,625 & $-2,104$ & $-11,924$ & $-2,375$ \\
\hline 20 & 337663,322 & 7442633,516 & 337666,445 & 7442648,268 & 933 & 936,823 & $-3,123$ & $-14,752$ & 3,823 \\
\hline 21 & 341822,713 & 7442828,382 & 341816,483 & 7442842,184 & 816 & 820,487 & 6,23 & $-13,802$ & 4,487 \\
\hline 22 & 360655,707 & 7449878,398 & 360637,225 & 7449869,892 & 916 & 914,09 & 18,482 & 8,506 & $-1,910$ \\
\hline 23 & 361084,241 & 7449924,054 & 361063,499 & 7449922,895 & 1006 & 1001,31 & 20,742 & 1,159 & $-4,690$ \\
\hline 24 & 361051,4 & 7449790,725 & 361030,866 & 7449789,282 & 951 & 945,85 & 20,534 & 1,443 & $-5,150$ \\
\hline 25 & 349310,938 & 7398714,313 & 349318,006 & 7398693,017 & 1036 & 1023,23 & $-7,068$ & 21,296 & $-12,770$ \\
\hline 26 & 349175,95 & 7396881,913 & 349178,44 & 7396873,76 & 818 & 822,593 & $-2,49$ & 8,153 & 4,593 \\
\hline 27 & 349984,254 & 7396384,768 & 349985,905 & 7396370,387 & 849 & 853,067 & $-1,651$ & 14,381 & 4,067 \\
\hline 28 & 353469,425 & 7393182,683 & 353465,14 & 7393151,547 & 933 & 924,243 & 4,285 & 31,136 & $-8,757$ \\
\hline 29 & 348817,025 & 7391758,206 & 348815,688 & 7391749,509 & 916 & 916,558 & 1,337 & 8,697 & 0,558 \\
\hline 30 & 348095,744 & 7390043,215 & 348088,601 & 7390031,979 & 873 & 865,345 & 7,143 & 11,236 & $-7,655$ \\
\hline 31 & 349645,611 & 7389518,792 & 349633,953 & 7389505,339 & 847 & 844,756 & 11,658 & 13,453 & $-2,244$ \\
\hline 32 & 348805,139 & 7387760,072 & 348797,462 & 7387745,671 & 831 & 829,575 & 7,677 & 14,401 & $-1,425$ \\
\hline 33 & 350816,68 & 7395037,179 & 350821,302 & 7395021,613 & 861 & 854,654 & $-4,622$ & 15,566 & $-6,346$ \\
\hline 34 & 350120,133 & 7394427,331 & 350119,721 & 7394410,034 & 858 & 856,348 & 0,412 & 17,297 & $-1,652$ \\
\hline
\end{tabular}


Apêndice F-201

Continuando Tabela 32 da página anterior

\begin{tabular}{|c|c|c|c|c|c|c|c|c|c|}
\hline & Ortc & foto & Ponto Corrego & Conv. Progrid & Cot & & & Diferenças & \\
\hline $\mathbf{n}^{\circ}$ & SIRGAS X (m) & SIRGAS Y (m) & Progrid X (m) & Progrid Y (m) & carta $Z(m)$ & mdt $Z(m)$ & DE (m) & DN (m) & DZ (m) \\
\hline 35 & 352265,09 & 7396130,693 & 352265,36 & 7396117,49 & 821 & 826,247 & $-0,27$ & 13,203 & 5,247 \\
\hline 36 & 351453,315 & 7396482,49 & 351454,684 & 7396471,77 & 811 & 809,466 & $-1,369$ & 10,72 & $-1,534$ \\
\hline 37 & 352197,497 & 7397283,43 & 352206,254 & 7397268,283 & 819 & 821,603 & $-8,757$ & 15,147 & 2,603 \\
\hline 38 & 352815,408 & 7399086,569 & 352823,047 & 7399064,33 & 884 & 883,239 & $-7,639$ & 22,239 & $-0,761$ \\
\hline 39 & 347804,255 & 7397536,716 & 347806,382 & 7397528,444 & 898 & 888,564 & $-2,127$ & 8,272 & $-9,436$ \\
\hline 40 & 352712,122 & 7400314,204 & 352719,42 & 7400296,298 & 875 & 871,045 & $-7,298$ & 17,906 & $-3,955$ \\
\hline 41 & 352489,947 & 7399698,806 & 352498,68 & 7399693,315 & 863 & 852,725 & $-8,733$ & 5,491 & $-10,275$ \\
\hline 42 & 349154,285 & 7399293,028 & 349164,951 & 7399271,456 & 876 & 865,887 & $-10,666$ & 21,572 & $-10,113$ \\
\hline 43 & 351730,022 & 7398356,709 & 351729,029 & 7398342,196 & 826 & 823,147 & 0,993 & 14,513 & $-2,853$ \\
\hline 44 & 353989,339 & 7395673,041 & 353983,442 & 7395656,528 & 888 & 882,543 & 5,897 & 16,513 & $-5,457$ \\
\hline 45 & 347422,696 & 7397162,711 & 347419,697 & 7397147,493 & 869 & 853,776 & 2,999 & 15,218 & $-15,224$ \\
\hline 46 & 347333,986 & 7397700,915 & 347321,901 & 7397672,521 & 807 & 798,056 & 12,085 & 28,394 & $-8,944$ \\
\hline 47 & 347456,188 & 7399526,848 & 347456,507 & 7399512,602 & 817 & 808,669 & $-0,319$ & 14,246 & $-8,331$ \\
\hline 48 & 348627,43 & 7396008,508 & 348628,582 & 7395992,105 & 808 & 797,858 & $-1,152$ & 16,403 & $-10,142$ \\
\hline 49 & 356071,468 & 7395657,187 & 356068,185 & 7395635,093 & 923 & 912,054 & 3,283 & 22,094 & $-10,946$ \\
\hline 50 & 357401,46 & 7399948,215 & 357403,699 & 7399933,643 & 973 & 960,199 & $-2,239$ & 14,572 & $-12,801$ \\
\hline 51 & 368232,743 & 7346641,902 & 368242,637 & 7346647,513 & 905 & 899,961 & $-9,894$ & $-5,611$ & $-5,039$ \\
\hline 52 & 367009,67 & 7346306,888 & 367015,423 & 7346305,796 & 174 & 169,727 & $-5,753$ & 1,092 & $-4,273$ \\
\hline 53 & 371700,212 & 7345398,155 & 371712,951 & 7345400,525 & 52 & 53,903 & $-12,739$ & $-2,37$ & 1,903 \\
\hline 54 & 367676,195 & 7351625,976 & 367671,745 & 7351613,39 & 59 & 54,922 & 4,45 & 12,586 & $-4,078$ \\
\hline 55 & 360952,206 & 7348451,993 & 360956,77 & 7348444,109 & 125 & 119,027 & $-4,564$ & 7,884 & $-5,973$ \\
\hline 56 & 360631,301 & 7350738,96 & 360642,494 & 7350727,321 & 155 & 153,151 & $-11,193$ & 11,639 & $-1,849$ \\
\hline 57 & 368085,586 & 7348041,523 & 368082,317 & 7348038,041 & 139 & 121,838 & 3,269 & 3,482 & $-17,162$ \\
\hline 58 & 364621,984 & 7352598,461 & 364631,611 & 7352586,995 & 91 & 88,993 & $-9,627$ & 11,466 & $-2,007$ \\
\hline 59 & 362795,167 & 7348692,062 & 362789,228 & 7348685,561 & 84 & 72,593 & 5,939 & 6,501 & $-11,407$ \\
\hline 60 & 364942,097 & 7352498,812 & 364937,843 & 7352478,993 & 72 & 62,88 & 4,254 & 19,819 & $-9,120$ \\
\hline 61 & 361961,919 & 7353105,018 & 361972,288 & 7353093,639 & 76 & 75,216 & $-10,369$ & 11,379 & $-0,784$ \\
\hline 62 & 366025,978 & 7351877,955 & 366023,193 & 7351868,18 & 159 & 144,986 & 2,785 & 9,775 & $-14,014$ \\
\hline 63 & 365283,765 & 7348195,609 & 365287,934 & 7348190,82 & 163 & 151,857 & $\begin{array}{l}-4,169 \\
\end{array}$ & 4,789 & $-11,143$ \\
\hline 64 & 369082,117 & 7346094,152 & 369084,44 & 7346091,718 & 29 & 21,276 & $-2,323$ & 2,434 & $-7,724$ \\
\hline 65 & 317406,306 & 7323467,354 & 317407,204 & 7323424,501 & 15 & 0,124 & $-0,898$ & 42,853 & $-14,876$ \\
\hline 66 & 318673,3 & 7324771,238 & 318653,427 & 7324723,794 & 24 & 33,164 & 19,873 & 47,444 & 9,164 \\
\hline 67 & & & & & 28 & 35,756 & & & 7,756 \\
\hline 68 & & & & & 48 & 66,266 & & & 18,266 \\
\hline
\end{tabular}




\section{ANEXO A}

Figura 87: Organização institucional do IGG e suas secções entre 1938/69

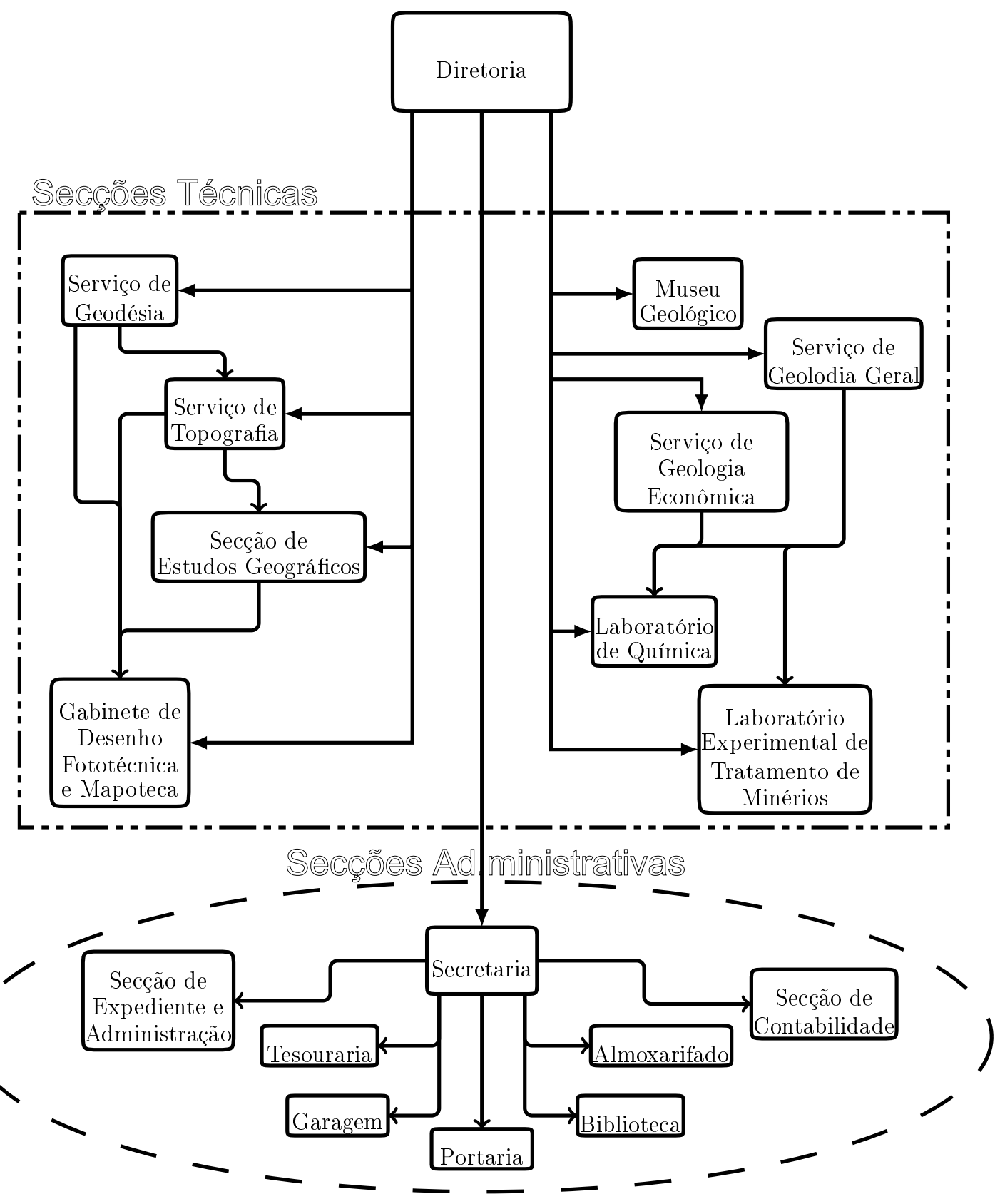


Figura 88: Organização institucional inicial do IGC - 1979

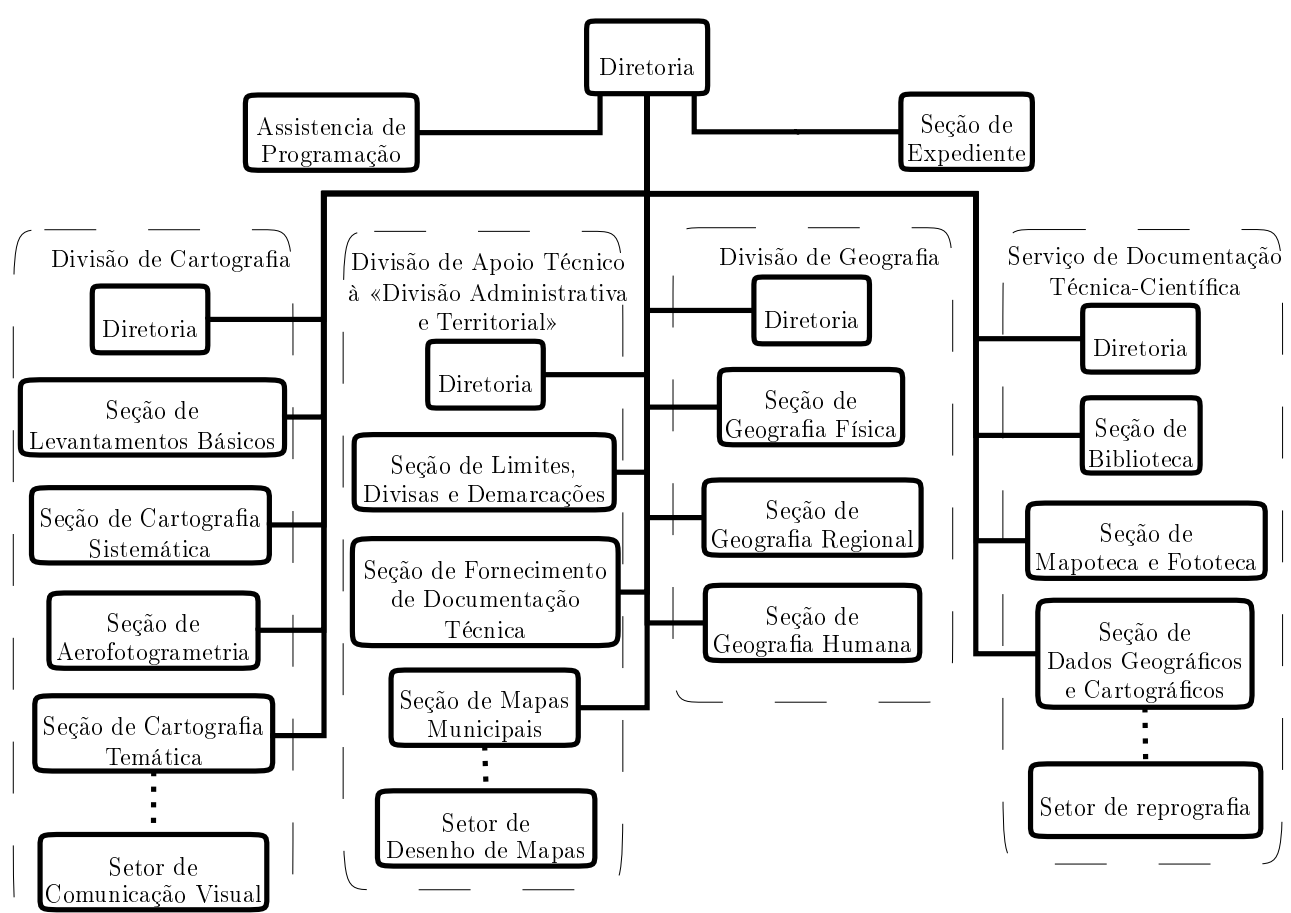




\begin{tabular}{|c|c|c|c|c|c|c|c|}
\hline Identificador & Nome da Folha 1:100.000 & Ano de Referência & Executor & Identificador & Nome da Folha & Ano de Referência & Executor \\
\hline 1 & GUARACY & 1930 & CGG & 30 & GUAREHY & 1913 & CGG \\
\hline 2 & GUAHYRA & 1930 & CGG & 31 & TATUHY & 1942 & CGG \\
\hline 3 & IGARAPAVA & 1930 & CGG & 32 & YTÚ & 1912 & CGG \\
\hline 4 & RIFAINA & 1930 & CGG & 33 & JUNDIAHY & 1925 & CGG \\
\hline 5 & BARRETOS & 1928 & CGG & 34 & ATIBAIA & 1912 & CGG \\
\hline 6 & ORLANDIA & 1929 & CGG & 35 & JACAREHY & 1913 & CGG \\
\hline 7 & FRANCA & 1920 & CGG & 36 & SÃO ROQUE & 1912 & CGG \\
\hline 8 & SÃO SEBASTIÃO DO PARAIZO & 1920 & CGG & 37 & SÃO PAULO & 1911 & CGG \\
\hline 9 & JABOTICABAL & 1929 & CGG & 38 & BARRA DE SANTOS & 1920 & CGG \\
\hline 10 & RIBEIRĀO PRETO & 1925 & CGG & - & São José do Rio Preto & 1959 & IGG \\
\hline 11 & SĀO SIMÃO & 1919 & CGG & - & Novo Horizonte & 1958 & IGG \\
\hline 12 & MOCOCA & 1920 & CGG & - & José Bonifácio & 1959 & IGG \\
\hline 13 & ARARAQUARA & 1928 & CGG & - & Pirajuí & 1954 & IGG \\
\hline 14 & RINCÃO & 1926 & CGG & - & Ibitinga & 1956 & IGG \\
\hline 15 & PIRASSUNUNGA & 1930 & CGG & - & Bauru & 1950 & IGG \\
\hline 16 & CASA BRANCA & 1930 & CGG & - & Jaú & 1950 & IGG \\
\hline 17 & CALDAS & 1914 & CGG & - & Lins & 1957 & IGG \\
\hline 18 & JAU & 1912 & CGG & - & Marília & 1952 & IGG \\
\hline 19 & SÃO CARLOS DO PINHAL & 1912 & CGG & - & Pompéia & 1957 & IGG \\
\hline 20 & RIO CLARO & 1912 & CGG & - & São Manuel & 1952 & IGG \\
\hline 21 & MOGY-MIRIM & 1921 & CGG & - & Santa Barbara do Rio Pardo & 1948 & IGG \\
\hline 22 & OURO FINO & 1919 & CGG & - & Avaré & 1945 & IGG \\
\hline 23 & BOTUCATU & 1912 & CGG & - & Pirajú & 1945 & IGG \\
\hline 24 & SÃO PEDRO & 1913 & CGG & - & Ipauçu & 1950 & IGG \\
\hline 25 & PIRACICABA & 1942 & $\overline{\mathrm{CGG}}$ & - & Santa Cruz do Rio Pardo & 1945 & IGG \\
\hline 26 & CAMPINAS & 1925 & CGG & - & Assis & 1956 & IGG \\
\hline 27 & BRAGANÇA & 1911 & CGG & - & Maracaí & 1956 & IGG \\
\hline 28 & SÃO BENTO & 1920 & CGG & - & Pirajuí & 1954 & IGG \\
\hline
\end{tabular}

Tabela 33: Cartas topográficas produzidas pela CGG/IGG - Fonte Acervo IGC 


\begin{tabular}{|c|c|c|c|c|c|c|c|}
\hline Ano & Produção textual & Mapas topográficos & Mapas municipais & Cartas e mapas gerais & Levantamentos top./geod./fot. & Processos atendidos & Levantamentos geológicos \\
\hline 1938 & 2 & 0 & 0 & 0 & 0 & 0 & 0 \\
\hline 1939 & 4 & 0 & 0 & 0 & 0 & 0 & 0 \\
\hline 1940 & 4 & 0 & 0 & 0 & 16 & 0 & 0 \\
\hline 1941 & 1 & 1 & 0 & 4 & 224 & 0 & 0 \\
\hline 1942 & 2 & 3 & 0 & 0 & 29 & 20 & 0 \\
\hline 1943 & 3 & 0 & 0 & 0 & 36 & 69 & 0 \\
\hline 1944 & 2 & 0 & 0 & 0 & 79 & 26 & 26 \\
\hline 1945 & 2 & 2 & 30 & 2 & 53 & 0 & 0 \\
\hline 1946 & 1 & 0 & 270 & 1 & 29 & 0 & 0 \\
\hline 1947 & 1 & 1 & 0 & 2 & 113 & 52 & 0 \\
\hline 1948 & 1 & 1 & 0 & 0 & 0 & 0 & 0 \\
\hline 1949 & 1 & 2 & 0 & 0 & 0 & 0 & 0 \\
\hline 1950 & 2 & 3 & 0 & 2 & 0 & 0 & 0 \\
\hline 1951 & 1 & 0 & 0 & 0 & 0 & 0 & 0 \\
\hline 1952 & 4 & 2 & 0 & 0 & 0 & 0 & 0 \\
\hline 1953 & 3 & 0 & 0 & 0 & 0 & 0 & 0 \\
\hline 1954 & 1 & 3 & 0 & 14 & 0 & 0 & 0 \\
\hline 1955 & 0 & 16 & 0 & 0 & 34 & 0 & 0 \\
\hline 1956 & 0 & 5 & 0 & 0 & 0 & 0 & 0 \\
\hline 1957 & 0 & 5 & 0 & 1 & 0 & 0 & 0 \\
\hline 1958 & 2 & 8 & 0 & 1 & 0 & 0 & 0 \\
\hline 1959 & 2 & 3 & 100 & 0 & 137 & 0 & 13 \\
\hline 1960 & 2 & 1 & 90 & 3 & 227 & 249 & 13 \\
\hline 1961 & 0 & 3 & 75 & 0 & 296 & 234 & 13 \\
\hline 1962 & 4 & 0 & 100 & 0 & 0 & 0 & 128 \\
\hline 1963 & 1 & 0 & 0 & 0 & 0 & 0 & 0 \\
\hline 1964 & 2 & 1 & 5 & 1 & 0 & 0 & 0 \\
\hline 1965 & 6 & 40 & 22 & 0 & 0 & 0 & 0 \\
\hline 1966 & 4 & 9 & 0 & 1 & 0 & 0 & 0 \\
\hline 1967 & 2 & 58 & 21 & 0 & 0 & 0 & 0 \\
\hline 1968 & 1 & 0 & 21 & 0 & 0 & 0 & 0 \\
\hline 1969 & 0 & 263 & 18 & 0 & 0 & 0 & 0 \\
\hline 1970 & 0 & 0 & 9 & 0 & 0 & 0 & 0 \\
\hline 1971 & 0 & 21 & 7 & 0 & 0 & 0 & 0 \\
\hline 1972 & 0 & 13 & 1 & 0 & 0 & 0 & 0 \\
\hline 1973 & 0 & 0 & 8 & 0 & 0 & 0 & 0 \\
\hline 1974 & 0 & 1 & 54 & 0 & 0 & 0 & 0 \\
\hline 1975 & 0 & 0 & 36 & 0 & 0 & 0 & 0 \\
\hline
\end{tabular}

Tabela 34: Produção do IGG entre 1938 e 1975 


\begin{tabular}{|c|c|c|c|c|c|c|c|c|c|c|c|}
\hline Município & Ano & Escala & Município & Ano & Escala & Município & Ano & Escala & Município & Ano & Escala \\
\hline Agudos & 1953 & $1: 25000$ & Iguape & 1953 & $1: 25000$ & Piracicaba & 1940 & $1: 20000$ & São Paulo & 1945 & - \\
\hline Alambari & 1951 & - & Indaiatuba & 1941 & $1: 20000$ & Piracicaba & 1940 & $1: 20000$ & São Roque & 1943 & - \\
\hline Alambari & 1951 & - & Itatinga & 1953 & $1: 25000$ & Pirassununga & 1955 & $1: 20000$ & São Roque & 1943 & $1: 10000$ \\
\hline Amparo & 1952 & $1: 7500(1: 4500)$ & Itu & 1949 & $1: 20000$ & Quintana & 1949 & - & São Roque & 1943 & $1: 10000$ \\
\hline Araraquara & 1953 & $1: 4500(1: 25000)$ & Jaboticabal & 1956 & $1: 20000$ & Ribeirão Preto & 1953 & $1: 20000$ & São Roque & 1943 & $1: 10000$ \\
\hline Avaré & 1953 & $1: 25000$ & Jacareí & 1954 & $1: 25000$ & Rio Claro & 1953 & $1: 25000$ & São Roque & 1943 & $1: 10000$ \\
\hline Bauru & 1953 & $1: 25000$ & Jarinu & 1956 & $1: 20000$ & Santa Rita do Passa Quatro & 1952 & $1: 5000$ & São Roque & 1943 & $1: 10000$ \\
\hline Caçapava & 1954 & $1: 25000$ & Jaú & 1953 & $1: 25000$ & São Carlos do Pinhal & 1953 & $1: 25000$ & São Roque & 1943 & - \\
\hline Campinas & 1940 & $1: 15000$ & Jundiaí & 1940 & $1: 18000$ & São José dos Campos & 1954 & $1: 25000$ & São Roque & 1943 & - \\
\hline Campinas & 1940 & - & Jundiaí & 1940 & - & São José dos Campos & 1941 & $1: 7500$ & Sorocaba & 1956 & $1: 21000$ \\
\hline Campinas & 1941 & $1: 2500$ & Leme & 1941 & $1: 20000$ & São Paulo & 1943 & $1: 10000$ & Sorocaba & 1941 & $1: 20000$ \\
\hline Campinas & 1941 & $1: 25000$ & Limeira & 1940 & - & São Paulo & 1954 & - & Sorocaba & 1941 & $1: 12400$ \\
\hline Campinas & 1941 & $1: 20000$ & Limeira & 1940 & $1: 20000$ & São Paulo & 1945 & $1: 25000$ & Sorocaba & 1941 & $1: 10000$ \\
\hline Campinas & 1944 & - & Limeira & 1941 & - & São Paulo & 1954 & $1: 7500$ & Sorocaba & 1941 & $1: 12400$ \\
\hline Campinas & 1940 & - & Limeira & 1941 & $1: 20000$ & São Paulo & 1950 & $1: 40000$ & Sorocaba & 1941 & - \\
\hline Campos do Jordão & 1941 & $1: 6000$ & Limeira & 1941 & $1: 20000$ & São Paulo & 1945 & $1: 25000$ & Sorocaba & 1941 & $1: 10000$ \\
\hline Campos do Jordão & 1956 & $1: 10500$ & Lins & 1952 & $1: 10000$ & São Paulo & 1945 & $1: 10000$ & Sorocaba & 1941 & $1: 10000$ \\
\hline Capivari & 1955 & $1: 20000$ & Lorena & 1953 & $1: 20000$ & São Paulo & 1945 & $1: 10000$ & Sorocaba & 1941 & $1: 10000$ \\
\hline Cotia & 1940 & $1: 18000$ & Mogi das Cruzes & 1940 & $1: 18000$ & São Paulo & 1945 & $1: 5000$ & Taubaté & 1954 & $1: 25000$ \\
\hline Cotia & 1940 & $1: 18000$ & Mogi-Mirim & 1942 & $1: 20000$ & São Paulo & 1945 & $1: 5000$ & Vargem Grande do Sul & 1953 & $1: 25000$ \\
\hline
\end{tabular}

Tabela 35: Voos Executados nas décadas 40 e 50 Acervo IGG/IGC 


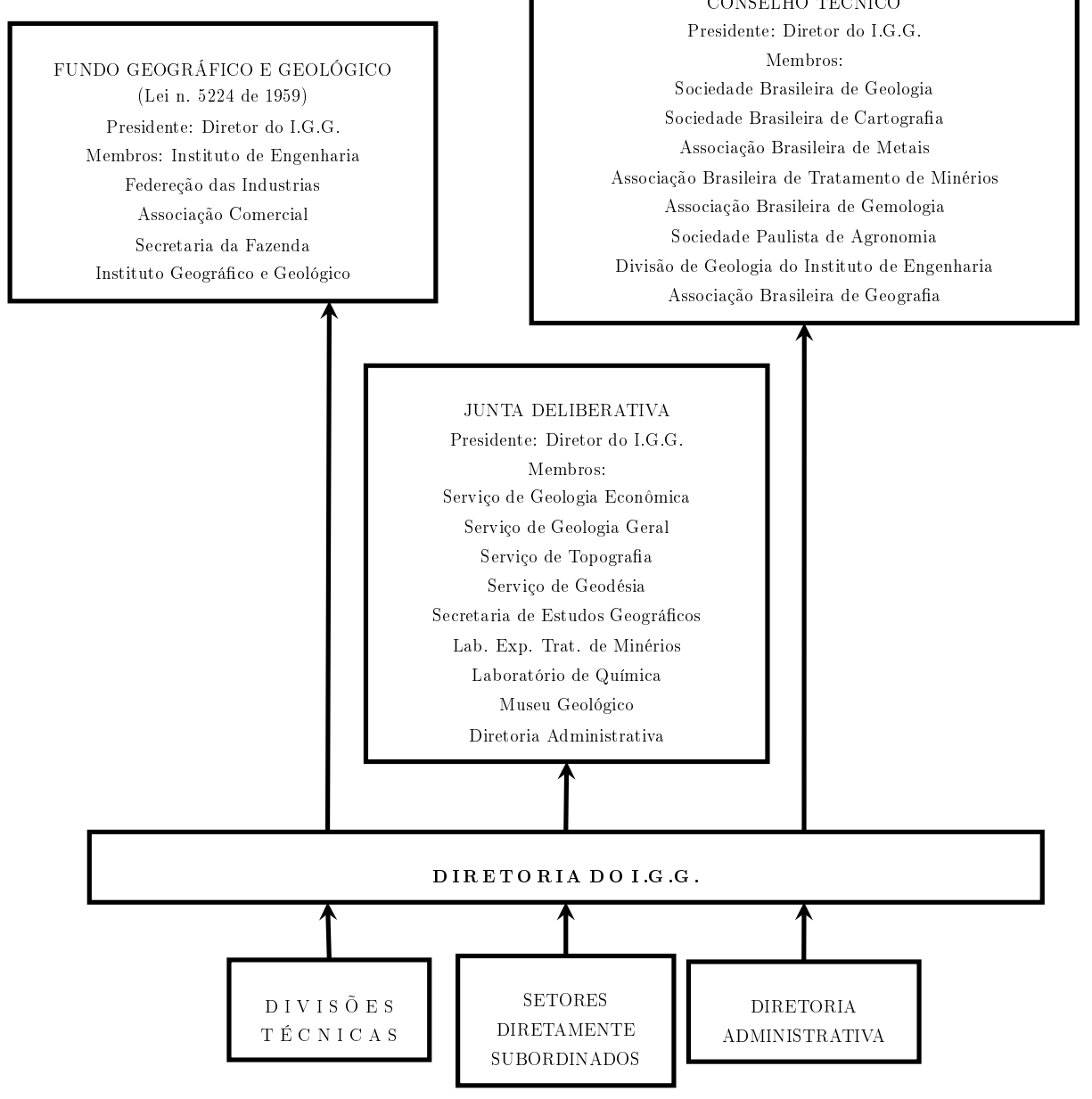

Figura 89: Organograma Institucional do IGG - Fonte: Acervo IG Museu Geológico

Tabela 36: Coordenadas de apoio horizontal córrego alegre IGG 1958/61 Fonte: $\operatorname{IGGSP} \sqrt{1959} 1962$

\begin{tabular}{|c|c|c|c|c|c|c|c|c|}
\hline $\mathbf{n}^{o}$ & Ärea & fuso & folha & Pol. & Desc. & nome & $\mathbf{E}(\mathbf{m})$ & $\mathbf{N}(\mathbf{m})$ \\
\hline 1 & 1 & 51 & 1 & A & Cosmorama-Cardoso & Marco $4 *$ & 625111,220 & 7735884,710 \\
\hline 2 & 1 & 51 & 1 & A & Cosmorama-Cardoso & Marco $27 *$ & 624658,760 & 7750787,160 \\
\hline 3 & 1 & 51 & 1 & $\mathrm{~A}$ & Cosmorama-Cardoso & Marco $3 *$ & 632925,470 & 7729361,540 \\
\hline 4 & 1 & 51 & 1 & A & Cosmorama-Cardoso & Marco $5 *$ & 609148,060 & 7778719,580 \\
\hline 5 & 1 & 51 & 1 & A & Cosmorama-Cardoso & Marco $24 *$ & 621050,540 & 7777043,850 \\
\hline 6 & 1 & 51 & 1 & A & Cosmorama-Cardoso & Marco $25 *$ & 627451,790 & 7767778,580 \\
\hline 7 & 1 & 51 & 2 & $\mathrm{~A}$ & Cosmorama-Cardoso & Estação A3( Saev Ambiental) & 607004,660 & 7742372,250 \\
\hline 8 & 1 & 51 & 2 & $\mathrm{~A}$ & Cosmorama-Cardoso & Marco A2 * & 613717,160 & 7739347,230 \\
\hline 9 & 1 & 51 & 2 & $\mathrm{~A}$ & Cosmorama-Cardoso & Estação A4 (Sabesp) & 578752,780 & 7757262,200 \\
\hline 10 & 1 & 51 & 2 & $\mathrm{~A}$ & Cosmorama-Cardoso & Marco A1 * & 619344,840 & 7737144,730 \\
\hline 11 & 1 & 51 & 3 & $\mathrm{~A}$ & 3 Fronteiras - Fernandópolis & PIQ, B5* & 512546,940 & 7763166,680 \\
\hline 12 & 1 & 51 & 3 & $\mathrm{~A}$ & 3 Fronteiras - Fernandópolis & Est, C 2* & 497658,830 & 7757868,960 \\
\hline 13 & 1 & 51 & 3 & $\mathrm{~B}-\mathrm{C}$ & 3 Fronteiras - Fernandópolis & PIQ, C1* & 509339,690 & 7756846,220 \\
\hline 14 & 1 & 51 & 4 & $\mathrm{C}$ & 3 Fronteiras - Aliança & Marco C4* & 478915,200 & 7743625,380 \\
\hline 15 & 1 & 51 & 4 & $\mathrm{C}$ & 3 Fronteiras - Aliança & PIQ, C5* & 485056,590 & 7725631,030 \\
\hline 16 & 1 & 51 & 4 & $\mathrm{C}$ & 3 Fronteiras - Aliança & Marco C3* & 489985,960 & 7750613,290 \\
\hline 17 & 1 & 51 & 5 & $\mathrm{~A}$ & Fernandópolis-Cosmorama & Marco A4-1* & 580622,460 & 7765132,700 \\
\hline 18 & 1 & 51 & 5 & A & Fernandópolis-Cosmorama & PIQ, A4-2* & 575850,710 & 7780715,420 \\
\hline 19 & 1 & 51 & 5 & $\mathrm{~A}$ & Fernandópolis-Cosmorama & PIQ, A4-3* & 571204,960 & 7795332,760 \\
\hline 20 & 1 & 51 & 5 & $\mathrm{~A}$ & Fernandópolis-Cosmorama & Marco A4-4* & 575048,090 & 7797081,160 \\
\hline 21 & 1 & 51 & 6 & $\mathrm{~B}$ & Sergipe-Fernandópolis & PIQ, B3* & 543944,690 & 7759726,110 \\
\hline 22 & 1 & 51 & 6 & $\mathrm{~B}$ & Sergipe-Fernandópolis & Marco B4* & 522913,040 & 7760851,420 \\
\hline 23 & 1 & 51 & 6 & $\mathrm{~B}$ & Sergipe-Fernandópolis & Marco B2* & 550274,830 & 7758957,760 \\
\hline 24 & 1 & 51 & 6 & $\mathrm{~B}$ & Sergipe-Fernandópolis & Marco B1* & 559460,670 & 7758695,240 \\
\hline
\end{tabular}


Continuando Tabela 36 da página anterior

\begin{tabular}{|c|c|c|c|c|c|c|c|c|}
\hline $\mathbf{n}^{o}$ & Área & fuso & folha & Pol. & Descr. & Nome & $\mathrm{E}(\mathrm{m})$ & $\mathrm{N}(\mathrm{m})$ \\
\hline 25 & 1 & 51 & 8 & $\mathrm{~B}$ & Sergipe-Fernandópolis & Estação B7* & 545713,960 & 7712449,140 \\
\hline 26 & 1 & 51 & 8 & $\mathrm{~B}$ & Sergipe-Fernandópolis & Marco B6* & 524687,680 & 7741268,740 \\
\hline 27 & 1 & 51 & 26 & $\mathrm{D}$ & Sapé-Nhandeara & Centro $\mathrm{Cx}, \mathrm{D}$ água Nhandeara & 600193,520 & 7711360,730 \\
\hline 28 & 2 & 51 & 17 & $\mathrm{~A}$ & Progresso-Lacerda & Marco A1* & 456322,950 & 7693289,590 \\
\hline 29 & 2 & 51 & 17 & A & Progresso-Lacerda & Marco Progresso* & 457577,620 & 7669342,390 \\
\hline 30 & 2 & 51 & 17 & $\mathrm{~A}$ & Progresso-Lacerda & Marco A2* & 452137,530 & 7691971,530 \\
\hline 31 & 2 & 51 & 17 & A & Progresso-Lacerda & $\mathrm{PIQ}, \mathrm{A} 3^{*}$ & 443705,860 & 7681296,450 \\
\hline 32 & 2 & 51 & 17 & A & Progresso-Lacerda & Torre Igr. Paroquia São José-Castilho & 449319,430 & 7691924,660 \\
\hline 33 & 2 & 51 & 17 & A & Progresso-Lacerda & Torre Igr. São Sebastião- Andradina & 460529,460 & 7689276,340 \\
\hline 34 & 2 & 51 & 17 & A & Progresso-Lacerda & Marco CNG Araçatuba* & 555404,780 & 7654168,360 \\
\hline 35 & 2 & 51 & 17 & A & Progresso-Lacerda & $\mathrm{PIQ}, \mathrm{AO}^{*}$ & 565245,840 & 7644745,040 \\
\hline 36 & 2 & 51 & 18 & A & Progresso-Lacerda & Chapa Araçatuba* & 555331,180 & 7654257,150 \\
\hline 37 & 2 & 51 & 18 & A & Progresso-Lacerda & Marco A1 * & 565258,400 & 7644758,970 \\
\hline 38 & 2 & 51 & 19 & A & Arçatuba-Araçatuba & Marco A2 * & 591911,810 & 7619688,380 \\
\hline 39 & 2 & 51 & 19 & $\mathrm{~A}$ & Arçatuba-Araçatuba & Marco A3* & 603213,090 & 7626145,570 \\
\hline 40 & 2 & 51 & 19 & $\mathrm{~A}$ & Arçatuba-Araçatuba & PIQ, A4* & 601916,140 & 7670385,630 \\
\hline 41 & 2 & 51 & 20 & $\mathrm{~A}$ & Arçatuba-Araçatuba & Marco Brejo Alegre* & 583665,050 & 7658221,720 \\
\hline 42 & 2 & 51 & 20 & A & Arçatuba-Araçatuba & Marco Bonito* & 601984,450 & 7671117,950 \\
\hline 43 & 2 & 51 & 20 & $\mathrm{~A}$ & Arçatuba-Araçatuba & Marco B2* & 462265,550 & 7636876,460 \\
\hline 44 & 2 & 51 & 21 & $\mathrm{~B}$ & Tabajara-Panorama & Marco B1* & 429067,340 & 7642878,840 \\
\hline 45 & 2 & 51 & 21 & $\mathrm{~B}$ & Tabajara-Panorama & PIQ, B5* & 418808,830 & 7622081,900 \\
\hline 46 & 2 & 51 & 21 & $\mathrm{~B}$ & Tabajara-Panorama & $\mathrm{PIQ}, \mathrm{B} 6=\mathrm{A}^{*}$ & 412040,710 & 7622362,900 \\
\hline 47 & 2 & 51 & 21 & B & Tabajara-Panorama & $\mathrm{PIQ}, \mathrm{B} 7=\mathrm{B}^{*}$ & 398757,260 & 7621849,860 \\
\hline 48 & 2 & 51 & 22 & $\mathrm{~B}$ & Tabajara-Panorama & PIQ, B3* & 445205,460 & 7627051,290 \\
\hline 49 & 2 & 51 & 22 & B & Tabajara-Panorama & PIQ, B4* & 430365,570 & 7622860,100 \\
\hline 50 & 2 & 51 & 24 & $\mathrm{~B}$ & Tabajara-Panorama & Marco CNG Cambau* & 468571,640 & 7681431,820 \\
\hline 51 & 2 & 51 & 25 & $\mathrm{~B}$ & Tabajara-Panorama & Marco Tabajara* & 487521,390 & 7647449,930 \\
\hline 52 & 2 & 51 & 25 & $\mathrm{~B}$ & Tabajara-Panorama & Marco Sapé* & 502704,640 & 7640955,840 \\
\hline 53 & 2 & 51 & 26 & $\mathrm{D}$ & Sapé-Nhandeara & Marco Bonito* & 601984,520 & 7671118,490 \\
\hline 54 & 2 & 51 & 26 & $\mathrm{D}$ & Sapé-Nhandeara & Marco Brejo Alegre* & 601463,980 & 7671131,770 \\
\hline 55 & 2 & 51 & 29 & $\mathrm{C}$ & Rubiácea & PIQ, C1* & 529460,120 & 7638732,190 \\
\hline 56 & 2 & 51 & 29 & $\mathrm{C}$ & Jangada Nova-Guararápes & Marco C2* & 525433,160 & 7625111,780 \\
\hline 57 & 2 & 51 & 29 & $\mathrm{C}$ & Salmourão & Marco CNG Salmorão* & 514718,860 & 7608410,910 \\
\hline 58 & 2 & 51 & 33 & $\mathrm{C}$ & Rubiácea & Marco Sta, Clara* & 527081,005 & 7645788,054 \\
\hline 59 & 2 & 51 & 8 & B & Sergipe-Fernandópolis & Marco CNG Sergipe* & 524257,290 & 7664094,050 \\
\hline 60 & 2 & 51 & 8 & $\mathrm{~B}$ & Sergipe-Fernandópolis & Marco B88 & 540029,920 & 7669816,160 \\
\hline 61 & 2 & 51 & 8 & $\mathrm{~B}$ & Sergipe-Fernandópolis & PIQ, B7A* & 553173,200 & 7690099,770 \\
\hline 62 & 3 & 45 & 28 & $\mathrm{C}$ & Pedra Bela-Salmorão & Marco C1 Pedra Bela* & 350780,550 & 7479524,180 \\
\hline 63 & 3 & 45 & 28 & $\mathrm{C}$ & Pedra Bela-Salmorão & Marco A1 * & 347017,810 & 7461528,820 \\
\hline 64 & 3 & 45 & 28 & $\mathrm{C}$ & Pedra Bela-Salmorão & $\mathrm{PIQ}, \mathrm{A} 5^{*}$ & 392328,540 & 7467600,940 \\
\hline 65 & 3 & 45 & 28 & $\mathrm{C}$ & Pedra Bela-Salmorão & Placa A3* & 390775,740 & 7470037,090 \\
\hline 66 & 3 & 45 & 28 & $\mathrm{C}$ & Pedra Bela-Salmorão & Igreja Eugenio Melo & 419490,660 & 7440808,720 \\
\hline 67 & 3 & 45 & 28 & $\mathrm{C}$ & Pedra Bela-Salmorão & $\mathrm{Cx}$, d'agua Gel Motors & 415585,640 & 7437985,030 \\
\hline 68 & 3 & 45 & 30 & $\mathrm{D}$ & Jaraguá-Esperança & Marco Esperança* & 323493,640 & 7513129,680 \\
\hline 69 & 3 & 45 & 30 & $\mathrm{D}$ & Jaraguá-Esperança & Marco D3* & 332472,850 & 7513253,860 \\
\hline 70 & 3 & 45 & 30 & $\mathrm{D}$ & Jaraguá-Esperança & Marco D2* & 327639,560 & 7497659,760 \\
\hline 71 & 3 & 45 & 31 & $\mathrm{D}$ & Com o Vale do Paraíba & Marco Boa Vista* & 391455,840 & 7429405,430 \\
\hline 72 & 3 & 45 & 31 & $\mathrm{D}$ & Com o Vale do Paraíba & Pedreira Sta, Isabel & 376927,370 & 7418936,100 \\
\hline 73 & 3 & 45 & 31 & $\mathrm{D}$ & Com o Vale do Paraíba & Chaminé Alvenária Providro & 423181,830 & 7441582,150 \\
\hline 74 & 3 & 45 & 31 & $\mathrm{D}$ & Com o Vale do Paraíba & Torre da Igreja Rosario Jacarei & 400859,270 & 7422278,430 \\
\hline 75 & 3 & 45 & 31 & $\mathrm{D}$ & Com o Vale do Paraíba & PIQ, D1* & 341527,400 & 7475730,670 \\
\hline 76 & 3 & 45 & 32 & $\mathrm{D}$ & Com o Vale do Paraíba & Montanhão & 345310,010 & 7374724,470 \\
\hline 77 & 3 & 45 & 32 & $\mathrm{D}$ & Com o Vale do Paraíba & Marco CNG Paranapiacaba* & 367061,025 & 7368378,949 \\
\hline 78 & 3 & 45 & 32 & $\mathrm{D}$ & Com o Vale do Paraíba & Pico do Jaraguá & 319692,390 & 7405052,520 \\
\hline 79 & 3 & 45 & 32 & $\mathrm{D}$ & Com o Vale do Paraíba & Mirante Ligth Cubatão & 351445,010 & 7359899,950 \\
\hline 80 & 3 & 45 & 32 & $\mathrm{D}$ & Com o Vale do Paraíba & Jambeiro* & 426503,400 & 7430415,260 \\
\hline 81 & 3 & 45 & 33 & $\mathrm{C}$ & Apoio Campinas & Marco Rapa* & 304812,214 & 7460721,083 \\
\hline 82 & 3 & 45 & 33 & $\mathrm{C}$ & Apoio Campinas & Terra Matriz Itatiba & 321010,671 & 7447712,794 \\
\hline 83 & 3 & 45 & 33 & $\mathrm{C}$ & Apoio Campinas & Marco A1* & 372673,260 & 7464780,840 \\
\hline 84 & 3 & 45 & 34 & $\mathrm{D}$ & S,Bernado do Campo-Salesopolis & IGG Itapeti* & 377429,660 & 7402691,670 \\
\hline 85 & 3 & 45 & 34 & $\mathrm{D}$ & S, Bernado do Campo-Salesopolis & IGG Pico do Jaraguá & 319689,380 & 7405052,700 \\
\hline 86 & 3 & 45 & 36 & $\mathrm{~B}$ & Peroibe-Boa Vista III & Placa 2 Itanhaen* & 296481,300 & 7306965,060 \\
\hline 87 & 3 & 45 & 36 & $\mathrm{~B}$ & Peroibe-Boa Vista III & Torre Capela Peroibe* & 316684,810 & 7322535,530 \\
\hline 88 & 3 & 45 & 36 & $\mathrm{~B}$ & Peroibe-Boa Vista III & Marco 2 Sta, Terezinha* & 362375,120 & 7349505,240 \\
\hline 89 & 3 & 45 & 36 & $\mathrm{~B}$ & Peroibe-Boa Vista III & Antena Barra* & 362378,020 & 7349524,540 \\
\hline 90 & 3 & 45 & 36 & $\mathrm{~B}$ & Peroibe-Boa Vista III & Cruzeiro Pelado* & 319692,370 & 7405052,520 \\
\hline 91 & 3 & 45 & 36 & $\mathrm{~B}$ & Peroibe-Boa Vista III & Torre Sul Igreja Mogi* & 377429,680 & 7402692,320 \\
\hline 92 & 3 & 45 & 36 & $\mathrm{~B}$ & Peroibe-Boa Vista III & Marco CNG Lageado* & 307780,530 & 7383222,540 \\
\hline 93 & 3 & 45 & 36 & $\mathrm{~B}$ & Peroibe-Boa Vista III & Igreja Cotia & 303641,110 & 7401179,700 \\
\hline
\end{tabular}


Anexo A-209

Continuando Tabela 36 da página anterior

\begin{tabular}{|c|c|c|c|c|c|c|c|c|}
\hline $\mathbf{n}^{o}$ & Área & fuso & folha & Pol. & Descr. & Nome & $\mathrm{E}(\mathrm{m})$ & $\mathrm{N}(\mathrm{m})$ \\
\hline 94 & 3 & 45 & 37 & B & Triangulo Butrantrin-Lageado-Jaraguá & Jaraguá- CHG (ok 2) & 319547,810 & 7404626,120 \\
\hline 95 & 3 & 45 & 38 & $\mathrm{C}$ & Boa Vista-Jambeiro-Palmital & Torre Ig, Matriz São José & 409163,750 & 7436259,350 \\
\hline 96 & 3 & 45 & 38 & $\mathrm{C}$ & Boa Vista-Jambeiro-Palmital & Marco Palmital* & 415087,830 & 7452721,550 \\
\hline 97 & 3 & 45 & 38 & $\mathrm{C}$ & Boa Vista-Jambeiro-Palmital & Igreja Caçapava & 427495,370 & 7445048,940 \\
\hline 98 & 3 & 45 & 39 & $\mathrm{C}$ & Boa Vista III-Jambeiro-Palmital & CX, Dágua Johnson & 405871,000 & 7430009,450 \\
\hline 99 & 3 & 45 & 39 & $\mathrm{C}$ & Boa Vista III-Jambeiro-Palmital & Marco Sta, Clara* & 320555,920 & 7462307,760 \\
\hline 100 & 3 & 45 & 40 & $\mathrm{~B}$ & Jaraguá- Litoral Sul & Farol da Ilha da Moela & 371559,674 & 7339583,200 \\
\hline 101 & 3 & 45 & 41 & $\mathrm{~B}$ & Jaraguá- Litoral Sul & Centro $\mathrm{Cx}$, d'agua Guaruja & 371290,786 & 7343727,357 \\
\hline 102 & 3 & 45 & 41 & $\mathrm{~B}$ & Jaraguá- Litoral Sul & Marco Sta, Terezinha* & 362398,016 & 7349524,542 \\
\hline 103 & 3 & 45 & 41 & $\mathrm{~B}$ & Jaraguá- Litoral Sul & Cx, D’Água Guarujá & 371273,444 & 7343733,267 \\
\hline 104 & 3 & 45 & 41 & $\mathrm{~B}$ & Jaraguá- Litoral Sul & Marco 2B Base Guarujá (ok 2) & 376695,860 & 7346906,886 \\
\hline 105 & 3 & 45 & 41 & $\mathrm{~B}$ & Jaraguá- Litoral Sul & PIQ, B Poligonal* & 378349,135 & 7347291,557 \\
\hline 106 & 3 & 45 & 42 & $\mathrm{~B}$ & Jaraguá- Litoral Sul & Placa Sta, Terezinha* & 362375,116 & 7349505,240 \\
\hline 107 & 3 & 45 & 42 & $\mathrm{~B}$ & Jaraguá- Litoral Sul & PIQ, Mongaguá* & 336265,224 & 7335188,364 \\
\hline 108 & 3 & 45 & 43 & $\mathrm{~B}$ & Jaraguá- Litoral Sul & Ilha do Farol Itanhaen & 328402,069 & 7318506,936 \\
\hline 109 & 3 & 45 & 43 & $\mathrm{~B}$ & Jaraguá- Litoral Sul & PIQ, Itanhaen* & 316708,075 & 7322535,770 \\
\hline 110 & 3 & 45 & 43 & $\mathrm{~B}$ & Jaraguá- Litoral Sul & Placa Peruibe* & 296469,432 & 7306958,365 \\
\hline 111 & 3 & 45 & 43 & $\mathrm{~B}$ & Jaraguá- Litoral Sul & Placa Itanhaen* & 316672,945 & 7322528,830 \\
\hline 112 & 3 & 45 & 44 & $\mathrm{~B}$ & Jaraguá- Litoral Sul & Marco a São Lourenço* & 398332,845 & 7367428,427 \\
\hline 113 & 3 & 45 & 46 & $\mathrm{~A}$ & PIQ, A2- Biruta & Marco A1 & 372665,310 & 7464781,080 \\
\hline 114 & 3 & 45 & 46 & A & Marco A1- Placa 05 & Pico do Selado & 392338,130 & 7467601,120 \\
\hline 115 & 3 & 45 & 46 & $\mathrm{~A}$ & Placa A3(B)- Placa A2 & Placa A3* & 390783,570 & 7470037,250 \\
\hline 116 & 3 & 45 & 47 & $\mathrm{~A}$ & Placa A5- Serra Negra & Pedra Grande Atibaia & 343742,440 & 7436766,790 \\
\hline 117 & 3 & 45 & 51 & $\mathrm{~A}-\mathrm{C}$ & Jaraguá-Atibaia & Marco A1* & 347017,810 & 7461528,820 \\
\hline
\end{tabular}




\section{REFERÊNCIAS}

AGuiAR, C. R. D.; CAMARGO, P. D. O.; GALO, M. Transformação de coordenadas e datum com propagação de covariâncias. Anais do Simpósio Brasileiro de Geomática, Presidente Prudente-SP, p. 9-13, 2002.

ALBUQUERQUE, J. P. C. d. et al. Relatório anual comissão de localização da nova capital federal, 1955. 2013.

ALENCAR, J. Sistema nacional de nivelamento de 1a ordem. In: Conferência Nacional de Geociências, IBGE, Rio de Janeiro. [S.l.: s.n.], 1968.

ALENCAR, J. C. M. de. Separata de cadernos de geociências. In: Datum Altimétrico Brasileiro. Rio de Janeiro - RJ: [s.n.], 1990. v. 5, p. 1-5.

ALFRED, L. Gps satellite surveying. A Wiley-Interscience publication. United States of America, 2004.

ALLIĖS, P. L'invention du territoire. Presses universitaires de Grenoble, 1980. (Collection Critique du droit). ISBN 9782706101748. Disponível em: <https://books.google. com.br/books?id=RxBbAAAAIAAJ $>$.

ALMEIDA, A. P. de. Memória histórica sôbre são sebastião. Revista de História, v. 16, n. 33, p. 177-222, 1958.

ALMEIDA, F. F. M. de; CARNEIRO, C. D. R. Origem e evolução da serra do mar. Revista brasileira de geociências, v. 28, n. 2, p. 135-150, 2017.

ALTIĆ, M.; DEMHARDT, I.; VERVUST, S. Dissemination of Cartographic Knowledge: 6th International Symposium of the ICA Commission on the History of Cartography, 2016. Springer International Publishing, 2017. (Lecture Notes in Geoinformation and Cartography). ISBN 9783319615158. Disponível em: $<$ https: //books.google.com.br/books?id=Qq80DwAAQBAJ>

ALTIMEYER, H. Y. Centro Histórico Mackenzie: memória institucional. Dissertação (Mestrado) - Educação, Arte e História da Cultura, 2016. Disponível em: $<$ http://tede.mackenzie.br/jspui/handle/tede/2923>.

ALVES, E.; MARRA, R. A persistente migração rural-urbana. Revista de Política Agrícola, v. 18, n. 4, p. 5-17, 2009.

ANBALAGAN, R. Landslide hazard evaluation and zonation mapping in mountainous terrain. Engineering geology, Elsevier, v. 32, n. 4, p. 269-277, 1992.

ANCIÃES, C. L. C. Transformação entre redes geodésicas: uso de coordenadas 3d, 3d com restrição e 2d. Tese (Doutorado) - Instituto Militar de Engenharia, 2003. 
ANDRADE, E. T. M. Devoçôes católicas de uma capitania em construção: vilas, freguesias e paróquias em sergipe d el rey. Anais dos Simpósios da ABHR, n. 2, 2016.

ARANA, J. Estratégia para determinação da ondulação do geoide com uso do gps/nivelamento. Universidade Federal do Paraná, p. 111-123, 2005.

ARCHELA, R. S. Evolução histórica da cartografia no brasil-instituições, formação profissional e técnicas cartográficas. Revista Brasileira de Cartografia, v. 3, n. 59, 2007.

ARCHIBALD, R. C.; KARL, P. Abraham de moivre. Nature, Nature Publishing Group, v. 117, n. 2946, p. $551,1926$.

ARID, F. M. Comportamento espacial da formação bauru na região norte-ocidental do estado de são paulo. Revista Brasileira de Geociências, v. 3, n. 1, p. 23-35, 2018.

ARMY, U. S. D. of the. Topographic Symbols. U.S. Government Printing Office, 1952. (Basic field manual). Disponível em: <https://books.google.com.br/books?id= LI9gL2wwK5UC>.

ARMY, U. S. D. of the; FORCE, U. S. D. of the A. Cartographic Aerial Photography. Departments of the Army and the Air Force, 1970. (Air Force manual). Disponível em: $<$ https://books.google.com.br/books?id=tSPF5CgwUqgC $>$.

ASHKENAZI, V. Triangulation, trilateration or traverse. Vladmiro K. Hristov Sptuagenario Academia Scientarum Bulgaria, p. 121-126, 1973.

ASPRS. Asprs positional accuracy standards for digital geospatial data. Photogrammetric Engineering \& Remote Sensing, v. 81, n. 3, p. A1-A26, 2015.

BARBATO, F. D.; REISSIG, J. H. y. Error analysis in cartographic data with application to the geographic information systems. In: ISPRS Symposium on Geospatial Theory, Processing and Applications, Ottawa. [S.l.: s.n.], 2002.

BARBOZA, G. G. A resistência ao acordo de limites e o estado das missões (1910-1917). Florianópolis, SC, 2017. Trabalho de Conclusãão de Curso (Licenciatura em História).

BARTH, F. T. O modelo de gestão de recursos hídricos no estado de são paulo. Comitês de Bacias Hidrográficas: uma revolução conceitual, organizado por Antonio Carlos de Mendes Thame, p. 17-30, 2002.

BASTOS, Z. P. S. de M. Noticiário e homenagens póstumas. Revista do Instituto Geográfico e Geológico, XX, p. 165-175, 1968.

BCB. Calculadora do cidadão - Banco Central do Brasil. 2018. Disponível em: <https://www3.bcb.gov.br/CALCIDADAO/publico/exibirFormCorrecaoValores. do? method=exibirFormCorrecaoValores\&aba $=1>$.

BEIER, J. R.; MARHTIN, D. Aspectos da representação do território paulista em sua cartografia impressa: uma análise cartobibliográfica (1833-1932). Confins. Revue francobrésilienne de géographie/Revista franco-brasilera de geografia, Théry, Hervé, n. $34,2018$. 
BIERRENBACH, L.; TALIBERTI, L. Determinação do meridiano por uma estrela em elongação, com o uso de tabelas para as latitudes de 20 grau a 25 grau. In: Boletim do Instituto Geográfico e Geológico. [S.l.]: Estado de São Paulo, Secretaria da Agricultura Industria e Comércio, Instituto Geográfico e Geológico, 1942. v. 28.

BLACHUT, T. J.; CHRZANOWSKI, A.; SAASTAMOINEN, J. H. Urban surveying and mapping. [S.l.]: Springer Science \& Business Media, 1979.

BLITZKOW, D.; CAMPOS, I. d. O.; FREITAS, S. d. Altitude: O que interessa e como equacionar. Anais do I Simpósio de Ciências Geodésicas e Tecnologias da Geoinformação. DECart/UFPE-Recife, v. 1, 2004.

BLITZKOW, D.; MATOS, A. C. Oliveira Cancoro de; GUIMARÃES, G. do N.; PACINO, M. C.; LAURÍA, E. A.; NUNES, M.; FlORES, F.; GUEVARA, N. O.; ALVAREZ, R.; HERNANDEZ, J. N. et al. Gravity and geoid model for south america. In: EGU General Assembly Conference Abstracts. [S.l.: s.n.], 2016. v. 18.

BORBA, V. Fronteiras e faixa de fronteira: expansionismo, limites e defesa. Historiae, v. 4, n. 2, p. 59-78, 2013.

BORGES, A. F. Modelagem geográfica de limites municipais-estudo de caso: Nova lima e belo horizonte-mg. Universidade Federal de Minas Gerais, 2014.

BOrGeS, A. F.; Elmiro, M. A. T.; NERO, M. A.; TEMBA, P. da C.; SARAIVA, C. C. S. Métodos de cartografia e geoprocessamento aplicados na gestão de inconsistências de limites intermunicipais-estudo de caso entre nova lima e belo horizonte, mg. Revista Geografias, v. 1, n. 21, p. 80-99, 2016.

BORGES, A. F.; TIMBÓ, M. A.; NERO, M. A.; TEMBA, P. da C. Sistemas geodésicos de referência adotados no brasil e a conversão dos dados geográficos para o sistema oficial sirgas2000: transformações e avaliação de erros. Revista Geografias, v. 12, n. 1, p. 45-63, 2017.

BRASIL. Decreto $\mathrm{n}^{\circ} 16.983$, de 22 de julho de 1925 Approva o regulamento para os serviços civis de navegação aerea. Diário Oficial da União, São Paulo, p. 16934, 1925.

BRASIL. Decreto-lei $\mathrm{n}^{\circ} 1.527$ de 24 de março de 1937. institue o conselho brasileiro de geografia e dá outras providências. Diário Oficial da União, Brasil, v. 1, n. 105, p. 1-4, 1937.

Decreto-lei $\mathrm{n}^{\circ}$ 311, de 2 de março de 1938. Dispõe sobre a divisão territorial do país, e dá outras providências. Coleção de Leis do Brasil, Brasil, v. 1, n. 105, p. 438, 1938.

BRASIL. Decreto ${ }^{o}$ 311, de 2 de março de 1938. Dispõe sobre a divisão territorial do páis, e dá outras providências. Coleção de Leis do Brasil, São Paulo, n. 41, p. 438, 1938 .

BRASIL. Decreto-lei $n^{\circ} 9.210$ de 29 de abril de 1946. fixa normas para a uniformização da cartográfia brasileira e dá outras providências. Diário Oficial da União, Brasil, v. 1, n. 105, p. 1-4, 1946. 
. Decreto-lei $\mathrm{n}^{\circ} 33.044$ de 15 de julho de 1953. promulga o acordo de assistência militar entre os estados unidos do brasil e os estados unidos da américa. Presidencia da República, Brasil, p. 11153, 1953.

. Decreto-lei $\mathrm{n}^{\circ}$ 57.814, de 15 de fevereiro de 1966. Dispõe sobre a divisão territorial do país, e dá outras providências. Coleção de Leis do Brasil, Brasil, v. 2, p. 481, 1966.

. Decreto-lei $\mathrm{n}^{\circ}$ 243, de 4 de fevereiro de 1967. fixa as diretrizes e bases da cartografia brasileira e dá outras providências. Coleção de Leis do Brasil, Brasil, v. 1, p. 398, 1967.

. Decreto-lei $n^{o} 5.447$, de 4 de junho de 1968. concede isenção dos impostos sobre produtos industrializados e de importação destinados a empresas que exploram serviços aerofotogramétricos. Coleção de Leis do Brasil, Brasil, v. 3, p. 51, 1968.

. Decreto-Lei $\mathrm{n}^{\circ} \mathbf{8 9 . 8 1 7}$ de 20 de junho de 1984: Normas Técnicas da Cartografia Nacional. [S.l.]: Diário Oficial da União Brasília, 1984.

. Emenda constitucional $\mathrm{n}^{\circ} 15$, de 13 de setembro de 1996. Altera o art. 18 da constituição que trata da criação e incorporação de municípios. Diário Oficial da União, Brasil, v. 1, n. 105, p. 18109, 1996.

BRASIL, L. D. Decreto lei no 71.267, de 25 de outubro. dispoõe sobre aerolevantamentos no território nacional e da outras providências. Brasília: Diário Oficial da União (DOU), v. 22, p. 06-84, 1972.

. Decreto no 89.817, de 20 de junho. estabelece as instruções reguladoras das normas técnicas da cartografia nacional (irntcn). Brasília: Diário Oficial da União (DOU), v. 22, p. 06-84, 1984.

- Decreto no 2.278, de 17 de julho. regulamenta o decreto-lei no 1.177, de 21 de junho de 1971. Coleção de Leis do Brasil, v. 7, p. 4652, 1997.

BRASSEL, K.; BUCHER, F.; STEPHAN, E.-M.; VCKOVSKI, A. Completeness. In: Elements of spatial data quality. 1. ed. [S.l.]: Elsevier, 1995. cap. 5, p. 81-108.

BRENNI, P.; GIATTI, A. Lo stereocartografo santoni modello iv: cronaca di un salvataggio. Nuncius, Brill, v. 13, n. 1, p. 187-191, 1998.

BUENO, B. P. S. Dilatação dos confins: caminhos, vilas e cidades na formação da capitania de são paulo (1532-1822). Anais do Museu Paulista: História e Cultura Material, SciELO Brasil, v. 17, n. 2, p. 251-294, 2009.

CALDEIRA, J. História da riqueza no Brasil: Cinco séculos de pessoas, costumes e governos. Estação Brasil, 2017. ISBN 9788556080264. Disponível em: <https: //books.google.com.br/books?id=Dak3DwAAQBAJ $>$

CAMARA, A. A.; MATTOS, A. H.; LEFÈVRE, V. Parecer da comição de uniformização da cartografia. Assembléia Geral do Conselho Nacional de Geográfia, 1941.

CAmARGO, A. A. Mensagem dirigida ao congresso legislativo do estado. Tpy. da Republica, feveiro 1920 . 
CAMPOS, J. B. Spatial and multi-temporal analysis of deforestation and quantification of the remnant forests on porto rico island, paraná, brazil. Brazilian Archives of Biology and Technology, SciELO Brasil, v. 42, n. 1, p. 0-0, 1999.

CAPEL, H. Institutionalization of geography and strategies of change. Geography, ideology and social concern, Basil Blackwell Oxford, p. 37-69, 1981.

CARDOSO, J. P. C. Relátorio da Comissão Geográfica e Geológica. São Paulo, 1907.

CARNEIRO, C. D. R.; SOUZA, J. J. de. Mapeamento geomorfológico em escala de semidetalhe da região de jundiaí-atibaia. Revista Brasileira de Geomorfologia, v. 4, n. 2, 2003 .

CARVALHO, M. d. Simplificação operacional em levantamentos geodésicos com o emprego de instrumentos eletrônicos. Revista do Instituto Geológico, Instituto Geológico, Secretaria do Meio Ambiente/SP, v. 4, p. 53-65, 1983.

CASTAÑEDA, R. M. Ensaio para Definição de Parâmetros de transformação entre o SAD69 e NSWC 9Z2. Dissertação (Mestrado) - Universidade Federal do Paraná, Curitiba, PR, nov 1986.

CASTRO, C. L. de. Mapas municipais. Revista brasileira de geografia, v. 1, n. 1, p. 81-94, jan 1939.

CASTRO, R.; CASATTI, L.; SANTOS, H. F.; FERREIRA, K. M.; RIBEIRO, A. C.; BENINE, R. C.; DARDIS, G. Z.; MELO, A. L.; STOPIGLIA, R.; ABREU, T. X. et al. Estrutura e composição da ictiofauna de riachos do rio paranapanema, sudeste e sul do brasil. Biota Neotropica, SciELO Brasil, v. 3, n. 1, p. 1-31, 2003.

CHIQUiTO, E. d. A. A Comissão Interestadual da Bacia Paraná-Uruguai: do planejamento de vale aos polos de desenvolvimento. Tese (Doutorado) - Universidade de São Paulo, 2011.

CIGOLINI, A. A. Ocupação do território e criação de municípios no período republicano brasileiro. Biblio 3W, p. 1-15, 2014.

CINTRA, J.; SILVA, M. O início da cartografia sistemática no brasil. v. 2, p. 763-772, 2001.

CINTRA, J. P. A primeira base geodésica do brasil. v. 21, 2003.

. Digital cartography and historical maps: techniques, applications and peculiarities. Revista Brasileira de Cartografia, n. 64/4, 2012.

- Reconstruindo o mapa das capitanias hereditárias. Anais do Museu Paulista: História e Cultura Material, SciELO Brasil, v. 21, n. 2, p. 11-45, 2013.

- Os limites das capitanias hereditárias do sul e o conceito de território. Anais do Museu Paulista: História e Cultura Material, SciELO Brasil, v. 25, n. 2, p. 203-223, 2017. 
CINTRA, J. P.; NERO, M. A. New method for positional cartographic quality control in digital mapping. Journal of Surveying Engineering, American Society of Civil Engineers, v. 141, n. 3, p. 04015001, 2015.

CINTRA, J. P.; RIBEIRO, S. C. L. Evolução da restituição aerofotogramétrica. Anais do Seminário sobre Computação gráfica em A.E.C., SOBRACON, nov 1991.

CINTRA, J. P.; SILVA, M. J. Teodoro sampaio and the beginning of systematic cartography in brazil. Memorias del Congreso Internacional de Geodesia y Cartografia, Congreso Internacional de Geodesia y Cartografia, v. 1, p. 1-6, 2002.

CLYNCH, J. R. Earth coordinates. Electronic Documentation, February, 2006.

CNG. Relato de atividades da divisão de Cartografia. [S.l.]: Instituto Brasileiro de Geografia e Estatística, 1952.

COLUCCI, A. Nivelamento geral do estado altitudes de precisão. Secretaria da Agricultura do Estado de São Paulo, v. 36, 1962.

- Tabela de determinação do meridiano verdadeiro, por meio de estrelas em elongação, nas latitudes -1 grau a -40 grau. In: Boletim do Instituto Geográfico e Geológico. [S.l.]: Estado de São Paulo, Secretaria da Agricultura, Instituto Geográfico e Geológico, 1966. v. 46.

CORRÊA FILHO, V. Mapa Etno-Histórico De Curt Nimuendaju. [S.l.], 1987.

CORREiA Júnior, C. A. E. C.; GUimarÃES, G. D. N.; FERREIRA, N. C. Evolução da infraestrutura gravimétrica no brasil. Geociências (São Paulo), v. 37, n. 2, p. 361$384,2019$.

COSTA, L. A. M. O ideário urbano paulista na virada do século: o engenheiro Theodoro Sampaio e as questões territoriais e urbanas modernas (1886-1903). [S.l.]: RiMa Editora, 2003.

COSTA, S. M. A. Integração da rede geodésica brasileira aos sistemas de referência terrestres. Tese (Doutorado) — Universidade Federal do Paraná, 1999.

COSTA, S. M. A. INTEGRAÇÃO DA REDE GEODÉSICA BRASILEIRA AOS SISTEMAS DE REFERENCIA TERRESTRES. Tese (Doutorado) - Universidade Federal do Paraná, Curitiba, 1999.

COSTA, S. M. A.; DUARTE, P. K.; BEAATTIE, D. Completeness. In: Advances in Positioning and Reference Frames: IAG Scientific Assembly Rio de Janeiro, Brazil, September 3-9, 1997. 1. ed. [S.l.]: Springer Berlin Heidelberg, 1997. p. 187204.

DEFFONTAINES, P. Geografia humana do brasil. REVISTA BRASILEIRA DE GEOGRAFIA, v. 1, n. 1, p. 9-19, jan 1939.

DERBY, O. A. Retrospecto Histórico dos Trabalhos Geographicos e Geológicos. Província de São Paulo, 1889.

DMA. DMA Tecnical Report Geodesy for de layman. [S.l.], 1983. 
DMA, U. S. D. M. A. Supplement to Department of Defense World Geodetic System 1984 Technical Report. Defense Mapping Agency, 1987. (Supplement to Department of Defense World Geodetic System 1984 Technical Report, v. 2). Disponível em: $<$ https://books.google.com.br/books?id=G44RAQAAIAAJ $>$

DONNELLY, G. Fundamentals of land ownership, land boundaries, and surveying. Intergovernmental committee on surveying and mapping, 2012.

DORNELlES, M. A.; IESCHECK, A. L. Análise da aplicabilidade da infraestrutura nacional de dados espaciais (inde) para dados vetoriais em escalas grandes. Boletim de Ciências Geodésicas, SciELO Brasil, v. 19, n. 4, 2013.

DORR, J. V. N. Geological Survey Professional Paper. U.S. Government Printing Office, 1969. (Geological Survey Professional Paper, v. 641,pt. 1-3). ISSN 0096-0446. Disponível em: <https://books.google.com.br/books?id=TsZRAQAAMAAJ $>$.

DOYLE, F. J. The historical development of analytical photogrammetry. American Society for Photogrammetry and Remote Sensing, v. 30, p. 259-265, 1964.

DSG, D. de S. G. Norma da Especificação Técnica para Aquisição de Dados Geoespaciais Vetoriais de Defesa da Força Terrestre (ET ADGV Defesa F Ter). $2^{\text {a }}$ Edição. 2016.

DCT - DEPARTAMENTO DE CIÊNCIA E TECNOLOGIA. Norma da especificação técnica para controle de qualidade de dados geoespaciais (ET-CQDG), v. 1. [S.l.]: Ministério da Defesa, Exército Brasileiro, 2016.

DUARTE, R.; CINTRA, J. P. História de um mapeamento não finalizado: a carta do instituto geográfico e geológico na escala 1:25.000. VII Simpósio Luso-Brasileiro de Cartografia Histórica, p. 1, 2017.

DUARTE, R.; ROMAnHOLI, M. P. Metodologia de Análise no Controle de Qualidade de vetores de hidrografia e modelos digitais de terreno no mapeamento do Estado de São Paulo. anais $18^{\circ}$. In: SBSR. SIMPÓSIO BRASILEIRO DE SENSORIAMENTO REMOTO. [S.l.], 2017. v. 18, p. 3323-3330.

EASTON, R.; FLEMING, J. The navy space surveillance system. Proceedings of the IRE, IEEE, v. 48, n. 4, p. 663-669, 1960.

ELLER, R. C. Surveying and Mapping. AMERICAN CON GRESS ON SURVEYING AND MAPPING, 1954. v. 14. (A QUARTERLY JOURNAL DEVOTED TO THE ADVANCEMENT OF THE SCIENCES OF SURVEYING AND MAPPING, 4). Disponível em: $<$ https://books.google.com.br/books?id=wDw4AAAAIAAJ $>$.

ENGELN, O. D. Geomorphology. first. NEW YORK: THE MACMILLAN COMPANY, 1941.

ETGES, F. M.; PEREIRA, L. C. A correção de limites territoriais municipais: Um olhar sob o princípio da subsiariedade. Os Grandes Temas do Municipalismo, p. 18, 2017.

EVANGELISTA, H. d. A. O serviço geográfico do exército. Revista Geopaisagem, v. 1, n. 2, 2002. 
FAIRCHILD, S. M. Aerial camera. [S.l.]: Google Patents, 1927. US Patent 1,612,860.

Aerial photography. its development and future. The Annals of the American Academy of Political and Social Science, [Sage Publications, Inc., American Academy of Political and Social Science], v. 131, p. 49-55, 1927. ISSN 00027162. Disponível em: <http://www.jstor.org/stable/1015745>.

FAVERO, E. Desmembramento territorial: o processo de criação de municípiosavaliação a partir de indicadores econômicos e sociais. Tese (Doutorado) - Universidade de São Paulo, 2004.

FEGEAS, R. G.; CASCIO, J. L.; LAZAR, R. A. An overview of fips 173, the spatial data transfer standard. Cartography and Geographic Information Systems, Taylor \& Francis, v. 19, n. 5, p. 278-293, 1992.

FELIX, F. K. L. Território, poder e litígio: conflitos territoriais entre parambu (ce) e pimenteiras. 2015.

FERGUSON, G. A. Statistical analysis in psychology and education. McGraw-Hill, 1959.

FERNANDES, L. A.; COIMBRA, A. M. O grupo caiuá $(\mathrm{ks})$ : revisão estratigráfica e contexto deposicional. Brazilian Journal of Geology, v. 24, n. 3, p. 164-176, 1994.

FERNANDES, V. O.; NOGUEIRA, R. E. Conseqüências da mudança de datum na representação cartográfica direcionada para ambiente SIG. Portal de Cartografia, v. 3, p. 5, 012010.

FERREIRA, M. d. M. Diário pessoal, autobiografia e fontes orais: a trajetória de pierre deffontaines. 1998.

FIGUEIRÔA, S. d. M.; VIEIRA, P.; BOCHICCHIO, V. Um século de pesquisas em geociências. [S.l.]: Instituto Geológico - IG, 1985.

FIGUEIRÔA, S. F. d. M. Modernos bandeirantes: a Comissão Geográfica e Geológica de São Paulo e a exploração científica do território paulista (1886-1931). Dissertação (Mestrado) — Universidade de São Paulo - USP/FFLCH, 1987.

FIGUEIRÔA, S. F. d. M. Trailblazers of science in the são paulo territory: exploratory expeditions and the settlement of the são paulo'sertão'at the turn of the twentieth century. História, Ciências, Saúde-Manguinhos, SciELO Brasil, v. 15, n. 3, p. 763-777, 2008.

FIGUEIRÔA, S. F. de M. Modernos bandeirantes: Commissão Geográfica e Geológica de São Paulo ea exploração científica do território paulista, 1886-1931. Dissertação (Mestrado) — Universidade de São Paulo, 1987.

FILHO, G. S. A.; SANTORO, J.; GOMES, L. A. Estudo da dinâmica evolutiva da boçoroca são dimas no município de são pedro, sp.

FILMER, M.; FEATHERSTONE, W. Error propagation for three common height-system corrections to differential levelling. Journal of Spatial Science, Taylor \& Francis, v. 56, n. 1, p. 39-58, 2011.

FISCHER, I. Does mean sea level slope up or down toward north? Bulletin Géodésique (1946-1975), Springer, v. 115, n. 1, p. 17-26, 1975. 
The figure of the earth - changes in concepts. Surveys in Geophysics, Springer, v. 2 , n. 1 , p. $3-54,1975$.

FORREST, R. B. An empirical study of relative orientation errors in aerial triangulation. Tese (Doutorado) — The Ohio State University, 1964.

FORTES, L. P. S. Sirgas: O sistema de referência para o novo milênio. I Semiário sobre referencial geocêntrico no Brasil, 2000.

FRANCO, A. d. S. Compensação dos erros nos trabalhos de triangulação. In: Boletim do Instituto Geográfico e Geológico. [S.1.]: Secretaria da Agricultura do Estado de São Paulo, 1943. v. 30.

. Aerotriangulação espacial. In: Boletim do Instituto Geográfico e Geológico. [S.l.]: Estado de São Paulo, Secretaria da Agricultura, Instituto Geográfico e Geológico, 1962. v. 37.

FRANCO, A. D. S. Adjustment of aerial triangulation. United Nations Regional Cartographic Conference for Africa, p. 169-183, 1963.

FREITAS, S. d.; BLITZKOW, D. Altitudes e geopotencial. IGeS Bulletin N, p. 47-62, 1999.

FREITAS, S. d. D.; BLITZKOW, D. Altitudes e geopotencial. IGeS Bulletin N, p. 47-62, 1999.

FURTADO, F. A. Evoluçao da diviçao territorial de minas gerais: os limites municipais desde 1711. Geografia, Associação de Geografia Teoretica, v. 32, n. 1, p. 199-214, 2007.

GALO, M.; CAMARGO, P. d. O. Utilização do gps no controle de qualidade de cartas. I - Congresso Brasileiro de Cadastro Técnico Multifinalitário, Florianópolis-SC, v. 1, p. 41-48, 1994.

GALO, M.; POZ, A. P. D.; FERREIRA, F. M. O uso de feições no controle de qualidade em cartografia. In: Proceedings of the XX CBC-Cartography Brazilian Congress. [S.l.: s.n.], 2001.

GARNERO, G. Use of ntv2 transformation grids in engineering applications. Earth Science Informatics, Springer, v. 7, n. 2, p. 139-145, 2014.

GEMAEL, C. Introdução à geodésia geométrica. Universidade Federal do Paraná. Curso de Pós-Graduação em Ciências Geodésicas. Curitiba, 1987.

Introdução ao ajustamento de observações: aplicações geodésicas. [S.l.]: Editora UFPr, 1994. 1999.

. Introdução à geodésia física. Curitiba: Editora da UFPR, v. 302, p. 2002,

GEOLÓGICO, I. Falece o paleontólogo Sérgio Mezzalira. Secretaria de Estado do Meio Ambiente, 2009. Disponível em: <http://www.igeologico.sp.gov.br/ler_noticia.asp? $\mathrm{id}=285>$. Acesso em: 03/09/2017. 
GHOSH, S. History of photogrammetry-analytical methods and instruments. International Archives of Photogrammetry and Remote Sensing, International Society For Photogrammetry \& Remote Sensing, v. 29, p. 311-327, 1993.

GIANNINI, M. B.; MAGLIONE, P.; PARENTE, C.; SANTAMARIA, R. Cartography and remote sensing for coastal erosion analysis. WIT Transactions on Ecology and the Environment, WIT Press, v. 149, p. 65-76, 2011.

GOODCHILD, M. F. Attribute accuracy. In: GUPTILL, S. C.; MORRISON, J. L. (Ed.). Elements of spatial data quality. 1. ed. [S.l.]: Elsevier, 1995. cap. 4, p. 60-79.

GOODCHILD, M. F.; HUNTER, G. J. A simple positional accuracy measure for linear features. International Journal of Geographical Information Science, Taylor \& Francis, v. 11, n. 3, p. 299-306, 1997.

GORDON, S. The normal distribution. University of Sydndey, 2006.

GORROOCHURN, P. Classic Topics on the History of Modern Mathematical Statistics: From Laplace to More Recent Times. Wiley, 2016. ISBN 9781119127925. Disponível em: $<$ https://books.google.com.br/books?id=Tdk9CgAAQBAJ $>$.

GRANICHER, J. W. The Inter American Geodetic SURVEY Twenty-Five Years of Cooperation. [S.l.], 1972.

GUEDES, H. J.; LEFÈVRE, V.; ARISTIDES, B. Os Limites São Paulo e Rio de Janeiro. São Paulo, 1950.

GUIER, W. H.; WEIFFENBACH, G. C. Theoretical analysis of doppler radio signals from earth satellites. Nature, Nature Publishing Group, v. 181, n. 4622, p. 1525, 1958.

GUIMARÃES, G. d. N. A altimetria e o modelo geoidal no Estado de São Paulo. Dissertação (Mestrado) — Universidade de São Paulo, São Paulo, SP, 2010.

GUIMARÃES, G. do N.; MATOS, A. C. O. C. de; BLITZKOW, D. Gravimetric densification in the state of são paulo aiming a geoid model. Brazilian Journal of Geophysics, v. 31, n. 4, p. 631-642, 2013.

GUPTILL, S. C.; MORRISON, J. L. Elements of spatial data quality. [S.l.]: Elsevier, 2013.

HAMILTON. Harvard Magazine, 1999. Disponível em: <https://www.harvardmagazine. com/1999/03/jhj.ham.html>.

HARDY, G. D. Galileo-santonistereo cartography modeliv. American Society for Photogrammetry and Remote Sensing, v. 21, n. 3, p. 417-419, 1955.

HARLEY, J. B. Deconstructing the map. Cartographica: The international journal for geographic information and geovisualization, University of Toronto Press, v. 26, n. 2, p. 1-20, 1989.

. The map and the development of the history of cartography. 2018.

HARTT, C. F.; AGASSIZ, L. Geology and physical geography of Brazil. [S.l.]: Fields, Osgood, 1870. 
HELMERT, F. R. Mathematical and Physical Theories of Higher Geodesy. [S.l.]: Geo-Sciences Branch, Chart Research Division, Aeronautical Chart and Information Center, 1880. v. 1.

HOFMANN-WELLENHOF, B.; KIENAST, G.; LICHTENEGGER, H. GPS in der Praxis. [S.l.]: Springer-Verlag, 1994.

HOFMANN-WELLENHOF, B.; LICHTENEGGER, H.; COLLINS, J. Global positioning system: theory and practice. [S.l.]: Springer Science \& Business Media, 1994. v. $3.355 \mathrm{p}$.

Global positioning system: theory and practice. [S.l.]: Springer Science \& Business Media, 2012.

HOWARTH, R. Gravity surveying in early geophysics. i. from time-keeping to figure of the earth. Earth Sciences History, History of Earth Sciences Society, v. 26, n. 2, p. 201-228, 2007.

Gravity surveying in early geophysics. ii. from mountains to salt domes. Earth Sciences History, History of Earth Sciences Society, v. 26, n. 2, p. 229-261, 2007.

HUGERSHOFF, N. Photogrammetrie und luftbildwesen. [S.l.]: Springer-Verlag, 2013.

IAGS1965. Inter American Geodetic Survey Comission relate 1952. 1965. Disponível em: <https://repository.library.brown.edu/studio/item/bdr:811522/>. Acesso em: $23 / 12 / 2018$.

. Telegrama do Consul americano William L. Wigth Junior. 1965. Disponível em: <https://repository.library.brown.edu/studio/item/bdr:327981/>. Acesso em: $23 / 12 / 2018$.

IBGE. Resolução 22, de 21 de julho de 1983. Instituto Brasileiro de Geografia e Estatística, 1983. Disponível em: $<\mathrm{ftp}: / /$ geoftp.ibge.gov.br/metodos_e_outros_ documentos_de_referencia/normas/legisla_resolucao_d.pdf $>$. Acesso em: 06/07/2019.

. Resolução 23, de 21 de fevereiro de 1989. Instituto Brasileiro de Geografia e Estatística, 1989. Disponível em: $<\mathrm{ftp}$ //geoftp.ibge.gov.br/metodos_e_outros_ documentos_de_referencia/normas/rpr.pdf $>$. Acesso em: 06/07/2019.

- Ajustamento da Rede Planimétrica do Sistema Geodésico Brasileiro. Instituto Brasileiro de Geografia e Estatística, 1996. Disponível em: $<\mathrm{ftp}$ //geoftp.ibge.gov.br/informacoes_sobre_posicionamento_geodesico/rede_ planialtimetrica/relatorio/rel_sad69.pdf $>$. Acesso em: 24/05/2017.

- Proposta preliminar para a adoção de um referencial geocêntrico no brasil. Instituto Brasileiro de Geografia e Estatística, 2000.

Programa de transformação de coordenadas ProGriD. Instituto Brasileiro de Geografia e Estatística, 2009. Disponível em: <ftp://geoftp.ibge.gov.br/informacoes_ sobre_posicionamento_geodesico/sirgas/aplicativos/transformacao_coordenadas/ progrid_guia_do_usuario.pdf $>$. Acesso em: 10/12/2017. 
Distribuição das estações gravimétricas terrestres utilizadas utilizadas no cálculo do MAPGEO2015. 2015. Disponível em: $<$ ftp://geoftp.ibge.gov.br/modelos_digitais_de_superficie/modelo_de_ondulacao_ geoidal/cartograma/rede_MAPGEO2015.pdf $>$. Acesso em: 15/04/2018.

. ProGriD - Guia do Usuário Fundação Instituto Brasileiro De Geografia E Estatística. 2018. Disponível em: <ftp://geoftp.ibge.gov.br/documentos/geodesia/ projeto_mudanca_referencial_geodesico/progrid_guia_do_usuario.pdf $>$. Acesso em: $23 / 12 / 2018$.

IDOETA, I.; IDOETA, I. V.; CINTRA, J. P. São Paulo vista do alto: $\mathbf{7 5}$ anos de aerofotogrametria. [S.1.]: Érica, 2004.

IGCSP. Acervo aerofotográfico e cartográfico. História e Gestão Documental do Instituto Geográfico e Cartográfico de São Paulo, 2017.

. Geoportal do Instituto Geográfico e Cartográfico de São Paulo - IGCSP. 2019. Disponível em: <www.igc.sp.gov.br>. Acesso em: 23/12/2019.

IGGSP. Segunda reunião brasileira de consulta sobre cartografia. In: ACERVO INSTITUTO GEOLÓGICO (MUGEO). Curitiba - PR: Instituto Geográfico Geológico de São Paulo, 1959. p. 1-6.

. Poligonais do instituto geográfico geológico de são paulo -iggsp (não publicadas). Acervo do Instituto Geográfico e Cartográfico de São Paulo - IGCSP, 19591962.

ING, H. S. An analytical treatment of the problem of triangulation by stereophotogrammetry. Photogrammetria, Elsevier, v. 13, p. 67-77, 1956.

ISO. Geographic Information - Quality evaluation procedures, v. 2. [S.l.]: ISO, 2003. $72 \mathrm{p}$. $72 \mathrm{p}$.

ISO 19157 Geographic information-data quality, v. 2. [S.l.]: ISO, 2013.

JAKOBSSON, A.; GIVERSEN, J. Guidelines for implementing the iso 19100 geographic information quality standards in national mapping and cadastral agencies. Eurogeographics Expert Group on Quality, 2007.

JENSEN, J. R.; EPIPHANIO, J. C. N. Sensoriamento remoto do ambiente: uma perspectiva em recursos terrestres. [S.l.]: Parêntese, 2011.

JERIE, H. Block adjustment by means of analogue computers. Photogrammetria, v. 14, p. 161 - 176, 1957. ISSN 0031-8663. Disponível em: <http://www.sciencedirect.com/ science/article/pii/S0031866357800222>.

JUNKINS, D.; ERICKSON, C. Version 2 of the national transformation between nad27 and nad83 and its importance for gps positioning in canada. Geodetic Survey Division Geomatics. Canadá, 1996.

KAHN, W. D. Determination of corrections to mark ii minitrack station coordinates from artificial satellite observations. Journal of Geophysical Research, Wiley Online Library, v. 65, n. 3, p. 845-849, 3 1960. ISSN 2156-2202. Disponível em: <http:https: //doi.org/10.1029/JZ065i003p00845>. 
KANIUTH, K.; COSTA, S. Results of the sirgas 2000 gps campaign campaign. 102002.

KERSHNER, C. of R. B. History of the space department, the applied physics laboratory. The Johns Hopkins University Applied Physics Laboratory, 1979.

KINGSBURY, D. Flodd rescue mission from Rio to Southern Brazil. Aerial Survey and Photomapping History, online, 1966. Disponível em: <http://www.1370th.org/ ASTs/ast10/ast10.html>. Acesso em: 23/12/2018.

KONVITZ, J. V. Redating and rethinking the cassini geodetic surveys of france, 17301750. Cartographica: The International Journal for Geographic Information and Geovisualization, University of Toronto Press, v. 19, n. 1, p. 1-15, 1982.

KOPER, R. Automated stereo-photogrammetric instrument. [S.l.]: Google Patents, 1974. US Patent 3,783,294.

LAURILA, S. Some aspects of hiran-photogrammetry. Photogrammetric Engineering, v. 23, n. $1,1957$.

LEAL, P. R. G. Controle de qualidade em cartografia: proposta metodológica para avaliação das cartas topográficas do mapeamento sistemático nacional. 156 p. Dissertação (Mestrado) — Universidade Federal de Santa Catarina - UFSC, 2007.

LEFÈVRE, V. Súmula referente aos serviços geográficos do Estado de São Paulo apresentada á segunda reunião panamericana de consuilta sobre geografia e cartografia. In: . São Paulo: Instituto Geográfico Geológico de São Paulo - IGGSP, 1944.

- Resumo do relatário das atividades do instituto geográfico e geológico durante o exercício de 1945. Revista Instituto Geográfico Geológico - IGG, São Paulo, v. 4, n. 1, p. 19-87, 1946.

Ata da licitação 1 de 1953 (n. 14968A). [S.l.]: Acervo Instituto Geológico MUGEO, 1953.

- Relatório apresentado na segunda reunião brasileira de cartografia. Instituto Geográfico e Geológico, Acervo Instituto Geológico MUGEO, 1959.

Relatório da atividades do diretório regional de geografia. XXI Assembléia Geral do Conselho Nacional de Geográfia, 1961.

. Relatório de atendimento ao artigo 34 da lei 32.715 1958. Instituto Geográfico

e Geológico, Acervo Instituto Geológico MUGEO, 1962.

LEFÈVRE, V. A evolução da cartografia paulista e o atual plano cartográfico. In: Revista do Instituto Geográfico e Geológico. [S.l.]: Secretaria da Agricultura do Estado de São Paulo, 1963. XVI.

Demarcação das divisas do Estado de São Paulo com o do Paranáfico e laudo do Dr. Epitácio Pessôa. In: Revista do Instituto Geográfico e Geológico. [S.l.]: Secretaria da Agricultura do Estado de São Paulo, 1966. XVIII, p. 119-133.

LEVANTAMENTO Aerophotographico em Bauru e Araquara. Jornal Estado de São Paulo, p. 4-1, 1938-39. 
LEYK, S.; BOESCH, R.; WEIBEL, R. Saliency and semantic processing: Extracting forest cover from historical topographic maps. Pattern recognition, Elsevier, v. 39, n. 5 , p. $953-968,2006$.

LI, R.; MA, R.; DI, K. Digital tide-coordinated shoreline. Marine Geodesy, Taylor \& Francis, v. 25, n. 1-2, p. 27-36, 2002. Disponível em: <https://doi.org/10.1080/ $014904102753516714>$.

LIEBENBERG, E.; DEMHARDT, I. History of Cartography: International Symposium of the ICA Commission, 2010. Springer Berlin Heidelberg, 2012. (Lecture Notes in Geoinformation and Cartography). ISBN 9783642190889. Disponível em: $<$ https://books.google.com.br/books?id=JeV $\backslash$ YoAZH3YC $>$.

LIMA, B.; COLUCCI, A. Serviço de geodésia - coordenadas geográficas e geodésicas. In: Boletim do Instituto Geográfico e Geológico. [S.l.]: Estado de São Paulo, Secretaria da Agricultura, Instituto Geográfico e Geológico, 1940. v. 28.

LIMA, E. C. d. O levantamento pioneiro da SARA Brasil: histórico, tecnologia empregada e avaliação dos produtos. Dissertação (Mestrado) - Universidade de São Paulo, São Paulo, SP, 2012.

LIMA, G. C. B. Terminologia geográfica. Revista do Instituto Geográfico e Geológico, III, p. 148-165, jun 1945.

LOBECK, A. K. Geomorphology. Science Education, Wiley, v. 24, n. 5, p. 1-296, oct 1939. Disponível em: <https://doi.org/10.1002/sce.3730240525>.

LONGWELL, C. R.; KNOPF, A.; FLINT, R. F.; SCHUCHERT, C.; DUNBAR, C. O. A Textbook of Geology: Physical geology, by Chester R. Longwell, Adolph Knopf and Richard F. Flint. [S.l.]: J. Wiley, 1939. v. 1.

LÓPEZ, F. J. A.; GORDO, A. D. A. Analysis of some positional accuracy assessment methodologies. Journal of surveying Engineering, American Society of Civil Engineers, v. 134, n. 2, p. $45-54,2008$.

LUCARIELLO, G. Terrain and Contour Model Instruction. [S.l.], 1987.

LUCIO, S. T. M. P. João Pedro Cardoso e a ação da Comissão Geográfica e Geológica na apropriação e produção do território paulista, 1905-1931. Tese (Doutorado) — Universidade de São Paulo, 2014.

LUDOVICO, T. Coordenadas geográficas de locais do Estado de São Paulo. In: Boletim do Instituto Geográfico e Geológico. [S.l.]: Estado de São Paulo, Secretaria da Agricultura, Instituto Geográfico e Geológico, 1953. v. 34.

LUGNANI, J. B. Introdução à fototriangulação. Curitiba: Ed. da UFPR, v. 134, 1987.

LUZ, R. T.; FREITAS, S. d.; DALAZOANA, R. Acompanhamento do datum altimétrico imbituba através das redes altimétrica e maregráfica do sistema geodésico brasileiro. In: VII Congresso Internacional de Ciências da Terra, Santiago, Chile. [S.l.: s.n.], 2002. 
LUZ, R. T.; GUIMARÃES, V. M. Realidade e perspectivas da rede altimétrica de alta precisão do sistema geodésico brasileiro. status and perspectives of the brazilian first order leveling network. Série em Ciências Geodésicas, v. 1, 2001.

MACEDO, M. R. A.; ROCHA, J.; SANTOS, C.; MIRANDA, R. S. Revisão dos limites municipais do estado do pará com uso das geotecnologias. Anais XVI Simpósio Brasileiro de Sensoriamento Remoto-SBSR, Foz do Iguaçu, PR, Brasil, v. 13, 2013.

MACEK, J. B. Marine charting by the united states. In: The History of Cartography, Volume 6: Cartography in the Twentieth Century. [s.n.], 2017. v. 56 , p. 830 - 835. Disponível em: <http://www.sciencedirect.com/science/article/pii/ S0305748816300275>.

MACKENZIE. Anuário de Cursos. São Paulo - SP, 1913.

MAGNA JÚNIOR, J. P. Modelagem de distorções entre realizações de referenciais geodésicos. Dissertação (Mestrado) - Universidade Estadual Paulista (UNESP), 2007.

MAGNA JÚNIOR, J. P. O uso de thin-plate splines na transformação de coordenadas com modelagem de distorções entre realizações de referenciais geodésicos. Tese (Doutorado) — Universidade Estadual Paulista - UNESP, 2012.

MANIÇOBA, R. S.; OLIVEIRA, D. V. Processo de formação e expansão urbana do distrito federal. Universitas Humanas, v. 11, n. 2, 2015.

MANN, T.; CINTRA, J. Teodoro sampaio e a medição da primeira base geodésica no brasil. Relatório de Iniciação Científica FAPESP, v. 2001, 2000.

MAROTTA, G. S.; RODRIGUES, D. D. Atualização de parâmetros na transformação em referenciais geodésicos históricos. Revista Brasileira de Cartografia, 2011.

MARTONNE, E. D. La Valachie, essai de monographie géographique, par Emmanuel de Martonne,... [S.l.]: A. Colin, 1902.

Traite de Geographie Physique: tome Notions Generales Climat Hydrographie. [S.l.]: Librairie Armand Colin, 1934.

MARTONnE, E. d. Problèmes morphologiques du brésil tropical. In: Annales de Géographie. [S.l.: s.n.], 1939. v. 49, p. 106-29.

MATOS, A. C. O. C. d.; BLITZKOW, D.; GUIMARÃES, G. d. N.; LOBIANCO, M. C. B.; COSTA, S. M. A. Validação do mapgeo2010 e comparação com modelos do geopotencial recentes. Boletim de Ciências Geodésicas, SciELO Brasil, v. 18, n. 1, p. 101-122, 2012.

MATTOS, A. H. D. A cartografia no brasil. Revista Geográfica, JSTOR, v. 3, n. 7/9, p. 133-144, 1943.

MCGLONE, C.; MIKHAIL, E.; BETHEL, J. Manual of photogrammetry. ASPRS, n. 15, 1980 . 
MCNAIR, A. J. General review of analytical aerotriangulation. Photogrammetric Engineering \& Remote Sensing, v. 23, n. 3, p. 573-582, 1957.

MENDITTO, A.; PATRIARCA, M.; MAGNUSSON, B. Understanding the meaning of accuracy, trueness and precision. Accreditation and Quality Assurance, Springer Nature, v. 12, n. 1, p. 45-47, oct 2006. Disponível em: <https://doi.org/10.1007/ s00769-006-0191-z>.

MENEZES, M. L. P. A noção geográfica de país na república velha: tratados e limites do brasil. Scripta Nova, v. 10, n. 218, 2006.

MENEZES, P. M. L. A cartografia do império do brasil. IV Simpósio Luso Brasileiro de Cartografia Histórica, 2011.

MERCHANT, D. Spatial accuracy standards for large scale line maps. In: Technical papers of the American Congress on Surveying and Mapping. [S.l.: s.n.], 1982. v. 1, p. 222-231.

MESQUITA, G. R.; SANDES, N. F. O projeto regionalista de gilberto freyre e o estado novo: da crise do pacto oligárquico à modernização contemporizadora das disparidades regionais do brasil. 2014.

MIKHAIL, E. M.; ACKERMANN, F. E. Observations and least squares. Harper and Row, 1976.

MILSOM, J. The Hunt for Earth Gravity: A History of Gravity Measurement from Galileo to the 21st Century. Springer International Publishing, 2018. ISBN 9783319749594. Disponível em: <https://books.google.com.br/books?id= 0rZhDwAAQBAJ $>$.

MITCHELL, H. L. Sea-surface topography around australia. Geophysical surveys, v. 2, n. 1, p. 117-129, Jan 1975. ISSN 1573-0956. Disponível em: <https://doi.org/10.1007/ BF01447940>.

MOELLERING, H. The proposed standard for digital cartographic data: report of the digital cartographic data standards task force. The American Cartographer, v. 15, n. 1 , p. 11-31, 1988.

MOI, C.; SCHIAVINATTO, I. L. et al. Explorações do olhar: ciência e arte nas fotografias da comissão geográfica e geológica de são paulo. [sn], 2005.

MONBEIG, P.; ARY, F.; SILVA, R. d. A. e. Pioneiros e fazendeiros de São Paulo. [S.l.]: Hucitec São Paulo, 1984.

MONICO, J. F. G. Posicionamento pelo GNSS. [S.1.]: Unesp, 2008.

MONICO, J. F. G.; POZ, A. P. D.; GALO, M.; SANTOS, M. C. D.; OliveIRA, L. C. D. Acurácia e precisão: revendo os conceitos de forma acurada. Boletim de Ciências Geodésicas, v. 15, n. 3, 2009.

MORATO, F. As Divisas de São Paulo e Minas Geraes. São Paulo: Empresa Graphica da Revista dos Tribunaes, 1937. 
MORITZ, H. Geodetic reference system 1980. Journal of Geodesy, Springer-Verlag, v. 74, n. 1 , p. $128-133,2000$.

MULLEN, R. Manual of photogrammetry. [S.l.]: Asprs Publications, 2004.

MURAKAMI, A. Revolução de 32. 1982.

MUSEN, P.; BAILIE, A.; UPTON, E. Development of the lunar and solar perturbations in the motion of an artificial satellite. 1961.

NASCIMENTO JÚNIOR, D. R.; GIANNINI, P. C. F.; TANAKA, A. P. B.; GUEDES, C. C. F. Mudanças morfológicas da extremidade ne da ilha comprida ( $\mathrm{sp}$ ) nos últimos dois séculos. Geologia USP. Série Científica, v. 8, n. 1, p. 25-39, 2008.

NERO, M. A. Propostas para o controle de qualidade de bases cartográficas com ênfase na componente posicional. Tese (Doutorado) - Universidade de São Paulo, 2005.

NERO, M. A.; CINTRA, J. P.; FERREIRA, G. de F.; PEREIRA, T. Á. J.; FARIA, T. S. A COMPUTATIONAL TOOL TO EVAlUATE THE SAMPLE SIZE IN MAP POSITIONAL ACCURACY. Boletim de Ciências Geodésicas, v. 23, n. 3, p. 445460, sep 2017. Disponível em: <https://doi.org/10.1590/s1982-21702017000300030>.

NETTO, N. P.; BLITZKOW, D.; NERO, M.; FONSECA, E. da; CINTRA, J.; ARAUJO, S. de. Methodology for different geodetic network integration for cartographic update: Case study in electrical energy company. IEEE Latin America Transactions, IEEE, v. 1, n. 1, p. 48-56, 2003.

NISTRI, U. The range of photogrammetric instruments of the ottico meccanica italiana rilevamenti aerofotogrammetrici. American Society for Photogrammetry and Remote Sensing, v. 20, n. 4, p. 675-680, 1954.

NOGUEIRA JÚNIOR, J. B. Controle de qualidade de produtos cartográficos: uma proposta metodológica. Dissertação (Mestrado) - Universidade Estadual Paulista (UNESP), Presidente Prudente, SP, 2003.

NOTARI, J. M. Restituição aerofotogramétrica. In: PRETO, E. de Minas de O. (Ed.). [S.l.]: Sociedade de intercâmbio cultural e estudos geológicos, 1972. v. 1, n. 11, p. 122-129. XI Semana de estudos - Fotografia Aérea Aplicações Técnicas de 26 a 31 de outubro 1970.

OGUNDARE, J. Understanding Least Squares Estimation and Geomatics Data Analysis. Wiley, 2018. ISBN 9781119501442. Disponível em: <https://books.google. com.br/books?id=-HRyDwAAQBAJ $>$.

OLIVEIRA, C. d. Dicionário cartográfico. 4. ed. Rio de Janeiro: IBGE, 1993. ISBN 852404576. Disponível em: <https://biblioteca.ibge.gov.br/visualizacao/livros/liv66318. pdf $>$.

OLIVEIRA, L. C.; SANTOS, M. C.; NIEVINSKI, F. G.; LEANDRO, R. F.; COSTA, S. M.; SANTOS, M. F.; MAGNA, J.; GALO, M.; CAMARGO, P. O.; MONICO, J. G. et al. Searching for the optimal relationships between sirgas2000, south american datum of 1969 and córrego alegre in brazil. In: Observing our Changing Earth. [S.l.]: Springer, 2009. p. $71-79$. 
OLIVEIRA, M. A. Compatibilização de dados, em diferentes referenciais, para atualização cartográfica: estudo de caso na SABESP. Dissertação (Mestrado) Universidade de São Paulo, São Paulo, SP, 2006.

OLIVEIRA, V. F. de. Crescimento, evolução e o futuro dos cursos de engenharia. Revista de Ensino de Engenharia, v. 24, n. 2, 2008.

ON, O. N. Rede Gravimétrica Fundamental Brasileira, 1976-1986. 1986. Disponível em: <http://www.on.br>. Acesso em: 23/12/2018.

ORTIZ, J. L.; FREITAS, M. I. C. d. Análise da transformação do uso da terra, vegetação e impactos ambientais por meio de sensoriamento remoto e geoprocessamento. Geociências, p. 77-89, 2005.

PACILÉO NETTO, N.; BLITZKOW, D.; NERO, M. Metodologia de integração de diferentes redes geodésicas para atualização cartográfica: Estudo de caso em concessionária de energia elétrica. IEEE Latin America Transactions, v. 1, n. 1, 2003.

PENHA, A.; MORITA, C. Y.; CERQUEIRA, R. Geração de base cartográfica digital a partir de produtos fotogramétricos para a geração de ortofotocarta, carta topográfica e banco de dados geográficos-o caso do projeto de mapeamento do estado da bahia. Simpósio Brasileiro de Ciências Geodésicas e Tecnologias da Geoinformação, v. 4, p. 1-9, 2012.

PEREIRA, F. d. C. A cartografia no Exército Brasileiro: um olhar sobre a construção das narrativas de patrimônio nacional. Dissertação (Mestrado) - Universidade Federal do Estado do Rio de Janeiro, Rio Janeiro, RJ, 2009.

PERIS, H. P. Histórico abreviado do instituto geológico, de suas publicações e mapas. Revista do Instituto Geológico, Instituto Geológico, Secretaria do Meio Ambiente/SP, v. 2, p. 65-72, 1981.

PERRONI, Z. S.; LEFÈVRE, V. Relações das áreas dos distritos e municípios do estado de são paulo, de acôrdo com a lei n. 5285, de 18 de fevereiro de 1959. Organizada pela Seção de Estudos Geográficos, do Instituto Geográfico e Geológico, Secretaria da Agricultura do Estado de São Paulo, 1960.

PETIT, C.; LAMBIN, E. Impact of data integration technique on historical land-use/landcover change: Comparing historical maps with remote sensing data in the belgian ardennes. Landscape Ecology, v. 17, n. 2, p. 117-132, Jun 2002. ISSN 1572-9761. Disponível em: <https://doi.org/10.1023/A:1016599627798>

PINHEIRO, M. R. Técnicas cartográficas e aerotogramétricas no estudo da erosão: alta bacia do Ribeirão Araguá-São Pedro e Charqueada/SP. Dissertação (Mestrado) - Universidade de São Paulo, 2009.

PMSP. Guia de Ruas. Arquivo Histórico do Município de São Paulo, 2009. Disponível em: <http://www.dicionarioderuas.prefeitura.sp.gov.br/PaginasPublicas/ ListaLogradouro.aspx >, Acesso em: 03/09/2017.

PRESTON, D. W.; DIETZ, E. R. The art of experimental physics. The Art of Experimental Physics, by Daryl W. Preston, Eric R. Dietz, pp. 448. ISBN 0-47184748-8. Wiley-VCH, January 1991., p. 448, 1991. 
QUINTÃO, J. O. Azimutes por circum-elongações em função de diferenças de distâncias zenitais: aplicação nas poligonais de precisão. In: Boletim do Instituto Geográfico e Geológico. [S.l.]: Estado de São Paulo, Secretaria da Agricultura, Instituto Geográfico e Geológico, 1962. v. 38.

RANGO, A.; HAVSTAD, K. The utility of historical aerial photographs for detecting and judging the effectiveness of rangeland remediation treatments. Environmental Practice, Cambridge University Press, v. 5, n. 2, p. 107-118, 2003.

RANKIN, W. After the Map: Cartography, Navigation, and the Transformation of Territory in the Twentieth Century. University of Chicago Press, 2016. ISBN 9780226339368. Disponível em: <https://books.google.com.br/books?id= SpuFDAAAQBAJ $>$

REDWEIK, P. Fotogrametria aérea. Lisboa Portugal, 2007.

RIBEIRO, J. dos S.; SOUSA, P. H. Gomes de O.; VIEIRA, D. R.; SIEGLE, E. Evolução da vulnerabilidade à erosão costeira na praia de massaguaçú $(\mathrm{sp})$, brasil. Revista de Gestão Costeira Integrada-Journal of Integrated Coastal Zone Management, Associação Portuguesa dos Recursos Hídricos, v. 13, n. 3, 2013.

RIBEIRO, O. Um mestre da geografia do nosso século-emmanuel de martonne (18731955). Finisterra, v. 8, n. 16, 1973.

ROCHA, J. F. Relatório anual de serviços topográficos. Instituto Geográfico e Geológico, 1941.

Relatório anual de trabalhos realizados. Instituto Geográfico e Geológico, Acervo Instituto Geológico MUGEO, 1947.

RODRIGUES, L. História do Supremo Tribunal Federal. Civilização Brasileira, 1991. (História do Supremo Tribunal Federal, v. 4). ISBN 9788520005842. Disponível em: <https://books.google.com.br/books?id=lJ-Ms7dXhdIC $>$.

ROSSETTO, C. J. The complex of sitophilus spp (coleoptera curculionidae) in the state of são paulo. Bragantia, SciELO Brasil, v. 28, n. UNICO, p. 127-148, 1969.

SÃO PAULO (Estado). Lei ${ }^{o}$ 2, de 22 de janeiro de 1842. divisas entre os municípios de Santo Amaro e Freguesia de s. bernardo. Diário Oficial do Estado, São Paulo, n. 449, p. $1,1842$.

. Decreto $\mathrm{n}^{\circ} 1.278$, de 26 de março de 1905. Aprova as Instruções para o Levatamento Geoáfico do extremo Sertão do Estado. Diário Oficial do Estado - Actos do poder Executivo, São Paulo, n. 69, p. 1-2, 1905.

. Decreto $n^{\circ} 1803$, de 29 de novembro de 1921. Fixa a Fronteira entre os Estados de São Paulo e paraná de acordo com laudo do senhor Presidente da República. Diário Oficial do Estado - Actos do poder Executivo, São Paulo, n. 285, p. 1-2, 1921.

. Decreto $\mathrm{n}^{\circ}$ 5.153, de 08 de agosto de 1931. Transfere a Commissão Geographica e Geológica para a Secretaria do Estado dos Negócios da Viação e Obras Publicas. Diário Oficial do Estado - Diário do Executivo - Atos do Governo Provisório, São Paulo, n. 183, p. 1-44, 1931. 
. Decreto $\mathrm{n}^{\circ}$ 5.161, de 12 de agosto de 1931. Organiza a Diretoria de Serviços Público e da Carta Geral do Estado da Secretaria da Viação e Obras Públicas e da outras providencias. Diário Oficial do Estado - Diário do Executivo - Atos do Governo Provisório, São Paulo, n. 183, p. 1-44, 1931.

. Decreto ${ }^{o}$ 5.174, de 27 de agosto de 1931. Subordina a Secretaria da Agricultura, Industria e Commercio, o Serviço de Estudo e Aproveitamento das Jazidas de Apatite. Diário Oficial do Estado - Diário do Executivo - Atos do Governo Provisório, São Paulo, n. 183, p. 1-44, 1931.

. Decreto $\mathrm{n}^{\circ}$ 5.320, de 30 de dezembro de 1931. cria e dá organização no Instituto Astronmico e Geográfico do Estado de São Paulo. Diário Oficial do Estado - Diário do Executivo - Atos do Governo Provisório, São Paulo, n. 299, p. 1-40, 1931.

Decreto $n^{\circ} 6.283$, de 25 de janeiro de 1934. Cria a universidade de são paulo e dá outras providências. Diário Oficial do Estado - Poder Executivo - Seção, São Paulo, n. 101, p. 1, 1934.

. Decreto $\mathrm{n}^{\circ}$ 7.309, de 5 de julho de 1935. Extingue o Instituto Agronomico e Geographico e reestabelecendo o Instituto Astronomico e Geophysico. Diário Oficial do Estado - Diário do Executivo - Atos do Governo Provisório, São Paulo, n. 155, p. 1-40, 1935.

. Decreto n ${ }^{o}$ 9.777, de 30 de novembro de 1938. Fixa o novo Quadro Territorial do Estado, que vigorará de janeiro de 1939 a dezembro de 1943. Diário Oficial do Estado - Diário da Assembléia, São Paulo, n. 280, p. 1-120, 1938.

. Decreto no 9.871, de 28 de dezembro de 1938. Reforma o Departamento Geográfico e Geológico da Secretaria da Agricultura, Industria e Comercio. Diário Oficial do Estado - Diário do Executivo - Atos do Governo Provisório, São Paulo, n. 290, p. 1-64, 1938.

. Decreto $\mathrm{n}^{\circ} 14.334$, de 30 de novembro de 1944. Divião administrativa e judiciária do Estado. Diário Oficial do Estado - Diário da Assembléia, São Paulo, n. 101, p. 1-100, 1944.

. Decreto $\mathrm{n}^{\circ}$ 233, de 24 de dezembro de 1948. Fixa o Quadro Territorial, Administrativo Judiciário do Estado, a vigorar no quinquênio 1949-1953. Diário Oficial do Estado - Diário da Assembléia, São Paulo, n. 290, p. 1-150, 1948.

. Decreto $\mathrm{n}^{\circ}$ 20.051, de 9 de dezembro de 1950. aprova a demarcação da linha de limites entre os estados de são paulo e rio de janeiro. Diário Oficial do Estado - Diário do Executivo, São Paulo, n. 277, p. 2, 1950.

. Lei Estadual no 1.350, de 12 de dezembro de 1951. Cria o Departamento águas e Esgotos do Estado de São Paulo. Diário Oficial do Estado - Diário do Executivo, São Paulo, n. 277, p. 1, 1951.

. Decreto $\mathrm{n}^{\circ} 2.456$, de 28 de dezembro de 1953. Dispõe sobre o Quadro Territorial Administrativo Judiciário do Estado para o quinquênio 1954-1958 e dá outras providências. Diário Oficial do Estado - Diário da Assembléia, São Paulo, n. 293, p. 1, 1953. 
. Decreto $\mathrm{n}^{\circ} 34.318$, de 24 de dezembro de 1958. Dispoõe sobre o levantamento aerofotogramétrico do território do Estado. Diário Oficial do Estado - Diário do Executivo, São Paulo, n. 286, p. 2, 1958.

. Decreto $\mathrm{n}^{\circ} 5.285$, de 28 de fevereiro de 1959. Dispõe sobre o Quadro Territorial Administrativo Judiciário do Estado para o quinquênio 1959-1963 e dá outras providências. Diário Oficial do Estado - Diário da Assembléia, São Paulo, n. 39, p. 43, 1959.

. Decreto $\mathrm{n}^{\circ}$ 8.092, de 28 de fevereiro de 1964. Dispõe sobre o Quadro Territorial Administrativo Judiciário do Estado de São Paulo. Diário Oficial do Estado - Diário da Assembléia, São Paulo, n. 41, p. 1-2, 1964.

. Decreto $\mathrm{n}^{\circ}$ 48.133, de 28 de junho de 1967. Dispõe sobre a Estrutura Funcional e Medidas para a Reforma Administrativa da Secretaria dos Negócios da Agricultura. Diário Oficial do Estado - Diário do Executivo, São Paulo, n. 117, p. 3-4, 1967.

. Decreto do dia 4 de novembro de 1967. Reorganiza o Instituto Geográfico e Geológico, da Secretaria da Agricultura e dá providências correlatas. Diário Oficial do Estado - Diário do Executivo, São Paulo, n. 212, p. 3-4, 1969.

- Decreto $\mathrm{n}^{\circ} 3.535$ de 9 de abril de 1974. Dispõe sobre a constituição de Grupo de Trabalho visando elaborar estudos técnicos necessários a definição institucional do Instituto Geográfico e Geológico. Diário Oficial do Estado - Diário do Executivo, São Paulo, n. 68, p. 3, 1974.

. Decreto $n^{\circ} 6.822$ de 9 de setembro de 1975. Altera a estrutura, a subordinação e a denominação do Instituto Geográfico e Geológico. Diário Oficial do Estado - Diário do Executivo, São Paulo, n. 186, p. 18, 1975.

. Decreto $n^{\circ} 13.413$ de 13 de março de 1979. Dispõe sobre a organização da Secretaria de Economia e Planejamento. Diário Oficial do Estado - Diário do Executivo, São Paulo, n. 48, p. 18, 1979.

. Decreto $\mathrm{n}^{\circ} 19.718$, de 8 de outubro de 1982. aposenta o engenheiro adhemar colucci na carreira de pesquisador científico. Diário Oficial do Estado - Diário do Executivo, São Paulo, n. 286, p. 2, 1982.

. Lei $\mathrm{n}^{\circ} 12.621$, de 4 de junho de 2007. Revoga as leis e resoluções que especifica, relativas ao período compreendido entre os anos de 1835 e 1890. Diário Oficial do Estado - Poder Executivo - Seção, São Paulo, v. 117, n. 105, p. 1-5, 2007.

SACK, D. The educational value of the history of geomorphology. Geomorphology, Elsevier, v. 47, n. 2-4, p. 313-323, 2002.

SALGÉ, F. Semantic accuracy. In: GUPTILL, S. C.; MORRISON, J. L. (Ed.). Elements of spatial data quality. 1. ed. [S.l.]: Elsevier, 1995. cap. 7, p. 139-152.

SAMPAiO, A. C. F.; MELO, A. d. Á. Datum córrego alegre: O estado da arte de sua existência ou não. Revista Brasileira de Cartografia, v. 67, n. 8, 2015.

SANTOS, A. D. P. D. Avaliação da acurácia posicional em dados espaciais com o uso da estatística espacial. Dissertação (Mestrado) — Universidade Federal de Viçosa, 2010. 
SANTOS, A. D. P. D.; MEDEIROS, N. D. G.; SANTOS, G. R. D.; RODRIGUES, D. D. Controle de qualidade posicional em dados espaciais utilizando feições lineares/positional quality control in spatial data using linear feature. Boletim de Ciências Geodésicas, Universidade Federal do Paraná, Centro Politécnico, v. 21, n. 2, p. 233, 2015.

SANTOS, A. L. G. dos; FURLAN, S. Â. Estudo multitemporal do manguezal de peruíbesp, entre 1962 e 2005. GEOUSP: Espaço e Tempo (Online), n. 28, p. 167-178, 2010.

SANTOS, A. P. d.; CARLOS, R. M. P. Theodoro sampaio e a primeira base geodésica do brasil. Terra Brasilis (Nova Série). Revista da Rede Brasileira de História da Geografia e Geografia Histórica, Rede Brasileira de História da Geografia e Geografia Histórica, n. 8, 2017.

SANTOS, C. J. B. d.; CASTIGLIONE, L. H. G. A atuação do ibge na evolução da cartografia civil no brasil. Terra Brasilis (Nova Série). Revista da Rede Brasileira de História da Geografia e Geografia Histórica, Rede Brasileira de História da Geografia e Geografia Histórica, n. 3, 2014.

SANTOS, M. F.; SANTOS, M. C.; OlIVEIRA, L. C.; COSTA, S. A.; AZEVEDO, J. B.; GALO, M. Progrid: the transformation package for the adoption of sirgas2000 in brazil. In: Geodesy for Planet Earth. [S.l.]: Springer, 2012. p. 869-875.

SCHMID, H. H. An analytical treatment of the orientation of a photogrammetric camera. [S.l.], 1953.

SCILAB. Open source software for numerical computation. 1994-2019. <https: //www.scilab.org/>.

SEEBER, G. Satellite geodesy: foundations, methods, and applications. [S.l.]: Walter de Gruyter, 2003.

SHELE, A. R.; COSTA, G. G. d.; FILHO, A. d. S. R. Arquitetura da base aérea de natal na $2^{\text {a }}$ guerra mundial. Secundo Seminário DOCOMOMO N-NE. Salvador, v. 4, 2011.

SICKLE, J. V. Basic GIS coordinates. [S.l.]: CRC press, 2010.

SIDALC, B. Título: Zoneamento agricola do estado de sao paulo; projeto de agua subterranea: levantamento dos recursos hidricos subterraneos da bacia hidrografica do rio sao jose dos dourados com extensao para a bacia do rio tiete (margem direita). sn, p. 1-2, 1978.

SILVA, E. A. da. 90 anos da missão cartográfica imperial militar austríaca no exército brasileiro-relato histórico da fotogrametria (1920-2010). I Simpósio Brasileiro de Cartografia Histórica, 2011.

SILVA, F. B. da. Insolitudes acres, híbridas e fronteiriças: As disputas pelas identidades. JAMAXI, v. 1, n. 1, 2017.

SILVA, F. H. N. Guerra do contestado: líderes militares que se destacaram. UniSul, 2017. 
SILVA, H. R.; ALTIMARE, A. L.; LIMA, E. A. Sensoriamento remoto na identificação do uso e ocupação da terra na área do projeto conquista da água, ilha solteira-sp, brasil. Engenharia Agrícola, Associação Brasileira de Engenharia Agrícola (SBEA), p. 328$334,2006$.

SILVA, N. L. da; FERREIRA, M. de M. Os caminhos da institucionalização do ensino superior de história. História \& Ensino, v. 17, n. 2, p. 283-306, 2011.

SILVARES, J. C. Capitania dos portos de São Paulo 170 anos (1847-2017). [S.1.]: Publicação Independente, 2007.

SKAGGS; HIRAM. Status of the Vertical Geodetic Data at the Defense Mapping Agency Hydrographic/Topographic Center for Mexico and Central America. [S.l.], 1980.

SMALLWOOD, J. Bouguer redeemed: The successful 1737-1740 gravity experiments on pichincha and chimborazo. Earth Sciences History, History of Earth Sciences Society, v. 29, n. 1, p. 1-25, 2010.

SMITH, J. T. A history of flying and photography: In the photogrammetry division of the national ocean survey 1919- 1979. 1979.

SOARES, J. C. M. Revista Brasileira de Geografia. [S.1.]: IBGE, 1939.

SOBEL, D. Longitude: The true story of a lone genius who solved the greatest scientific problem of his time. Academy of Management Learning and Education, ACADEMY OF MANAGEMENT, v. 3, p. 220-220, 2004.

SOUTHARD, R. B. The development of us national mapping policy. The American Cartographer, Taylor \& Francis, v. 10, n. 1, p. 5-15, 1983.

SOUZA, A. C. R. d. Escola politécnica e suas múltiplas relações com a cidade de São Paulo 1893-1933. Tese (Doutorado), 2006. História. Disponível em: $<$ https: //tede2.pucsp.br/handle/handle/12981>.

SOUZA, C. R. de G.; LUNA, G. d. C. Variação da linha de costa e balanço sedimentar de longo período em praias sob risco muito alto de erosão do município de caraguatatuba (litoral norte de são paulo, brasil). Revista de Gestão Costeira Integrada-Journal of Integrated Coastal Zone Management, Associação Portuguesa dos Recursos Hídricos, v. 10, n. 2, p. 179-199, 2010.

SOUZA, O. de; OLIVEIRA, A. M. dos S.; QUEIROZ, W. de. Produção de sedimentos na região metropolitana de são paulo. o caso da microbacia do córrego do pau d'alho, guarulhos, sp. Revista Brasileira de Geomorfologia, v. 10, n. 1, 2009.

SOUZA, T. d.; OLIVEIRA, R. C. d. Avaliação da potencialidade de imagens tridimensionais em meio digital para o mapeamento geomorfológico. Revista Geonorte, Manaus, v. 2, n. 4, p. 1348-1355, 2012.

SPROTT, D. A. Gauss's contributions to statistics. Historia Mathematica, Elsevier, v. 5, n. 2, p. 183-203, 1978. 
STAPLES, J. Cartographic experiment for latin america.[santa cruz, bolivia and concepcion, paraguay]. 1974.

STIGLER, S. The History of Statistics: The Measurement of Uncertainty Before 1900. Belknap Press of Harvard University Press, 1986. (Belknap Series). ISBN 9780674403413. Disponível em: $<$ https://books.google.com.br/books?id= M7yvkERHIIMC>.

SUDENE. Inventário dos Levantamentos de Recursos Naturais do Nordeste. [S.l.]: Ministério do interior Superintendência de Desenvolvimento do Nordeste, 1968.

ÖSTMAN, A. (Ed.). The specification and Evaluation of Spatial Data Quality, v. 2, n. 18. Swedish Cartographic Society, [S.l.]: Proceedings ICA International Cartographic Conference, 1997. 836-847 p.

SZTUTMAN, P. Análise da qualidade posicional das bases do Google Maps, Bing Maps e da Esri para referência espacial em projetos em SIG: aplicação para o município de São Paulo. Dissertação (Mestrado) - Universidade de São Paulo - Escola Politécnica/PTR, 2014.

TEMBA, P. Fundamentos da fotogrametria. Belo Horizonte: UFMG, 2000.

TESSLER, M. G.; FURTADO, V. V. Dinâmica de sedimentação das feições de assoreamento da região lagunar cananéia-iguape, estado de são paulo. Boletim do Instituto Oceanográfico, SciELO Brasil, v. 32, n. 2, p. 117-124, 1983.

THOMPSON, M. M. Manual of photogrammetry. Geoscience Abstracts, 1966.

TOMMASELli, A.; MONICO, J.; CAMARGO, P. Análise da exatidão cartográfica da carta imagem são paulo. 5o, Simpósio Brasileiro de Sensoriamento Remoto, p. $253-257,1988$.

TORGE, W. Geodesia. [S.1.]: Editora Diana, 1983. 289p p.

TORGE, W.; MÜLLER, J. Geodesy. [S.l.]: Walter de Gruyter, 2012.

TORTORA, A.; CAPOBIANCO, R.; PICUNO, P. Historical cartography and gis for the analysis of carbon balance in rural environment: a study case in southern italy. Agricultural Engineering International: CIGR Journal, 2006.

TUCCI, M.; GIORDANO, A. Positional accuracy, positional uncertainty, and feature change detection in historical maps: Results of an experiment. Computers, Environment and Urban Systems, Elsevier, v. 35, n. 6, p. 452-463, 2011.

UAGS, U. A. G.; STATES. National geodetic satellite program: a report. Washington, D.C.: National Aeronautics and Space Administration, Scientific and Technical Information Office : for sale by the Supt. of Docs., U.S. Govt. Print. Off., 1977. 2 v. (viii, 1030) p. p. 2 v. (viii, 1030) p. Disponível em: <http://catalog.hathitrust.org/Record/ $008329035>$

UN. Specifications of the international map of the world on the millionth scale (imw). In: United Nations technical conference on the international map of the world on the millionth scale. [S.l.: s.n.], 1962. v. 2, p. 1-107. 
USBB. United States National Map Accuracy Standards. Washington, D.C, 1947.

USGS. Historical reference for topographic mapping. US geological survey, online, 1990. Disponível em: <https://pubs.usgs.gov/gip/topomapping/topo.html>. Acesso em: $03 / 01 / 2018$.

USP. Anuário da universidade de são paulo - usp. Revista dos Tribunais, São Paulo, v. 1, n. 105, p. 30, 1937.

VERONEZ, M. R. Proposta de parâmetros de transformação entre os sistemas WGS-84 e o SAD-69 para a região de São Carlos-SP. Dissertação (Mestrado) Universidade de São Paulo, 1998.

VOTUPORANGA. Histórico da Paróquia Nossa Senhora Aparecida de Votuporanga-SP. Catedral Nossa Senhora Aparecida, 1961. Disponível em: $<$ http: //www.nossasenhoravotuporanga.com.br/historia.php $>$. Acesso em: 03/01/2018.

WADDELL, W. Inspetoria Federal - Relatórios 1923-1932. São Paulo - Acervo do Centro Histórico e Cultural Mackenzie, 1923.

WEBER, E.; ANZOLCH, R.; FILHO, J. L.; COSTA, A. C.; IOCHPE, C. Qualidade de dados geoespaciais. Porto Alegre: UFRGS, 1999.

WIENS, J.; MOSS, M.; MLADENOFF, D.; TURNER, M. Foundation Papers in Landscape Ecology. Columbia University Press, 2007. (Foundation Papers in Landscape Ecology). ISBN 9780231126809. Disponível em: <https://books.google.com.br/ books?id=8jfmor8wVG4C $>$.

WOLF, P. R.; GHILANI, C. D. Adjustment computations: statistics and least squares in surveying and GIS. [S.l.]: Wiley-Interscience, 1997.

WOOD, H. The Role of the Defense Mapping Agency Inter American Geodetic Survey (DMA IAGS) in Nation-Building. [S.l.], 1974.

YIONOULIS, S. M. The transit satellite geodesy program. Johns Hopkins APL technical digest, JOHN HOPKINS UNIV APPLIED PHYSICS LABORATORY, v. 19, n. 1, p. $37,1998$.

ZANETTI, M. A. Z. Implicaçôes atuais no relacionamento entre sistemas terrestres de referęncia de origem local e geocęntrica. Tese (Doutorado) - Universidade Federal do Paraná, Curitiba, PR, 2006. 